ERIC HOMERO ALBUQUERQUE PASCHOAL

Biomarcadores genéticos na hemorragia subaracnoidea aneurismática em pacientes da Amazônia

Tese apresentada à Faculdade de Medicina da Universidade de São Paulo para obtenção do Título de Doutor em Ciências 
ERIC HOMERO ALBUQUERQUE PASCHOAL

Biomarcadores genéticos na hemorragia subaracnoidea aneurismática em pacientes da Amazônia

Tese apresentada à Faculdade de Medicina da Universidade de São Paulo para obtenção do Título de Doutor em Ciências Programa: Neurologia

Programa de Neurologia

Orientador: Prof. Dr. Edson Bor-Seng-Shu 
Dados Internacionais de Catalogação na Publicação (CIP)

Preparada pela Divisão de Biblioteca e Documentação da Faculdade de Medicina da Universidade de São Paulo

Creprodução autorizada pelo autor

Paschoal, Eric Homero Albuquerque

Biomarcadores genéticos na hemorragia subaracnóidea aneurismática em pacientes da Amazônia / Eric Homero Albuquerque Paschoal -- São Paulo, 2017.

Tese(doutorado)--Faculdade de Medicina da Universidade de São Paulo. Programa de Neurologia.

Orientador: Edson Bor-Seng-Shu.

Descritores: 1.Hemorragia subaracnóidea 2.Aneurisma intracraniano 3.Polimorfismo genético 4.Vasoespasmo intracraniano 5.Isquemia cerebral 6.Mutação INDEL

USP/FM/DBD-187-/17 
- A Deus, pela sabedoria e oportunidade de chegar a este momento tão importante de minha vida profissional.

- Dedico ao Prof. Dr. Fernando Mendes Paschoal "in memorian" que, na figura de Pai e de Mentor, me inspirou a buscar a pesquisa como fonte de crescimento intelectual para aliviar a dor alheia.

- À minha mãezinha Ruth Paschoal, pelo Amor, ensinamentos de vida e da arte da Medicina, bem como, pela dedicação à minha educação como ser humano. Você fez de mim a pessoa que sou, e eu só tenho motivos para agradecer.

- Aos meus irmãos Fernando e Vanessa, pelo companheirismo e apoio nos momentos de conquistas e decepções, sempre estivemos unidos.

- Às minhas sobrinhas Maitê e Mariana, que trouxeram alegria à família.

- À minha cunhada e aos meus cunhados (Joca, Daniel e Fernando), pelo apoio e conselhos para os desafios do dia a dia.

- Aos meus sogros Ronaldo e Valquíria, que me apoiaram em todas as etapas do desafio profissional.

- A todos os pacientes e familiares que contribuíram na elaboração desta tese. 
- Dedico esta obra científica à minha amada esposa Aline pela cumplicidade, amor, lealdade, respeito e compreensão da minha ausência.

- Dedico aos meus filhos, Felipe e Fernanda, meus tesouros e minha vida. 
- Ao Prof. Dr. Edson Bor-Seng-Shu, pela amizade e ensinamentos da arte da vida e da ciência. Meu privilégio de tê-lo conhecido, certamente, me fez amadurecer no campo da ciência médica e como ser humano. Obrigado pela oportunidade e amizade, sempre transmitindo sábias palavras de conforto e orientação.

- À Profa. Dra. Ândrea Ribeiro dos Santos, pela amizade e ensinamentos, em especial, pela disponibilidade incondicional às pesquisas genéticas desta obra, o que permitiu a conclusão deste trabalho. Obrigado por todo o compromisso e pelo apoio.

- Ao Prof. Dr. Sidney Emanuel Batista dos Santos, pela amizade e orientações no mundo da genética, transmitidos com simplicidade.

- À Profa Dra. Elizabeth Sumi Yamada, pela oportunidade e incentivo à Neurociência.

- Ao Prof. Dr. Evandro de Oliveira, pelo convívio e aprendizagem neurocirúrgica, o que aprimorou meu conhecimento anatômico, fundamental para o tratamento dos pacientes com doença cerebrovascular. Sua experiência e dedicação me levaram a esse momento.

- Ao Prof. Dr. Feres Eduardo Aparecido Chaddad Neto, pela amizade de longa data e ensinamentos neurocirúrgicos e da vida. Você é minha inspiração como ser humano e como profissional. Obrigado por me orientar no caminho do bem e do conhecimento científico. 
- Ao Prof. Dr. Ronie Leo Piske, pela amizade e ensinamentos sobre Neurorradiologista Intervencionista, que me lapidaram ao caminho das doenças cérebro e medulovasculares.

- Ao amigo e mestre Prof. Dr. Juvenal de Sousa Rogério, que sempre me incentivou o caminho do ensino da neurocirurgia; o Senhor é um exemplo a ser seguido e admirado. Obrigado pela amizade, respeito e ensinamentos.

- Aos meus queridos alunos que tanto me auxiliaram na coleta dos dados desta pesquisa, em especial ao Dr. Tarcísio Silva de Oliveira, Dr. Vitor Nagai Yamaki, Dra. Glaucia Suzanna Jong A. Liem, Dr. José Antonio e Dra. Maria Luana. Vocês foram de suma importância neste estudo.

- Aos amigos Dr. Francinaldo Lobato Gomes, Dr. José Reginaldo Nascimento Brito e Dr. Sandro Cavalcante, que apoiaram o desenvolvimento desta obra.

- Aos amigos do Instituto Neurológico do Hospital Ofir Loyola (HOL): Dr. Joel Monteiro de Jesus, Dr. Mário Hermes Júnior, Dr. Mauro Almeida, Dr. José Takao Yamaki, Dra. Simone Mendes Rogério e Dr. Alexandre Maués.

- Aos amigos do HOL e do Hospital Universitário do Complexo UFPa que me apoiaram na elaboração desta pesquisa. Em especial, à equipe de enfermagem Raimunda Dirce Acácio, Ermínia Lima Ramos, Viviane Ferreira, Alessandra Navegantes, Janete do Socorro Rodrigues Trindade e Edicelma Góes da Costa. - Aos amigos do Laboratório de Genética Médica e Humana (LGMH) da UFPa que desenvolveram parte fundamental dos nossos trabalhos, sem medir esforços na construção desse projeto; não tenho palavras para mensurar minha gratidão por vocês: André Ribeiro dos Santos, Giovanna Cavalcante, Glória Tatiana Vinasco, Amanda Vidal, Pablo Diego do Carmo Pinto, Leandro Magalhães, entre outros. 
- Aos amigos Prof. Dr. Alberto Gomes Ferreira, Prof. Dr. Fabricio Tuji e Prof. Dr. Rommel Mário Rodriguez Burbano, que sempre acreditaram e incentivaram o meu potencial como pesquisador; eles fizeram parte fundamental da estruturação e concretização deste objetivo.

- Aos amigos Marcos Leandro Menezes, Fernando Santana e Caio Cunha, pelo apoio incondicional na estruturação desta obra.

- Ao amigo Dr. Edmur Piza Filho, que me ensinou os caminhos da arte neurocirúrgica e, com amizade e respeito, sempre acreditou no meu potencial durante minha residência médica.

- Às amigas Chiara Smith, Estela Lacerda, Janira Ferreira, Erica Nascimento, Thais Charchar e Erica Oeiras, pelo apoio ao tratamento dos doentes envolvidos nesta pesquisa pesquisa.

- À secretaria da Pós-graduação em Neurologia da FMUSP, em especial, à Thais Figueira que me orientou a respeito dos caminhos burocráticos.

- A todos que contribuíram no desenvolvimento desta pesquisa e que não foram citados. 
"Determinação, coragem e autoconfiança são fatores decisivos para o sucesso. Não importa quais sejam os obstáculos e as dificuldades. Se estamos possuídos de uma inabalável determinação, conseguiremos superá-los. Independentemente, das circunstâncias, devemos ser sempre humildes, recatados e despidos de orgulho"

Dalai Lama (Tezin Gyatso, O Livro de Dias). 
Normatização adotada

Esta tese está de acordo com as normas em vigor no momento desta publicação:

Referências: adaptado de International Committee of Medical Journals Editors (Vancouver).

Universidade de São Paulo. Faculdade de Medicina. Divisão de Biblioteca e Documentação. Guia de apresentação de dissertações, teses e monografias. Elaborado por Anneliese Carneiro da Cunha, Maria Julia de A. L. Freddi, Maria F. Crestana, Marinalva de Souza Aragão, Suely Campos Cardoso,Valéria Vilhena. 3a ed. São Paulo: Divisão de Biblioteca e Documentação; 2011. 
ACSD

AI

AngioTC

APOE

AVC

AVE

CASP8

$\mathrm{CpG}$

CT perfusão

DCI

DIND

DNA

DTC

ECM

eNOS

ET-1

HAS

$\mathrm{Hp}$

HSA

HSAa

IEL
Angiografia encefálica por subtração digital

Aneurisma intracraniano

Angiotomografia

Apolipoproteína E

Acidente vascular cerebral

Acidentes vasculares encefálicos

Caspase 8

Citosina-fosfato-guanina

Tomografia computadorizada com perfusão

Déficit neurológico isquêmico

Déficit neurológico isquêmico tardio

Ácido desoxirribonucleico

Doppler transcraniano

Matrix extracelular

Óxido nítrico sintase endotelial

Endotelina 1

Hipertensão arterial sistêmica

Haptoglobina

Hemorragia subaracnoidea

Hemorragia subaracnoidea aneurismática

Camada elástica interna 


\begin{tabular}{|c|c|}
\hline IL-1ß & Interleucina-1ß \\
\hline IL4 & Interleucina 4 \\
\hline IL-6 & Interleucina 6 \\
\hline INDEL & Insertion/deletion \\
\hline iNOS & Óxido nítrico sintase induzível \\
\hline IRM & Imagem por ressonância magnética \\
\hline ISUIA & International Study of Unruptured Intracranial Aneurysms \\
\hline LCR & Líquido cefaloraquidiano \\
\hline miRNA & Micro RNA \\
\hline MMP & Metaloproteinase \\
\hline NO & Óxido nítrico \\
\hline OMS & Organização Mundial de Saúde \\
\hline PAR-1 & Receptor da proteinase ativada \\
\hline PDGF & Fator de crescimento derivado de plaqueta \\
\hline PNU & Polimorfismo nucleotídeo único \\
\hline RNA & Ácido ribonucleico \\
\hline ROS & Reação oxigênio específica \\
\hline SM-MHC & Miosina muscular lisa de cadeia pesada \\
\hline SNP & Single nucleotide polimorphism \\
\hline STR & Short tandem repeat \\
\hline $\mathrm{TC}$ & Tomografia computadorizada \\
\hline TNF - $\alpha$ & Fator de necrose tumoral - $\alpha$ \\
\hline TP53 & Tumor protein p53 \\
\hline $\mathrm{VC}$ & Vasoespasmo cerebral \\
\hline VE & Vasoespasmo encefálico \\
\hline
\end{tabular}


VNTR

VSMC

WFNS

$X R C C 1$
Variable numbers of tandem repeat

Células musculares lisas do vaso

World Federation of Neurosurgical Societies

$X$-ray repair complementing defective repair in Chinese

hamster cells 1 
Tabela 1. Escala de graduação modificada do risco de isquemia pós-HSAa segundo escala VASOGRADE.

Tabela 2. Caracterização técnica dos polimorfismos investigados com base no painel gênico existente.

Tabela 3. Avaliação do vasoespasmo pela angiografia encefálica por subtração digital

Tabela 4. Distribuição quanto ao sexo entre os grupos de hemorragia.. 97

Tabela 5. Distribuição da idade conforme o grupo de hemorragia. 99

Tabela 6. Distribuição quanto à instalação do vasoespasmo encefálico 100

Tabela 7. Distribuição demográfica da admissão hospitalar ao desfecho clínico.

Tabela 8. Distribuição genotípica e alélica dos biomarcadores genéticos.... 112 Tabela 9. Distribuição amostral de acordo com a ancestralidade da população Amazônica.

Tabela 10. Distribuição genotípica da $e N O S$ em sua associação com vasoespasmo encefálico segundo DIND e escala VASOGRADE 
Figura 1. Distribuição da incidência de HSAa em diferentes continentes......

Figura 2. Mecanismo fisiopatológico do cigarro em termos de formação e rotura de aneurisma intracraniano e desenvolvimento de vasoespasmo encefálico......

Figura 3. Distribuição dos aneurismas conforme a localização intracraniana.

Figura 4. Correntes migratórias para América do Sul através do estreito de Bering.

Figura 5. Fisiopatologia do vasoespasmo encefálico pós-HSAa

Figura 6. Classificação da hemorragia subaracnoidea segundo escala de Fisher modificada. 67

Figura 7. Fluxograma de assistência e coleta dos dados pós-HSAa.............. 85

Figura 8. Modelo da $1^{\mathrm{a}}$ pergunta estruturada.............................................. 94

Figura 9. Modelo da $2^{\mathrm{a}}$ pergunta estruturada............................................ 94

Figura 10. Caso clínico 1............................................................................ 114

Figura 11. Caso clínico 2 ....................................................................... 115

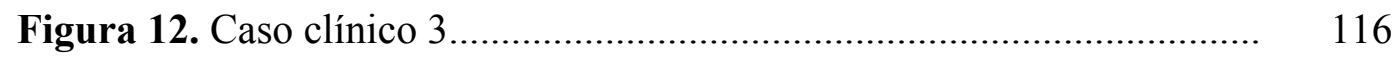

Figura 13. Caso clínico 4..................................................................... 117

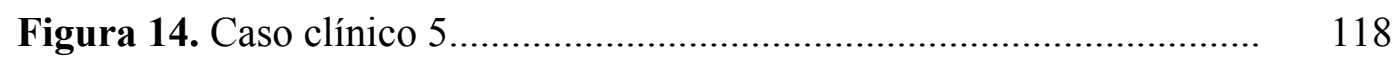

Figura 15. Caso clínico 6........................................................................ 119

Figura 16. Estrutura do gene NOS3 (eNOS) localizado em 7q35-36.......... 125 
Gráfico1. Distribuição da hemorragia subaracnoidea de acordo com fatores de confusão.

Gráfico 2. Contribuição da ancestralidade no tipo de hemorragia

subaracnoidea, com vasoespasmo (I) ou sem vasoespasmo (II).

Gráfico 3. Influência dos marcadores genéticos sobre os grupos de hemorragia

Gráfico 4. Distribuição dos grupos conforme o desenvolvimento de DIND.. 104

Gráfico 5. Resposta dos marcadores sobre o DIND.................................... 106

Gráfico 6. Influência da ancestralidade sobre o DIND................................. 108

Gráfico 7. Distribuição dos fatores confundidores conforme desfecho.......... 108

Gráfico 8. Distribuição da ancestralidade conforme desfecho clínico........... 109

Gráfico 9. Influência dos fatores confundidores com a apresentação clínica. 109

Gráfico 10. Ancestralidade e a influência mediante a apresentação inicial.... 110

Gráfico 11. Marcador do gene da CASP8 e graduação VASOGRADE........ 111

Gráfico 12. Distribuição do polimorfismo do gene $X R C C 1$ e sobrevida dos

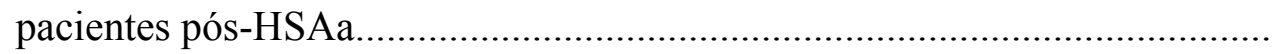

Gráfico 13. Curva de Kaplan Meier para os pacientes com o alelo 1 e 2 do $X R C C 1$ 
Anexo A. Escore de risco de rotura do aneurisma PHASES

Anexo B. Escala Hunt e Hess para HSAa.

Anexo C. Escala de graduação clínica da World Federation of Neurological

Surgeons (WFNS)

Anexo D. Classificação da hemorragia subaracnoidea segundo Fisher original e modificada e as taxas de risco de vasoespasmo clínico.

Anexo E. Escala VASOGRADE.

Anexo F. Sensibilidade e especificidade do DTC na detecção do vasoespasmo encefálico e critérios por artérias estudadas

Anexo G. Critérios para detecção de espasmo da artéria cerebral média através de Doppler transcraniano.

Anexo H. Critérios de progressão do vasoespasmo encefálico através de Doppler transcraniano.

Anexo I. Biomarcadores genéticos envolvidos na patogênese da formação e/ou da rotura aneurismática - alterações estruturais do DNA

Anexo J. Definições de DCI ou DIND e infarto encefálico após HSAa

Anexo K. Protocolo de dados dos pacientes com hemorragia subaracnoidea aneurismática.

Anexo L. Termo de consentimento livre e esclarecido.

Anexo M. Carta de aceite do Comitê de Ética em Pesquisa HCFMUSP.

Anexo N. Carta de aceite da pesquisa no Laboratório de Genética Médica e Humana - Universidade Federal do Pará.

Anexo O. Aprovação do Comitê de Ética em Pesquisa do Hospital Ofir Loyola. 
Paschoal EHA. Biomarcadores genéticos na hemorragia subaracnoidea aneurismática em pacientes da Amazônia [Tese]. São Paulo: Faculdade de Medicina, Universidade de São Paulo; 2017.

Hemorragia subaracnoidea aneurismática (HSAa) é considerada causa importante de morte e de sequelas neurológicas. A taxa de mortalidade desta doença pode alcançar $50 \%$ nos primeiros dois meses após sangramento de aneurisma encefálico. Apesar dos avanços científicos da modernidade, o resultado do tratamento da HSAa não mudou nos últimos anos. O presente estudo avaliou o papel de 14 biomarcadores genéticos, incluindo o polimorfismo $(S N P)$ do gene $e N O S$, em pacientes da Amazônia com HSAa, para verificar as alterações alélicas associadas ao risco de vasoespasmo encefálico e déficit neurológico tardio. Avaliou-se a ancestralidade desta amostra de pacientes em que se utilizou 48 marcadores para identificar possível etnia associada à predisposição ao VE. Investigou-se 14 biomarcadores genéticos no tocante à resposta inflamatória encefálica na HSAa. Foram avaliados 265 doentes que foram divididos em dois grupos: grupo I (pacientes com vasoespasmo encefálico) e grupo 2 (pacientes sem vasoespasmo). A média das idades foi 51 anos, havia 224 mulheres (84\%) e 124 pacientes $(46,79 \%)$ apresentaram vasoespasmo encefálico (VE). A maior incidência de VE ocorreu na idade entre 50 e 59 anos. Tabagismo e hipertensão arterial sistêmica foram os fatores de risco mais associados à VE. Aneurismas encefálicos de tamanho pequeno e médio predominaram nesta casuística. As escalas amarela e vermelha do VASOGRADE associaram-se ao risco de $\operatorname{VE}(p<0,001)$. Não houve variação na distribuição ancestral entre os grupos estudados e o que ocorre na população brasileira saudável na região Amazônica. $\mathrm{O}$ gene da $e N O S$ com seus respectivos polimorfismos T-786C e 27VNTR4 correlacionaram-se com VE. Outros marcadores observados foram TP53, CASP8, ACE2, IL4 e XRCC1. O gene TP53 (modelo recessivo alelo 1) mostrou-se ser um fator protetor de VE, enquanto que genes com mutações INDEL CASP8 (modelo recessivo alelo 2) e o XRCC1 (modelo recessivo alelo 1) mostraram tendência ao desenvolvimento de VE com risco 2 vezes maior e 1,4 vezes maior que o grupo II $(p<0,001)$. Conclui-se que $S N P S$ da $e N O S$ se correlacionam com desenvolvimento de VE sintomático pós-HSAa. Este estudo também mostrou o papel dos marcadores inflamatórios na HSAa, o que auxiliaria na condução da terapia clínica.

Descritores: Hemorragia subaracnoidea, aneurisma intracraniano, polimorfismo genético, vasoespasmo intracraniano, isquemia encefálica, mutação INDEL. 
Paschoal EHA. "Genetic biomarkers in patients with Aneurysmal Subarachnoid Hemorrhage in the Amazon patients." [Thesis]. São Paulo: Faculdade de Medicina, Universidade de São Paulo; 2017.

Aneurysmal subarachnoid hemorrhage (aSAH) is a leading cause of premature death and neurological disability. It is considered as a devastating condition that accounts to $50 \%$ of mortality during the first two months after a hemorrhagic event. Despite foremost advances in the clinical management of post-aSAH patients, the rates of mortality and morbidity have not changed in recent years. This study appraised the role of 14 genetic biomarkers, including the eNOS polymorphism (SNP) between Amazon's patients with aSAH, as means to document how variant alleles are related to a higher disposition to cerebral vasospasm (CV) and delayed cerebral ischemia (DCI). 265 patients were evaluated and then divided into two clusters: Group I (with symptomatic CV) and group II (presenting no symptomatic CV). The median ages of patients were 51.61 years of age, $224(84.52 \%)$ were women and 124 patients (46.97\%) had symptoms of cerebral vasospasm (CV). Tobacco smoking and systemic arterial hypertension are the risk factors most associated to $\mathrm{CV}$. In the course of this research, most aneurysms found were small and medium-sized. The score VASOGRADE yellow and VASOGRADE red presented a high risk of $\mathrm{CV}$ ( $p$ $<0.001)$. We established a panel of 48 ancestry informative markers for estimating which ethnicity could present a predisposition to $\mathrm{CV}$. There was no variation in the ancestral distribution between study groups and healthy brazilian folk over the Amazon region. The eNOS gene with its polymorphisms $T-786 C$ and 27 VNTR4 were correlated to CV. Other markers were accomplished: TP53, CASP8, ACE2, IL4, and $X R C C 1$. The TP53 gene (recessive genetic model allele 1) supporting evidence of the protective role to $\mathrm{CV}$. Whilst other genes with INDEL mutation like as CASP8 (recessive model allele 2) and the XRCC1 (recessive model allele 1) indicated a propensity to spread out $\mathrm{CV}$ with odds 2 -fold higher, and 1.414 times greater than group II $(p<0.001)$. It follows that $e N O S$ SNPs correlate to a positive association with a syntomatic CV post-aSAH. Also, this study showed up the role of inflammatory markers at aSAH to a further educated therapeutic choice for a better clinical response.

Descriptors: Subarachnoid hemorrhage, intracranial aneurysm, genetic polymorphism, cerebral vasospasm, cerebral ischemia, INDEL mutation 
Lista de Abreviaturas, símbolos e siglas

Lista de tabelas

Lista de figuras

Lista de gráficos

Lista de anexos

Resumo

Summary

1. INTRODUÇÃ O............................................................................ 1

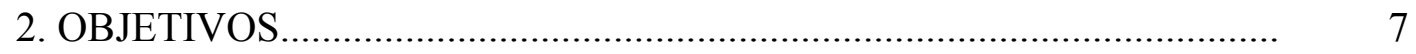

3. REVISÃO DE LITERATURA.......................................................... 9

3.1. Problemática da hemorragia subaracnoidea aneurismática.................... $\quad 10$

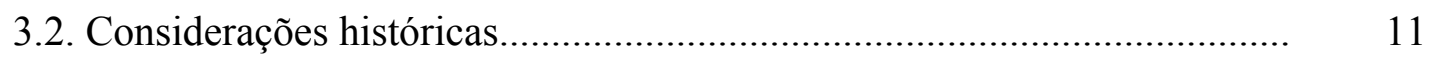

3.3. Incidência e prevalência da HSAa.......................................................... 13

3.4. Fatores de risco para desenvolvimento, crescimento e rotura dos 15 aneurismas intracranianos.

3.4.1. Fatores de risco modificáveis.............................................. 15

a) Papel fisiopatológico do cigarro............................................................ 17

3.4.2. Fatores de risco não modificáveis.......................................... 21

3.5. Mecanismos moleculares da formação e progressão dos aneurismas 26 intracranianos e parâmetros inflamatórios após HSAa...

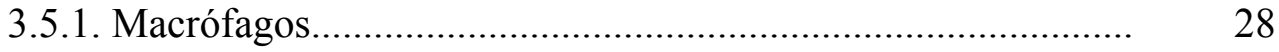

3.5.2. Achados patológicos da saculação aneurismática..................... 29

3.6. Contribuição genética no desenvolvimento e rotura dos aneurismas........ $\quad 30$

3.6.1. Biomarcadores genéticos.................................................... 33

a) Marcadores genéticos para HSAa e vasoespasmo encefálico.......... 33 


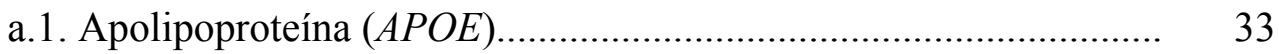

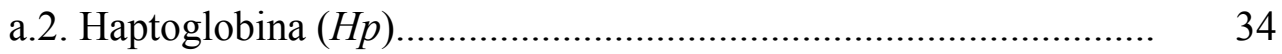

a.3. Óxido nítrico sintase endotelial (eNOS ou NOS3)....................... 35

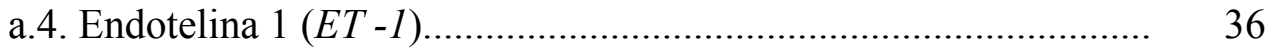

b) Marcadores inflamatórios e imunológicos da HSAa e do

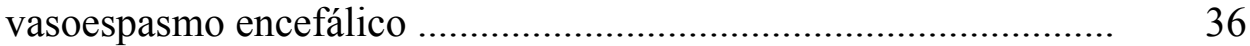

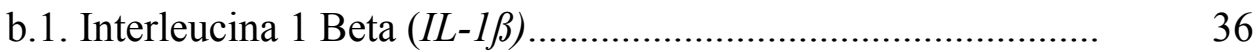



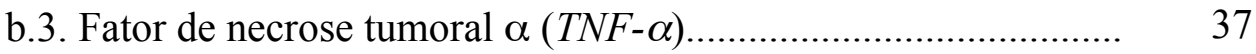

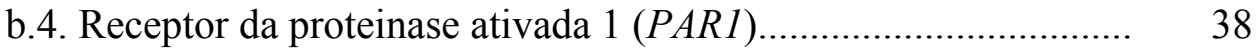



c) Marcadores genéticos associados à estabilidade genômica e com a morte celular

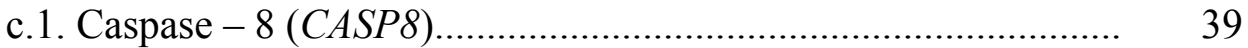

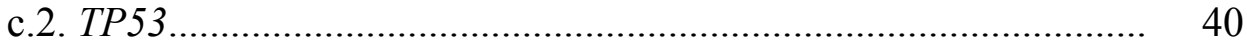



3.6.2.Biomarcadores epigenéticos................................................. 41

3.6.3 Influência genética na formação da população brasileira ....... 44

3.7. História natural dos aneurismas intracranianos e a hemorragia

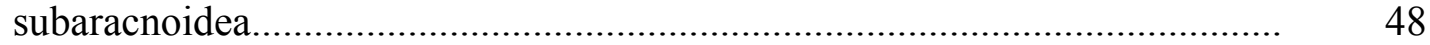

3.7.1. Apresentação clínica e escalas prognósticas.......................... 48

3.7.2. Complicações da hemorragia subaracnoidea......................... 51

a) Hipertensão intracraniana e a apoptose após HSAa...................... 51

b) Ressangramento.................................................................. 52

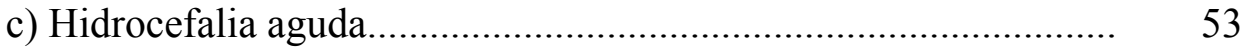


d) Crise convulsiva....................................................................... 54

e) Vasoespasmo encefálico sintomático e déficit isquêmico tardio.. $\quad 55$

e.1. Critérios diagnósticos do vasoespasmo encefálico e do déficit

isquêmico tardio

e.2. Fisiopatologia do vasoespasmo encefálico.................................... 61

3.8. Métodos de investigação e monitorização do paciente com HSAa............. 65

3.8.1. Métodos de diagnóstico do sangramento................................... 66

a) Tomografia computadorizada do encéfalo...................................... 66

b) Análise do líquido cefalorraquidiano............................................... $\quad 67$

c) Imagem de ressonância magnética................................................. 68

3.8.2. Métodos de avaliação da angioarquitetura.................................................. 68

a) Angiotomografia dos vasos encefálicos ………………….... 68

b) Angiografia encefálica por subtração digital.................................. 69

3.8.3. Métodos de avaliação da funcionalidade hemodinâmica encefálica........ $\quad 70$

a) Doppler transcraniano..............................................................

b) Tomografia computadorizada com perfusão.................................. 72

c) Eletroencefalograma................................................................

d) Microdiálise intracerebral.................................................................

3.9. Abordagem do paciente após HSAa.......................................................

3.9.1. Cuidados iniciais................................................................ 75

3.9.2. Intervenção precoce ou tardia................................................... 76

3.9.3. Monitoramento e conduta no vasoespasmo encefálico e DCI pós-HSAa 78

3.9.4. Conduta na hidrocefalia, crise convulsiva e complicações pós-HSAa, Medidas de prevenção de vasoespasmo encefálico e isquemia encefálica tardia. 
4.1. Casuística.

4.2. Caracterização geral da amostra.

4.3. Desenho do estudo.

a) Critérios de inclusão.

b) Critérios de exclusão

4.4. Coleta dos dados.

4.4.1. Variáveis epidemiológicas.

4.4.2. Diagnóstico vascular......

4.4.3. Investigação dos biomarcadores genéticos e da

ancestralidade

a) Escolha dos marcadores................................................. $\quad 88$

b) PCR multiplex e análise de fragmento ................................ $\quad 89$

c) Marcadores informativos da ancestralidade..

4.4.4. Métodos de diagnóstico do vasoespasmo e monitoramento para isquemia encefálica tardia.

4.4.5. Critérios éticos.

4.4.6. Modelo da pergunta estruturada.

4.4.7. Análise estatística.

5.1. Caracterização geral da amostra...

5.2. Avaliação dos marcadores genéticos do painel

5.3. Avaliação dos marcadores e dos fatores confundidores de 
desfecho.

5.5. Avaliação dos marcadores e dos fatores confundidores com a escala VASOGRADE

5.6. Casos clínicos...

6. DISCUSSÃO.

6.1. Influência do gene eNOS na HSAa..

6.2. Influência dos genes envolvidos na inflamação.

6.3. Achados demográficos da amostra.

6.4. Perspectivas.

7. CONCLUSÕES.

8. ANEXOS

9. REFERÊNCIAS. 
I 


\section{Introdução}

A hemorragia subaracnoidea aneurismática (HSAa) representa 5\% das causas de acidentes vasculares encefálicos (AVE) e cursa com taxa elevada de morbimortalidade. A incidência anual de HSAa é variável dependendo de regiões geográficas e condições climáticas ${ }^{1}$. A Organização Mundial da Saúde (OMS) reportou incidência (idade ajustável) de 10/100.000 em países da Ásia e Europa; de 2/100.000 na China e de 22,5/100.000 na Finlândia. Estimou-se uma incidência menor de HSAa na América Central e do Sul (Brasil). Na revisão sistemática de Feigin et al. demonstraram incidência variando de 2 a 16/100.000 ${ }^{6}$. Esses dados indicam influência de fatores ambientais ajuntados aos fatores de herança ancestral ${ }^{2,3}$.

A gênese dos aneurismas intracranianos permanece incerta, embora a teoria multifatorial seja mais apropriada. A influência étnica pode refletir a importância do fator genético no desenvolvimento e na evolução clínica dos aneurismas intracranianos ${ }^{4,5}$.

Os fatores de risco que influenciam a gênese e rotura dos aneurismas intracranianos podem ser modificáveis ou não modificáveis. Entre os diversos fatores, destacam-se o tabagismo e a hipertensão arterial sistêmica. Fatores como sazonalidade, localização e morfologia dos aneurisma podem influenciar o risco de rotura dos aneurismas intracranianos ${ }^{6}$.

Até o momento, não foram identificados biomarcadores genéticos que predizem risco de formação e sangramento de aneurismas intracranianos. Pesquisas no campo da genética poderão identificar os fatores de risco, genômicos e/ou epigenéticos, associados à HSAa. Cerca de $10 \%$ das HSAa possuem história familiar. Esse evento pode ocorrer em $2 \%$ dos parentes de primeiro grau que apresentaram 
HSAa, o que poderia aumentar o risco de HSA de 4 a 10 vezes quando comparado com população em geral ${ }^{7}$.

Trata-se de uma condição neurológica grave uma vez que, após rotura de aneurisma intracraniano, aproximadamente $12 \%$ a $15 \%$ dos pacientes morrem antes de receber atendimento pré-hospitalar. Embora haja ampla variação na incidência de aneurismas intracranianos nas diferentes populações do mundo, $25 \%$ dos doentes com HSAa morrem e $50 \%$ dos doentes evoluem com déficit neurológico permanente ${ }^{1}$.

O vasoespasmo encefálico (VE) representa uma das principais causas de morbimortalidade associadas à HSAa, alcançando 30\% de letalidade em 30 dias. Em geral, cerca de $70 \%$ dos pacientes com HSAa poderá apresentar vasoespasmo detectado por angiografia; deste grupo, 25 a 30\% apresentará sinais e sintomas clínicos associados à isquemia encefálica ${ }^{8,9,10}$.

No momento, não se conhece marcadores fidedignos para predição de prognóstico clínico da HSAa e VE. Na prática clínica, utiliza-se a escala de Fisher modificada, que leva em conta a quantidade de sangue nas cisternas e ventrículos encefálicos, e a escala de Hunt-Hess, que se baseia na apresentação neurológica inicial ${ }^{11,12}$.

Déficits neurológicos secundários ao VE apresentam amplo espectro de expressão clínica e evolutiva, mesmo nos pacientes com estratificação clínico-tomográfica similar e submetidos à mesma abordagem terapêutica, o que sugere que fatores proteicos, codificados geneticamente, estejam implicados na evolução natural da doença $^{13}$. A evolução clínica de pacientes com HSAa parece ser modulada geneticamente em termos genômicos (do DNA) e/ou epigenéticos ${ }^{14,15}$.

Esta hipótese foi levantada quando comprovou a possibilidade de predisposição genética para o espasmo coronariano ou angina de Prinzmetal ${ }^{16,17}$. A incidência mais elevada de espasmo coronariano na população japonesa comparada com a da 
população caucasiana ofereceu subsídios para esta hipótese ${ }^{18,19}$. Esta teoria fundamenta-se na predisposição genética dos indivíduos com polimorfismo no gene da óxido nítrico sintase endothelial (eNOS ou NOS3). Embora outros genes tenham sido relacionados ao stress oxidativo dos vasos, os resultados da literatura ainda não são consistentes. Nakayama relatou forte correlação entre espasmo coronariano e polismorfismo na posição T-786C do gene da eNOS, associado à citosina como alelo aberrante $^{20}$.

O gene eNOS promove a regulação do tônus vasomotor e o controle de mecanismos vasculares antitrombóticos a partir da síntese e liberação do óxido nítrico pelo endotélio vascular. Desde a década de 90, inúmeras variações alélicas do gene eNOS foram pesquisadas no contexto de doenças cardiovasculares. O gene da eNOS, localizado no cromossomo 7q35-36, apresenta três classes de variações que foram correlacionadas com doenças clínicas: $T-786 C$, que ocorre em região periférica do gene (conhecida como região promotora), 4-VNTR27, que ocorre na região íntron codificada e $G-894 T$, que ocorre na região éxon $7^{6}$.

Embora o polimorfismo do gene eNOS não seja considerado fator de risco de HSAa, a interação entre estes genes e fatores como sazonalidade, etnia, sexo, tabagismo e hipertensão arterial sistêmica podem influenciar o risco de HSAa e de suas complicações pós hemorragia ${ }^{21}$.

Starke et al. demonstraram que a ocorrência de $T-786 C$ no gene eNOS pode aumentar o risco de VE pós-HSAa; a identificação deste polimorfismo permite identificar indivíduos com risco elevado de VE pós- HSAa, o que possibilita intervenções individualizadas precoces e melhora do resultado clínico ${ }^{21}$. Segundo os autores, este genótipo pode ser considerado fator preditor de VE, independente da etnia, idade, sexo, uso de estimulantes, tabagismo, história familiar de sangramento de 
aneurisma e da escala de Fisher. Neste trabalho, pacientes com alelo $\mathrm{T}$ tiveram risco de VE sintomático 3 vezes maior, e aqueles com genótipo TT apresentaram risco 11 vezes maior ${ }^{21}$. Embora alguns estudos tenham demonstrado correlação entre polimorfismo do gene da eNOS e VE pós-HSAa, a maioria dos trabalhos não reproduziu esta correlação, provavelmente devido às diferenças étnicas e climáticas das diversas regiões do mundo ${ }^{22}$. Variações étnicas influenciam a incidência e prevalência do polimorfismo do gene $e N O S$ e podem determinar a evolução do VE pós-HSA ${ }^{21,23}$.

O Brasil possui heterogeneidade étnica bastante marcante. A classificação brasileira de raça, proposta por Nina Rodrigues (1890 e 1894), agrupou a questão étnica brasileira em raças puras (caucasoide, negroide, vermelha ou indígena) e mestiços (oriundos do cruzamento entre as raças). Os mestiços foram distribuídos em mulato (cruzamento entre caucasoide e negroide), mameluco ou caboclo (miscigenação entre caucasoide e indígena), curiboca ou cafuzo (entre caucasoide e índio ou mulato claro e índio) e pardo (mistura das raças). Durante a jornada evolutiva, novas etnias raciais surgiram após chegada da raça mongoloide, aumentando o número de cruzamentos e, por conseguinte, de mestiços no país. A fim de compreender a distribuição étnica no Brasil, Cardena et al. propuseram a distribuição genômica em haplogrupos mitocondriais, que reflete a ancestralidade materna; conforme percentuais de influência na população brasileira, três subgrupos podem ser considerados: ameríndio, europeu e africano ${ }^{24,25}$. Estudos da frequência alélica da população brasileira (da região Norte à Sul) confirmou esses três grupos étnicos ${ }^{26}$. 
Considerando que a população brasileira apresenta grande variabilidade étnica, resultante de miscigenação, espera-se igualmente grande variação de apresentação fenotípica, em termos de risco de VE pós-HSAa, na população geral.

Neste cenário, torna-se relevante traçar o perfil genético de pacientes com HSAa na região Amazônica e pesquisar potenciais biomarcadores que possam influenciar o prognóstico clínico destes pacientes. 
2. Objetivos

\subsection{Primário}

- Avaliar o papel de 14 biomarcadores genéticos no tocante ao vasoespasmo encefálico e déficit neurológico tardio nos pacientes da região Amazônica com HSAa.

2.2. Secundário

- Demonstrar a distribuição ancestral étnica nos grupos com e sem vasoespasmo clínico. 
REVISÃO DA LITERATURA 


\section{Revisão da Literatura}

\subsection{Problemática da hemorragia subaracnoidea aneurismática}

Dor em região cefálica (ou cefaleia) representa 1 a $2 \%$ dos atendimentos nas unidades de urgência, e mais de 4\% das consultas eletivas. A maioria destes pacientes apresentam cefaleia primária, tais como cefaleia vascular (migrânea), cefaleia do tipo tensional e cefaleia em salvas (cluster headache). Por outro lado, uma minoria destes pacientes pode apresentar cefaleia secundaria à HSAa, trombose venosa encefálica, tumor intracraniano, hidrocefalia, meningite, hipertensão intracraniana, dentre outras. Cefaleia do tipo "trovão" (thunderclap headache), sem sinais e sintomas neurológicos associados, podem ocorrer em $12 \%$ dos doentes com HSAa; quando associada a sinais e sintomas neurológicos, HSAa pode ser encontrada em $25 \%$ destes doentes ${ }^{27}$. Cerca de $30-40 \%$ dos doentes com HSAa apresentam cefaleia sentinela de forte intensidade, cerca de 2 semanas antes do sangramento do aneurisma) ${ }^{28}$.

A rotura de aneurisma encefálico manifesta-se com cefaleia de forte intensidade, descrita como "raio", "aperto" e/ou "pior cefaleia da vida" e é, com frequência, acompanhada de náuseas, vômitos, rigidez nucal e, às vezes, febre e diarreia $^{27}$; pacientes podem também cursar com disfunção cardiovascular, dentre outras $^{36}$. Dependendo da gravidade da HSA, sonolência, déficits neurológicos focais, coma e até morte súbita podem ocorrer (esta última pode ser observada em 10 a 15\% dos pacientes $)^{28}$.

Metade dos pacientes não possuem manifestação clínica típica devido a sangramento subaracnoideo discreto. Edlow e Caplan afirmaram que as principais causas da falta detecção da HSAa são: (1) não apreciação da possibilidade de HSAa devido a amplo espectro de apresentação clínica desta condição; (2) difículdade de 
interpretação da tomografia computadorizada (TC) do encéfalo no tocante à detecção de sangue em pouca quantidade; e/ou (3) limitação da punção do liquido cefalorraquidiano (não indicação de punção do líquido cefalorraquidiano ou falha técnica) $^{27}$. Esta falha não é rara, ocorrendo em $4 \%$ a $25 \%$ dos pacientes que tiveram $\mathrm{HSAa}^{27}$.

A HSA espontânea é considerada problema de saúde pública e é causada por rotura de aneurisma intracraniano em 80 a $85 \%$ dos casos. O rompimento de aneurisma encefálico causa sangramento no espaço subaracnoideo ${ }^{28}$. Complicações como morte súbita (10-15\%), hipertensão intracraniana $(25 \%)$, ressangramento precoce (nas primeiras 24h) $(12,3 \%)$, hidrocefalia aguda (15-20\%), vasoespasmo sintomático (25-30\%), déficit neurológico isquêmico (40\%) e mortalidade ao longo do tratamento $(50 \%)$ ocorrem frequentemente ${ }^{28}$.

\subsection{Considerações Históricas}

Após 25 séculos da primeira descrição da HSAa, essa entidade nosológica ainda apresenta taxa elevada de morbidade e mortalidade. Embora as descrições de Hipócrates apontem para um caso clínico clássico de evento hemorrágico intracraniano, foram Wiseman (1669) e Bonet (1679) que descreveram a possiblidade de ruptura de aneurisma intracraniano causando $\mathrm{HSA}^{29}$.

Essa possibilidade foi confirmada por Biumi, em 1778, ao demonstrar o primeiro caso de HSAa em termos anatomopatológico ${ }^{29}$. Em 1861, Quincke estudou a punção lombar para coleta do líquido cefalorraquidiano e demonstrou os primeiros casos in vivo de $\mathrm{HSAa}^{29}$. Em 1859, Sir William W. Gull, buscando compreender a HSA em necropsia, descreveu a constrição das artérias encefálicas, fenômeno atualmente conhecido como vasoespasmo encefálico ${ }^{29}$. 
O conhecimento sobre a doença foi sendo incorporado até a descrição clássica da síndrome clínica feita por Symonds em 1924 e a demonstração, feita por Sir. Howard Walter Florey, em estudos de laboratório evidenciando os efeitos mecânicos e elétricos na musculatura espástica das artérias intracranianas de felinos $(1925)^{29}$.

Em 1927, o português Antonio Egas Moniz, com a descrição do estudo encefalografia arterial cerebral, permitiu a identificação anatômica tanto da causa da HSAa como de suas possíveis complicações associadas ${ }^{29,30}$.

Zucker, em 1944, foi quem estudou o papel dos componentes do sangue relacionados com o desenvolvimento do espasmo nas artérias intracranianas ${ }^{29}$.

Em 1949, Robertson revisou uma casuística de pacientes com aneurismas cerebrais rotos e encontrou evidências de infartos cerebrais em locais com vasos patentes circundados por coágulos sanguíneos. A partir destes dados, propôs a hipótese da isquemia (déficit isquêmico tardio) estar associada ao espasmo temporário das artérias nas proximidades à área da hemorragia ${ }^{29}$.

Em 1951, Ecker e Riemenschneider descreveram pela primeira vez o vasoespasmo angiográfico em 6 casos de estreitamento arterial intradural reversível após rotura de aneurismas cerebrais ${ }^{29,31}$. Pool descreveu o quadro clínico clássico do déficit isquêmico tardio (DCI) em $1958^{29}$.

Nos últimos 60 anos, muitos avanços no conhecimento da fisiopatologia da HSAa e suas complicações possibilitaram a melhora no atendimento aos pacientes com aneurisma roto $^{32}$; assim como o conhecimento da biologia molecular e da genética médica aplicada tem auxiliado a desenvolver novas abordagens a fim de auxiliar na investigação e na terapêutica ${ }^{33,34}$. 


\subsection{Incidência e Prevalência da HSAa}

A HSAa é uma condição clínica grave com altas taxas de morbidade e mortalidade, representando cerca de $5 \%$ de todos os casos de acidentes vasculares cerebrais (AVC), em que que cerca de 30.000 americanos são afetados anualmente 35,36. Sua incidência anual é bastante variável, considerando regiões e condições climáticas distintas. Um estudo da Organização Mundial de Saúde (OMS) encontrou uma variação com incidência anual idade-ajustada em países da Europa e Ásia, de 2 casos por 100.000 população na China para 22,5 casos por 100.000 na Finlândia ${ }^{6}$. Uma recente revisão sistemática demonstrou que, em países como Japão e Finlândia, a incidência de HSAa foi alta e, para populações da região da América do Sul e Central, a incidência era baixa e, em outras regiões do planeta, a incidência foi intermediária de 9,1 para 100.000 habitantes $^{5,6}$ (Figura 1).

O banco de dados dos Estados Unidos da América (EUA) estima uma taxa anual de 14,5 casos por 100.000 ao ano entre adultos em 2007. Esses dados consideram os pacientes que evoluem à óbito antes de chegar ao atendimento hospitalar e perfazem cerca de $12-15 \%$ dos casos, o que subestima as estatísticas de eventos HSAa. Com isso, acaba determinando uma estimativa mais alta do que se consegue registrar ${ }^{2}$.

Embora seja incomum na infância a HSAa, as taxas de incidência têm aumentado tanto nas crianças como nos idosos, perfazendo de 0,18 a 2/100.000. A maioria dos estudos indica uma incidência maior em mulheres do que em homens, em torno de 1,24 vezes maior (intervalo de confiança de 1,09-,1,42), assim como uma média etária em torno de 45 a 55 anos de idade. Quando os grupos são estratificados quanto à idade-sexo, existe incidência mais elevada de homens jovens (25-45 anos de idade), mulheres entre 55 e 85 anos de idade e homens $>85$ anos de idade ${ }^{37}$. 
Em 2016, Malinova et al. demonstraram em uma amostra com 753 pacientes que o grupo < 38 anos possui maior risco de complicações hemodinâmicas encefálicas após um HSAa, podendo evoluir com altas taxas de morbi-mortalidade, secundárias ao déficit neurológico isquêmico tardio ${ }^{12}$.

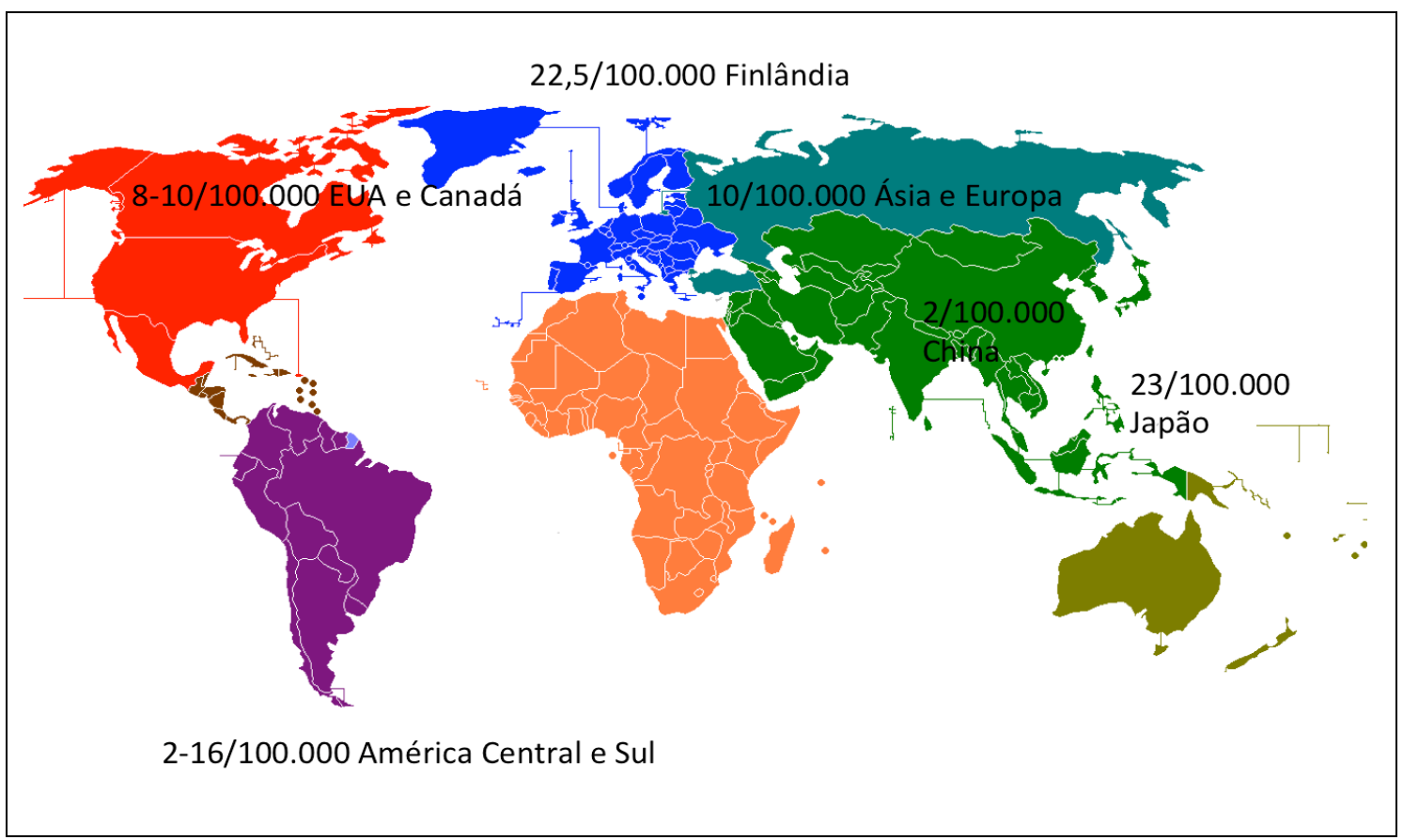

Fonte: https://www.google.com.br/search?q=mapa+mundi\&source Figura 1. Distribuição da incidência de HSAa nos continentes.

Apesar da gravidade da apresentação das HSAa com altas taxas de morbidade e mortalidade permanecerem elevadas globalmente, as taxas de letalidade no momento do ictus têm demonstrado uma tendência a declínio nos países desenvolvidos ou em desenvolvimento ao longo dos últimos 30 anos. A HSAa é considerada uma emergência médica e deve ser investigada imediatamente ao chegar em pronto atendimentos (Classe I, nível B segundo Guideline 2012 AHA/Stroke) ${ }^{2}$.

Em 1994, Inagawa demonstrou uma diminuição aproximada de 1\% ao ano entre 1974 e 1994. Esse padrão foi observado com o tempo, por outros autores, com a melhoria na assistência aos pacientes, determinando mudança no paradigma quanto à letalidade de $57 \%$ nos anos 1970 para 26 a $36 \%$ nos anos 80 e $90^{78,79}$. 
As taxas de mortalidade têm atingido cifras com uma variabilidade muito grande entre 8 a $67 \%$. E essas variações se tornam perceptíveis conforme o número de diferentes estudos vem sendo comparado em regiões distintas ${ }^{80}$.

A fim de compreender melhor e minimizar os riscos das complicações envolvidas no contexto dos aneurismas rotos, destacam-se alguns estudos que contribuíram para seleção de candidatos com AI incidental ao tratamento antes do evento hemorrágico se instalar ${ }^{61,62,63,64}$.

\subsection{Fatores de Risco para Desenvolvimento, Crescimento e Rotura dos}

\section{Aneurismas Intracranianos}

Autores como D'Souza (2015) estratificam os fatores de risco em dois grupos: aqueles em que se pode interferir na evolução natural, reduzindo as taxas de ocorrência de surgimento e até rotura dos aneurismas, conhecidos como fatores de risco modificáveis, e o outro grupo conhecido como fatores intrínsecos dos pacientes, os quais não podem ser alterados ${ }^{28}$.

\subsubsection{Fatores de Risco Modificáveis:}

Entre os fatores de risco modificáveis, estão os seguintes: hipertensão arterial sistêmica (HAS), tabagismo, etilismo, dislipidemia, uso abusivo de cocaína e diabetes mellitus. Entre estes, alguns possuem uma associação íntima com a indução à rotura, tais como o tabagismo e a HAS. O cigarro possui um papel fundamental neste contexto, considerando que acima de $80 \%$ dos indivíduos com experiência de HSAa foram expostos a história de uso do cigarro em algum momento da vida. A exposição aos agentes químicos é consistente, mas o mecanismo fisiopatológico ainda é pouco compreendido. Acredita-se que as vias das respostas imunológicas/inflamatórias sobre o sistema cerebrovascular sejam a luz no fim do túnel quanto à gênese $\mathrm{e}^{38}$. 
Alguns autores advogam que a formação e rotura dos aneurismas comecem com a disfunção endotelial, determinando alterações no fluxo e um estresse turbilhonado, em especial, nas bifurcações dos vasos intracranianos. A disfunção endotelial conduz a respostas compensatórias que alteram as propriedades do endolélio. O gatilho inflamatório com a liberação de citocinas, células inflamatórias e componentes imunológicos determinam um evento inflamatório endotelial no ponto com injúria vascular. Um importante aspecto nesta modulação fenotípica é a reação inflamatória sobre as células do músculo liso vascular ${ }^{39}$.

Essas mudanças conduzem ao remodelamento da matrix extracelular por meio da ativação das metaloproteinases (MMP), determinando a perda da camada elástica interna, afinando a camada média e formando o aneurisma, o que é conhecido como "vasculopatia aneurismática embriologicamente adquirida". Quando o processo inflamatório se perpetua, ocorre a perda das células musculares lisas com redução da síntese do colágeno e culminando com a quebra da matrix extracelular, e, por fim, a rotura do aneurisma com $\mathrm{HSAa}^{40,41}$.

Em um estudo de coorte com 487 pacientes, Connolly et al. avaliaram a importância do tabagismo na formação e na indução ao riso de desenvolver HSAa com apenas este fator de risco, comparando os diversos grupos etários, bem como, outros fatores de risco, como a hipertensão arterial sistêmica. Os mesmos autores mostraram que pacientes tabagistas possuem uma chance de desenvolver um aneurisma ou de este romper quando comparado ao grupo controle não tabagista é maior e atinge cifras dependentes da quantidade de cigarro utilizado. No grupo tabagista de mais de 2 maços/dia o risco é oito vezes maior, assim como quando comparado aos não fumantes este risco se mantém 8 vezes mais frequente. Esses 
dados são verdadeiros tanto para desenvolver aneurisma como para a rotura do aneurisma $(17 \% \text { versus } 2 \%, \mathrm{p}<0,001)^{38}$.

Os autores também mostraram que fumantes jovens possuem um risco similar aos indivíduos de meia-idade, assim como o cessar do cigarro parece proteger quanto ao risco de rotura e pacientes hipertensos tabagistas possuem um aumento pequeno de rotura quando comparado ao tabagismo isolado ${ }^{38}$. Segundo Connolly et al. ${ }^{38}$, a patogênese da formação e da rotura dos AI parece envolver não apenas forças degenerativas, tais como hipertensão ateroesclerose, mas também toxinas ambientais, tais como o tabaco, os contraceptivos orais e o álcool.

a) O Papel fisiopatológico do cigarro:

Chalouhi et al., em um artigo de revisão, reportam que mais de $80 \%$ dos indivíduos com história de HSAa tiveram, em algum momento, tabagismo e, entre 50$60 \%$ dos que apresentaram o quadro ictal, estavam na vigência do tabagismo. Segundo os autores, a exposição aos produtos químicos do cigarro tem mostrado dados consistentes com inúmeras vias com resposta imunológica/inflamatória no sistema cerebrovascular ${ }^{41}$.

O fumo passivo tem sido demonstrado como um importante contribuinte para doença cardiovascular, bem como, para o AVC isquêmico, porém com dados que subestimam sua importância na gênese da HSAa ${ }^{42}$.

Segundo Kataoka et al., dados demonstram que os aneurismas intracranianos começam sua formação com a disfunção endotelial a partir de respostas nas alterações do fluxo e da força dos vetores em "tosqueamento" 40.

A disfunção endotelial conduz a uma resposta compensatória que alteraas propriedades homeostáticas do endotélio normal. Na sequência, ocorre a mudança funcional e estrutural do endotélio, com um gatilho dependente da quantidade de 
resposta inflamatória na parede do vaso que se encontrará envolto de leucócitos, citocinas, adesão de moléculas, imunoglobulinas, complemento e muitas outras vias da cascata inflamatória ${ }^{43}$.

Um aspecto importante da reação inflamatória é a modulação fenotípica das células musculares lisas do vaso $(V S M C)$ de uma fenotipagem contrátil e diferenciada para uma fenotipagem pró-inflamatória e diferenciada. Essas mudanças de forma coletiva conduzem a mudanças na matriz extracelular remodelando por meio das matrizes de metaloproteinases (MMP) com perda da camada elástica interna, afinando a espessura da parede da média do vaso e, assim, formando o aneurisma ${ }^{44}$. O processo inflamatório quando se perpetua, e a perda da VSMC com diminuição da síntese do colágeno e o excessivo desarranjo da matrix extracelular culmina com a ruptura do aneurisma e a $\mathrm{HSAa}^{45}$.

A habilidade do cigarro em induzir a disfunção endotelial nas artérias cerebrais tem sido muito bem documentada por meio de experiências, tais como evidenciado em um experimento em que células lipídicas solúveis ao fumo foram cultivada em células de cultura endoteliais e, assim, reduziram o relaxamento das artérias cerebrais. Do mesmo modo, o cigarro parece induzir a apoptose endotelial por meio da caspase $-3^{46}$.

A disfunção endotelial cigarro induzida parece ser primariamente causada pela inativação acelerada do NO (uma importante substância crítica vasodilatadora para homeostase endotelial normal) devido à aumentada produção da reação oxigênio específica (ROS). O mecanismo parece envolver inúmeros sistemas enzimáticos chave, incluindo a oxidase NADH/NADPH e a oxidase xantina, ambos dos quais contribuem para a $\operatorname{ROS}^{46}$. 
A óxido nítrico endotelial síntase (eNOS) protege a parede arterial da inflamação vascular por meio do alívio ao estresse hemodinâmico via produção de óxido nítrico (NO). Com base nesta, teoria Aoki et al. examinaram o papel da eNOS na patogênese do aneurisma cerebral e relataram um papel protetor da eNOS contra a formação do aneurisma cerebral e contra a inflamação cerebrovascular. Pois a nicotina no cigarro mostrou suprimir o papel protetor da eNOS por meio da produção de superóxido de ânions, além disso, aumenta a expressão de óxido nítrico induzível sintase (iNOS), que ativa as resposta de estímulo inflamatório e contribui para várias doenças inflamatórias ${ }^{47}$.

Esta situação é de extrema relevância para os aneurismas cerebrais, pois a iNOS está envolvida com o crescimento do tamanho dos aneurismas, assim como com a morte celular da parede do vaso, o que pode determinar a rotura desse determinando uma $\mathrm{HSAa}^{48}$.

A atividade pró-inflamatória do cigarro no nível endotelial estende-se para aexpressão da adesão vascular de inúmeras moléculas por meio das células endoteliais que promovem a aderência de células inflamatórias circulantes para a superfície endotelial luminal, seguido de suas migrações e resultante das respostas inflamatórias vasculares. Além disso, a nicotina afeta as "tight junctions" por meio da diminuição da expressão do ZO-1, ocludina, caderina e de proteínas de junção que conduzem a migração de macrófagos e outras células inflamatórias para dentro da parede do vaso e, por conseguinte, dos aneurismas quando formados, contribuindo a perpetuação do processo inflamatório ${ }^{49}$.

Uma série de evidências sugerem que a VSMC constitui uma parte integral das vias que conduzem à formação e rotura dos AIs. Assim como na ateroesclerose, a VSMC migra para dentro da íntima da parede dos aneurismas em que eles proliferam 
e produzem a hiperplasia miointimal ${ }^{50}$. O VSMC experimenta uma modulação fenotípica de um fenótipo diferenciado envolvido com a contração primariamente (caracterizado pela expressão de genes/proteínas contráteis, tais como a miosina muscular lisa de cadeia pesada (SM-MHC) e a actina $\alpha$ muscular lisa) para um fenótipo remodelado pró-inflamatório/ pró-matrix caracterizado pela expressão aumentada de citocinas, MMP e $\operatorname{ROS}^{51}$.

Essa modulação fenotípica é mediada por algumas substâncias mediadoras e de conhecimento na atualidade de uma via bem estabelecida é feita por meio do fator transcriptante KLF4, e parece sofrer influência de vários fatores inflamatórios, incluindo a interleucina-1ß (IL-1ß), fator de crescimento derivado de plaqueta (PDGF), fosfolípide oxidase, fator de necrose tumoral - $\alpha$ (TNF - $\alpha$ ), Est-1 e AT II. Um último evento envolve a perda da VSMC da parede dos aneurismas cerebrais com resultante afinamento da camada média e consequente rotura do aneurisma com $\operatorname{HSAa}^{52}$.

Inúmeras citocinas estão aumentadas mediante o uso ativo do cigarro. Especialmente, entre os fumantes, níveis mais altos de IL-1 $\beta, T N F \alpha$ e IL-6, em que todos contribuem de forma significativa para fisiopatologia do AI e seu desenvolvimento até rotura quando se instala ${ }^{53}$.

De fato, acredita-se que a IL-1 $\beta$ é a chave responsável como mediadora inflamatória no AI, assim como no rompimento, no gene da IL-1, está diminuída a incidência de aneurismas maduros em modelos animais. A IL-1 $\beta$ age, primariamente,

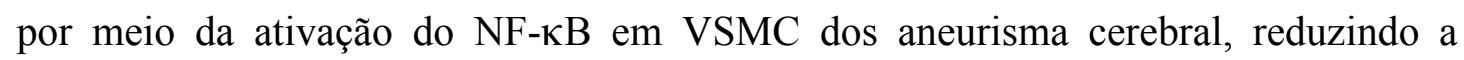
biossíntese de colágeno e promoção da morte celular apoptótica. Da mesma forma o TNF $\alpha$ mostrou induzir que a apoptose do VSMC na parede dos AIs enquanto são também ativados MMP e degradação da parede vaso. A IL-6 pode também ter um 
papel importante na gênese do AI de acordo com a informação genética individual, assim como outros mediadores inflamatórios ${ }^{54}$.

Enfim, de um modo geral, existe um complexo de interação bastante interessante entre a exposição do cigarro e suas toxinas com a inflamação vascular, culminando com a formação e a rotura dos aneurismas intracranianos. O cigarro parece afetar cada etapa na cascata de eventos que conduzem à HSAa desde o estresse hemodinâmico e disfunção endotelial até a fragilidade da parede do aneurisma e sua rotura (Figura 2).

\subsubsection{Fatores de Risco Não Modificáveis:}

Por outro lado, fatores de risco não modificáveis independem da interferência externa em adquirir ou não o risco de desenvolver, crescer e romper um aneurisma. Entre esses, estão envolvidos: o sexo feminino, o grupo etário, a presença de parentes de $1^{\circ}$ grau com história de sangramento (risco aumenta em 4\%), assim como as doenças tais como: displasia fibromuscular, síndrome de Ehlers Danlos, síndrome de Marfin, Doença Renal Policística, Neurofibromatose tipo I, doenças do colágeno tipo III, Pseudoxantoma Elasticum e Coarctação da Aorta. Entre outras situações não modificáveis, estão os portadores de malformação $\operatorname{arteriovenosa~}^{36}$.

As doenças cujo risco se faz inerente e não modificável abre a luz do conhecimento para genes candidatos que estão associados com o aparecimento e com a rotura, assim como seu desfecho mediado biologicamente por meio de mecanismos moleculares inflamatórios.

Neste cenário, se faz importante o conhecimento da genética e da epigenética como fatores delineadores do curso a ser traçado para cada paciente ao longo da vida até o desfecho de uma HSAa. 
Além dos critérios da informação genômica para gênese, rotura e o grau resposta inflamatória ao sangramento, tanto a localização como a geometria (variação anatômica do vaso adjacente, tamanho e regularidade) do aneurisma são importantes na determinação do sangramento e da quantidade de sangue que se distribui tanto nas cisternas como nas cavidades ventriculares. Isto é, aneurismas maiores e mais irregulares tendem a sangrar mais e a terem uma morbi-mortalidade maior $28,55,56$.

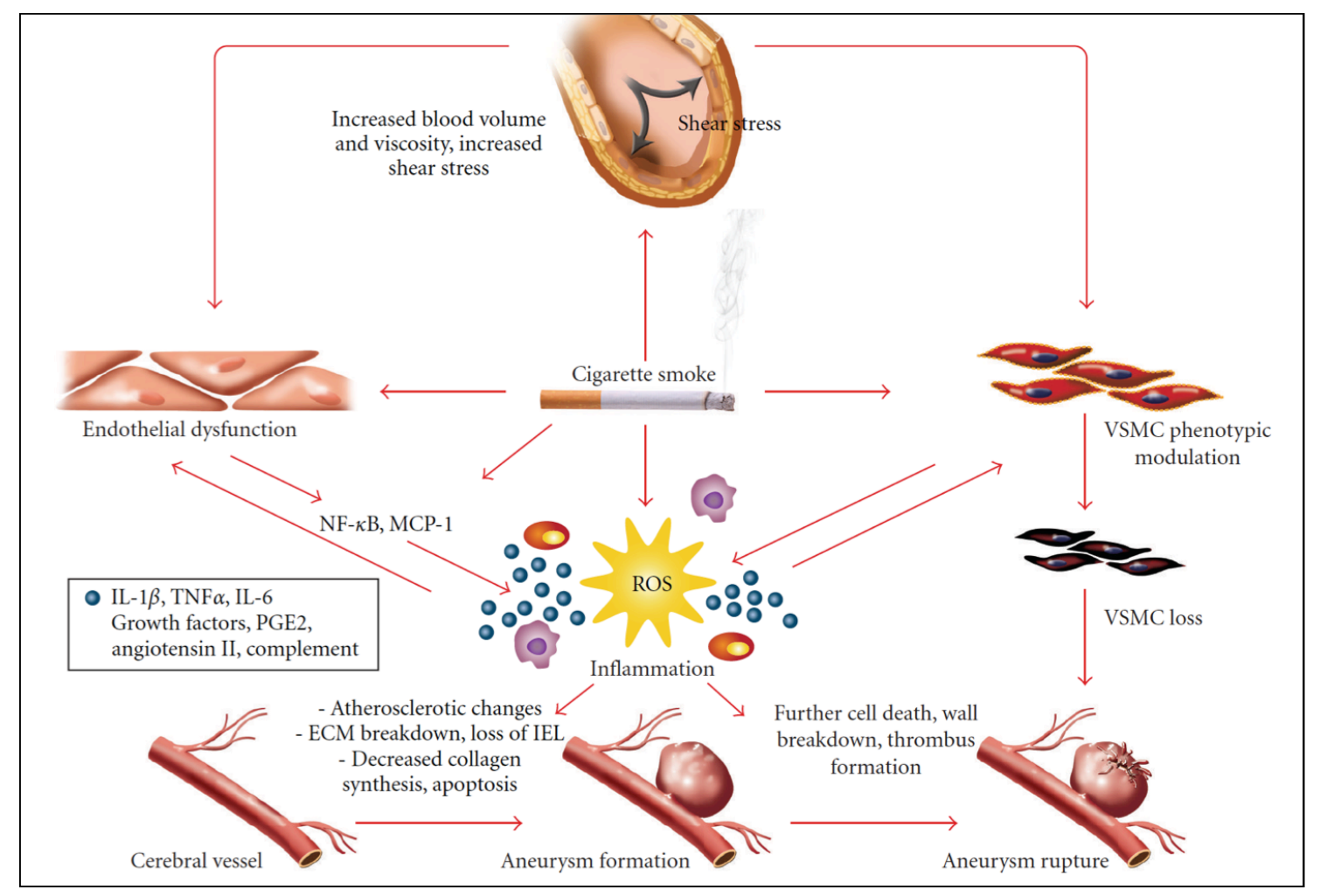

Fonte: Chalouhi et al., 2012.

Figure 2. Mecanismos fisiopatológicos do cigarro, influenciando a formação e rotura dos aneurismas com influência no vasoespasmo encefálico.

A maioria dos aneurismas intracranianos ocorre na circulação anterior do Círculo de Willis, enquanto aneurismas da circulação posterior representam em torno de $14 \%$, em qe os aneurismas em situação da basilar são os mais frequentes (Figura 3). De acordo com o ISUIA (International Study of Unruptured Intracranial Aneurysms), em que 4060 pacientes com aneurismas não rotos foram incluídos no 
estudo, cerca de $35 \%$ dos pacientes apresentavam mais de um aneurisma. O aneurisma mais frequente foi o sacular em $90 \%$ dos casos. Uma coorte retrospectiva do ISUIA identificou o risco de rotura de $0,05 \%$ ao ano para aneurismas $<1 \mathrm{~cm}$, enquanto aneurismas com $\geq 1 \mathrm{~cm}$ e da circulação posterior possuíam um risco aumentado para rotura. Uma coorte prospectiva em 5 anos com os dados do ISUIA foi desempenhada mostrando que o risco cumulativo neste período para aneurismas abaixo de $7 \mathrm{~mm}$ era de $0 \%$ na circulação anterior e $2,5 \%$ para o mesmo tamanho na circulação posterior. $O$ risco de rotura é maior nos aneurismas gigantes $(\geq 2,5 \mathrm{~cm})$, o que se observou foi de $40 \%$ para circulação anterior e de $50 \%$ para circulação posterior. Em ambos as versões do ISUIA demonstraram alta incidência de rotura na circulação posterior ${ }^{62,63}$.

Com base nos dados do ISUIA, Greving et al. descreveram um score PHASES para predizer o risco de rotura dos aneurismas intracranianos, considerando inúmeros fatores de risco, que, por meio de uma análise multivariada, permitiram estratificar o risco em 5 anos de rotura de um aneurisma; entre esses: a etnia, a presença de HAS, a idade, o tamanho do aneurisma, a história de HSAa precoce e a localização do aneurisma ${ }^{64}$ (Anexo A).

Alguns achados se mostram bastante favoráveis a um risco maior ou menor quanto à chance de rompimento do AI. Entre esses, destacam-se: (1) aneurismas na circulação anterior são mais propensos a romper em pacientes com $<55$ anos de idade, com as características de se situarem no segmento comunicante anterior da carótida interna no sexo masculino e aneurismas da artéria basilar na associação com o etilismo; (2) o tamanho dos aneurismas rompem parece ser menor naqueles pacientes em combinação da hipertensão com o tabagismo do que comparado com aqueles com fatores de risco isolado; (3) eventos problemáticos pessoais de vida no 
período de um mês mostraram-se estatisticamente relevantes para aumentar o risco de HSAa; e (4) aneurismas $>7 \mathrm{~mm}$ têm sido relacionados como um fator de risco importante para rotura ${ }^{6,57,58}$.

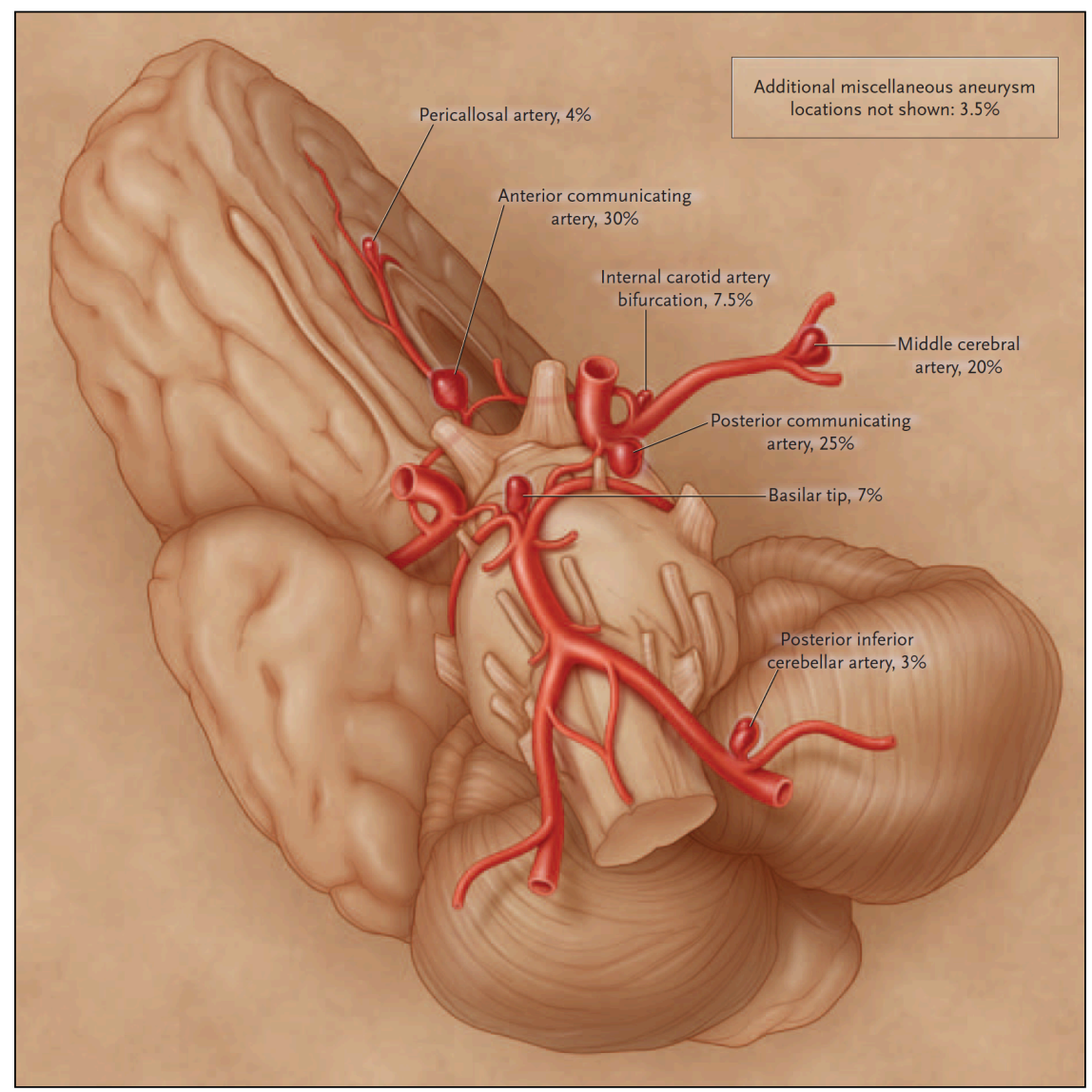

Fonte: Brisman et al., 2006.

Figura 3. Distribuição dos aneurismas conforme a localização

Entre outros fatores de risco que contribuem para reduzir o risco de HSAa, estão claramente atribuíveis menor massa corporal, menor taxa de colesterol e menor uso de nicotina ao longo do tempo. Os estudos têm demonstrado que o tipo de dieta aumenta do risco de stroke e, em particular, de HSAa ${ }^{6}$.

$\mathrm{O}$ crescimento de um AI incidental individual e seu potencial risco de rotura ainda permanece como um problema quanto a prever a chance de HSAa. Alguns achados com imagem de ressonância magnética em pacientes acompanhados com 
aneurismas $\geq 8 \mathrm{~mm}$ tendem a crescer mais ao longo do tempo, o que implicaria em maiores chances de rotura pelo aumento do diâmetro circunferencial ${ }^{59}$.

Por outro lado, outros estudos de imagem tentaram demonstrar a atividade inflamatória na parede dos vasos de doenças cerebrovasculares com o intuito de demonstrar que esta atividade pode estimar a chance de rompimento daquele vaso quer em um aneurisma quer em uma malformação arteriovenosa, esses estudos serviram para demonstrar como funcionariam como sinalizadores do risco de rotura de uma AI incidental analisado por IRM; nesta série de pacientes com a lesão aneurismática, foram avaliados com o uso de um contraste à base de ferro (Ferumoxitol, 5mg/Kg), e obtidas imagens de IRM nas sequências em T2 GE e T1 na aquisição inicial, e comparadas 72 horas após a infusão do meio de contraste ${ }^{61}$.

O princípio do experimento se baseia no uso do meio de contraste Ferumoxitol em IRM, o qual permite a detecção da atividade fagocitária das principais células inflamatórias envolvidas com a formação e rotura dos AIs, os macrófagos, que acabam por fagocitar o meio de contraste, que é rico em Ferro e permite a emissão de sinal detectável pelas sequências de IRM. O princípio se baseia na possibilidade de um processo inflamatório em atividade na parede de um AI com um biomarcador disponível pela imagenologia capaz de predizer o risco de rotura iminente. O ferumoxitol se torna absorvível pelos macrófagos da ECM quando da presença de processo inflamatório em atividade, demonstrando ser um fator de risco para HSAa $41,55,60$

Outros autores demostraram em relatos de caso que o edema perilesional na parede de um AI incidental avaliado nas sequências em T2 e FLAIR seriam preditores de uma possível hemorragia, assim como descrito por Hiu et al., que descreveu o primeiro caso com esse tipo de achado. A explicação que os autores sugerem é 
baseada na formação das lobulações, o que determinaria adelgaçamento da parede , funcionando com uma hemorragia sentinela e, com isso, permitindo o aumento até o ictus propriamente dito. Esse mecanismo visualizado macroscopicamente pela IRM, nas sequências em especial, representa o marco anatomopatológico da disfunção endotelial $^{61}$.

\subsection{Mecanismos Moleculares da Formação e da Progressão dos} Aneurismas Intracranianos e Parâmetros Inflamatórios Após a HSAa

Apesar dos avanços tecnológicos na abordagem cirúrgica e no manejo medicamentoso da HSAa, ainda assim, existe uma resultante com altas taxas de morbidade e mortalidade neste grupo de pacientes. Embora seja alarmante sua apresentação, e não usual, ocorrendo em 1 a $2 \%$ dos indivíduos portadores de aneurisma/ por ano, a descoberta de um aneurisma incidental se torna um dilema em que o paciente se encontra diante da possibilidade de uma lesão encontrada acidentalmente se tornar rota e o prognóstico se desenvolver completamente diferente quando comparado ao tratamento eletivo. Neste contexto, inúmeros esforços tanto no aspecto de selecionar os casos com maiores chances de rotura de um aneurisma como de pesquisas com esforços no que concerne a identificação de biomarcadores tanto de imagem como laboratoriais para determinação dos candidatos sob maior risco de rotura tem sido a premissa e o foco de muitas pesquisas no campo das doenças cerebrovasculares, isto com o objetivo de encontrar subsídios que expliquem a formação e a rotura dos AIs por meio de mecanismos biomoleculares e que permitam novos tipos de intervenção ${ }^{65}$.

A formação do AI é caracterizada por um grupo distinto de mudanças na arquitetura da parede arterial. Modelos animais têm sugerido que a perda da camada elástica interna (IEL) ocorre precoce no curso da doença, seguida pela hiperplasia da 
túnica íntima e que uma desorganização da VSMCs na túnica média estariam envolvidos neste processo histopatológico. Além disso, existe uma diminuição geral na celularidade do tecido, que, ao longo das mudanças na composição da matrix extracelular, corroboram para a formação da vasculopatia. O colágeno I e a Fibronectina são distribuídos ectopicamente, e a predominância normal do colágeno tipo III/IV e da lâmina encontram-se diminuídos. Funcionalmente, os aspectos-chave do AI demonstrados em modelos animais incluíram a disfunção endotelial com a ativação do endotélio vascular no curso do processo, bem como, a apoptose da VSMC e a modulação das VSMCs para um fenótipo polarizado em direção ao remodelamento da matrix extracelular (ECM) e sinalização inflamatória. A história natural dos AIs não parece ser homogênea; o processo de formação, progressão e rotura são conduzidos por mecanismos diversificados ${ }^{66}$.

Descobertas recentes suportam a teoria que a rotura (HSAa) em particular venha a ser um evento distinto, que possui implicações importantes para o desenvolvimento de estratégias terapêuticas, considerando o impacto socioeconômico que a apresentação manifesta como doença de importância em saúde pública ${ }^{42}$. No momento, muitos dos achados histopatológicos subjacentes aos AIs são considerados como resultante final de um processo inflamatório crônico na parede dos vasos arteriais, mas, até o nosso conhecimento nos dias atuais, as informações disponíveis quanto aos mediadores, biomarcadores e mecanismos biológicos envolvidos permanecem fragmentados ${ }^{66}$.

As características biológicas dos AIs compartilham de muitas similaridades com a ateroesclerose. De fato, as duas entidades parecem se sobrepor para um âmbito significativo. Um destes aspectos-chave na ateroesclerose é o acúmulo e a oxidação lipídica na parede vascular ${ }^{68}$. 
As similaridades no aspecto histopatológico, em conjunto com fatores de risco, sugerem que os mecanismos subjacentes à patogênese da vasculopatia aneurismática e a ateroesclerose são similares ${ }^{68}$.

Considerando a hipótese dos achados entre duas doenças com desfechos diferentes, mas como achados incomuns os mediadores inflamatórios no processo de cronificação, algumas considerações sobre toda a cascata inflamatória deve ser considerada na fisiopatologia da formação progressão e rotura dos AIs.

\subsubsection{Os Macrófagos}

A presença dos macrófagos nas doenças vasculares tem mostrado ser uma característica central tanto nos AIs como na ateroesclerose. Essas células do tecido conjuntivo derivam dos monócitos do sangue e de células conjuntivais e endoteliais, sendo que, na situação dessas duas entidades, representam a maioria do infiltrado leucocitário e estão associadas com alto risco de rotura ${ }^{44,68}$.

Os macrófagos são imputados no processo da ateroesclerose, bem como na formação e no desenvolvimento, e como biomarcadores associados à rotura dos aneurismas cerebrais ${ }^{44}$. Kanematsu et al. replicaram as características histológicas do aneurisma humano no modelo do rato, mostrando um grande infiltrado leucocitário dentro da parede dos aneurismas, composto, em especial, pelos macrófagos. Os mesmos autores demonstraram que a depleção dessas células por meio do tratamento com clodronato lipossomal reduz a incidência de aneurismas ${ }^{69}$.

O mecanismo pelo qual os macrófagos participam da patogênese do AIs pode ser dividido em duas categorias: remodelagem da ECM e elaboração das citocinas inflamatórias $^{71-74}$.

Os efeitos direcionados dos macrófagos sobre o remodelamento da ECM são o ponto-chave na sinalização dos efeitos pró-inflamatórios. Os macrófagos secretam um 
número de fatores que têm sido implicados na gênese dos AIs, incluindo o TNF- $\alpha$ IL- $1 \beta$ e IL- $6^{41}$.

O fator de necrose tumoral alfa está bem caracterizado como um mediador da patogênese do AI. Um certo número de polimorfismos nucleotídeos únicos (PNU) no gene regulador do TNF- $\alpha$ foi identificado como um fator de risco para AI e HSAa em pacientes, e, em espécimes humanas com aneurismas, mostraram aumento desta molécula $^{54,76}$. Evidências em níveis séricos aumentados do TNF- $\alpha$ estão associadas à HSA e também sinalizam que o evento foi relacionado à rotura de um AI, podendo também sinalizar a formação de um AI ainda não roto ${ }^{54}$.

Existem evidências científicas de que a inflamação é o fator principal na patogênese dos AI rotos e não rotos, bem como elucida os mecanismos envolvidos que poderiam servir de alvos para o desenvolvimento de um melhor tratamento. Esforços em pesquisas focadas e sustentadas financeiramente serão necessárias para caracterizar completamente a imunopatologia do $\mathrm{AI}^{39}$.

\subsubsection{Achados Patológicos da Saculação Aneurismática}

A existência de um infiltrado despositado de fibrina no espaço subintimal, com a presença de trombo laminar organizado, hematoma intramural, neurovascularização e infiltração monocitária, é achado muito frequentemente observado nos aneurismas rotos e que está aumentado nos rotos. Os achados de depósito subintimal de fibrina e da inflamação cronificada têm um forte impacto sob a degeneração da parede dos aneurismas, conduzindo para sua rotura e os mesmos achados possuem o cerne do problema na disfunção endotelial ${ }^{77}$.

A formação, o aumento e a rotura dos aneurismas estão fortemente associados a um intenso processo inflamatório crônico, especialmente, mediado pelos linfócitos T e macrófagos ${ }^{77}$. A inflamação crônica possui um papel fundamental na condução da 
degeneração da parede do aneurisma e um aumento potencial no risco de rotura, determinando $\mathrm{HSAa}^{40,43}$. Estudos anatomopatológicos sugerem que a inflamação na parede do aneurisma e a trombose laminar estão associadas à rotura dos aneurismas, porém, ainda assim, os mecanismos que conduzem à hemorragia subaracnoidea, permanecem obscuros ${ }^{43}$.

Hokari et al. analisando 40 peças de indivíduos com aneurisma demonstrou que alguns achados anatomopatológicos são comuns entre os aneurismas rotos e não rotos, entre eles: fragmentação da camada elástica interna, hiperplasia miointimal e afinamento da parede do aneurisma. Por outro lado, alguns achados foram típicos do grupo de pacientes com rotura, assim como: trombo laminar organizado, deposição de fibrina subintimal, hemorragia intramural e neovascularização ${ }^{76}$.

\subsection{Contribuição Genética no Desenvolvimento e Rotura dos Aneurismas}

Muitas das terapias que vêm sendo testadas para as diversas doenças, em especial aquelas envolvidas com o erros inatos do metabolismo e as doenças com forte componente inflamatório associado, baseiam-se no rastreio ou no tratamento como fundamentação na informação da genética.

O conhecimento dos tipos de alterações genéticas que podem estar envolvidos com o desenvolvimento e até rotura de um aneurisma auxiliam na melhor forma de compreender o prognóstico de uma possível rotura, assim como tem estimulado pesquisadores a desenvolverem fármacos capazes de estabilizar ou evitar a progressão da vasculopatia aneurismática, muito embora ainda não seja possível avaliar de forma pragmática o que se encontra no laboratório na prática diária, considerando preceitos éticos humanos ${ }^{76}$.

Neste contexto, os genes são considerados as unidades elementares na informação genética. Eles, quando se apresentam com alelos variantes, podem ser 
caracterizados tecnicamente como polimorfismos se a segunda forma mais comum possuir frequência igual ou superior a $1 \%$ em uma população ${ }^{81}$. Alguns polimorfismos podem interferir nos níveis de expressão gênica, além de representar a fonte de uma parte considerável na variabilidade estrutural e funcional de uma proteína $^{82}$.

Uma diversidade de tipos de polimorfismos estão presentes no genoma humano, tanto em regiões codificantes como não codificantes. Algumas formas conhecidas e investigadas em diversas linhas de pesquisa são os SNP's (Single Nucleotide Polymorphism) conhecidos como polimorfismo nucleotídeo único (PNU), INDEL's (Insertion/Deletion), STR's (Short Tandem Repeat) e VNTR's (Variable Numbers of Tandem Repeat $)^{83}$.

Os polimorfismos apresentam, em geral, frequências alélicas distintas entre os subgrupos populacionais humanos. Essas diferenças foram estabelecidas no decorrer do processo de ocupação e distribuição dessas populações entre os continentes, por meio de mecanismos que alteraram a composição gênica (efeito de fatores evolutivos) ou tão somente a frequência genotípica pelo aumento da homozigose (efeito dos casamentos consanguíneos, por exemplo) ${ }^{83}$.

Entre outras implicações, diferenças populacionais em relação à distribuição alélica de polimorfismos funcionais podem originar variabilidade na susceptibilidade às doenças, no desenho e na interpretação de ensaios clínicos farmacogenéticos, na prescrição de medicamentos e, ainda, inviabilizam a extrapolação imediata dos resultados de estudos envolvendo esses processos para outras populações ${ }^{84-86}$.

Nas últimas décadas, com os avanços tecnológicos e com o conhecimento a acerca da arquitetura genômica, foram desenvolvidos métodos capazes de caracterizar fenótipos de interesses científicos e/ou econômicos. Uma das possibilidades é a 
identificação e uso de polimorfismos genéticos associados a esses fenótipos. Esses polimorfismos são denominados marcadores genéticos e possuem ampla utilização em estudos de associação clínica, em farmacogenética, em análises forenses, na antropologia biológica $^{88-89}$.

De forma pragmática, esses marcadores podem auxiliar na avaliação dos pacientes em diversos estágios de uma doença, incluindo na avaliação dos riscos em desenvolver doenças e suas complicações, na identificação de indivíduos com doenças subclínicas, no diagnóstico e prognóstico adequado da doença, bem como no monitoramento da resposta ao tratamento ${ }^{90}$.

Quando consideradas doenças complexas, tal como os aneurismas intracranianos e suas complicações, em adição ao alto risco propiciado por mutações altamente penetrantes, existem inúmeras mutações de baixa e moderada penetrância (risco baixo ou moderado, respectivamente) que, cumulativamente, aumentam o risco de um indivíduo desenvolver doença e que podem representar bons marcadores ou potenciais marcadores genéticos ${ }^{91-94}$.

Embora novos marcadores possam ser identificados em qualquer classe de polimorfismo, as variantes do tipo INDEL vêm tornando-se alvo constante em estudos de associação genética das doenças, em vista do seu potencial para afetar a função gênica e, consequentemente, causar doenças ${ }^{95}$. Esta classe de polimorfismo representa o segundo tipo mais comum de variante estrutural humana e pode causar disfunção gênica de modos variados, podendo afetar diretamente a sequência de aminoácidos ou, ainda, a expressão gênica quando presente em regiões reguladoras ${ }^{96-}$ 98

Uma característica importante dos "INDEL's" é que o grau de modificações ou danos causados está relacionado ao número de nucleotídeos inseridos ou deletados. 
Se esse número for múltiplo de três, ocorre adição ou eliminação pontual de aminoácidos. Por outro lado, se o número de nucleotídeos não for múltiplo de três (mutações frameshift), ocorre mudança completa da matriz de leitura ou término prematuro da tradução, alterando toda a sequência de aminoácidos após o segmento modificado ${ }^{97}$.

Uma série de genes candidatos têm sido imputados como participantes na gênese e na rotura dos aneurismas intracranianos (AIs), determinando fatores capazes de pior o evento após uma hemorragia. A maior parte desses genes tem sido associados com a formação da parede vascular, assim como, no remodelamento da matrix extracelular ${ }^{33,99}$ (Anexo I).

A HSAa é uma apresentação grave dos AI, possuindo no seu cerne os distúrbios genéticos como os determinantes da susceptibilidade para desenvolver, aumentar, romper e complicar as vasculopatias desta natureza. Apesar de uma série de pistas e informações já terem sido mapeadas, os biomarcadores ainda não possuem evidências científicas capazes de permitir a atuação de forma mais efetiva, reduzindo o risco da gênese, rotura ou complicações dos AIs. Muito embora esses marcadores possam auxiliar na investigação ou no manejo de forma mais cuidadosa em grupos selecionados ${ }^{65}$.

\subsubsection{Biomarcadores Genéticos}

a) Marcadores genéticos para HSAa e VE

\section{a.1 - Apolipoproteína $\mathrm{E}(\boldsymbol{A P O E})$}

O polimorfismo do gene APOE, situado no cromossomo 19q13.32, é um dos mais estudados em doenças vasculares e neurológicas. Seu produto proteico é uma glicoproteína de 34-KD (quilogramas Dalton) com 3 isoformas, E2, E3 e E4, codificadas pelos alelos $\varepsilon 2$, $\varepsilon 3$ e $\varepsilon 4$, respectivamente. Portanto, 6 combinações de 
genótipos são possíveis na população em cerca de 50 a $66 \%$. A $A P O E$ é um importante mediador do transporte do colesterol no cérebro, com um papel na redistribuição dos lipídios que são cruciais para a manutenção da membrana, reparo neuronal, regeneração e regulação do remodelamento sináptico após um evento isquêmico cerebral e lesão cerebral. Em geral, a presença do genótipo ع4+ pode estar associado com um pior prognóstico da HSAa, com risco relativo de 1,4-2,6 maior ${ }^{100}$.

Muito embora, Wu et al. enfatizaram os achados de PNU no gene da apolipoproteína E $(A P O E)$ associados com o acidente vascular cerebral hemorrágico $(\mathrm{AVCH})$ entre outras doenças neurológicas ser intimamente relacionado ${ }^{113}$. Porém, quanto à formação e rotura dos aneurismas, o gene está associado em sua região promotora com o maior risco de $\mathrm{VE}^{101}$. Com base nesses achados, Juvela et al., em um estudo de coorte prospectivo, descreveram que o PNU da $A P O E$ não está associado com pior prognóstico ${ }^{100}$.

\section{a.2 - Haptoglobina $(\boldsymbol{H p})$}

A haptoglobina foi primeiro descrita por Polonovski e Jayle (1938), caracteriza-se por ser uma $\alpha 2$-sialoglicoproteína sintetizada pelos hepatócitos em resposta à secreção de citocinas, tais como $I L-6$ (interleucina - 6), $I L-1$ (interleucina1) e fator de necrose tumoral $(T N F)$. A estrutura desta proteína é tetramérica similar a certas imunoglobulinas por ocasião da presença de duas cadeias leves e pesadas. Seu gene situa-se no cromossomo $16 \mathrm{q} 22.2^{102}$.

A destruição intravascular dos eritrócitos no percentual de 10-20\%, libera a hemoglobina que se liga à haptoglobina para formar o grupo heme. A função primária da Hp é se ligar à hemoglobina, e, com isso, prevenir a excreção renal de ferro e proteger os vasos sanguíneos dos efeitos oxidativos desta proteína ${ }^{102-103}$. 
Alguns estudos encontraram variações da haptoglobina $(\mathrm{Hp})$ envolvidos com a possibilidade de piora dos pacientes após a HSAa ${ }^{103-104}$. A haptoglobina é uma molécula que se liga à hemoglobina liberada pelos eritrócitos após a HSAa e possui alta afinidade, prevenindo os processos oxidativos. O gene da $H p$ no ser humano possui 3 polimorfismos (Hp 1-1, 2-1 e 2-2). Recentemente, uma metanálise demonstrou que, entre os polimorfismos genéticos estudados, o alelo 2 na Hp está associado com evidências de forte associação VE e maior correlação com DIND (déficit isquêmico neurológico tardio) em populações de ratos e humanos na América do Norte ${ }^{105}$.

\section{a.3 - Óxido Nítrico Sintase Endotelial (eNOS ou NOS3)}

O gene da óxido nítrico sintase endotelial (eNOS) possui um papel fundamental na regulação do tônus vascular e encontra-se situado no braço longo do cromossomo (7q35-36.1). As células endoteliais expressam a eNOS como um substrato fundamental na fonte de origem do óxido nítrico (NO), sendo considerado: um importante vasodilatador, um inibidor inflamatório, um importante elemento da proliferação das células musculares lisas e importante na agregação das plaquetas ${ }^{105-}$ 107. Este gene possui três PNUs (SNPS) conhecidamente envolvidos e descritos na formação, rotura e espasmo arterial envolvendo os AIs.

Seus genótipos são: (1) o T-786C (na região promotora), com descrições de envolvimento com a formação de aneurisma e com o espasmo coronariano em populações asiáticas; (2) o G894-T (situado na região exônica 7) envolvido na ateroesclerose; e (3) o variable number tandem repeat - 4-VNTR27 (na região intrônica com 4 pares de base na posição 27), que sugere envolvimento com maior chance de vasoespasmo e DIND em uma revisão sistemática ${ }^{105}$, não corroborado pelos achados de duas metanálises estudando exclusivamente a eNOS ${ }^{106-107}$. 


\section{a.4 - Gene Endotelina 1 (ET-1)}

O gene da ET-1 situa-se no cromossomo 4q31.23 e possui como PNU envolvido com a doença aneurismática nas alterações do aleto $\mathrm{C} / \mathrm{T}$ (C323T). O produto deste gene é um potente mediador da vasoconstrição, e parece iniciar e manter o processo de vasoespasmo cerebral ${ }^{108}$. Inúmeros achados em estudos clínicos e animais revelaram que existem níveis elevados no LCR de ET-1 pós-HSAa, sugerindo seu papel no desenvolvimento do vasoespasmo cerebral ${ }^{110}$.

\section{b) Marcadores Inflamatórios e Imunológicos da HSAa e VE}

Neste contexto, ganha destaque o papel que o genes desempenham no processo fisiopatológico tanto na formação e rotura dos aneurismas como na cascata inflamatória e imunológica que ocorre na hemorragia subaracnoidea e no vasoespasmo cerebral. Os achados da literatura demonstram que as vias e os mecanismos responsáveis por toda essa cascata sofrem influência direta dos genes por meio da expressão proteica.

\section{b.1 - Gene da Interleucina $1 \beta(I L-1 \beta)$}

O gene da $\boldsymbol{I L}-\mathbf{1} \boldsymbol{\beta}$ encontra-se com substrato aumentado em doenças agudas e crônicas. Esse gene situa-se no braço longo do cromossomo 2 ( 2 q12.1) e possui um polimorfismo na região promotora na posição $511 \mathrm{C} / \mathrm{T}$ influencia a produção de proteína com aumento dos níveis elevados no alelo $\mathrm{T}^{110}$.

Entre todos os polimorfismos, possui importância na HSAa quando ocorre inserção do alelo T. Entre os achados, existe uma maior predisposição para ocorrência de HSAa em populações polacas ${ }^{112}$. 
Elas são importantes mediadoras da resposta imune e inflamatória e são sintetizadas por uma variedade de células, incluindo macrófagos, queratinócitos, linfócitos B e fibroblastos ${ }^{110}$.

\section{b. 2 - Gene da Interleucina 6 (IL-6)}

O gene da $I L 6$, localizado em $7 \mathrm{p} 15.3$, é um importante componente das vias de respostas inflamatórias. O gene $I L 6$ codifica uma pró-proteína que, em resposta a danos celulares, é processada em uma citocina. Essa citocina induz apoptose e está envolvida em diversas respostas imunes, processos inflamatórios e hematopoiese ${ }^{113}$.

Esse gene possui um aumento após o evento da HSAa no LCR a fim de regular inúmeros processos fisiológicos pró-inflamatórios. Há dois polimorfismos funcionais envolvidos com os aneurismas intracranianos. O G572C está associado à formação e rotura de AI em caucasianos e chineses ${ }^{113-114}$. Pera et al. falharam em demonstrar a associação do outro polimorfismo da $\operatorname{IL6}((174 \mathrm{G}>\mathrm{C})$ em europeus com $\operatorname{HSAa}^{115}$.

\section{b.3. Fator de Necrose Tumoral $\alpha(T N F-\alpha)$}

O gene da TNF-alfa encontra-se situado no cromossomo 6 p21.33 e se encontra envolvido em inúmeras vias pró-inflamatórias. É considerada uma citocina envolvida com o processo de formação e rotura dos AI. É uma citocina que sofre a influência da lipoxigenase 5 (5-LO) que se encontra envolvida com a síntese de leucotrienos ${ }^{113}$.

O gene da $T N F \alpha$ possui dois genótipos com base no tipo de receptor que possui, TNFR1 e TNFR2. O polimorfismo TNF-alfa 308G/A tem sido extensivamente estudado em inúmeras doenças com comportamento inflamatório. 
Existem outros PNUs (-238, -1031, -863 e -857) e são mais observados em populações japonesas ${ }^{75}$.

Beeftink et al. evidenciaram que pacientes com níveis séricos baixos de TNF alfa tendem a ter menos isquemia associada no desfecho da HSAa ${ }^{116}$.

\section{b.4 - Gene do Receptor da Proteinase Ativada - 1 (PAR1)}

O gene PARl, também conhecido como F2R, Coagulation factor II (Thrombin) Receptor, é um gene situado no braço longo do cromossomo 5, na região q11.2-q13.3. Este gene codifica o receptor protease 1 envolvido com a cascata da coagulação e trombose ativada pela trombina. Este receptor está envolvido com a regulação da resposta durante a trombose, esse mecanismo atuando de forma protetiva envolvendo o "estancamento" do sangue em cessar o sangramento. O gene PAR1 pertence ao grupo da família de proteínas acopladas em receptores $\mathrm{G}$ e é ativado pela presença de trombina $^{117}$.

A hiperexpressão da proteína PAR1 vem sendo relacionada às propriedades de aumento da contratilidade, envolvendo-se com um risco aumentado de vasoespasmo cerebral pós-HSAa ${ }^{118,119}$.

A ativação de plaquetas está diretamente relacionada à atividade do receptor PARl. Assim, variantes em PARl podem afetar condições como a doença tromboembólica venosa e o infarto do miocárdio ${ }^{143}$.

Perspectivas no tratamento com o uso dos receptores de trombina no sistema nervoso central têm sido considerada por meio do uso da administração intratecal de um antagonista da PAR1, prevenindo a hiperexpressão e a reatividade aumentada para trombina. Isto sugere o papel da PAR1 como chave no vasoespasmo cerebral e pode ser útil como alvo terapêutico na prevenção e no tratamento do vasoespasmo ${ }^{120}$. 


\section{b.5 - Gene da Interleucina - (IL-4)}

A Interleucina 4 (IL4) é uma citocina anti-inflamatória produzida por células Th2 CD4+, basófilos e mastócitos. Elas participam da regulação do sistema imune em vários níveis, por isso são conhecidas como citocinas pleiotrópicas ${ }^{110}$.

O gene IL4 está localizado no braço longo do cromossomo 5 (região q31-q33). Os polimorfismos presentes nesse gene são alvos potenciais de estudos que visam caracterizar a etiologia, progressão e relação com doenças isquêmicas ${ }^{111}$. Um polimorfismo do tipo VNTR (Íntron 3 VNTR - 70pb, rs79071878) situado no terceiro íntron do gene $I L 4$ está associado à isquemia cerebral ${ }^{111}$.

c) Marcadores genéticos envolvidos com a estabilidade genômica e com a morte celular

\section{c.1 - Gene da CASP-8}

O gene da caspase-8 (CASP8) está localizado no cromossomo 2q33.1, adjacente a dois outros genes, CASP10 e ALS2CR12, que estão associados, respectivamente, ao processo de apoptose e a doenças como Esclerose Lateral Amiotrófica 2 (juvenil). O gene $C A S P 8$, assim como CASP10, são considerados iniciadores ou mediadores positivos do processo apoptótico celular ${ }^{121}$.

Apoptose é um processo conduzido por essas enzimas conhecidas como caspases, e é a morte celular programada que é fundamental para o controle do desenvolvimento neoplásico. Dessa forma, variações genéticas em genes de caspases vêm sendo sistematicamente estudadas com relação a risco de câncer ${ }^{122}$.

A ativação de caspases pode ser executada por duas vias: a extrínseca ou mediada por receptores e a intrínseca ou mitocondrial. O gene CASP8 é fundamental para vias extrínsecas de morte celular iniciadas por membros da família de fatores de necrose tumoral (TNF). Primeiramente, receptores recrutam um complexo de 
sinalização de morte para ligação a membros TNF específicos. Em seguida, moléculas de procaspase- 8 podem ser induzidas a este complexo e são ativadas por meio de uma clivagem recíproca, iniciando a chamada cascata apoptótica, clivando outras caspases 123.

Os estudos demonstram que o polimorfismo do tipo INDEL da CASP8 está associado a uma maior probabilidade de evoluir com esclerose múltipla, bem como, outras doeças crônico degenerativas ${ }^{121}$.

\section{c.2. - Gene da TP53}

O gene TP53 (Tumor Protein p53) está localizado em 17p13 e apresenta 11 éxons. A sua proteína codificada, p53, atua na preservação da estabilidade genômica a partir de diversas ameaças, tais quais: o estresse metabólico, a ativação oncogênica e os danos no DNA ${ }^{124}$.

O bom funcionamento de p53 é vital para o ciclo celular, pois a proteína está envolvida em processos como a senescência celular e o reparo de DNA, sendo essa proteína inativada em vários cânceres humanos para que o tumor atinja uma resistência ao processo apoptótico ${ }^{125}$.

O códon 72 (Arg72Pro) na região exônica do TP53 é um PNU funcional que conduz a conversão para uma metionina prolina. O PNU Arg72Pro do TP53 resulta na mudança da estrutura da proteína e só existe no ser humano este polimorfismo. Neste momento, sabe-se que o TP53 pode regular a expressão de miRNA ( RNA de cadeia não codificada), em especial, a família do $m i R$-34. A região promotora de ambos transcritos contém p53 ligado em diversas regiões. Um PNU potencialmente funcionante rs $4938723(\mathrm{~T}>\mathrm{C})$ tem sido encontrado na região promotora do miR-34 b/c que pode contribuir para susceptibilidade de hepatocarcinoma em chineses. Li et al., idealizaram com este conhecimento que, nesta região e com esses PNUs, pode 
estar mais associado com AI em populações de chineses, o estudo mostrou que a inserção do alelo C é protetora com um OR de $0,27^{126}$.

\section{c.3 - Gene XRCC1}

$\mathrm{O}$ gene XRCC1 (X-ray repair complementing defective repair in Chinese hamster cells 1), localizado em 19q13.2, codifica uma proteína envolvida no reparo de quebras em fitas únicas de DNA formadas por exposição a agentes alquilantes e radiação ionizante. Vias de reparo de excisão de base são muito importantes para a manutenção da integridade do genoma ${ }^{127}$.

O polimorfismo deste gene pode alterar sua atividade antioxidante relacionada ao reparo do DNA. Não existem estudos mostrando o papel desse gene no espasmo cerebral, mas como sua associação com a isquemia se faz presente, poderia se extrapolar que os pacientes com tendência a um desfecho desfavorável após HSAa, que cursem com vasoespasmo cerebral, possam evoluir com altos níveis de estresse oxidativo $^{128}$.

\subsubsection{Biomarcadores epigenéticos}

O estado da arte dos estudos genéticos tem procurado explicar com inúmeros modelos a hereditariedade envolvida nos Ais. Esta condição pode ser atribuída ao fator de variação genética com maior efeito, mas com penetrância incompleta. Os esforços nas pesquisas se fundamentam na identificação de inúmeros PNUs, assim como, na investigação epigenética ${ }^{70}$.

A palavra epigenética deriva do termo Greco "epi", que significa sobre, e genética, que constitui a gama de informações complementares codificadas pelo DNA. O termo epigenética foi, primeiramente, usado por Conrad Waddington em 1942, que definiu o termo como a parte da biologia que estuda as interações causais 
entre os genes e os seus produtos. Atualmente, este termo é referido como os processos e mecanismos que atuam diretamente sobre o DNA, afetando a atividade do DNA, principalmente a expressão gênica, sem causar alterações propriamente ditas na sequência do $\mathrm{DNA}^{70}$.

O DNA encontra-se enrolado ao redor das histonas, formando a unidade fundamental da cromatina, o nucleossomo. Esta organização permite que o DNA consiga se apresentar de forma compacta o suficiente para se conter dentro do núcleo celular. A cromatina é o complexo de DNA associado às histonas proteicas. Se a forma como o DNA se dispõe ao redor das histonas se alterar, a expressão gênica também se altera ${ }^{70}$.

Este remodelamento da cromatina ocorre, principalmente, devido a dois mecanismos epigenéticos: a modificação das histonas ou devido à metilação do DNA. As modificações das histonas ocorrem pós-tradução proteica, portanto, não é um defeito na formação da proteína. Esta modificação, comumente, ocorre quando a histona já está envolvida pelo DNA disposto como nucleossomo, e resulta da ligação de inúmeras moléculas às partes mais externas das histonas. Ainda não existem técnicas que podem analisar estas modificações das histonas em humanos e ainda representa um campo desconhecido a se explorar ${ }^{70}$.

Estes mecanismos epigenéticos apresentam um papel crucial na diferenciação das células pluripotentes, na disposição arquitetônica das cromatinas e na regulação gênica. Assim, a epigenética emergiu como um mecanismo potencial que explica como estímulos do meio ambiente podem resultar em alterações persistentes na expressão gênica.

Além das metilações no DNA e as alterações nas histonas, outros coadjuvantes foram descobertos recentemente: os RNAs não codificantes (ncRNA). 
Estes foram descritos desde 1990 na literatura, mas como não apresentavam potencial codificante, foram negligenciados de análise mais minuciosa. Porém, estudos mais recentes evidenciaram que estes RNAs não codificantes formam uma rede reguladora dos processos fenotípicos.

Os miRNAs ou micro-RNAs ou miRs são pequenas sequências de, aproximadamente, 20 nucleotídeos, que atuam no momento pós-transcrição, portanto, na tradução de RNA para proteína, ao degenerar o RNA ou bloqueando a tradução do RNA. Percebe-se então que os genes carreiam o código com as instruções, mas os mecanismos epigenéticos que determinam quais instruções a seguir ${ }^{129}$.

Inúmeras pesquisas epigenéticas foram conduzidas nos últimos 40 anos. Porém, a análise epigenética em humanos ganhou mais espaço na última década. Desde que o projeto genoma humano foi publicado em 2000, novos questionamentos surgiram quanto à regulação do genoma humano. Assim, deu-se início ao projeto epigenoma europeu em 2004, seguido pelo projeto norte-americano National Institute of Health Roadmap Epigenome Project em 2009. O estudo da epigenética se expandiu e explora variadas doenças, como as oncológicas, endócrinas, cardiovasculares, imunodeficitárias, neurológicas, entre outras. A epigenética recentemente apresentase como uma nova fronteira de pesquisa, de interesse a vários pesquisadores no mundo, que demonstraram que estes reguladores moleculares, como o micro-RNA, influenciam de alguma forma desde a expressão gênica ao prognóstico de variadas doença $^{129}$.

Neste contexto, também associaram os miRNAs às doenças cerebrovasculares ao perfil apresentado de micro-RNA a fim de encontrar alguma evidência que possa ser útil para a compreensão destas doenças complexas ${ }^{130}$. 
Com este propósito, alguns autores realizaram uma metanálise entre os achados de miRNA nos AIs e na HSAa, demonstrando que as lesões possuem um importante papel na gênese, mas não na ruptura das lesões. Os autores ressaltam a necessidade de novos estudos focando nos grupos de miRNA (mirnoma) envolvidos no processo ${ }^{130,227}$.

\subsubsection{A influência genética sobre a formação da população brasileira}

A população brasileira é uma das mais heterogêneas do mundo, conhecida pela notável diversidade cultural, étnica e genética. Essa grande diversidade observada na população brasileira atual é resultado de um complexo processo de miscigenação envolvendo, principalmente, nativos americanos, africanos e europeus 131-132. Esse processo de miscigenação teve início no século XVI a partir do contato inicial dos conquistadores portugueses e negros africanos com os povos nativos americanos que aqui viviam, e foi intensificado nos séculos XIX e XX com a imigração para o Brasil de outros grupos, como italianos, espanhóis, alemãs, japoneses, sírios, libaneses, etc. ${ }^{133}$

Os ancestrais dos povos nativos americanos chegaram às Américas há, no mínimo, 23.000 anos antes do presente ${ }^{133}$. Eles eram asiáticos nômades e cruzaram o estreito de Bering (pequena ponte de terra entre a Ásia e o Noroeste da América do Norte), tanto por via marítima, pela costa Noroeste da América do Norte, como pelo interior do continente, favorecidos pelos efeitos da última glaciação, em que o nível dos oceanos diminuíra em função do congelamento de grande parte de suas águas $(\text { figura } 4)^{134}$.

Esses povos se espalharam e ocuparam todas as três Américas, e, provavelmente, já ocupavam a América do Sul há cerca de 12.000 anos antes do presente $^{24}$. Acredita-se que de um a seis milhões de nativos americanos habitassem o território brasileiro no período da chegada dos conquistadores portugueses, no século 
XVI. Este número foi rapidamente reduzido devido ao modelo de ocupação e dominação imposto pelos conquistadores, e também pela introdução de doenças, como o sarampo, a coqueluche, varicela, febre tifoide e malária, todas introduzidas pelos europeus no continente americano ${ }^{135}$.

Esses povos se espalharam e ocuparam todas as três Américas, e, provavelmente, já ocupavam a América do Sul há cerca de 12.000 anos antes do presente. Acredita-se que de um a seis milhões de nativos americanos habitassem o território brasileiro no período da chegada dos conquistadores portugueses, no século $\mathrm{XVI}^{24,136}$.

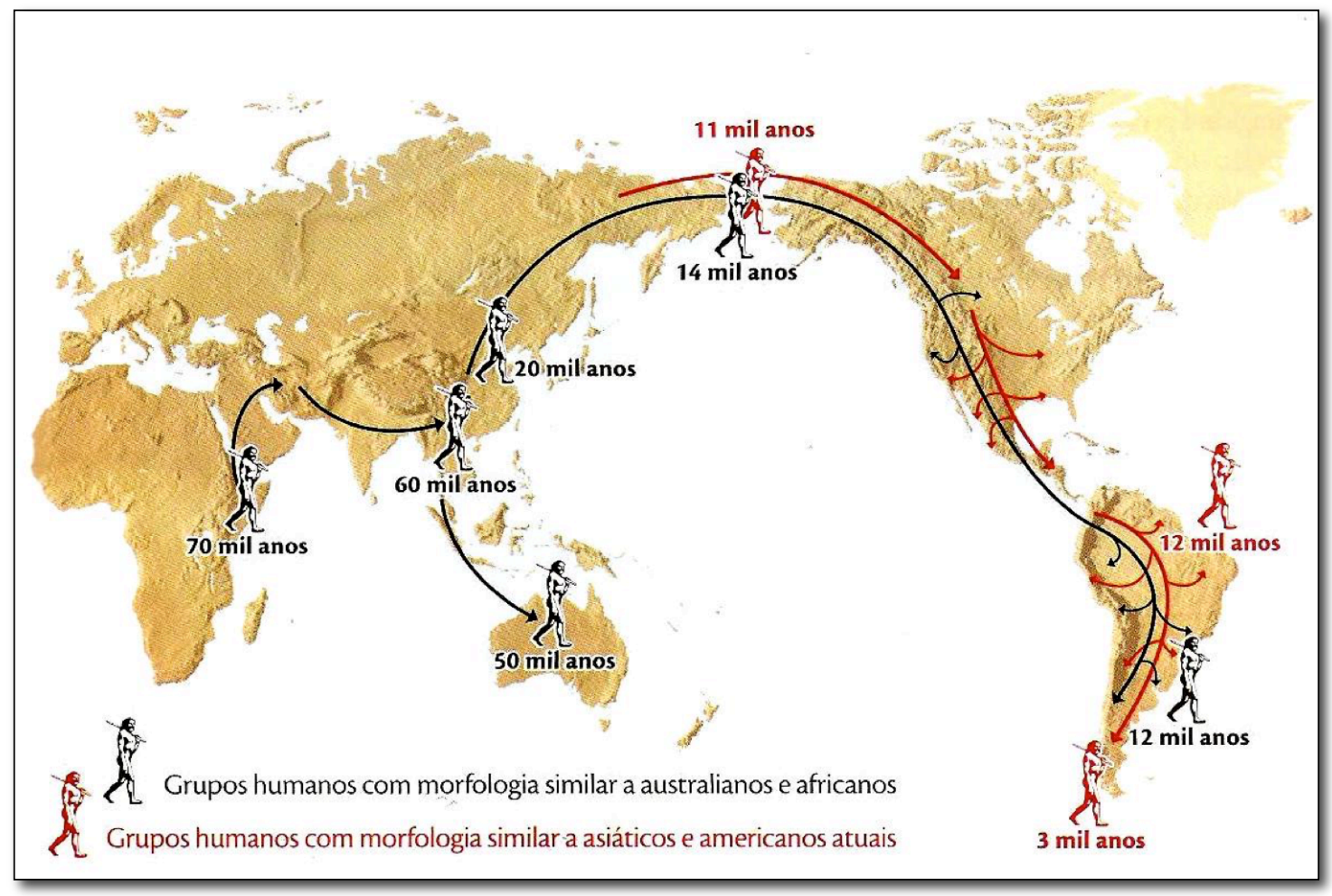

Fonte:

https://www.google.com.br/search?q=povoamento+da+america\&biw=1400\&bih=669 \&source $=1 \mathrm{nms} \& \mathrm{tbm}=\mathrm{isch} \& \mathrm{sa}=\mathrm{X} \& \mathrm{sqi}=2 \& \mathrm{ved}=0$ ahUKEwifr5KpqJPSAhXBiJAKHU FrDIAQ_AUIBigB\#imgrc=lsBJoiJg-yUHJM:

Figure 4. Correntes migratórias para América do Sul pelo estreito de Bering.

A imigração europeia para o Brasil iniciou no século XVl, com a vinda dos conquistadores portugueses que tinham como principal objetivo explorar 
economicamente a região. Desde a chegada da primeira nau portuguesa, no ano de 1500, até o ano de 1808, foi registrada a entrada de, aproximadamente, 500.000 portugueses no Brasil ${ }^{137}$. Nesse interstício, a colonização envolveu, principalmente, portugueses do sexo masculino, majoritariamente marinheiros, comerciantes ou soldados deportados ${ }^{135}$.

O terceiro grupo étnico, que, juntamente aos nativos americanos e europeus constitui a base fundamental da população brasileira, é representado pelos africanos ${ }^{24}$. Esses povos foram trazidos ao Brasil, já no início do século XVI, em número relativamente reduzido, pelos primeiros conquistadores portugueses. Posteriormente, este importante grupo populacional foi introduzido de forma maciça como mão de obra escrava, inicialmente na cultura da cana de açúcar, depois na extração de minérios e, por fim, na monocultura cafeeira ${ }^{139}$.

Estima-se que, até o ano de 1860, o tráfico de escravos tenha trazido ao Brasil, aproximadamente, quatro milhões de africanos. De acordo com os dados históricos, os africanos trazidos ao Brasil eram embarcados em duas grandes regiões: (a) CentroOeste/Sudeste da África, que inclui, basicamente, Angola, Moçambique e o Congo, e (b) a África Ocidental, que abrange toda a região ao Norte do golfo da Guiné ${ }^{132}$.

A partir de meados do século XIX, após a abertura dos portos brasileiros, o fim do tráfico de escravos africanos e a abolição da escravatura, iniciou uma nova fase de imigração para o Brasil, que incluía a vinda de europeus não portugueses, japoneses, judeus, sírios e libaneses. Além desses, outros povos de etnias e nacionalidades variadas também migraram para o Brasil, porém, em número relativamente menor ${ }^{140}$.

Essa segunda onda de imigração (1872 a 1975) trouxe, aproximadamente, 1.600.000 portugueses, 1.900 .000 italianos, 800.000 espanhóis, 200.000 alemãs e 
250.000 japoneses ao Brasil. Um contingente de, aproximadamente, 500.000 libaneses imigrou para o Brasil neste período. No entanto, Parra et al. cita um valor bem menor, aproximadamente, 100.000 migrantes entre sírios e libaneses ${ }^{133}$.

A distribuição dos imigrantes não foi homogênea entre as regiões e estados brasileiros. Os imigrantes alemães, por exemplo, ocuparam, principalmente, os estados do Rio Grande do Sul e Santa Catarina, enquanto italianos fixaram-se principalmente, nos estados de São Paulo e Rio Grande do Sul. Os japoneses estabeleceram vários núcleos coloniais, principalmente em São Paulo, no norte do Paraná, no Mato Grosso do Sul, Pará e Amazonas ${ }^{134}$. Já os imigrantes sírios e libaneses espalharam-se para praticamente todas as regiões brasileiras ${ }^{140}$.

Um conjunto de 48 AIM, desenvolvido por Santos et al., foi capaz de identificar um alto grau de subestruturação populacional na região Norte do Brasil e outras populações miscigenadas do Brasil (como o estado de Piauí e Quilombos) ${ }^{138}$. Esses marcadores vêm sendo sistematicamente empregados para determinar ancestralidade individual e controlar possíveis erros de interpretação decorrentes de subestruturação populacional, em investigações tipo caso-controle, de populações brasileiras ${ }^{132}$.

Este complexo processo de formação, que possibilitou a miscigenação de populações continentais, resultou na composição genética heterogênea e, majoritariamente, tri-híbrida observada na população brasileira atual ${ }^{132}$. Nos últimos anos, a caracterização genética desse processo vem sendo intensificada a partir da análise de polimorfismos de DNA conhecidos como marcadores informativos de ancestralidade. Esses marcadores encontram-se espalhados pelo genoma (DNA mitocondrial, cromossomos $\mathrm{X}, \mathrm{Y}$ ou Autossômicos) e fornecem estimativas mais precisas do grau de mistura interétnica individual e populacional ${ }^{134}$. 
Os resultados de estudos que fizeram uso desses marcadores demonstram que as populações de todas as regiões brasileiras apresentam algum grau de miscigenação envolvendo nativos americanos, africanos e europeus ${ }^{133-135}$. Entretanto, devido às peculiaridades na ocupação de cada região, a contribuição genética de cada grupo ancestral é heterogênea entre essas populações. A contribuição de nativos americanos, por exemplo, é mais pronunciada no Norte do país, a de africanos é mais elevada no Nordeste, e, no Sul, há predominância da contribuição europeia com pouca participação de nativos americanos e africanos ${ }^{138}$.

Em recente revisão acerca da ancestralidade genética de populações das cinco regiões geográficas brasileiras, foram utilizados 46 marcadores autossômicos informativos de ancestralidade e observaram a seguinte proporção de contribuição gênica nativa americana, europeia e africana nessas populações: a região Norte apresentou 51\% de ancestralidade europeia, 32\% nativa americana (ameríndia) e 17\% africana; a região Nordeste apresentou 56\% de ancestralidade europeia, 16\% nativa americana e $28 \%$ africana; a região Centro-Oeste 58\% europeia, $16 \%$ nativa americana e $26 \%$ africana; a região Sudeste $61 \%$ europeia, $12 \%$ nativa americana e $27 \%$ africana; a região Sul 74\% europeia, $11 \%$ nativa americana e $15 \%$ africana $^{137,138}$.

De maneira semelhante, Parra et al. investigaram populações de quatro das cinco regiões geográficas brasileiras, e também observaram diferenças regionais quanto à proporção de ancestralidade nativa americana, europeia e africana no Brasil $^{133}$. No entanto, este estudo mostrou contribuições gênicas ancestrais bem mais uniformes entre essas populações, com aumento da contribuição europeia e redução da contribuição nativa americana em todas as populações investigadas ${ }^{138}$.

\subsection{História Natural da Hemorragia Subaracnoidea Aneurismática}

\subsubsection{Apresentação Clínica e Escalas de Prognóstico}


O paciente após evento com a suspeita típica ou atípica confirmadas devem nortear a condução do quadro de acordo com a sintomatologia, de forma a escalonar com base na clínica o prognóstico da HSAa. O exame físico pode revelar uma arritma cardíaca que ocorre em 91\% dos casos, mimetizando um infarto agudo do miocárdio, o que, em muitos casos, pode se associar com a morte súbita ${ }^{27}$.

Por outro lado, sintomas neurológicos podem estar presentes como: turvação visual secundária a hemorragias retinianas ou sub-hialoideas, o que indica um quadro grave como na síndrome de Terson ${ }^{141}$. Nesta síndrome, há um aumento súbito da pressão intracraniana e alto índice de mortalidade associada, ocorrendo em 13\% das apresentações.

Entre outros achados, pode se observar meningismo, déficit neurológico apendicular focal, perda do nível de consciência, oftalmoplegias e até estado de coma. Alguns achados localizatórios podem inferir a localização do aneurisma, tais como: paralisia do terceiro nervo (aneurisma do segmento comunicante da artéria carótida); paralisia do sexto nervo (aumento da pressão intracraniana); fraqueza nos membros inferiores e abulia (aneurisma de comunicante anterior); e hemiparesia com afasia (aneurisma de artéria cerebral média) ${ }^{27}$.

Os pacientes com diagnóstico de HSAa confirmado pela clínica e corroborado pelo exame de imagem, classicamente, eram graduados pela escala de Hunt \& Hess, o que permitia compreender a gravidade clínica da apresentação, porém nem sempre refletiam o quadro clínico por completo do paciente, pois não apresenta a escala de coma como um parâmetro selecionador de maior ou menor gravidade (Anexo B). Com isso, a escala como prognóstico clínico se tornou em desuso permitindo espaço para escala WFNS (World Federation of Neurosurgical Societies) que fornece mais informações tanto da clínica neurológica como do estado de coma. Além disso, a 
mesma escala permite a avaliação do prognóstico quanto ao risco de vasoespasmo quando corroborada pela escala tomográfica de Fisher modificada (Anexos C e D) ${ }^{142-}$ 144.

A gravidade da HSAa é clinicamente avaliada e graduada tanto pela Escala de Hunt \& Hess como pela Escala WFNS. Para alguns autores, a vantagem prognóstica de uma sobre a outra é questionável e muito variável. Altos níveis de score em ambas as escalas estão associados com um pior prognóstico. A mortalidade é comumente causada pela lesão neurológica resultante de um sangramento inicial ou ressangramento e de uma isquemia cerebral tardia (DCI $)^{28}$.

No momento do diagnóstico da HSAa, medidas clínicas são tomadas com o objetivo de evitar complicações neurológicas imediatas, dentre as quais são mais evidentes de se estabelecerem ao longo de duas semanas, podendo se estender até 4 semanas pós-ictus ${ }^{146}$. Essa doença de instalação súbita e curso inexorável curto necessita de intervenção precoce, a fim de evitar um pior prognóstico por ocasião das suas possíveis complicações ${ }^{27}$.

Recentemente, mecanismos patológicos da HSAa que se iniciam após o ictus e que determinam a morte neuronal nas primeiras 72 horas têm sido referenciados como lesão cerebral precoce (EBI - early brain injury) ${ }^{190}$; enquanto os mecanismos que conduzem à isquemia tardiamente determinam as consequências de um vasoespasmo sintomático com ou sem DCI.

Os mecanismos que conduzem à EBI e DCI somente ocorrem quando ambos se encontram: um que se inicia com a hipertensão intracraniana (HIC) com consequente redução da pressão de perfusão cerebral, o que ocorre nas primeiras $24 \mathrm{~h}$ pós-hemorragia e possui relação direta com a quantidade de sangue no espaço subaracnoideo, e outro que se estabelece tardiamente, de forma a se correlacionar 
quer com o vasoespasmo diretamente quer com as alterações do metabolismo $\operatorname{cortical}^{187,189}$.

\subsubsection{Complicações da Hemorragia Subaracnoidea}

a) Hipertensão Intracraniana e a Apoptose após HSAa

Quando ocorre a rotura de um aneurisma e o sangue extravasa para o espaço subaracnoideo, instala-se um aumento súbito da pressão intracraniana (PI) como se determinasse uma súbita parada circulatória cerebral no evento hemorrágico. Neste momento, ocorre uma vasoconstrição reativa local para coibir o sangramento. Nas situações em que o sangramento é maciço e uma rápida HIC se instala, com um período de oliguemia prolongado (primeira fase pós-rotura), estabelece-se a morte súbita do paciente que pode ocorrer em até $12 \%$ dos eventos de hemorragia ${ }^{169}$.

A ruptura aneurismática ocorre em $25 \%$ dos casos com a formação de hemorragias intracerebrais nas séries patológicas. Hematomas com volumes maiores que $80 \mathrm{ml}$ são sempre fatais. Dois terços dos pacientes com hemorragia intracerebral maior que $3 \mathrm{~cm}$ de diâmetro morrem dentro de três dias ${ }^{146}$.

Segundo Fukuhara et al.(1998), a hipertensão intracraniana piora o vasoespasmo e o controle da PIC com monitorização perioperatória da PIC têm potencialmente evitado o desenvolvimento do vasoespasmo ${ }^{147}$.

A morte após ruptura do aneurisma é devido à hemorragia intraventricular, intracerebral ou ambas e menos devido à HSAa propriamente dita. Na hemorragia intraventricular, a taxa de mortalidade global é de cerca de $66 \%$. O grau de dilatação 
ventricular, visto na TCC precoce, também é a chave do prognóstico, pois, quanto mais dilatado o ventrículo, pior é o prognóstico ${ }^{148}$.

A magnitude e a duração da HIC, assim como a quantidade de sangue cisternal, possuem uma correlação direta com as condições da apresentação clínica do paciente, assim como as maiores chances de desenvolverem um VASOGRADE vermelho e indução da morte neuronal a partir dos mecanismos de EBI e de DCI $^{187}$.

A apoptose é o mais comum processo patológico dos mecanismos de EBI. Park et al. encontraram que a HSAa em experimentos conduz à apoptose nas células endoteliais resultando em aumento da permeabilidade da barreira hematoencefálica (BBB) e a aumento do conteúdo de água. Os mesmos autores observaram apoptose nos neurônios corticais e do hipocampo ${ }^{191}$.

\section{b) Ressangramento}

A recidiva hemorrágica continua sendo uma séria complicação da HSAa, atingindo uma taxa de mortalidade de $70 \%{ }^{149}$. No estudo cooperativo (Cooperative Aneurysm Study), o ressangramento foi máximo no primeiro dia após a HSA (4\%), seguido por uma taxa constante de $1 \%$ a $2 \%$ por dia durante as quatro primeiras semanas subsequentes ${ }^{150-151}$. O mais provável momento para acontecer o ressangramento é durante as horas iniciais após a ruptura. No estudo japonês, com 150 pacientes admitidos nas seis primeiras horas após a hemorragia, 15\% ressangraram nas seis primeiras horas, e 19\% ressangraram nas 24 primeiras horas ${ }^{152}$.

No estudo sueco, no qual 95\% dos pacientes foram admitidos nas 24 primeiras horas e $50 \%$ nas seis primeiras horas após a hemorragia inicial, $60 \%$ das mortes foram atribuídas à hemorragia inicial, apesar de $10 \%$ dos pacientes admitidos nas 24 
primeiras horas terem sido vítimas de ressangramento precoce. Pacientes que ressangraram, $82 \%$ morreram e $9 \%$ tiveram um resultado ruim. Muitos desses ressangramentos precoces ocorreram nas primeiras 24 horas ${ }^{153}$. O pico de incidência do ressangramento ocorreu dentro das primeiras 24 horas e no fim da primeira semana. Ressangramento ocorreu em 16\% dos pacientes com pressão sistólica entre $170 \mathrm{mmHg}$ a $240 \mathrm{mmHg}$ e $9 \%$ naqueles com pressão entre $94 \mathrm{mmHg}$ e $160 \mathrm{mmHg}$, sendo que a taxa de ressangramento aumentou com a idade ${ }^{154}$.

$\mathrm{Na}$ fase tardia, o ressangramento, após um mês da HSAa inicial, tem sido atribuível à localização do aneurisma, ao seu tamanho e à pressão arterial sistêmica persistentemente elevada ${ }^{154}$.

O ressangramento ultraprecoce acontece nas 24 primeiras horas após o sangramento inicial e antes que a cirurgia precoce possa ser realizada. Fuji et al. (1996) em 179 pacientes admitidos nas 24 primeiras horas após a hemorragia constatou $31(12,3 \%)$ ressangramentos ultraprecoces e 27 deles $(87,1 \%)$ ocorreram nas primeiras seis horas após esta hemorragia ${ }^{155}$. A taxa de ressangramento durante a angiografia cerebral realizada após a HSAa é estimada em $3 \%{ }^{156}$.

\section{c) Hidrocefalia Aguda}

A incidência de hidrocefalia aguda após ruptura aneurismática se situa entre $15 \%-20 \%$, conforme achados de vários estudos, inclusive do estudo cooperativo ${ }^{158}$. Sonolência progressiva nas primeiras 24 horas após a HSAa, algumas vezes acompanhada de resposta pupilar lenta ao estímulo luminoso e desvio conjugado dos olhos para baixo, é característico de hidrocefalia aguda. O mecanismo de instalação da hidrocefalia aguda é devido a uma diminuição da absorção do LCR, causada por bloqueio estrutural das vilosidades aracnoideas pelos eritrócitos ${ }^{158}$. 
Hemorragia intraventricular, nível de consciência na admissão, hipertensão arterial precedente, idade elevada, HSA na TCC, aneurisma da circulação posterior e hipertensão arterial no pós-operatório foram fatores associados com hidrocefalia. A Hidrocefalia aguda é mais comum em pacientes com estado neurológico grave ${ }^{157}$.

Pacientes com hidrocefalia aguda têm $50 \%$ a $80 \%$ de possibilidade de melhorar com DVE ${ }^{154}$. Sangue nos ventrículos é visto em $47 \%$ dos pacientes com hidrocefalia aguda, comparado com $31 \%$ naqueles sem hidrocefalia ${ }^{157}$.

A hidrocefalia sintomática ocorrem agudamente em cerca de $15 \%$ pós-HSAa. A incidência da hidrocefalia tende a ocorrer com o grau de sangramento mais exuberante, em que o status clínico é pior. A hidrocefalia determina HIC, o que reduz a PPC e induz à isquemia. Aproximadamente, $30 \%$ dos pacientes necessitam de shunt ventricular para alívio da $\mathrm{PI}^{157}$.

\section{d) Crise Convulsiva}

As crises convulsivas e a epilepsia após HSAa são eventos bastantes comuns de ocorrer como complicações, podendo variar de 1 a 27,5\%. Apesar de ser uma complicação grave quando instalada, não existe um consenso no uso profilático para os pacientes pós-ictus ${ }^{159}$.

A crise convulsiva e uma despolarização alastrante cortical após um evento de HSAa podem ocorrer em vista da grande demanda metabólica cerebral que se estabelece na fase aguda. Isso determina um grande gasto de energia e do fluxo sanguíneo cerebral ${ }^{160}$. 
e) O Vasoespasmo encefálico sintomático e o Déficit isquêmico tardio

O vasoespasmo encefálico (VE) é uma constrição de início gradual prolongado das artérias cerebrais no espaço subaracnoideo, após HSA. A principal causa é a presença de coágulo de sangue no espaço subaracnoideo. A importância do vasoespasmo é que o fluxo através das artérias em espasmo pode ser reduzido suficientemente para causar infarto cerebral. Coágulos subaracnóideos são suficientes para causar vasoespasmo, não requerendo lesão arterial adicional, hipertensão intracraniana ou infarto cerebral, embora estes elementos estejam frequentemente coexistindo $^{161}$.

Após a ruptura do aneurisma, ocorre a mistura de inúmeros elementos extracelulares e intracelulares que desenvolvem, como ocorre na coagulação, desintegração celular, inflamação local, fagocitose e reparo. A constrição severa da artéria altera o metabolismo e a estrutura de sua parede, bem como, o equilíbrio de substâncias vasoconstritoras e vasodilatadoras produzidas pelo endotélio, rede neurogênica e talvez células musculares lisas ${ }^{161}$.

O VE permanece como uma complicação grave pós-HSAa, sendo a causa de morte ou incapacidade em $13,5 \%$ dos pacientes no estudo cooperativo sobre o momento operatório ${ }^{150}$. Ele, usualmente, começa em torno do terceiro dia após a HSAa e desaparece após dez a 15 dias, deixando cerca de um terço dos pacientes com déficit neurológico isquêmico permanente.

Os sinais clínicos de deterioração neurológica após VE são diminuição do nível de consciência, aumento da cefaleia e sinais focais, tais como disfasia e hemiparesia $^{162}$. 
O VE constitui uma importante complicação da HSAa, em que sua presença tem sido correlacionada com aumento de 1,5 a três vezes a taxa de mortalidade nas primeiras duas semanas após a rotura do aneurisma. Isquemia cerebral secundária ao vasoespasmo - déficit isquêmico tardio (DCI) - classicamente ocorre durante o período entre o quarto e o $12^{\circ}$ dia após a hemorragia inicial. No entanto, a DCI pode surgir sem a evidência de VC prévio, assim como pode se instalar após o pico das duas semanas iniciais, por ocasião de uma crise metabólica ${ }^{160}$. O vasoespasmo angiográfico ocorre em $70 \%$ de todos os pacientes que apresentam HSAa, mas evoluem para a isquemia cerebral sintomática ou infarto em $36 \%$ de todos os pacientes $^{163}$.

O DCI se manifesta com alteração da consciência, desorientação, déficit neurológico focal ou rigidez de nuca. Diante deste quadro, uma investigação radiológica com TCC seria praticada para afastar o diagnóstico de hidrocefalia, hematoma subdural ou ressangramento. Em 2010, foi estabelecido um consenso por um grupo multidisciplinar que propôs as novas definições de DCI ou DIND (déficit neurológico isquêmico tardio) mediante as deteriorações clínicas após um evento hemorrágico subaracnóideo ${ }^{163,164}$ (Anexo J).

Em cerca de metade dos casos, o DCI se estabelece em decocorrência do VE, o qual pode regredir ou progredir para um infarto cerebral. Vinte a $25 \%$ de tais pacientes sofrem de isquemia definitiva ou morrem de vasoespasmo, apesar da terapia otimizada $^{165}$. O infarto cerebral, associado com vasoespasmo sintomático, usualmente, aparece logo após o início do vasoespasmo angiográfico com desenvolvimento agudo ou subagudo de sinais e sintomas focais ou generalizados ${ }^{150}$. 
Por outro lado, nem todos os casos de DCI cursam com vasoespasmo sintomático, entre as muitas hipóteses associadas, contribuem para essa fisiopatologia: constricção da microcirculação, microtrombose, depressão alastrante cortical e apoptose $\operatorname{tardia}^{163}$. A perda ou a anormalidade da autorregulação cerebral decorrente das variações da circulação arterial, microcirculação, circulação colateral, metabólicas, genéticas e epigenéticas influencia quanto ao grau de vasoespasmo angiográfico conduzindo ou não à $\mathrm{DCI}^{163}$.

\section{e.1. Critérios diagnósticos do vasoespasmo encefálico e do déficit isquêmico}

$\underline{\text { tardio }}$

Pacientes com alto risco de vasoespasmo podem ser identificados cedo, no curso da HSAa, usando um índice de risco. O índice de risco baseado na combinação de variáveis pode representar paradigma preditivo superior aos já convencionalmente usados, com critérios baseados em espessura do coágulo ou velocidade média de fluxo da artéria cerebral média ${ }^{164,166}$. Entre os parâmetros que devem ser considerados, estão: (1) Espessura do coágulo na TC; (2) Elevação precoce da velocidade média de fluxo na artéria cerebral média ( $>110 \mathrm{~cm} / \mathrm{seg}$ ); (3) Escala de coma de Glasgow inferior a 14; e (4) Ruptura de aneurisma da artéria cerebral anterior ou da artéria carótida interna ${ }^{167}$.

Além disso, os pacientes pós-HSAa devem ser monitorados por meio de métodos não invasivos de imagem (Doppler transcraniano ou imagens de perfusão cerebral); métodos invasivos de imagem (angiografia cerebral por subtração digital); métodos não invasivos neurofisiológicos (eletroencefalograma contínuo); e/ou métodos invasivos laboratoriais (extração tecidual de oxigênio, microdiálise, fluxometria de difusão térmica, monitorização da PIC). Toda essa metodologia de 
acompanhamento auxilia na detecção precoce de pacientes em evolução para o vasoespasmo sintomático e até para os casos de DCI sem correlação com o vasoespasmo $^{185}$.

Charpentier et al. (1999), em um estudo coorte de 244 pacientes submetidos à cirurgia ou tratamento endovascular de HSAa, pesquisaram os fatores de risco para o vasoespasmo cerebral sintomático. O vasoespasmo sintomático foi visto em $22,2 \%$ dos pacientes cirúrgicos, comparado com $17,2 \%$ de pacientes submetidos a tratamento endovascular. Estes autores concluíram que a idade inferior a 50 anos, estado neurológico bom e hiperglicemia foram todos associados com aumento do risco de vasoespasmo cerebral $^{168}$.

A vasoconstrição aguda após a HSAa ocorre independentemente de mudanças na PIC e na pressão de perfusão cerebral, associadando-se com diminuição do fluxo sanguíneo cerebral, grandes hemorragias e elevação persistente do glutamato extracelular (Teoria de Leão). Vasoconstrição aguda parece contribuir diretamente para a lesão isquêmica cerebral após a HSAa ${ }^{169}$.

A monitorização contínua do metabolismo cerebral seria desejável para a detecção precoce do vasoespasmo em pacientes com HSAa. A microdiálise à beira do leito, uma nova técnica de monitorização on line do metabolismo cerebral, pode refletir mudanças observadas no vasoespasmo cerebral diagnosticado pelo Doppler transcraniano ${ }^{170}$. Os autores fazem uma revisão da metodologia deste tipo de monitorização, bem como descrevem os principais biomarcadores envolvidos na evolução do processo isquêmico cerebral pós-mecanismo inflamatório agudo como no trauma e na hemorragia pós-rotura de aneurisma ${ }^{170}$. 
O mais importante fator de risco para o desenvolvimento do vasoespasmo é a quantidade de sangue no espaço subaracnóideo. Indicadores prognósticos adversos adicionais incluem apresentação do paciente entre o quarto e o $14^{\circ}$ dia após HSAa, desidratação espontânea ou deliberada, uso de agentes antifibrinolíticos, hipotensão arterial, anestesia prolongada com hipotensão arterial e compressão cerebral pelo afastador, PIC aumentada, baixo débito cardíaco, arritmia cardíaca, anemia e hipóxia. ${ }^{171}$

A presença contínua de coágulos sanguíneos no espaço subaracnóideo também é um fator de risco importante para o vasoespasmo sintomático após ruptura de aneurisma cerebral. Os coágulos não estão sempre localizados perto do aneurisma roto e o curso clínico pode ser imprevisível. ${ }^{173}$

O VE, habitualmente, não se inicia nos três primeiros dias após a hemorragia inicial. Desenvolve-se de forma lenta e progressiva, com pico de incidência entre o sétimo e o décimo dia após a HSAa. ${ }^{166}$ Pacientes tratados precocemente, tendem a ter um melhor prognóstico em relação àqueles tratados tardiamente. ${ }^{172}$ Quando o vasoespasmo aparece nos primeiros três dias após a HSAa, alguns autores acreditam que houve uma hemorragia anterior nestes pacientes, não reconhecida e tendem a evoluir com um pior prognóstico. ${ }^{173}$

Entre os pacientes com HSAa que sobrevivem ao sangramento inicial, inúmeros fatores podem contribuir com a deterioração neurológica tardia, em que apenas uma parcela pode ser atribuída ao vasoespasmo, nesse contexto, ganha importância a DIND. ${ }^{178}$ O DIND é a causa mais frequente de mortalidade e de resultado neurológico desfavorável, podendo afetar mais de $30 \%$ dos pacientes e determinar disfunções motoras e/ou cognitivas ${ }^{163}$. 
Sua instalação pode corroborar para o incremento nas taxas de morbidade e mortalidade. E ainda que os pacientes com HSAa estejam monitorados com exames de imagem para identificação precoce do VE, sua instalação pode não ser observada pelos métodos de imagem, considerando que nem sempre existe espasmo arterial intracraniano na vigência de um quadro de DIND ${ }^{174}$.

No entanto, existe evidência de que o DIND quando não ocorre associado com o VE, o mesmo se estebalece como consequência aos mecanismos de depressão alastrante cortical ou disfunção microcirculatória. Cerca de 20\% dos DIND após HSAa não são detectáveis precocemente e isso pode corroborar com um prognóstico piorado em pacientes pós-HSAa ${ }^{174}$.

O risco de desenvolver DIND está diretamente relacionado ao maior escore "VASOGRADE", onde se considera a quantidade sangue na primeira imagem de TCC e o status clínico neurológico do paciente como fatores fundamentais na análise $^{174,177}$.

O estado da arte na condução na Unidade de Terapia Intensiva (UTI) influencia no resultado quanto a maior chance de desenvolver DIND. Com isso, intervenções baseadas em evidência quando implementadas ajudam a reduzir o risco de desenvolver isquemia ${ }^{178}$. As medidas são dividadas em linhas de ação: (1) Prevenção; (2) Monitoração; e (3) Terapêutica direcionada ${ }^{163}$.

$\mathrm{Na}$ prevenção, o foco se situa quanto a evitar os distúrbios hidroeletrolíticos (hiponatremia, hipomagnesemia e/ou desidratação), em que o uso de fludrocortisona (entre 0,2 e $0,4 \mathrm{mg} / \mathrm{dia}$ ) tem se mostrado bastante eficaz em reduzir a ocorrência de hiponatremia. Anedotamente, evidências indicam que a correção da hiponatremia 
aguda sintomática com solução hipertônica salina (3\%) é efetiva ${ }^{163}$. Outra linha de ação direta é feita através do uso de medicações com evidências científicas com o uso da nimodipina (antagonista do canal de cálcio - dihydropiridina) por 21 dias na redução do infarto cerebral e do pior resultado pós-HSAa ${ }^{179}$.

\section{e.2. Fisiopatologia do Vasoespasmo Encefálico}

A fisiopatologia do vasoespasmo é bastante complexa. Os principais mecanismo biológicos são constituídos pela contração direta das artérias cerebrais e a disfunção da atividade vasodilatadora provocada pelo endotélio, embora outros mecanismos não possam ser excluídos ${ }^{180}$.

Algumas das mudanças biológicas observadas são induzidas pelo sangue cisternal, com formação de oxi-hemoglobina, ativação da peroxidação lipídica e consequente lesão endotelial por disfunção da nutrição da parede arterial. Outras mudanças biológicas ocorrem em artérias cerebrais, com diminuição da síntese de prostaciclinas, redução da disponibilidade de fosfato de alta energia, disfunção do fator de relaxamento derivado do endotélio (EDRF) indutor de vasodilatação e produção do poderoso vasoconstritor - a endotelina A. O resultado final é a contração arterial, devido à fosforilação da proteína contrátil da célula do músculo liso ${ }^{180}$.

Neste contexto, dois mecanismos concorrem para a contração: a) ativação da proteinoquinase dependente de calmodulina-cálcio; e b) elevação da proteinoquinase C. Enquanto o primeiro mecanismo conduz a uma contração transitória, a contração induzida pela proteinoquinase $\mathrm{C}$ é duradoura ${ }^{180}$.

A literatura enfatiza que a patogênese do vasoespasmo cerebral tardio está relacionada com vários processos patológicos que incluem a destruição endotelial e 
contração de células musculares lisas devido a substâncias espasmogênicas geradas durante a lise de coágulos sanguíneos subaracnóideos, mudanças das respostas vasculares, e reações inflamatórias e imunológicas da parede vascular, entre elas, destacam-se hiperexpressão de fatores como: $T N F \alpha$, hiperexpressão de $P A R-1$ (receptor ativado de proteinase 1), linfócitos B e híper- ou a hipo- regulação de miRNA podem influenciar na expressão de genes envolvidos com o VE ${ }^{121,129}$.

Em 3 dias após a HSAa, o vasoespasmo cerebral torna-se mais proeminente podendo causar a morbidade neurológica. Na média, este fenômeno possui seu pico em sete (7) dias após a rotura do aneurisma. O vasoespasmo é mais grave com grandes quantidades de sangue nas cisternas ${ }^{182,183}$.

A presença de moléculas espasmogênicas (oxihemoglobina com liberação do grupo heme, endotelina, cálcio, prostaglandinas, tromboxanos, leucotrienos, radicais livres) ou moléculas da perda vasodilatadora (óxido nítrico - NO, magnésio) têm sido sugerido como os mecanismos do $\mathrm{VE}^{183}$. A cascata se inicia com o extravasamento da hemoglobina que se torna um agente pró-inflamatório, sua presença neste espaço libera a enzima oxigênio reativa (ROS) que resulta em peroxidação da membrana de lipídeos das células endoteliais e na proliferação muscular ${ }^{186}$.

A presença do sangue no espaço subaracnoideo, prejudica em parte a biodisponibilidade e a ação das moléculas vasodilatadoras como o NO. Quando o NO é inativado pela reação com ânion superóxido resultando na formação de peroxinitrito, a inativação da NO por esta reação pode contribuir para impedir a ação desse na parede vascular. A eNOS é hiporregulada pela presença do TNF e o NO por um mecanismo "feedback" negativo ${ }^{187}$.

As substâncias que estimulam o stress oxidativo inibem as bradicininas mediadas pelo relaxamento vascular após o ictus hemorrágico. A presença do sangue 
no espaço cisternal é um potente estimulante para o fator Kappa B $(N F-\kappa B)$, mediando-o a liberar as citocinas inflamatórias $(I L-1 \beta, I L-6, T N F-\alpha)$ e aumentando, assim, a reação inflamatória. As citocinas aumentam o recrutamento dos leucócitos e, assim, aumentam a interação dos leucócitos no endotélio por meio da adesão molecular. A inibição da selectina-E com anticorpo monoclonal demonstrou um VE reduzido em modelos animais, o que representaria um fator protetor ${ }^{187}$.

A exposição da hemoglobina nas cisternas acaba sendo a mesma ligada hepaticamente e produzindo a haptoglobina $(H P)$ que possui duas isoformas e está relativamente ligada ao processo da inflamação ${ }^{186}$.

A inflamação possui um papel importante no processo do VE em que inúmeras citocinas são identificadas no LCR e no sangue, e possuem seu maior pico no $7^{\circ}$ dia pós-HSAa, o que pode se correlacionar com sua maior gravidade. Nesta mesma fase, ocorre o aumento dos leucócitos se aderindo ao endotélio dos $\operatorname{vasos}^{186}$ (Figura 5).

A prostaglandina E2 (PGE2) é a molécula de eucosanoide presente em altas concentrações no LCR após a HSAa. Sua concentração aumenta em mais de 25 vezes o valor normal e permanece alta por vários dias. O seu aumento explica a presença de estado febril, sendo induzida pela ciclooxigenase 2 a induzir os mediadores inflamatórios, incluindo o $T N F$ nas plaquetas e nas células endoteliais de microvasos determinando microtrombos ${ }^{186}$. 


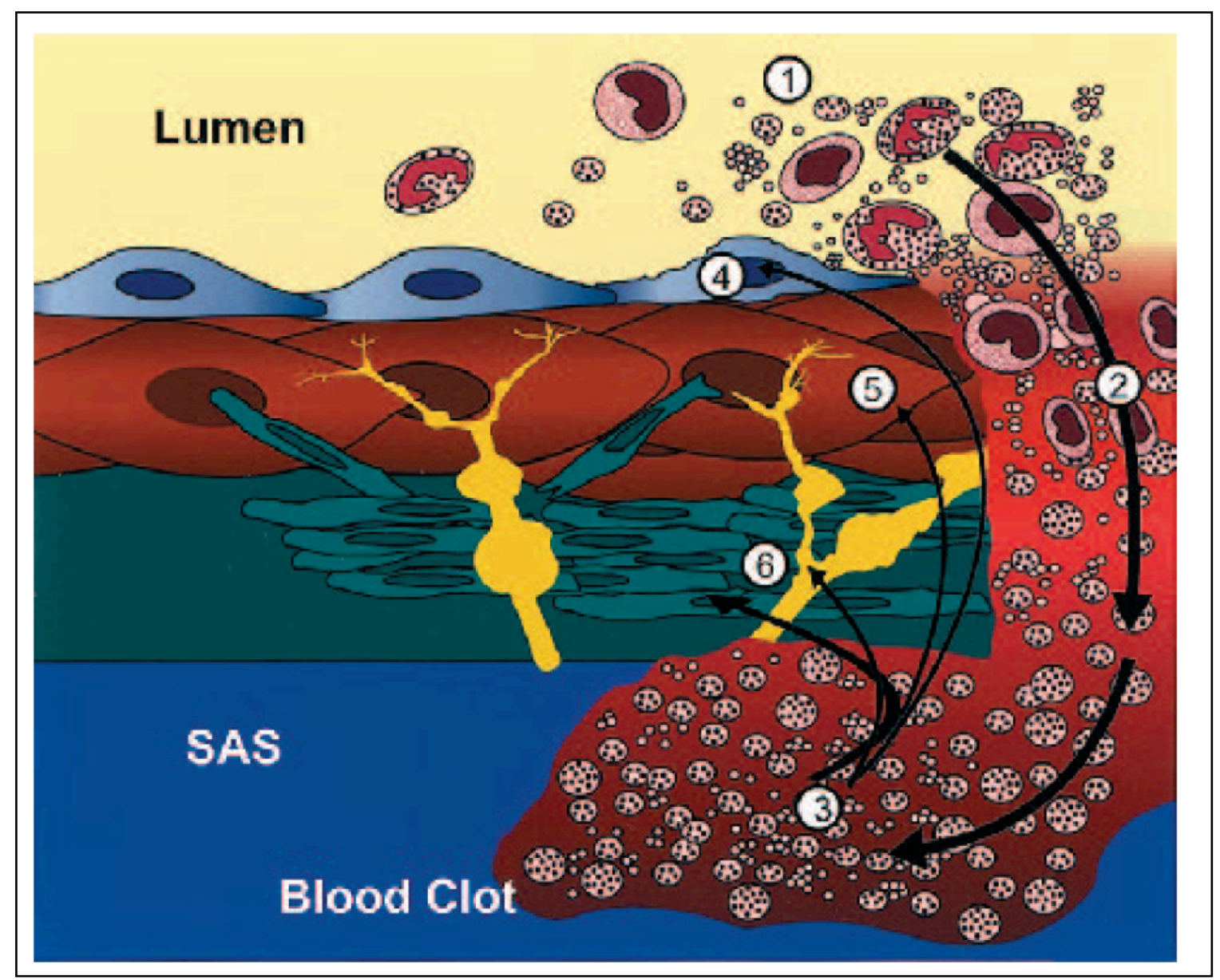

Fonte: Khurana et al., 2003

Figure 5. Fisiopatologia do vasoespasmo encefálico após HSAa. (1) Após a rotura, o sangue atravessa a parede luminal (2) através da parede do vaso para o espaço subaracnoideo, aqui o coágulo ativa o gene PARl, bem como, (3) os genes NOS3 e ET-1 que são antagônicos. Em (4), a degeneração da hemoglobina se forma a oxihemoglobina que ativa o gene da haptoglobina e dispara toda a cascata inflamatória com os genes TNF-alfa, CASP8, XRCC1 e MMP-9, atuando nas células musculares lisas em (5) e, ao final, reduzindo a $\mathrm{NO}$ e aumentando a ET-1, contribuindo para o vasoespasmo encefálico e DCI em (6).

Existe uma evidência de que as concentrações de TNF quanto mais aumentadas no LCR, pior será o prognóstico do evento hemorrágico devido à reação inflamatória associada ${ }^{113}$.

O fator mais importante na condução para vasoconstrição encefálica é o ET-1 (endotelina -1), o qual apresenta sua forma constituída por 21 peptídeos aminoácidos com três isopeptídeos separados produzidos por genes distintos ${ }^{181}$. 
Uma análise do conteúdo LCR dos pacientes pós-HSAa mostrou níveis elevados de $I L-1$ beta, porém, neste estudo, a TNF-alfa não está aumentada ao ponto de contribuir para o vasoespasmo tardio ${ }^{116}$. A $I L-1$ age por meio da proteína G por três vias:

(1) Ativação da fosfolipase $\mathrm{C}$ causando liberação do cálcio e conduzindo a ativação quinase cadeia de miosina suave (MLC).

(2) Ativação da proteína quinase $\mathrm{C}(\mathrm{PKC})$ por meio da fosfolipase $\mathrm{C}$ gerando o diaglicerol e, assim, prolongando a vasoconstrição por duas semanas.

(3) A ativação v da PKC regula a fosforilação da MLC por meio da ativação da rhokinase e da subunidade miosina ligante.

Outro mecanismo em que a IL-1 medeia o VE pode ser através da influência sobre o fator de crescimento derivado das plaquetas $^{188}$.

Não menos importante, mas bastante relevante, o fenômeno da Despolarização alastrante cortical se mostrou bastante expressivo nos pacientes com HSAa na fase 1 de oliguemia. A compreensão dos estados metabólicos e da despolarização cortical é a nova fronteira no tratamento dos cuidados neurocríticos e da terapia individualizada na HSAa, a fim de reduzir os efeitos inflamatórios e suas repercussões clínicas que podem se manifestar em fases tardias determinando isquemia encefálica (após os 21 dias iniciais) ${ }^{185,189}$.

\subsection{Métodos de Investigação e Monitorização do paciente pós-HSAa}

Sem dúvida alguma, os métodos de imagem são fundamentais para a complementação diagnóstica a partir de uma suspeita de HSAa, e devem estar disponíveis por meio de um fácil e rápido acesso. Entre os métodos, destacam-se aqueles relacionados ao diagnóstico por imagem ou laboratorial forneçam subsídios de um sangramento do tipo hemorragia meníngea; aqueles que estudam a 
angioarquitetura da origem do sangramento; aqueles que auxiliam na terapêutica escolhida; e os que avaliam funcionalmente a hemodinâmica encefálica, de forma a servirem também como exames na monitorização dos pacientes.

Na monitorização dos pacientes com HSAa, destaca-se a avaliação clínica do quadro neurológico diário em UTI, com foco na piora do nível de consciência ou no aparecimento de déficits focais e/ou cognitivos. Esses exames são centrados na detecção precoce e prevenção do vasoespasmo cerebral e/ou déficit isquêmico tardio. Entre os exames, destacam-se: Doppler transcraniano, imagens de perfusão cerebral, eletroencefalografia contínua, monitorização do oxigênio tecidual, microdiálise, fluxometria térmica tecidual e espectroscopia próxima infravermelho ${ }^{185}$.

\subsubsection{Métodos de Diagnóstico do Sangramento}

\section{a) Tomografia Computadorizada de Crânio (TCC)}

A TCC sem contraste é a modalidade de escolha na urgência, com acesso rápido e alta sensibilidade nas primeiras $24 \mathrm{~h}$ após hemorragia com cifras de $90 \mathrm{a}$ $95 \%{ }^{151}$. O sangue para ser bem visualizado no exame de TCC deve possuir um hematócrito/hemoglobina acima de 30/10 para não incorrer no falso negativo ${ }^{192}$.

O sangue no espaço cisternal se torna claro, com absorção rápida, em que a sensibilidade decai para $80 \%$ em 3 dias pós-ictus, $70 \%$ ao $5^{\circ}$ dia, $50 \%$ em uma semana e $30 \%$ em duas semanas ${ }^{151}$. O estudo com TCC é utilizado como fator preditor do risco de vasoespasmo sintomático, o que pode ocorrer entre $20-40 \%$ dos pacientes pós-HSAa (Figura 6). O clareamento do coágulo nas cisternas, de forma espontânea ou mecânica, está associado a uma redução do risco de vasoespasmo sintomático $^{193}$. 
A TCC possui o papel tanto diagnóstico para confirmar a presença de uma HSA, assim como tem o papel prognóstico, pois estima o risco de desenvolver uma complicação isquêmica encefálica ${ }^{164}$. Sua importância como fator preditivo para o processo inflamatório do espasmo arterial é demonstrada tanto isoladamente como corroborando na graduação do risco estimado no escore VASOGRADE (Anexos D e E). De forma a correlacionar, mais precisamente, o grau de complicações com fundamentos na clínica e na imagem ${ }^{164,177}$.

Nas situações em que existe uma forte suspeita clínica de HSAa, mas com uma TCC sem sangramento evidente, nesta situação, a punção lombar deve ser realizada com o objetivo de avaliar a presença de sangue no $\mathrm{LCR}^{164}$.

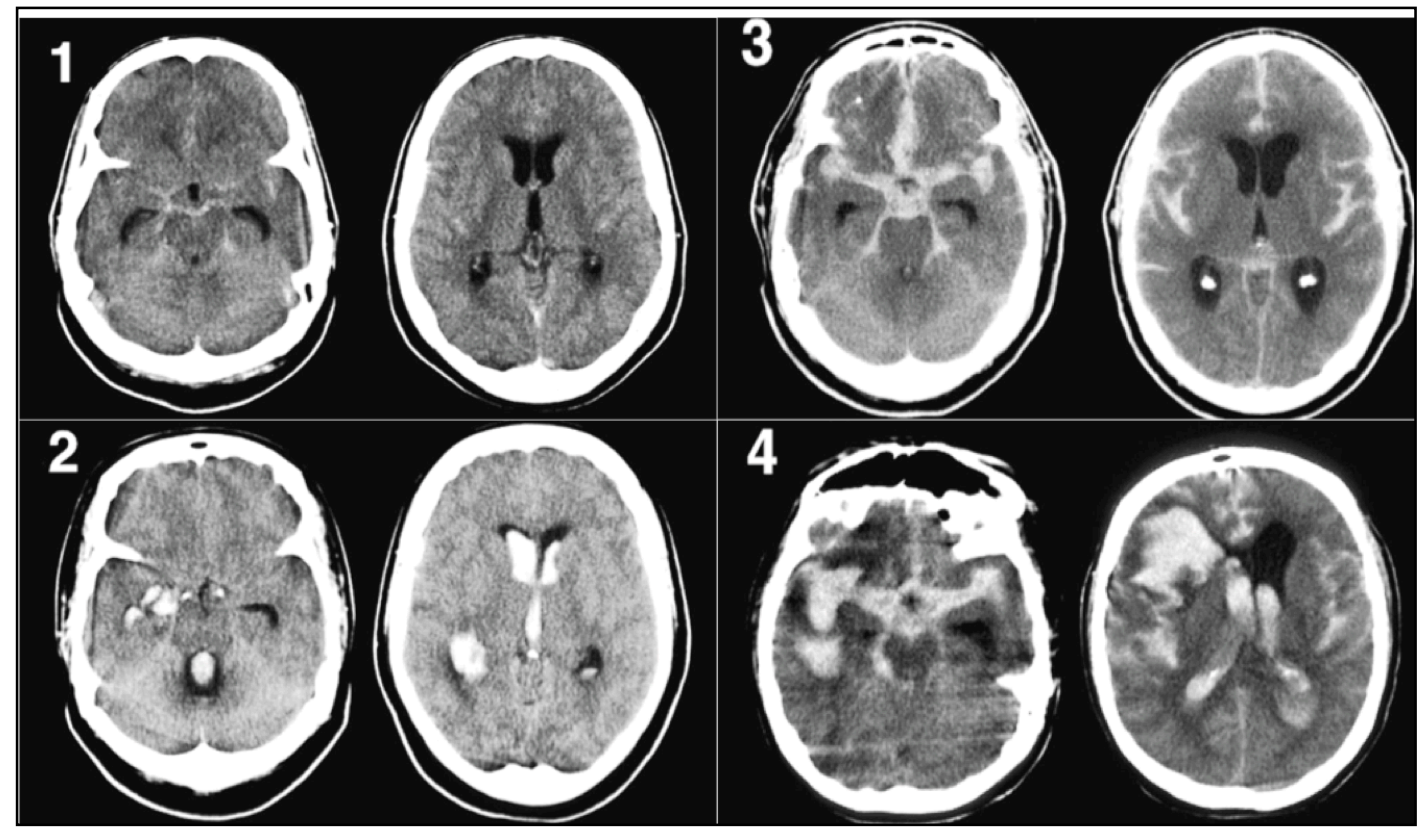

Fonte: Frontera et al., 2006.

Figura 6. Classificação do aspecto de sangramento segundo escala de Fisher modificada.

\section{b) Análise do Líquido Cefalorraquidiano (LCR)}

A técnica na realização da coleta deve ser sistematizada com o objetivo de evitar as falhas por acidente que ocorrem em $20 \%$ das coletas. Com isso, a coleta com três tubos, assim como a contagem de hemácias crenadas auxilia na avaliação e 
diferenciação de um possível acidente de punção para uma verdadeira hemorragia meníngea $^{27}$, (Classe I, Evidência nível B segundo Guideline 2012 AHA/Stroke). No entanto, deve ser lembrado que, após a HSAa, os eritrócitos se disseminam rapidamente por meio do espaço subaracnoideo, em que persistem por dias e semanas até se degradarem. A hemoglobina é liberada e metabolizada para moléculas pigmentadas da oxihemoglobina (rosa avermelhada) e bilirrubina (amarela), resultando em xantocromia. A oxihemoglobina pode ser detectada após o evento hemorrágico. A formação da bilirrubina, um processo que depende de uma enzima, é diagnosticada de forma mais confiável, porém necessita de mais de $12 \mathrm{~h}$ para sua metabolização, perdurando até 2 semanas. A análise do LCR nesta condição requer o estudo com espectrofotometria para maior segurança ${ }^{196}$.

c) Imagem por Ressonância Magnética (IRM)

A informação fornecida com as sequências em T2 gradiente eco e FLAIR não distinguem a origem do sangue no espaço subaracnoideo, o sinal paramagnético evidenciado reflete a presença pregressa de substratos da hemoglobina neste espaço ${ }^{197}$ (Classe IIb, nível C segundo Guideline 2012 AHA/Stroke).

\subsubsection{Métodos de Avaliação da Angioarquitetura}

a) Angiotomografia (AngioTC) dos Vasos Encefálicos

Esta é uma ferramenta bastante útil e que, com o advento de melhores equipamentos de tomografia com recursos de reconstrução 3D nas workstations, auxilia inclusive na celeridade no diagnóstico por meio do estudo da angioarquitetura. Considerando que, no momento da chegada ao atendimento após a suspeita de ictus de uma HSAa ou de qualquer evento cerebrovascular, essa ferramenta diagnóstica pode também ser realizada no momento da realização da primeira TCC, o que auxilia na decisão de qual o tipo de lesão aneurismática está envolvida e ajuda ao time que 
presta a primeira assistência em decidir qual o método de tratamento poderia ser encaminhado o paciente o mais breve possível sem procrastinar o tratamento (Classe IIb, nível C segundo Guideline 2012 AHA/Stroke $)^{2}$.

A angioTC, como qualquer ferramenta diagnóstica, possui vantagens e desvantagens. Entre os fatores positivos, estão a acessibilidade rápida ao método diagnóstico, que pode ser obtida em média dentro de $15 \mathrm{~min}$, bem como, permitir uma reconstrução tridimensional sem intervenção, como na angiografia por subtração $\operatorname{digital}^{197}$.

Entre os fatores não favoráveis, estão os seguintes: a acurácia do método para estudar outras lesões vasculares associadas que é menor, não permite a intervenção terapêutica no momento do diagnóstico nem permite o estudo funcional da hemodinâmica cerebral, o que determina uma impossibilidade no estudo das alterações com hipertensão intracraniana ou aumento do tempo de circulação $\operatorname{arteriovenoso~}^{198}$.

\section{b) Angiografia Encefálica por Subtração Digital (ACSD)}

A primeira angiografia encefálica realizada por Egaz Moniz é considerada um marco histórico para o desenvolvimento do diagnóstico e tratamento dos aneurismas cerebrais, bem como, de muitas outras doenças vasculares (Moniz, 1927). Com o advento desta ferramenta diagnóstica, inúmeras melhorias na performance dos equipamentos permitiram tanto o diagnóstico como o tratamento em um único procedimento, pois se tornaram mais rápidos e com menor exposição à radiação ${ }^{29,30}$.

A melhoria na aquisição das imagens permitiu tanto o diagnóstico como o planejamento terapêutico por meio de softwares $3 \mathrm{D}$, permitindo a reconstrução em estações de trabalho que simulam o tratamento antes do ato propriamente dito (Classe 
I, Evidência B do Guideline 2012 para $H S A a)^{2}$. A imagem tridimensional na angiografia auxilia na melhor opção de tratamento, inclusive permitindo visualizar lesões tipo "blister" aneurismas que, em outras ocasiões, eram despercebidos como causa da HSAa em aparelhos sem este recurso ${ }^{2}$.

Não há duvidas quanto às vantagens do estudo hemodinâmico cerebral, no entanto, representa um exame dispendioso, demorado, e que necessita do auxílio de uma equipe multidisciplinar maior e com anestesista ${ }^{199}$.

A evolução tecnológica chegou ao ponto de permitir com o mesmo software 3D fazer exames de tomografia na suíte angiográfica (exemplo: Dyna CT, Siemens), que permitem uma aquisição desta mesma TCC com perfusão a fim de avaliar o grau de comprometimento tecidual de acordo com o estudo hemodinâmico. Este recurso auxilia em um mesmo ato tanto o diagnóstico de um suposto vasoespasmo encefálico como a intervenção terapêutica endovascular, e norteia quanto ao risco do paciente desenvolver uma complicação do tipo isquemia encefálica tardia (DCI) ${ }^{199}$.

3.8.3. Métodos de Avaliação da Funcionalidade Hemodinâmica Encefálica e Detecção Precoce de Vasoespasmo Encefálico elou Déficit Neurológico Isquêmico Tardio

a) Doppler Transcraniano (DTC)

Em 1982, Aslid descreveu um método não invasivo à beira do leito capaz de avaliar e monitorar o desenvolvimento de vasoespasmo encefálico. Uma série de estudos com DTC demonstrou que o grau de VC possui uma correlação direta com o desenvolvimento de DCI. Os dados se mostram mais confiáveis com o uso do index de probabilidade de VE, o qual é baseado nas velocidades médias de fluxo das artérias da circulação anterior e da circulação posterior, bem como, por meio dos índices de 
Lindegaard (para circulação anterior, razão entre ACM/ACI) e o de Soustiel (para circulação posterior, razão Vertebral/Basilar) ${ }^{200}$.

As velocidades acima de $120 \mathrm{~cm} / \mathrm{s}$ na artéria cerebral média (ACM) já indicam a presença de VE, assim, velocidades acima de $200 \mathrm{~cm} / \mathrm{s}$ sugerem VE $\operatorname{grave}^{167}$ (Anexos F, G e H).

Os pacientes com HSAa apresentam um percentual elevado de complicações que estão associadas com o pior prognóstico da doença. Os efeitos inflamatórios da fase aguda do evento hemorrágico determinam uma mudança no fluxo sanguíneo cerebral e no metabolismo encefálico ${ }^{201}$. Tudo ocorre como uma tempestade encefálica que hoje a literatura médica compreende melhor por meio das explicações da teoria de Leão, com a despolarização cortical como um fenômeno agudo elétrico observado na maioria das doenças neurológicas ${ }^{202-203}$.

No nível celular, existe uma completa perda do gradiente iônico, completa despolarização e perda da atividade elétrica, resultando em edema citotóxico neuronal. A resposta vascular para uma despolarização alastrante cortical (DAC) é a vasodilatação, o que determina hiperemia ${ }^{204}$. Essa resposta hiperêmica é seguida de uma vasoconstrição com redução no fluxo sanguíneo cerebral, resultando na fase de oligemia. Em estados patológicos graves (pós-HSAa com estado grave) com grupos de DAC perdurando mais de 3 min, existe uma longa vasoconstrição que, ao final, resulta na fase isquêmica da DAC, em que essa possui uma relação direta com os estados de $\mathrm{DCI}^{205}$.

De um modo geral, todas essas fases da DAC após uma HSAa podem ser acompanhadas com o auxílio do estudo hemodinâmico com DTC, o que poderia auxiliar na tomada de decisão terapêutica para melhoria do prognóstico individualizado $^{189}$. 


\section{b) Tomografia Computadorizada com Perfusão (CT perfusão)}

O exame de CT perfusão consiste em um estudo com tomografia computadorizada de crânio em um aparelho com requisitos mínimos de 64 canais para a aquisição após a injeção do meio de contraste e análise por meio de um software específico para avaliação dos mapas de fluxo sanguíneo cerebral (CBF - cerebral blood flow), de volume sanguíneo cerebral (CBV - cerebral blood volume) e da média de tempo de trânsito (MTT - mean transient time), sendo reconstruídos sobre o território vascular de cada região do encéfalo de interesse (ROI), permitindo a comparação de um lado com o outro ${ }^{206}$.

Neste contexto, a CT perfusão tem sido utilizada como uma ferramenta para detectar o VE após $\mathrm{HSAa}^{12}$. A ferramenta ideal deve ser não invasiva, de fácil realização e reproduzível, de forma a ser capaz não apenas de identificar o vasoespasmo, mas também os pacientes sob risco de DCI. A ACSD é considerada o padrão-ouro para o diagnóstico de vasoespasmo cerebral, mas sua invasividade dificulta sua proposta como exame para monitorização ${ }^{207}$.

Por outro lado, o DTC já é uma ferramenta realizável à beira do leito, permitindo o monitoramento diário, mas dependente da experiência do examinador, o que dificulta a reprodutibilidade similar em grandes séries, bem como não detecta vasoespasmo distal. De um modo geral, sem a informação do status clínico do paciente, tanto o DTC como a ACSD não permitem a identificação da progressão de um vasoespasmo assintomático para um sintomático num determinado tecido sob risco $^{208-210}$. 
Com isso, ferramentas como a CT perfusão têm procurado cobrir ao máximo de vantagens em um método capaz de nos trazer esta informação preditiva e real do risco de DCI. Mas com a desvantagem de ter que expor à radiação de forma rotineira com dificuldade de uso pragmático. Segundo Murphy et al., a CT perfusão na fase aguda pós-HSAa mostrou que o MTT, nas primeiras 72h, esteve associado com DCI e infarto cerebral ${ }^{211}$.O princípio de uso da CT perfusão na fase precoce da HSAa é baseado nas mudanças que podem refletir distúrbios cerebrais de autorregulação que podem ser determinantes para DCI.

No entanto, apesar de inúmeras ferramentas serem utilizadas para avaliar o vasoespasmo encefálico sintomático e o risco de DIND e DCI, até o momento, nenhum dos métodos para este fim tem mais correlação funcional que o exame neurológico detalhado. Porém, depende do paciente acordado e consciente, o que nem sempre é possível ${ }^{212}$.

\section{c. Eletroencefalograma (EEG)}

Pacientes pós-HSAa são potenciais candidatos tanto às crises convulsivas como à isquemia cerebral. O EEG contínuo (quantitativo) é uma ferramenta capaz de identificar ambas as complicações precocemente ${ }^{185}$. Estudos demonstram que a monitorização contínua com esta ferramenta permite a detecção precoce tanto do vasoespasmo como do DCI, considerando que o método tem a sensibilidade de espelhar a deterioração metabólica e os distúrbios de atividade neuronal após uma redução do fluxo sanguíneo cerebral (FSC) ${ }^{174}$.

As mudanças no EEG quantitativo, tais como o achatamento ou a perda de altas frequências, são encontradas rapidamente se o FSC reduzir abaixo de 0,16-0,17 $\mathrm{ml} \mathrm{g}^{-1} \min ^{-1}$, em que a redução focal no poder espectral alfa pode representar um 
potente marcador, quando a monitorização é feita de forma contínua, evidenciando risco de vasoespasmo/ $\mathrm{DCI}^{174}$.

Quando o FSC se torna comprometido, mudanças metabólicas e da atividade elétrica encefálica se estabelecem, de forma que, ao declinar para limites de 25$35 \mathrm{ml} / 100 \mathrm{~g} / \mathrm{min}$, o EEG perde as frequências mais rápidas (derivadas das células nas camadas IV e V do córtex cerebral, na faixa de 8-12 Hz - frequência alfa). Porém, ao atingir valores de 17 a $18 \mathrm{ml} / 100 \mathrm{gr} / \mathrm{min}$, as menores frequências (com origem nas células das camadas II-VI do córtex e do tálamo - frequências típicas delta 0,5-3 Hz e theta $4-7 \mathrm{~Hz}$ ) aumentam gradualmente ${ }^{213}$.

O VE e a DIND estão associados com a possibilidade de um pior prognóstico, especialmente nos pacientes comatosos, neste contexto, o uso do EEG contínuo nas unidades de terapia intensiva ganha importância como ferramenta de monitorização e avaliação precoce do risco de desenvolver uma destas complicações ${ }^{213}$. Nos dias atuais, o DTC é a ferramenta utilizada de forma seriada para detecção dessas complicações, quando utilizado, sua sensibilidade é 70\% em predizer a chance de uma isquemia ${ }^{214}$. Porém, os estudos com EEG contínuo têm demonstrado que essa ferramenta pode predizer o risco de vasoespasmo/DCI em até 1-2 dias antes dos fenômenos mecânicos se estabelecerem, predizendo em 78\% inclusive nos pacientes com VASOGRADE vermelho ${ }^{177,213,215}$.

\section{d. Microdiálise Intracerebral}

Esse método tem sido usado nas UTI, a fim de monitorar alterações do metabolismo encefálico associados com isquemia e hipóxia. Em 1995, Haemberger et al. demonstraram uma correlação inversa entre os níveis de aminoácidos excitatórios e nucleosídeos na recuperação de pacientes com HSAa ${ }^{216-217}$. Entre os metabólitos 
avaliados, destaca-se o glutamato que, quando aumentado, demonstra ser um potencial marcador da isquemia encefálica, assim como o piruvato, o glicerol intersticial e o lactato envolvidos no processo do metabolismo anaeróbico encefálico $^{185}$.

Outros autores como Unterberg et al. advogam que a microdiálise é uma ferramenta mais efetiva capaz de identificar o DCI do que o DTC e ACSD, sua especificidade seria $89 \%$ comparada a $63 \%$ para o DTC e $53 \%$ para $\mathrm{ACSD}^{218}$.

\subsection{Abordagem ao Paciente Pós-HSAa}

\subsubsection{Cuidados Iniciais}

Após a admissão do paciente com o diagnóstico de HSAa, esse deve ser conduzido à investigação diagnóstica e aos cuidados de uma unidade de terapia intensiva (UTI), em que esse será mantido em regime de controle pressórico, a fim de evitar o ressangramento nas primeiras $24 \mathrm{~h}$ ou durante o seu período mais crítico nas primeiras $72 \mathrm{~h}$. A chance deste grupo de pacientes apresentar uma nova hemorragia varia de 5 a $22 \%$ neste período $^{219}$.

O paciente com HSAa deve ser graduado quanto à agressividade da apresentação inicial, isso irá permitir uma inferência inicial de cada grupo, separando os de melhor e os de pior prognóstico, tanto no momento do acontecimento do ictus por ocasião da magnitude do evento (conforme mecanismo EBI) como também pelo maior risco de VE e DCI (por meio do mecanismo inflamatório). Na avaliação clínica inicial, são considerados o exame neurológico graduando segundo as escalas de Hunt e Hess, e o escore WFNS (Anexos B e C) $)^{220}$. 
Além disso, é de extrema importância a avaliação da apresentação com a TCC para fins de estratificação dos grupos de maior ou menor risco para vasoespasmo cerebral, conforme a escala de Fisher modificada (Anexo D) ${ }^{164}$.

Na avaliação inicial, com achados clínicos e de imagem da TCC permitem a estratificação dos grupos segundo o score VASOGRADE, que permite estimar o percentual de chance de desenvolver DCI ou DIND (Anexo E) ${ }^{177}$.

$\mathrm{Na}$ abordagem inicial ao paciente com HSAa, o objetivo é evitar o ressangramento e minimizar o risco de DCI, secundária em grande parte pelo vasoespasmo cerebral. Com isso, as medidas iniciais são de extrema importância para uma boa condução ${ }^{2}$.

Os mesmos autores demonstraram que os fatores genéticos não estão envolvidos com a maior expectativa de ressangramento ${ }^{162}$.

O guideline da AHA/Stroke 2012, estabeleceu algumas recomendações:

- Entre o sintoma da HSAa e a oclusão do aneurisma, a PA deve ser controlada com agentes específicos, a fim de balancear o riso de stroke (Classe I, Nivel B de evidência);

- A magnitude do controle da PA para reduzir o risco de ressangramento com níveis da sistólica abaixo de $160 \mathrm{mmHg}$ (Classe IIb, evidência nível C);

- Para pacientes em que o retardo da oclusão do aneurisma é inevitável, o risco de ressangramento está aumentado, e o uso do ácido trenaxêmico ou aminocaproico está indicado para reduzir o risco de ressangramento (Classe IIa, Evidência nível B).

\subsubsection{Intervenção Precoce ou Tardia}


A terapia precoce $(<72 \mathrm{~h})$ quer por microcirurgia quer por endovascular deve ser preferencial, pois reduz as taxas de ressangramento, reduz o risco de vasoespasmo cerebral e $\mathrm{DCI}^{222}$.

O International Subarachnoid Aneurysm Trial (ISAT) mostrou uma redução de $23 \%$ no risco relativo e de $7 \%$ no risco absoluto nos pacientes submetidos ao tratamento endovascular comparado à cirurgia. Este ensaio multicêntrico randomizado selecionou 2.143 de 9.559 pacientes com HSAa ao longo de 42 centros neurocirúrgicos. Esse estudo inicial mostrou que o grupo microcirúrgico se mostrava mais protegido de ressangramento a longo prazo e que o grupo endovascular possuía uma morbidade menor a curto prazo $222-223$.

Um estudo em centro único na Finlândia não encontrou diferenças no tratamento microcirúrgico com o endovascular, considerando as taxas de morbidade, recuperação e morte 1 ano após o evento ${ }^{224}$.

O Ensaio do Instituto Barrow (BRAT - Barrow Ruptured Aneurysm Trial) mostrou que os pacientes tratados por via endovascular tiveram uma sobrevida de 1 ano melhor com um score de Rankin menor que $2^{225}$.

A última revisão do ISAT (2015) após 18 anos de sua primeira edição mostrou que houve maior mortalidade e dependência no grupo neurocirúrgico do que comparado ao grupo endovascular ${ }^{223}$.

O guideline da AHA/Stroke, 2012, orienta algumas recomendações²:

- Clipagem cirúrgica ou embolização com coils deve ser realizada o mais precoce possível para evitar o ressangramento pós-HSAa (Classe I, Nível de Evidência B);

- Oclusão completa do aneurisma é recomendada (Classe I, Nível de Evidência B); 
- A escolha do método deve ser feita por um cirurgião experiente no método escolhido com decisão multidisciplinar, e baseado nas características do aneurisma e do paciente (Classe I, nível de evidência C);

- Os pacientes com HSAa são elegíveis a qualquer um dos métodos (Classe I, nível de evidência $B$ );

- A clipagem cirúrgica deve ser considerada em paciente com hematomas > 50ml, aneurismas de ACM, enquanto a endovascular para pacientes $>70$ anos, com pior grau prognóstico no score e aneurismas do topo da basilar (Classe IIb, nivel C de evidência).

\subsubsection{Monitoramento e Conduta no Vasoespasmo Encefálico e DCI pós-}

$\underline{H S A a}$

O vasoespasmo encefálico permanece como a mais importante complicação pós-HSAa quando se manifesta clinicamente, o que ocorre em 20 a $40 \%$ dos pacientes. No estudo de ACSD, os pacientes acometidos pela HSAa cerca de $70 \%$ apresenta o VE, porém nem todos desenvolvem sintomas clínicos que necessitem de intervenção a fim de evitar o risco de DCI, responsabilizada pelas taxas de morbidade e mortalidade elevadas ${ }^{164,200}$.

A manifestação mecânica expressa pelo estreitamento das artérias após a HSAa ocorre, mais comumente, com o pico entre o $7^{\circ}$ e $10^{\circ}$ dia pós-ictus, podendo perdurar a chance de manifestação clínica por até 3 semanas. A cascata de eventos inflamatórios que se estabelecem depois do sangramento culmina com a exposiçãoo extraluminal da oxi-hemoglobina ${ }^{41}$.

Possivelmente, entre os inúmeros mecanismos físicos e químicos envolvidos com isquemia e infarto a partir do VE, incluem falha da microcirculação distal (perda 
da autorregulação), deficiência da circulação colateral e de variações anatômicas, fisiológicas e genéticas que dificultam a tolerância isquêmica celular ${ }^{145,227}$.

A DCI, especialmente o associado ao VE permanece como a principal causa de morbidade e mortalidade nos pacientes com HSAa. O mecanismo do VE permanece bastante complexo com múltiplas variáveis capazes de influenciar no desenvolvimento de um desfecho favorável ou não. Após inúmeros ensaios clínicos e metanálises, o comitê da AHA/Stroke determinou algumas recomendações ${ }^{2,163}$ :

- Nimodipina oral em todos os pacientes (Classe I, nível de evidência A);

- Manutenção da euvolemia e balanço hídrico normal para prevenir DCI (Classe I, nível de evidência B);

- Hipervolemia profilática ou angioplastia com balão após evoluir e evidenciar vasoespasmo angiográfico, isto não é recomendado (Classe III, nível de evidência $B)$;

- DTC é razoável para monitorar o desenvolvimento de vasoespasmo (Classe IIa, nível de evidência B);

- A CT perfusão ou a IMR podem ser utilizadas para avaliar áreas de sofrimento isquêmico (Classe IIa, nível de evidência B);

- Induzir hipertensão é recomendado para os pacientes com DCI sem PA elevada como linha de base (Classe I, nível de evidência B);

- Angioplastia cerebral e/ou terapia vasodilatadora seletiva é razoável em pacientes com vasoespasmo sintomático, para os que não respondem clinicamente (Classe IIa, nível de evidência B).

O VE e o DCI permanecem como as complicações neurológicas mais graves e debilitantes após HSAa, em que 25-30\% dos que sobrevivem ao evento hemorrágico apresentam algum grau dessas complicações. Entre os que morrem após um quadro 
debilitante grave secundário, a isquemia tardia o percentual atinge cifras de $15 \%$. Neste contexto, inúmeras terapias medicamentosas vêm sendo aplicadas, porém a evidência científica demonstra que ainda muito deve ser investigado no que concerne a uma ou alguns fármacos capazes de atuar minimizando os efeitos do $\mathrm{VE}^{194,203}$.

Em uma revisão sistemática Weyer et al. demonstraram que a única que mostrou algum efeito no combate ao vasoespasmo foi a nimodipina, entre outras drogas, como tirilazd, não houve resposta efetiva. E, como terapia de resgate, a angioplastia com o balão e uso de vasodilatadores intra-arterial mostraram alguma resposta favorável ${ }^{226}$.

Boulouis et al., em uma metanálise, mostraram que o tratamento endovascular pode melhorar o desfecho de pacientes graves refratários ao tratamento medicamentoso 227 .

3.9.4. Conduta na Hidrocefalia, Crise convulsiva e Complicações pós-HSAa para evitar progressão ao Vasoespasmo Encefálico e a Isquemia Encefálica Tardia $(D C I):$

A propósito da hidrocefalia aguda que pode ocorrer entre $15-87 \%$ dos casos pós-HSAa, piorando o prognóstico, quando não tratada, piora e aumenta as chances de DCI. Na fase crônica pós-HSAa, a chance de desenvolver a hidrocefalia está entre 8,9 a $48 \%{ }^{2}$.

No que tange o uso de medicações para reduzir as complicações pós-HSAa, os autores recomendam no protocolo algumas medidas conforme a evidência:

- Pacientes com HSAa e evidências de hidrocefalia, devem ter o LCR drenado (Classe I, nível de evidência B);

- Hidrocefalia crônica em paciente pós-HSAa deve ser submetido a um shunt (Classe I, nível de evidência C); 
- Retirada do shunt ventricular $>24 \mathrm{~h}$ não parece ser efetiva para reduzir o risco da necessidade de shunt (Classe III, nível de evidência B);

- Fenestração da lâmina terminalis não é útil na redução da taxa de shunt dependente na hidrocefalia e não deve ser rotineira (Classe III, nível de evidência B);

- Uso de anticonvulsivante pode ser usado de imediato ao sangramento (Classe III, nível de evidência B);

- Uso de grandes volumes de fluído hipotônico e não é recomendado (Classe III, nivel de evidência B);

- Evitar hipertermia, ajuda no prognóstico na fase aguda (Classe IIa, nível de evidência $B)$;

- Cuidado com os níveis de glicose acima de 129 mg/dl; evitar anemia < 10 para reduzir o risco de isquemia (Classe IIb, nível de evidência B). 
MÉTODOS 


\section{Métodos}

\subsection{Casuística}

Foram incluídos dados de 300 pacientes com HSAa, oriundos do estado do Pará, que foram referenciados ao Serviço de Neurocirurgia da Clínica Neurológica do Hospital Ofir Loyola (HOL), no período de janeiro de 2014 a março de 2016. Coletou-se sangue de 265 pacientes para avaliação genética. Os dados foram coletados conforme protocolo (Anexo K).

\subsection{Caracterização da amostra}

Os pacientes foram agrupados quanto à presença após a hemorragia em dois grupos: Grupo I - Aneurisma roto com vasoespasmo sintomático, correspondendo a 124 casos (46,8\%) e Grupo II - Aneurisma roto sem vasoespasmo sintomático com 141 pacientes $(53,20 \%)$. Os pacientes alocados no grupo II foram considerados o grupo controle para esta pesquisa, a fim de buscar a influência dos biomarcadores genéticos no grupo vasoespasmo sintomático. A amostra se distribuiu em 41 (15,4\%) indivíduos do sexo masculino e $224(84,52 \%)$ do sexo feminino, com a faixa etária variando de 12 a 81 anos de idade, com uma mediana de 51,61 anos de idade.

A amostra foi distribuída de acordo com os grupos selecionados para análise estatística. Sendo que cerca de 76,22\% (202 casos) dos pacientes apresentaram um tempo de chegada até o hospital referência entre 3 a 4 semanas após a ocorrência do ictus, em virtude das grandes dimensões territoriais do estado do Pará.

$\mathrm{Na}$ distribuição amostral, a maioria dos pacientes foi graduada com o escore da escala WFNS entre I $(31,3 \%)$ e II $(43,7 \%)$, bem como a maior distribuição dos pacientes quanto à quantidade de sangue na primeira TCC segundo Fisher modificado 
foi de escore 2, caracterizada por 136 pacientes (51,76\%). Quanto ao risco de evolução para um vasoespasmo cerebral, os pacientes ficaram distribuídos entre a escala VASOGRADE da seguinte forma: Grupo Verde com 157 casos (59,24\%); Grupo Amarelo com 69 casos (26,03\%) e Grupo Vermelho com 39 casos (14,71\%).

\subsection{Desenho do Estudo}

Este é um estudo observacional tipo caso controle de genética de populações unicêntrico, conforme protocolo de atendimento ao paciente com HSAa, em que foram coletadas informações a partir das variáveis descritas no protocolo e da coleta do sangue para análise do DNA (figura 7).

O estudo foi baseado a partir dos critérios de diagnóstico de HSAa e na condução clínica dessa, conforme os critérios internacionais dos Guidelines para Hemorragia Subaracnoidea descritos pela American Heart Association/ American Stroke Association (AHA/ASA) ${ }^{2}$.

Os pacientes foram admitidos nesta pesquisa conforme os critérios abaixo:

\section{a) Critérios de inclusão}

a.1. Pacientes com diagnóstico de HSAa avaliados por ACSD ou AngioTC cerebral;

a.2. HSAa admitidas com até 4 semanas pós-hemorragia;

a.3. Pacientes naturais da região Amazônica.

\section{b) Critérios de exclusão}

b.1. HSA de origem não aneurismática;

b.2. Casos de HSA sem investigação angiográfica, por qualquer método;

b.3. Pacientes com HSAa naturais e procedentes de outras localidades, excetuando a Amazônica; 
b.4. Pacientes admitidos após 4 semanas de evolução da hemorragia.



Figura 7. Fluxograma de assistência e coleta dos dados pós-HSAa.

Inicialmente, os pacientes incluídos na pesquisa foram assistidos em outras unidades de atendimento médico no estado do Pará, e, após estabilização do caso e conforme a disponibilidade de leitos, eram referenciados ao HOL, em que foram submetidos ao estudo angiográfico cerebral e decisão terapêutica apropriada. 
Os pacientes foram distribuídos quanto à escala VASOGRADE com base nas informações clínicas no momento do ictus e dos achados de TCC inicial, a fim de caracterizá-los tanto nas escores WFNS como nos escores de Fisher modificado (Anexos C e D). Essa distribuição foi realizada a fim de avaliar a chance de desenvolver vasoespasmo clínico (2 semanas iniciais pós-ictus) ou até déficit isquêmico encefálico tardio ( $3^{\mathrm{a}}$ e $4^{\mathrm{a}}$ semanas pós-ictus).

O critério de distribuição, quanto a ser do grupo I ou II, foi fundamentado na clínica (sintomática) e na imagem da TCC com evidências de VE e/ou DCI até 4 semanas após hemorragia; e/ou com a evidência de algum método de imagem com DTC ou ACSD com sinais VE no período associada à presença de alterações sugestivas de DCI.

\subsection{Coleta dos Dados}

\subsubsection{Variáveis Epidemiológicas}

a) Variáveis Quantitativas: Idade

Neste grupo, a idade foi considerada tanto no momento da ocorrência do ictus como na faixa de acometimento de acordo com os grupos abaixo:

- $\quad<30$ anos;

- 30-39 anos;

- 40-49 anos;

- 50-59 anos;

- 60-69 anos;

- $\quad \geq 70$ anos.

b) Variáveis Qualitativas: Sexo; etnia inferida pelo paciente (branco, negro, índio e japonês); fatores de risco modificáveis maiores (tabagismo e hipertensão arterial sistêmica); classificação escala WFNS, classificação de Fisher modificada; tamanho e 
localização do aneurisma roto; classificação preditiva de risco de vasoespasmo sintomática modificada $^{177}$; tipo de tratamento; desfecho pós-tratamento (favorável ou desfavorável); óbito; vasoespasmo encefálica e déficit neurológico isquêmico tardio (DIND) (tabela 1 e 3).

Tabela 1. Escala de graduação modificada do risco de isquemia pós HSAa, segundo escala original VASOGRADE. WFNS (World Federation of Neurosurgical Societies) + Escala de Fisher na TC de crânio modificada.

\begin{tabular}{|cccc|}
\hline Graduação por Cor & Escala WFNS & Escala de Fisher & Risco de Isquemia \\
\hline Azul & I & 0 & $0 \%$ \\
Verde & I - II & I - II & $15 \%$ \\
Amarelo & I - III & III - IV & $19 \%$ \\
Vermelho & IV - V & I - IV & $37 \%$ \\
\hline
\end{tabular}

\subsubsection{Diagnóstico Vascular}

A circulação encefálica foi estudada pela angiografia cerebral por subtração digital (ACSD), permitindo identificar a morfologia, localização e tamanho do(s) aneurisma(s) intracraniano(s), envolvidos com a HSA, bem como; a presença ou não de vasoespasmo encefálico com sua graduação (I a IV) respectiva no momento do diagnóstico. O exame foi realizado apenas pelo pesquisador em um sistema de formação de imagens por raios-x monoplanar FD20, para fins de estudo vascular hemodinâmico com resolução de 1024 x 1024, com reconstrução 3D, de acordo com as técnicas de radiologia intervencionista. A análise angiográfica foi realizada pelo mesmo examinador-pesquisador. Os exames foram realizados em um único centro de referência no Hospital Ophir Loyola. 


\subsubsection{Investigação dos Biomarcadores Genéticos e da Ancestralidade}

A análise genética foi realizada no Laboratório de Genética Humana e Médica em Cooperação com o Laboratório de Neurociências ambos da Universidade Federal do Pará (UFPA) para todos os pacientes envolvidos na série.

Foi coletada uma amostra de $10 \mathrm{ml}$ de sangue periférico, a partir da punção arterial transfemural; no momento da realização do estudo angiográfico cerebral, para identificação do aneurisma e a presença de espasmo arterial. A extração de DNA dessas amostras foi realizada com base no método de fenol-clorofórmio.

\section{a) Escolha dos Marcadores}

Os 14 biomarcadores de susceptibilidade inflamatória rs3833129 em CASP8, uma deleção de 96 pb em CYP2E1, rs11575899 em CYP19A1, rs3783553 em IL1A, rs79071878 em IL4, rs3730485 em MDM2, rs28362491 em NFKB1, rs11267092 em PAR1, rs17878362 em TP53, rs16430 em TYMS, rs8175347 em UGT1A1 e rs3213239 em XRCC1) são INDEL (inserção/deleção) em sua maioria e foram escolhidos considerando a importância de cada gene para potencial influência na susceptibilidade de desenvolvimento inflamatório, visando ao desenho de um painel de marcadores para a susceptibilidade para inflamatória envolvida com a rotura dos aneurismas intracranianos e suas complicações isquêmicas. A Tabela 2 expõe os polimorfismos selecionados e seus respectivos iniciadores.

Além desses biomarcadores, foi realizada a análise principal do marcador $T$ 786C (rs2070744) do gene da NOS3 (eNOS), sendo que a análise molecular do seu polimorfismo foi investigada por meio da técnica de genotipagem utilizando sondas marcada com fluoroforo VIC/FAM (Real Time PCR-Thermo Fisher Scientific, CA, USA), de acordo com as recomendações do protocolo do fabricante. O protocolo da reação de cada amostra utilizou $1,4 \mu \mathrm{L}$ de água; $2,5 \mu \mathrm{L}$ de MasterMix; $0,1 \mu \mathrm{L}$ da 
sonda fluorescente TaqMan; e 2,0 $\mu \mathrm{L}$ de DNA dos pacientes. A reação padrão foi conduzida no equipamento ABI 7500 Real Time PCR System (Thermo Fisher Scientific, Foster City, CA, USA).

Outro biomarcador correspondente à região intrônica do gene eNOS, o VNTR (27VNTR), teve sua genotipagem realizada a partir de repetições de 27 pb no íntron 4 e foi realizada com amplificação por PCR convencional e eletroforese em gel de agarose a 4\% e corante SYBR Safe. O protocolo da reação de cada amostra utilizou $18,9 \mu \mathrm{L}$ de água; $2,5 \mu \mathrm{L}$ de tampão; $0,75 \mu \mathrm{L}$ de $\mathrm{MgCl}_{2} ; 0,5 \mu \mathrm{L}$ de dNTP; $0,5 \mu \mathrm{L}$ para o primer forward; $0,5 \mu \mathrm{L}$ para o primer reverse; $0,1 \mu \mathrm{L}$ da enzima Taq polimerase; e 2,0 $\mu \mathrm{L}$ da amostra de DNA de cada pacientes. $\mathrm{O}$ equipamento empregado foi $\mathrm{o}$ termociclador Veriti ( Thermo Fisher Scientific).

Quanto ao biomarcador na região exônica do gene da NOS3 em que se situa o PNU G894T, sua análise foi abandonada, considerando que apenas 50\% da amostra analisada mostrou confiabilidade nos resultados com isso a mesma foi desconsiderada para análise.

\section{b) PCR Multiplex e análise de fragmento}

O PCR multiplex aqui desenvolvido permite genotipar 12 marcadores do tipo INDEL em apenas uma reação de PCR seguida de eletroforese capilar. Para as amplificações multiplex, utilizou-se 5,0 $\mu \mathrm{L}$ do kit QIAGEN Multiplex PCR (QIAGEN, Alemanha), 1,0 $\mu \mathrm{L}$ de Q-solution, 1,0 $\mu \mathrm{L}$ de Primer Mix, 2,0 $\mu \mathrm{L}$ de água e $1,0 \mu \mathrm{L}$ de DNA (20ng). As amostras serão incubadas a $95^{\circ} \mathrm{C}$ por 15 minutos, então, 35 ciclos a $94^{\circ} \mathrm{C}$ por 45 segundos, $60^{\circ} \mathrm{C}$ por 90 segundos e $72^{\circ} \mathrm{C}$ por 60 segundos, com uma extensão final a $70^{\circ} \mathrm{C}$ por 30 minutos. Essa reação foi realizada no termociclador ABI Verity (Thermo Fisher Scientific, Foster City, CA, EUA). 
Para a eletroforese capilar e análise de fragmento, $1,0 \mu \mathrm{L}$ do produto de PCR foi adicionado a 8,5 $\mu \mathrm{L}$ da formamida deionizada HI-FI (Life Technologies, Foster City, CA, EUA) e a $0,5 \mu \mathrm{L}$ de GeneScan 500 LIZ pattern size (Thermo Fisher Scientific, Foster City, CA, EUA). A separação desses fragmentos de DNA foi realizada com o ABI PRISM 3130 Genetic Analyzer e a leitura dos picos, com o uso do programa GeneMapper ID v3.2, também da Thermo Fisher Scientific (Foster City, CA, EUA).

c) Marcadores Informativos da Ancestralidade

Para o controle de ancestralidade, foram usados os marcadores genéticos conhecidos como Marcadores Informativos de Ancestralidade (AIM, do Inglês, Ancestry Informative Markers), que são ferramentas muito importantes na determinação de ancestralidade genômica individual e, em maior escala, populacional. Esses marcadores permitiram a distinção de populações parentais e a identificação da subestruturação em populações miscigenadas.

Sendo, nesse estudo, demonstrada a distinção entre etnia europeia, africana e ameríndia.

\subsubsection{Métodos de Diagnóstico do Vasoespasmo e Monitoramento para Isquemia Encefálica Tardia (DCI)}

a) Critérios Clínicos: considerar até 28 dias

- Piora do nível de consciência (queda de dois pontos da Escala de Glasgow de Coma $>2)$;

- Estado confusional instalado de forma súbita;

- Déficit neurológico apendicular instalado subitamente;

- Aparecimento de cefaleia persistente.

b) Critérios de risco para vasoespasmo encefálico: febre; crise convulsiva; leucocitose persistente sem tratamento; desidratação; distúrbios eletrolíticos (hiponatremia e/ou hipomagnesemia; e anemia (hemoglobina $<10 \mathrm{mg} / \mathrm{dl}$ ). 


\section{c) Critérios do Doppler transcraniano:}

Esse critério foi utilizado para monitorar os pacientes na UTI, em que estudo foi desenhado com a utilização de equipamento de Doppler transcraniano (DTC) de um ou dois canais, com transdutores de $2 \mathrm{MHz}$ (Doppler Box ${ }^{\mathrm{TM}}$ DWL ou Doppler Easy Dop ${ }^{\mathrm{TM}}$ ). O método permitiu a avaliação da evolução da velocidade de fluxo sanguíneo nas artérias cerebral média (na janela temporal) e basilar (janela subocciptal).

Os critérios de alerta considerados para investigação com ASCD ou tratamento endovascular (químico e/ou mecânico) foram:

- análise do índice quanto à velocidade de FSC na artéria cerebral média $(\mathrm{ACM}) /$ artéria carótida interna $(\mathrm{ACI})$;

- análise do índice quanto à velocidade de FSC na artéria basilar (AB)/ artéria vertebral extradural (AV);

- a velocidade na $\mathrm{ACM}>120 \mathrm{~cm} / \mathrm{seg}$ - atenção (de acordo com o dia de ictus);

- $\quad$ aumento de $50 \mathrm{~cm} / \mathrm{seg} / \mathrm{dia}$ (sugere risco iminente de clínica);

- $\quad$ aumento progressivo $>50 \%$ em um dia (risco iminente de piora) ou velocidade ACM $200 \mathrm{~cm} / \mathrm{seg}$.

\section{d) Exame de tomografia computadorizada encefálica}

O exame de imagem foi realizado no dia 1 pós-tratamento e exames subsequentes de imagem para avaliar absorção do sangue e sinais de possível hidrocefalia. A presença do apagamento de sulcos e giros, associada à instalação de 
alterações neurológicas associadas às alterações de laboratório de forma súbita inferiram a possibilidade de quadro de espasmo cerebral em curso.

Tabela 2. Caracterização dos 14 biomarcadores investigados, com base no painel gênico elaborado.

\begin{tabular}{|c|c|c|c|c|c|}
\hline Gene & Identif. & Tipo & Comp. & Primers & Amplif. \\
\hline CASP8 & rs3834129 & INDEL & $6 \mathrm{bp}$ & $\begin{array}{l}\text { F-5'CTCTTCAATGCTTCCTTGAGGT3' } \\
\text { R-5'CTGCATGCCAGGAGCTAAGTAT3' }\end{array}$ & $249-255 \mathrm{pb}$ \\
\hline CYP2E1 & - & INDEL & $96 \mathrm{pb}$ & $\begin{array}{l}\text { F-5'TGTCCCAATACAGTCACCTCTTT3' } \\
\text { R-5'GGCTTTTATTTGTTTTGCATCTG3' }\end{array}$ & $303-399 \mathrm{pb}$ \\
\hline CYP19A1 & rs11575899 & INDEL & $3 \mathrm{pb}$ & $\begin{array}{c}\text { F-5'TGCATGAGAAAGGCATCATATT3' } \\
\text { R-5'AAAAGGCACATTCATAGACAAAAA3' }\end{array}$ & $122-125 \mathrm{pb}$ \\
\hline ILIA & rs 3783553 & INDEL & $4 \mathrm{pb}$ & $\begin{array}{l}\text { F-5'TGGTCCAAGTTGTGCTTATCC3' } \\
\text { R-5'ACAGTGGTCTCATGGTTGTCA3' }\end{array}$ & $230-234 \mathrm{pb}$ \\
\hline IL4 & rs79071878 & INDEL & $\begin{array}{c}70 \mathrm{pb} \\
(1 / 2 / 3 \\
\text { repeats })\end{array}$ & $\begin{array}{l}\text { F-5'AGGGTCAGTCTGGCTACTGTGT3' } \\
\text { R-5'CAAATCTGTTCACCTCAACTGC3' }\end{array}$ & $147 / 217 / 287 \mathrm{pb}$ \\
\hline$M D M 2$ & rs3730485 & INDEL & $40 \mathrm{pb}$ & $\begin{array}{l}\text { F-5'GGAAGTTTCCTTTCTGGTAGGC3', } \\
\text { R-5'TTTGATGCGGTCTCATAAATTG3' }\end{array}$ & $192-232 \mathrm{pb}$ \\
\hline$N F K B 1$ & rs28362491 & INDEL & $4 \mathrm{pb}$ & $\begin{array}{l}\text { F-5'TATGGACCGCATGACTCTATCA3' } \\
\text { R-5'GGCTCTGGCATCCTAGCAG3' }\end{array}$ & $366-370 \mathrm{pb}$ \\
\hline PARI & rs11267092 & INDEL & $13 \mathrm{pb}$ & $\begin{array}{l}\text { F-5'AAAACTGAACTTTGCCGGTGT3' } \\
\text { R-5'GGGCCTAGAAGTCCAAATGAG3' }\end{array}$ & $265-277 \mathrm{pb}$ \\
\hline TP53 & rs17878362 & INDEL & $16 \mathrm{pb}$ & $\begin{array}{l}\text { F-5'GGGACTGACTTTCTGCTCTTGT3' } \\
\text { R-5'GGGACTGTAGATGGGTGAAAAG3' }\end{array}$ & $148-164 \mathrm{pb}$ \\
\hline TYMS & rs 16430 & INDEL & $6 \mathrm{pb}$ & $\begin{array}{l}\text { F-5'ATCCAAACCAGAATACAGCACA3' } \\
\text { R-5'CTCAAATCTGAGGGAGCTGAGT3' }\end{array}$ & $213-219 \mathrm{pb}$ \\
\hline$U G T 1 A 1$ & rs8175347 & VNTR & $\begin{array}{c}2 \mathrm{pb}-\mathrm{TA} \\
(5 / 6 / 7 / 8 \\
\text { repeats })\end{array}$ & $\begin{array}{l}\text { F-5'CTCTGAAAGTGAACTCCCTGCT3' } \\
\text { R-5'AGAGGTTCGCCCTCTCCTAT3' }\end{array}$ & $\begin{array}{c}133 / 135 / 137 / 139 \\
\mathrm{pb}\end{array}$ \\
\hline$X R C C 1$ & rs3213239 & INDEL & $4 \mathrm{pb}$ & $\begin{array}{l}\text { F-5'GAACCAGAATCCAAAAGTGACC3' } \\
\text { R-5'AGGGGAAGAGAGAGAAGGAGAG3' }\end{array}$ & $243-247 \mathrm{pb}$ \\
\hline eNOS & rs2070744 & SNP & $2 \mathrm{pb}$ & $\begin{array}{l}\text { CCAGGGCATCAAGCTCTTCCCTGGCC/TG } \\
\text { GCTGACCCTGCCTCAGCCTAGTC }\end{array}$ & \\
\hline eNOS & - & VNTR & $27 \mathrm{pb}(4)$ & $\begin{array}{c}\text { CCAGGGCATCAAGCTCTTCCCTGGCC/TG } \\
\text { GCTGACCCTGCCTCAGCCTAGTC }\end{array}$ & \\
\hline
\end{tabular}

SNP (Single Nucleotide Polymorphism) conhecidos como polimorfismo nucleotídeo único (PNU), INDEL (Insertion/Deletion) e VNTR (Variable Numbers of Tandem Repeat).

e) Critérios da Angiografia Cerebral por Subtração Digital:

O estudo angiográfico cerebral considerou como critérios de graduação do vasoespasmo os achados de imagem segundo Inagawa et al., 2014. Considerar o estreitamento com irregularidade da parede arterial maior que 50\% do lúmen habitual $^{232}$. Conforme distribuído na Tabela 3 abaixo: 


\subsubsection{Critérios Éticos}

A coleta dos dados e das amostras de sangue periférico dos participantes dos estudo foi aprovada pelos Comitês de Ética em Pesquisa do Hospital Ophir Loyola (instituição coparticipante) número CAAE 21159913.9.0000.5550 e da Faculdade de Medicina da Universidade de São Paulo CAAE 24228813.3.0000.0065, Parecer 015/14 (instituição proponente) e carta de aceite em participar da pesquisa, bem como; declaração de coparticipante da pesquisa por parte do Laboratório de Genética Humana e Médica em Cooperação com o Laboratório de Neurociências ambos da Universidade Federal do Pará (UFPA) (Anexos M, N e O).

Tabela 3. Avaliação do vasoespasmo pela angiografia cerebral por subtração digital. A1 segmento arterial 1 da artéria cerebral anterior; A2 segmento arterial 2 da artéria cerebral anterior; M1 e M2 segmentos arteriais 1 e 2 da artéria cerebral média.

Escore de Espasmo Características no estudo angiográfico

\begin{tabular}{|c|c|}
\hline Grau 0 & Sem vasoespasmo detectável \\
\hline Grau I & $\begin{array}{l}\text { Leve vasoespasmo em qualquer vaso e/ou moderado em } \\
\text { somente um dos seis segmentos arteriais estudados (duas A2 } \\
\text { ou } 4 \mathrm{M} 2 \text { ) }\end{array}$ \\
\hline Grau II & $\begin{array}{l}\text { Moderado vasoespasmo em mais do que dois dos seis } \\
\text { segmentos arteriais; sem aumento do tempo de circulação } \\
\text { arteriovenoso }\end{array}$ \\
\hline Grau III & $\begin{array}{l}\text { Vasoespasmo grave em um dos segmentos, duas M1, } \\
\text { segmento A1 dominante em qualquer das } 4 \mathrm{M} 2 \text { ou ambas A2, } \\
\text { tempo de circulação arteriovenoso moderamente aumentado }\end{array}$ \\
\hline Grau IV & $\begin{array}{l}\text { Vasoespasmo grave em mais do que duas localizações no grau } \\
\text { III, e aumento considerável do tempo de circulação } \\
\text { arteriovenoso. }\end{array}$ \\
\hline
\end{tabular}

Fonte: Inagawa T et al. 2014.

\subsubsection{O Modelo da Pergunta Estruturada}

O estudo foi fundamentado na investigação dos pacientes com HSAa, distribuídos em Grupo I (com vasoespasmo clínico) e Grupo II (sem vasoespasmo clínico). Os pacientes foram investigados quanto à presença de 14 biomarcadores 
genéticos e quanto ao marcadores informativos de ancestralidade com validados no Brasil envolvidos ou não com as complicações do tipo VE e/ou DCI.

Considerando os grupos e as investigações biomoleculares dos pacientes com HSAa, foram estruturadas duas perguntas principais para o estudo.

\begin{tabular}{|l|l|}
\hline P & $\begin{array}{l}\text { Pacientes com Hemorragia Subaracnóidea Aneurismática } \\
\text { 14 Biomarcadores Genéticos }\end{array}$ \\
\hline E HSAa com Vasoespasmo Clínico (Grupo I) & - HSAa sem Vasoespasmo Clínico (Grupo II) \\
\hline - Importância dos 14 biomarcadores genéticos com 仓 Morbi- \\
\hline Mortalidade
\end{tabular}

Figura 8. Modelo da $1^{\text {a }}$ Pergunta Estruturada.

\begin{tabular}{|l|l|}
\hline - Pacientes com Hemorragia Subaracnóidea Aneurismática \\
- Marcadores Informativos de Ancestralidade
\end{tabular}

Figura 9. Modelo da $2^{\text {a }}$ Pergunta Estruturada. 


\subsubsection{Análise Estatística}

As estimativas de média de idade, proporção de gênero, estimativas de ancestralidade (Teste-T de Student e Teste de Mann-Whitney) e as análises estatísticas relacionadas à genotipagem dos 14 biomarcadores (Qui-quadrado de Pearson para estimativa de frequências genotípicas e Odds Ratio, além de regressão logística binária para controle em função da ancestralidade) foram desenvolvidas com a utilização do programa estatístico SPSS v.20.0 (SPSS Ins. Chicago, IL, EUA). A verificação de Equilíbrio de Hardy-Weinberg das amostras estudadas para os marcadores do painel e o Teste Exato de Fisher para mensuração de diferença em frequências alélicas foram realizadas por meio dos programas Arlequin v.3.5 (Excoffier \& Lischer) e BioEstat v.5.0 (Ayres et al.). Os valores de $p$ foram considerados estatisticamente significativos quando iguais ou menores que $0,05(5 \%)$ e, quando ajustados pelo fator de correção FDR (false discovery rate), proposto por Benjamini \& Hochberg, a proporção esperada das hipóteses nulas rejeitadas erroneamente, foi corrigido para um $p$ quando valores menores ou iguais a $0,01(1 \%)$. O método de ajuste do $p$ foi utilizado para reduzir a proporção de falsos positivos, limitando o número de variáveis-resposta em estudo. 
RESULTADOS 
5. Resultados

\subsection{Caracterização da Amostra}

Os pacientes foram distribuídos nos grupos I e II com variação na faixa etária de 12 até 81 anos de idade com uma mediana de 51,61 anos de idade. O grupo I (HSAa com vasoespasmo sintomático), apresentou um $\mathrm{N}$ de 124 casos (46,79\%) e, no grupo II (HSAa sem vasoespasmo) com 141 casos, a distribuição em relação aos acometidos está demonstrada na Tabela 4. Em relação ao período de maior percentual de hemorragia ao longo das faixas de idade, a distribuição amostral evidenciou um pico entre a $4^{\mathrm{a}}$ e a $5^{\mathrm{a}}$ décadas de vida, inclusive com uma ligeira prevalência dos pacientes no grupo espasmo (Gráfico 1, Tabela 5).

Tabela 4. Distribuição quanto ao sexo entre os grupos de hemorragia.

\begin{tabular}{cccc}
\hline Grupo de HSAa & Masculino & Feminino & Total \\
\hline I & $10(8,06 \%)$ & $114(91,9 \%)$ & 124 \\
II & $31(21,98 \%)$ & $110(88,7 \%)$ & 141 \\
Total & 41 & 224 & 265 \\
\hline
\end{tabular}

O sexo feminino foi o mais afetado em ambos os grupos com o percentual de $84,52 \%$ (224 casos) (Gráfico 1). Os fatores de risco modificáveis mais importantes na série, tais como tabagismo e hipertensão arterial sistêmica, apresentaram associação com a hemorragia, porém somente o tabagismo apresentou significância estatística para o evento com OR de 6,71 ( $p$ avaliado $=0,0104 ; p$ ajustado $=0,0314)$. Nenhum dos fatores de risco confundidores apresentou maior relevância na distribuição para qualquer dos grupos de hemorragia. Assim, todas as análises do painel devem considerar o gênero, idade, tabagismo, hipertensão arterial sistêmica, tamanho do 
aneurisma e escala VASOGRADE como fatores confundidores a serem controlados com a regressão logística binária.

Quando considerado o tamanho do aneurisma, houve ligeira prevalência na distribuição entre os aneurismas pequenos e médios para ambos os grupos de hemorragia (Anexo K). E, quando considerada faixa de tamanho, em que mais ocorreram as hemorragias, a distribuição se mostrou similar ao longo de todas as faixas (Gráfico 1).

Entre os fatores confundidores, a distribuição conforme o risco de vasosepasmo na escala VASOGRADE (aspectos clínicos e de imagem tomográfica na admissão), houve, nesta avaliação, significância estatística entre o grupo vasoespasmo com as graduações desta escala na tonalidade amarelo e vermelha, que refletem maiores chances de vasoespasmo sintomático (Gráfico 1).

Gráfico 1. Distribuição da hemorragia de acordo com os fatores de confusão.

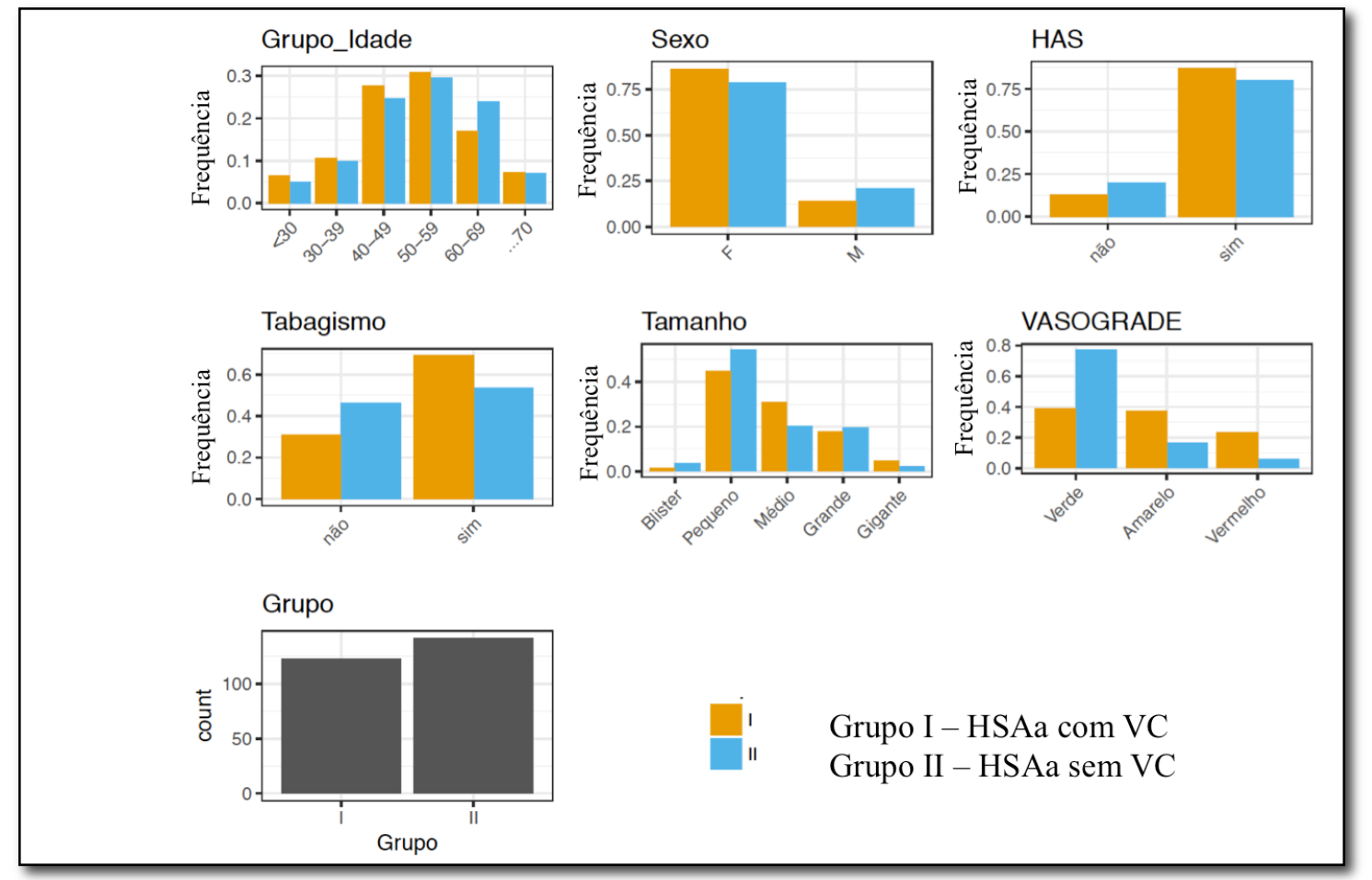

VASOGRADE OR de 42,01 ( $p$ aval. $=0,000099 ; p$ ajustada $=0,00059$ ); Tabagismo OR de 6,71 ( $p$ aval $=0,012 ; p$ ajustado $=0,037$ ). 
Tabela 5. Distribuição da idade conforme o grupo de hemorragia.

\begin{tabular}{ccccc}
\hline $\begin{array}{c}\text { Grupo Etário } \\
\text { (em anos) }\end{array}$ & $\mathbf{N}^{\circ}$ casos & \% & I & II \\
\hline$<\mathbf{3 0}$ & 9 & 3,39 & 5 & 4 \\
$\mathbf{3 1 - 3 9}$ & 26 & 9,81 & 14 & 12 \\
$\mathbf{4 0 - 4 9}$ & 73 & 27,54 & 39 & 34 \\
$\mathbf{5 0 - 5 9}$ & 95 & 35,84 & 49 & 46 \\
$\mathbf{6 0 - 6 9}$ & 48 & 18,11 & 19 & 29 \\
$\mathbf{2 7 0}$ & 14 & 5,28 & 8 & 6 \\
& 265 & 100 & 124 & 141 \\
\hline
\end{tabular}

$p$ ajustado $=0,842$

$\mathrm{Na}$ amostra, houve distribuição dos pacientes entre a escala VASOGRADE conforme o risco de desenvolver vasoespasmo da seguinte forma: 1) Verde com 157 casos (59,24\%); 2) Amarelo com 69 casos (26,03\%); e 3) Vermelho com 39 casos (14,73\%). O vasoespasmo angiográfico foi observado em $66,79 \%$ dos pacientes (177 casos) na admissão ao serviço (Tabela 6). Ressaltando que, entre os indivíduos transferidos ao centro de referência, houve um retardo no encaminhamento dentro da faixa de 3 a 4 semanas após o ictus, em cerca de 202 casos (76,22\%). A circulação arterial mais prevalente na amostra foi a anterior com 255 casos.

Com relação à ancestralidade, analisando a contribuição de cada grupo parenteral entre indivíduos do grupo controle sem vasoespasmo (grupo II) e indivíduos do grupo doença com vasoespasmo (grupo I), os resultados demonstraram que não existe diferença entre as contribuições na ancestralidade influenciando para qual grupo de apresentação da hemorragia existe maior tendência. Isto significa dizer que o padrão das estimativas de ancestralidade média nos grupos de indivíduos sintomáticos e assintomáticos quanto ao espasmo arterial não foram observadas diferenças estatisticamente entre os grupos (Gráfico 2). 
Tabela 6. Distribuição dos pacientes quanto à instalação do vasoespasmo encefálico.

\begin{tabular}{lcccc}
\hline & Vasoespasmo Inicial & \multicolumn{2}{c}{ Vasoespasmo Tardio } \\
\hline $\begin{array}{l}\text { Evidência de Espasmo } \\
\text { Arterial }\end{array}$ & $\mathrm{N}^{\mathrm{o}}$ & $\%$ & $\mathrm{~N}^{\mathbf{o}}$ & $\%$ \\
Sim & 177 & 66,79 & 130 & 49 \\
Não & 88 & 33,21 & 135 & 51 \\
\hline
\end{tabular}

Gráfico 2. Contribuição da ancestralidade no desenvolvimento do tipo de hemorragia, com vasoespasmo (I) ou sem vasoespasmo (II).

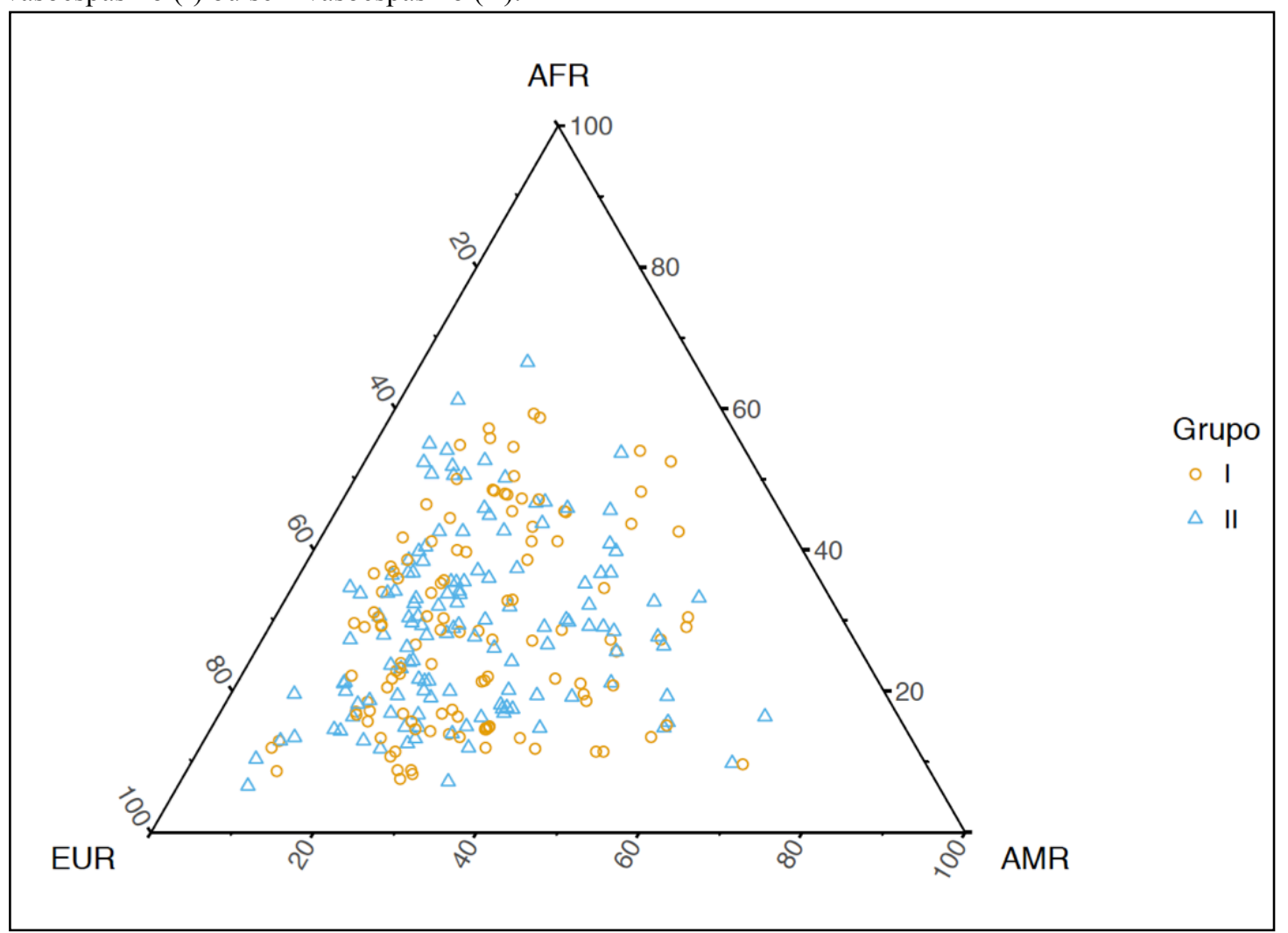

AFR (africano) 25,68\%; AMR (ameríndio) 28,86\%; EUR (europeu) 45,44\% ( $p>0,05)$.

Os pacientes incluídos na amostra foram distribuídos ao tratamento em duas modalidades terapêuticas: endovascular com 155 casos e microcirúrgico com 110 casos.

A contribuição de populações ancestrais entre pacientes (HSAa grupo I) e controles (HSAa grupo II) indicam que, em todas as análises estatísticas isoladas de todos os marcadores aqui investigados, foram empregadas metodologias estatísticas que permitiram usar a contribuição de cada etnia como um provável fator de confusão 
para as avaliações. Essa abordagem foi empregada sucessivamente para todos os 14 biomarcadores analisados.

\subsection{Avaliação dos Marcadores Genéticos do Painel}

Foram investigadas as frequências genotípicas e alélicas dos 14 biomarcadores genéticos, a fim de responder a influência de um ou de vários desses fatores na contribuição da apresentação e do desfecho da doença. Inicialmente, foi testada a distribuição genotípica de acordo com o estabelecido pelo Equilíbrio de HardyWeinberg (EHW) com correção do critério FDR (false discovery rate) para múltiplos testes, proposto por Benjamini \& Hochberg. Esse método permitiu a redução da proporção de falsos positivos. A amostra estudada demonstrou estar em equilíbrio, permitindo, assim, a análise das mutações (Tabela 8).

O biomarcador do gene eNOS no modelo recessivo do polimorfismo na região promotora $(T-786 C)(\mathrm{T} / \mathrm{T}$ versos $\mathrm{T} / \mathrm{C}$ e $\mathrm{C} / \mathrm{C})$, mostrou a relação dos pacientes com aneurisma roto com a inserção do alelo T $(\mathrm{OR} \mathrm{0,39,} \mathrm{IC} \mathrm{95 \% ,} p$ avaliado = 0,0378). O mesmo pôde-se observar para o biomarcador da região intrônica 4-VNTR27 da NOS3, que apresentou significância estatística na influência em ser do grupo I após a hemorragia ( OR 0,04, IC 95\%, $p$ avaliado $=0,049$ ).

O biomarcador da angiotensina representado pelo gene $A C E 2$ demonstrou, em seu modelo aditivo para o alelo $\mathrm{C}$ (genótipos $\mathrm{CC}+\mathrm{A} / \mathrm{C}$ ), maior chance para desenvolver vasoespasmo arterial (OR 0,49, IC 95\%, $p$ avaliado $=0,00009)$.

Foram investigadas possíveis associações entre os marcadores genéticos avaliados e o risco de desenvolver vasoespasmo cerebral sintomático (grupo I). Com este objetivo, o gene TP53 com seu polimorfismo tipo INDEL, rs 4938723, evidencia dados relevantes em seu modelo recessivo para o alelo 1 (genótipo $\mathrm{CC}$ ) que está associado como fator de proteção contra a formação de aneurismas intracranianos 
rotos com espasmo cerebral (OR 2,27, IC 95\%, $p$ avaliado $=0,009)$, como para o modelo aditivo (OR 1,86, IC 95\%, $p$ avaliado $=0,017)$. Siginifca dizer que este biomarcardor é um fator protetor para desenvolver vasoespasmo (Gráfico 3).

Gráfico 3. Influência dos marcadores genéticos sobre os grupos de hemorragia .

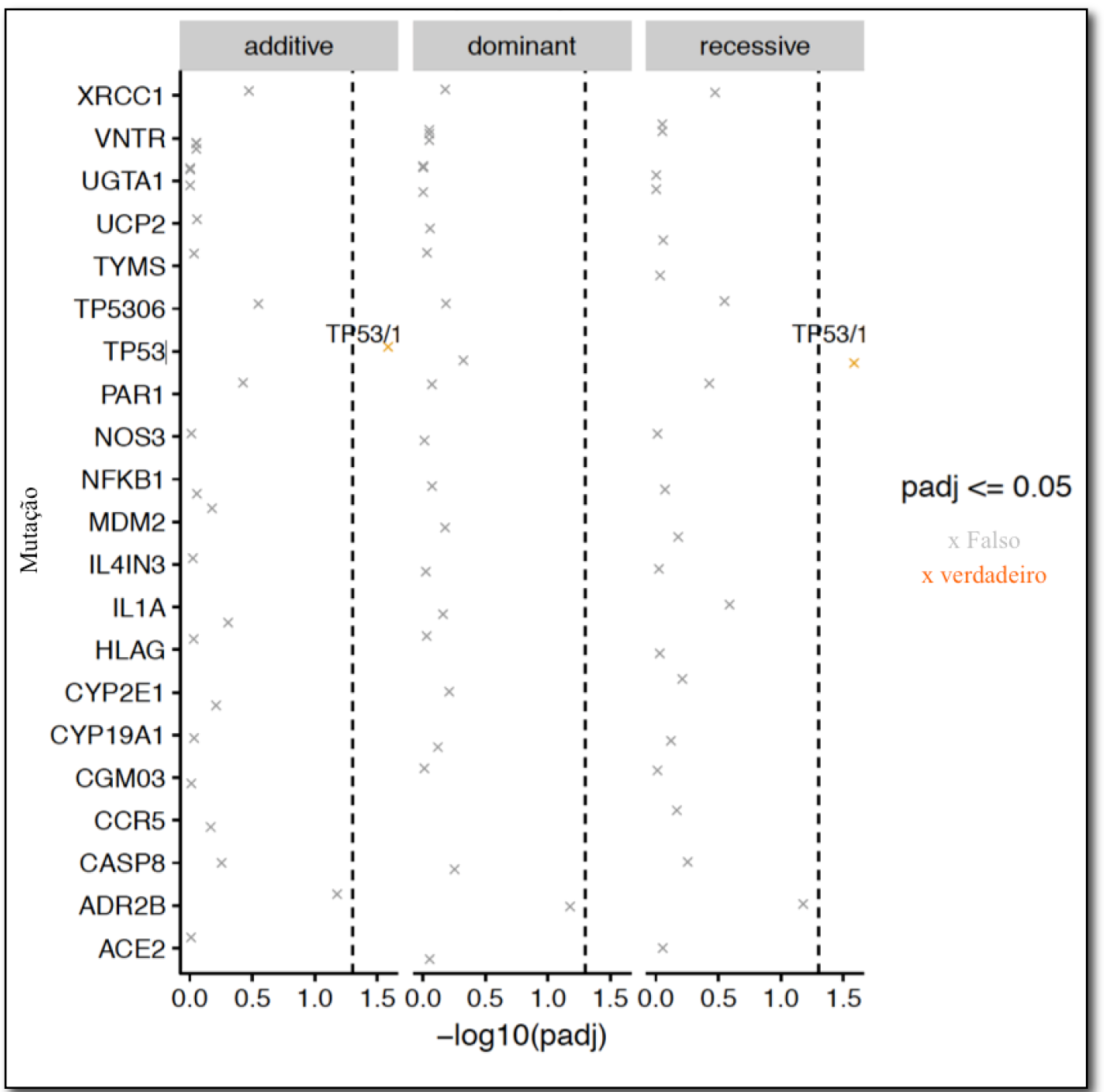

\subsection{Avaliação dos Marcadores e dos Fatores Confundidores de DIND}

Considerando a presença de déficit neurológico isquêmico tardio (DIND), a faixa etária que apresentou maior prevalência foi o grupo etário de 50-59 anos, com maior influência no grupo de fumantes com risco 20 vezes maior de desenvolver a isquemia sintomática (RR 20,32, IC 95\%, $p$ avaliado $=0,00019, p$ ajustado $=$ 0,00059). Entre os 116 casos $(43,77 \%)$ que cursaram com DIND, o maior percentual 
foi observado entre os pacientes do grupo amarelo da escala VASOGRADE e os em uso de tabaco.

Em relação ao tamanho do aneurisma, houve uma tendência a um maior número de efeitos com DIND para os aneurismas conforme o diâmetro da saculação se mostrou maior, porém, como o número amostral foi bem menor em comparação ao tamanho pequeno, isso determinou não haver relevância estatística quando a restrição era aplicada a $1 \%$, o que pode ser explicado pelo número de casos na amostra que não é equilibrado e, assim, necessitária de um número de casos bem maior para mostrar sua importância $(\operatorname{RR} 9,7$, IC 95\%, $p$ avaliado $=0,04, p$ ajustado $=0,08)$. O que significa dizer, quanto maior o aneurisma, maior a chance de complicações isquêmicas pós-hemorragia.

A escala VASOGRADE evidenciou maior poder estatístico correlato ao desenvolvimento de DIND, em que se observa um risco de desenvolver a isquemia sintomática de 67 vezes maior, conforme aumenta a graduação da escala de verde para amarelo e, depois, para vermelho (RR 66,9, IC 95\%, $p$ avaliado $=0,00009, p$ ajustado $=0,00059)$. O que denota a grande influência da apresentação clínica e de imagem quanto à maior chance de desenvolver isquemia sintomática.

Isto significa dizer que mais vasoespasmo exuberante depende de escores iniciais mais graves no início, assim como a correção com fatores pró-inflamatórios como o marcador gênico IL4IN3, que se encontra ligeiramente aumentado neste grupo, presdispondo a mais chance de isquemia tardia (Gráficos 4 e 5). O gene IL4IN3 mostrou-se importante no contexto da resposta ao DIND (OR 0,48, IC 95\% e $p$ avaliado $=0,047$, porém, o $p$ ao ser ajustado para aumentar o poder da amostra, a força da relação é perdida. Isto pode estar associado ao tamanho amostral que, por se 
tratar de uma doença comum, necessitaria de um NNT muito maior para força estatística (Gráfico 5).

Considerando a distribuição conforme a ancestralidade, não houve relevância significativa entre os que desenvolveram DIND e os que não desenvolveram a isquemia, o que denota equilíbrio amostral como nos percentuais populacionais da região Norte (Gráfico 6).

\subsection{Avaliação dos Marcadores e dos Fatores Confundidores de Desfecho}

Considerando o desfecho, a faixa etária que apresentou maior prevalência desfavorável foi o grupo etário de 50-59 anos para o grupo II, quando comparada as demais.

Gráfico 4. Distribuição dos grupos conforme o desenvolvimento de DIND.



Ao analisar o desfecho da doença, pôde-se observar que o tabagismo e o tamanho do aneurisma foram importantes na maior associação com um quadro desfavorável na história natural da doença. O tabagismo aumentou o risco em 15 
vezes ( $p=00029)$, enquanto o tamanho, tanto maior o aneurisma, maior é a chance de o desfecho, ser ruim aumentando em 25 vezes $(p<0,05)$. Ainda neste contexto do desfecho os pacientes que tiveram maiores escores de VASOGRADE apresentaram 65 vezes mais chance de desenvolver um desfecho desfavorável com óbito (Gráfico 7).

Entre as variáveis que contribuíram para um desfecho piorado, destacam-se: o quadro clínico e a imagem na admissão (tabela 7). Entre os pacientes que apresentaram crise convulsiva, apenas 14,71\% (39 casos) entre estes 23 casos (58,97\%) desenvolveram vasoespasmo clínico e 7 casos/39 evoluíram a óbito $(17,94 \%)$

A ancestralidade no grupo desfecho não sofreu mudança estatística nas contribuições para um pior resultado (Gráfico 8).

\subsection{Avaliação dos Marcadores Genéticos e Fatores Confundidores com a}

\section{Escala de VASOGRADE}

Considerando os fatores confundidores os que apresentaram relevância quanto ao desenvolvimento do VASOGRADE, isto é, a forma de apresentação da HSAa foi o tabagismo (RR 19,45 e $p$ ajustado=0,0004) e o tamanho do aneurisma ( $p$ ajustado 0,037) (Gráfico 9).

No que se refere a ancestralidade do grupo quanto a influência da forma de VASOGRADE a ser instalada, não houve resultado significativamente importante (Gráfico 10). 
Gráfico 5. Resposta dos marcadores sobre o DIND.



IL4IN3 alelo 2 - recessivo (OR 0,48, IC 95\%, $p$ avaliado $=0,047)$ ).

Já em relação ao marcador do gene CASP8 (rs3834129), nossa investigação identificou uma associação do alelo 2 (recessivo) desse polimorfismo para desenvolver uma escala de VASOGRADE mais grave e associada com vasoespasmo e isquemia, por conseguinte, o risco estimado foi de 2 vezes maior (OR 2,06, IC 95\%, $p$ avaliado $=0,01)$. A associação inicial do genótipo DEL/DEL com um efeito de risco para o desenvolvimento de uma apresentação mais agressiva se manteve após a correção (ajuste do $p$ ) (Gráfico 11). 
Tabela 7. Distribuição demográfica da admissão e do desfecho clínico.

\begin{tabular}{|c|c|c|c|c|}
\hline \multirow[t]{2}{*}{ Grupos da HSAa } & \multicolumn{4}{|c|}{ Apresentação Clínica na Admissão } \\
\hline & Escala de Coma de Glasgo & & $\mathbf{N}^{\mathbf{0}}$ & $\%$ \\
\hline & Leve (15-13) & & 92 & 74,19 \\
\hline & Moderado (12 - 9) & & 12 & 9,67 \\
\hline \multirow[t]{3}{*}{ Grupo I } & Grave $(<9)$ & & 20 & 16,12 \\
\hline & & & 124 & \\
\hline & Leve (15-13) & & 126 & 89,36 \\
\hline \multirow[t]{6}{*}{ Grupo II } & Moderado (12-9) & & 9 & 6,38 \\
\hline & Grave $(<9)$ & & 6 & 4,83 \\
\hline & & & 141 & \\
\hline & Escala WFNS & & $\mathbf{N}^{\mathbf{0}}$ & $\%$ \\
\hline & I & & 24 & 19,3 \\
\hline & II & & 49 & 39,51 \\
\hline \multirow[t]{6}{*}{ Grupo I } & III & & 21 & 16,9 \\
\hline & IV & & 19 & 15,32 \\
\hline & $\mathrm{V}$ & & 11 & 8,87 \\
\hline & & & 124 & \\
\hline & I & & 59 & 41,84 \\
\hline & II & & 62 & 43,97 \\
\hline \multirow[t]{8}{*}{ Grupo II } & III & & 10 & 7,09 \\
\hline & IV & & 6 & 4,25 \\
\hline & $\mathrm{V}$ & & 4 & 2,83 \\
\hline & & & 141 & \\
\hline & Escala Glasgow Outcome & $\mathbf{N}^{0}$ & Escala de Rankim & $\mathbf{N}^{\circ}$ \\
\hline & 5 & 50 & 0 & 4 \\
\hline & 4 & 30 & 1 & 29 \\
\hline & 3 & 6 & 2 & 47 \\
\hline Grupo I & 2 & 2 & 3 & 4 \\
\hline \multirow[t]{6}{*}{124} & 1 & 36 & 4 & 3 \\
\hline & - & - & 5 & 1 \\
\hline & - & - & 6 & 36 \\
\hline & 5 & 113 & 0 & 32 \\
\hline & 4 & 18 & 1 & 70 \\
\hline & 3 & 1 & 2 & 27 \\
\hline Grupo II & 2 & 0 & 3 & 2 \\
\hline \multirow[t]{3}{*}{141} & 1 & 9 & 4 & 0 \\
\hline & - & - & 5 & 1 \\
\hline & - & - & 6 & 9 \\
\hline
\end{tabular}


Gráfico 6. Influência da ancestralidade sobre o DIND

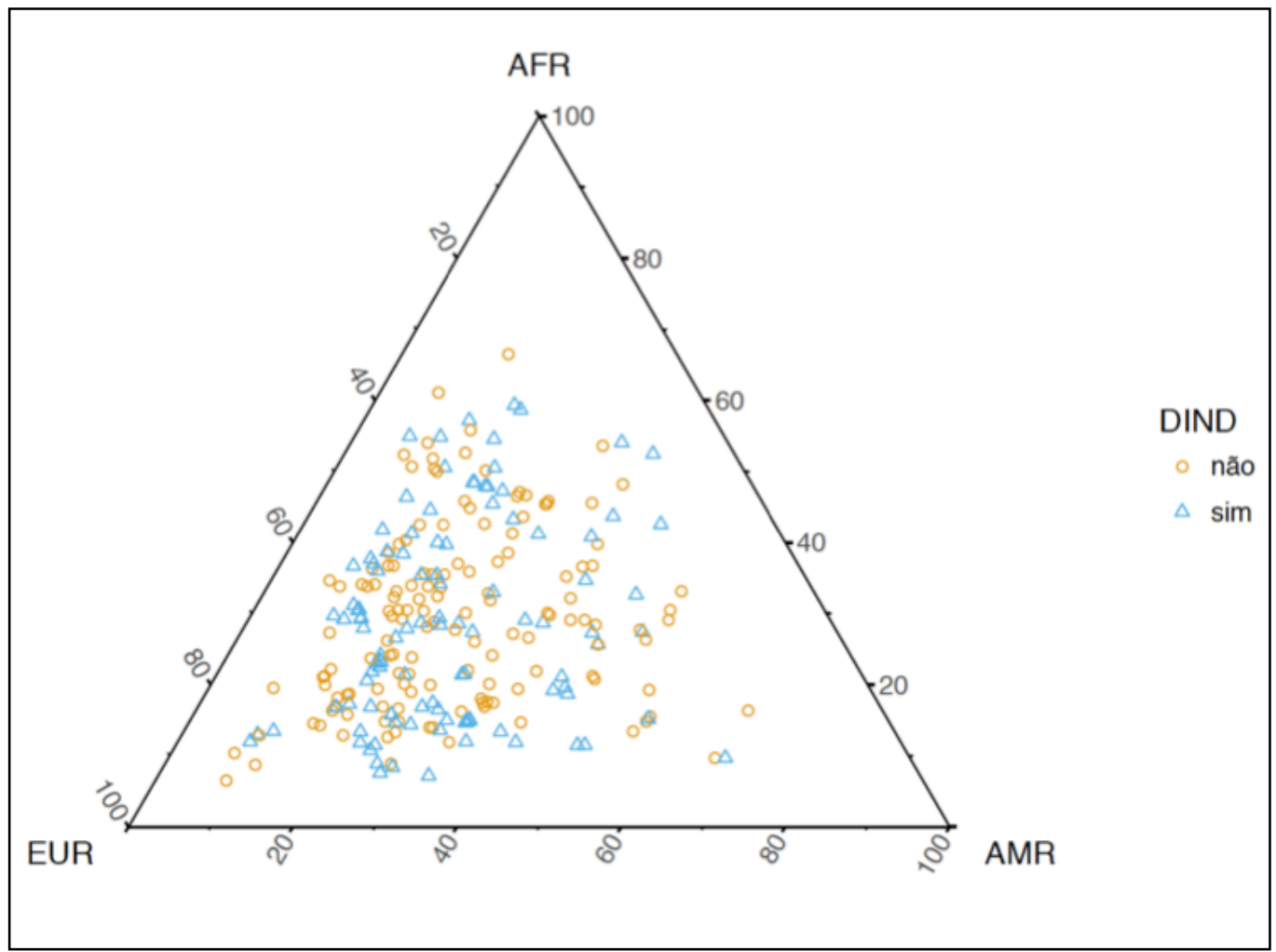

Gráfico 7. Distribuição dos fatores confundidores conforme o desfecho.

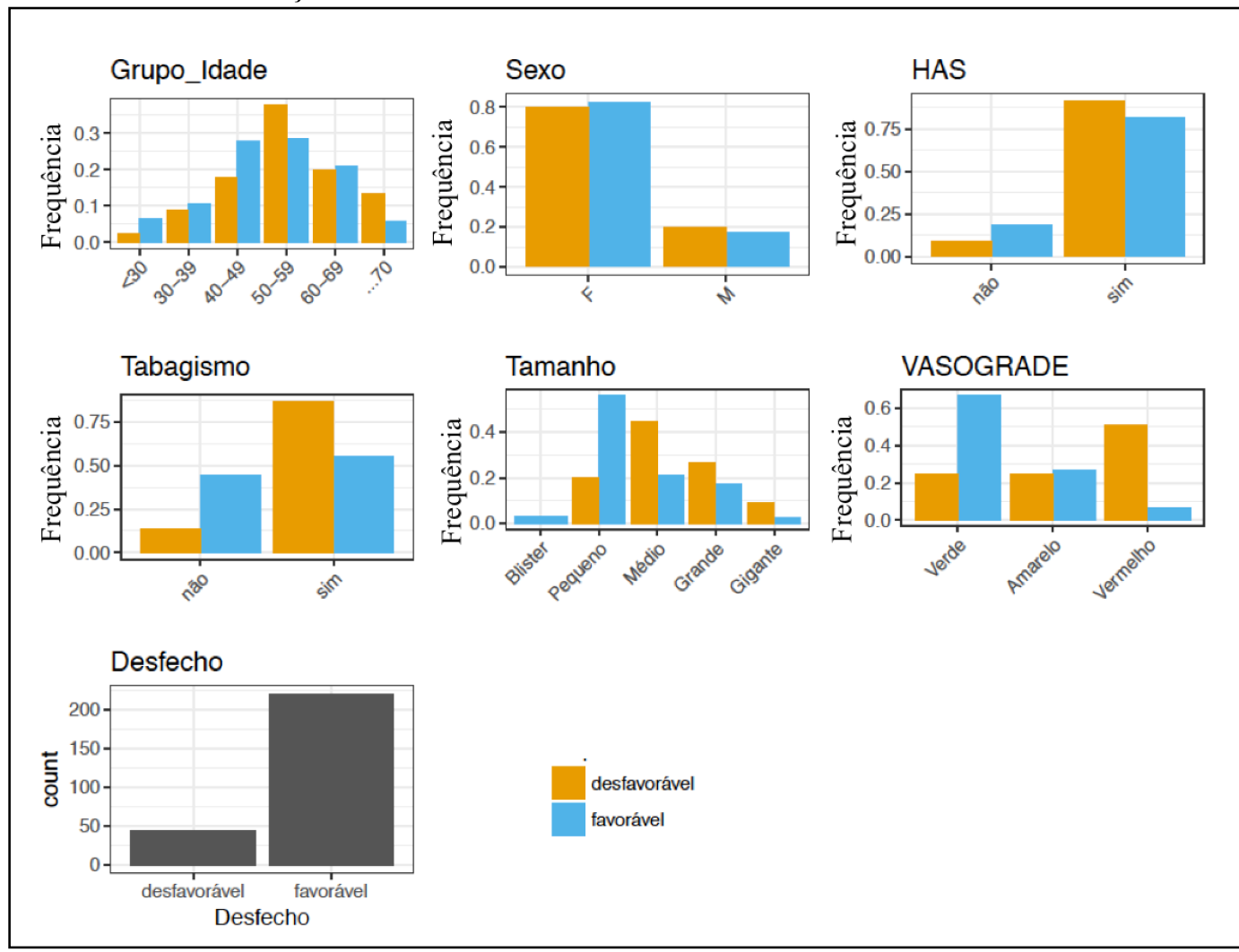

O desfecho considerado para cálculo foi até 30 dias após o ictus. 
Gráfico 8. Distribuição da ancestralidade conforme desfecho clínico.

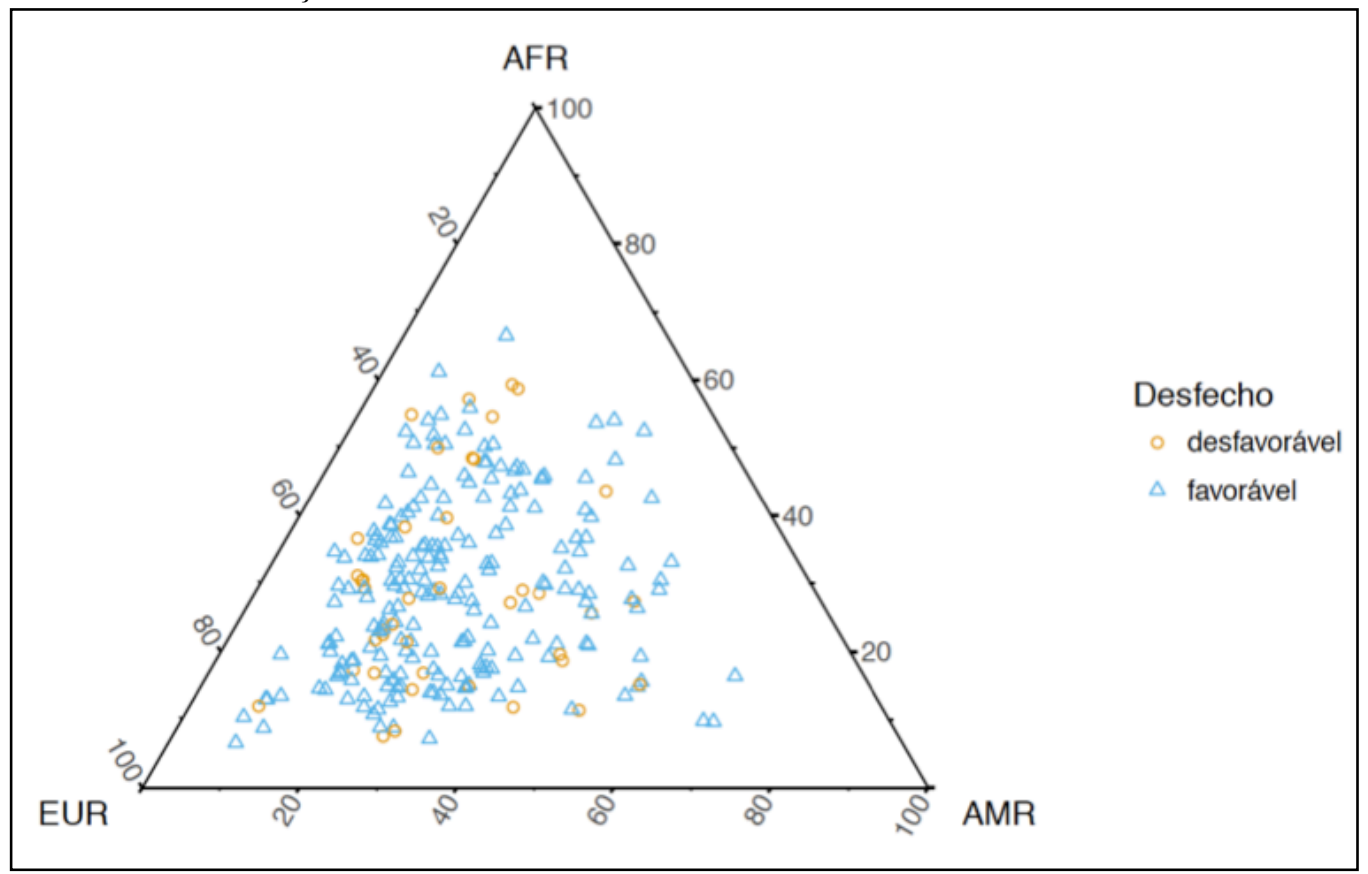

Gráfico 9. Distribuição dos fatores confundidores sobre a apresentação VASOGRADE.


Verde

Amarelo

Vermelho 
Gráfico 10. Ancestralidade e a influência mediante a apresentação inicial.

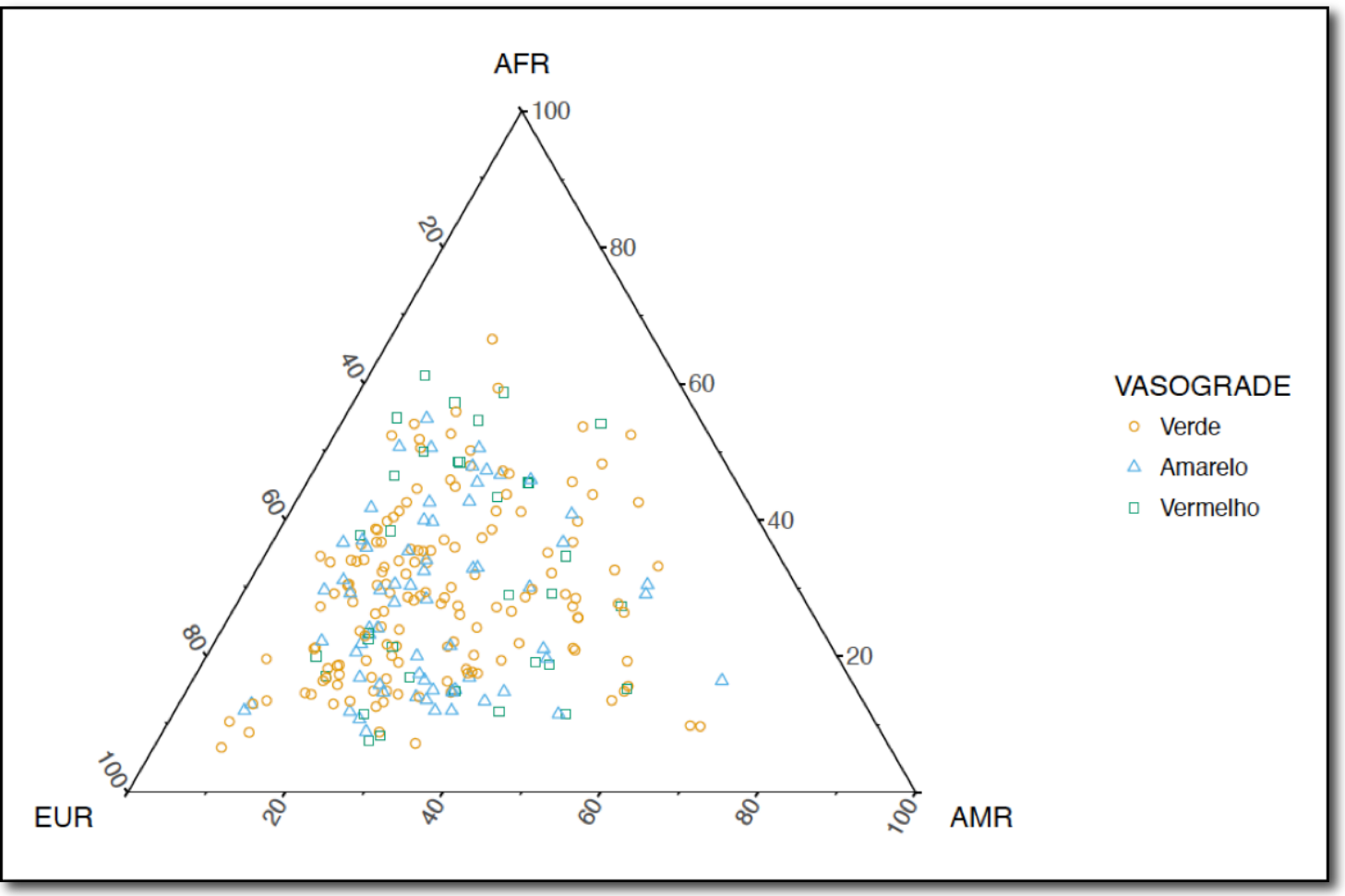

A ancestralidade se manteve sem relevância estatística quanto à distribuição etária.

Com a análise logística binária do biomarcador $4 V N T R 27$ com 4 alelos em sua forma dominante, mostrou-se com influência no desenvolvimento de vasoespasmo sintomático (OR 0,04, IC 95\%, $p$ avaliado $=0,04)$.

Outro marcador que se apresentou com dados estatísticos com significância foi o gene $X R C C 1$ em seu modelo recessivo e maior força na evidência no modelo aditivo com um $\mathrm{HR}=1,414$ para o alelo 1 , mostrando que os indivíduos com este alelo estão mais predispostos a desenvolver vasoespasmo arterial após HSAa. Por outro lado, o alelo 2 como fator protetor $\mathrm{HR}=0,707$ ( $p$ ajustado $=0,035$, evidenciando uma sobrevida maior entre os pacientes portadores do alelo 2 (Gráficos 12 e 13). 
Gráfico 11. Marcador do gene da CASP8 e sua relação com a graduação VASOGRADE.



A mortalidade foi dividida em dois momentos: o primeiro momento ao longo dos primeiros 28 dias pós-ictal (grupo avaliado no desfecho) e o segundo momento no período de 4 a 8 semanas após o ictus. Nas primeiras 4 semanas, em que se situa o período mais crítico, a taxa de mortalidade foi de 16,9\% (45 casos). Cerca de 29 casos dos que evoluíram a óbito pertenciam ao Grupo I, perfazendo $64,44 \%$ dos pacientes 
que evoluíram à óbito nas primeiras quatro semanas entre os pacientes que conseguiram ser assistidos nesta série de casos.

Tabela 8. Distribuição genotípica e alélica dos biomarcadores investigados nos pacientes com HSAa grupo I em comparação com o grupo II (controle).

\begin{tabular}{|c|c|c|c|c|c|c|}
\hline Gene & $\begin{array}{l}\text { Mutação do } \\
\text { Biomarcador }\end{array}$ & Alelo & Efeito & OR & $\begin{array}{c}p \text { avaliado } \\
(0,05)\end{array}$ & $\begin{array}{c}p \text { ajustado } \\
(0,01)\end{array}$ \\
\hline \multirow[t]{2}{*}{ TP53 } & INDEL & 1 & aditivo & 1,86 & 0,0172 & 0,025 \\
\hline & INDEL & 1 & recessivo & 2,27 & 0,009 & 0,025 \\
\hline \multirow[t]{2}{*}{$A C E 2$} & INDEL & 2 & aditivo & 0,49 & 0,00009 & 0,002 \\
\hline & INDEL & 2 & dominante & 0,49 & 0,191 & 0,365 \\
\hline \multirow[t]{2}{*}{$e N O S$} & SNP & $\mathrm{T}$ & dominante & 0,391 & 0,038 & 0,279 \\
\hline & VNTR & 4 & dominante & 0,049 & 0,045 & 0,279 \\
\hline IL4 & INDEL & 2 & recessivo & 0,482 & 0,047 & 0,141 \\
\hline \multirow[t]{2}{*}{ CASP8 } & INDEL & 2 & recessivo & 2,06 & 0,01 & 0,031 \\
\hline & INDEL & 2 & aditivo & 1,40 & 0,069 & 0,104 \\
\hline \multirow[t]{2}{*}{$I L 1 A$} & INDEL & 2 & recessivo & 0,475 & 0,353 & 0,636 \\
\hline & INDEL & 2 & aditivo & 0,737 & 0,062 & 0,098 \\
\hline \multirow[t]{2}{*}{ PARl } & INDEL & 1 & dominante & 2,95 & 0,0308 & 0,092 \\
\hline & INDEL & 1 & aditivo & 1,41 & 0,082 & 0,123 \\
\hline \multirow[t]{2}{*}{ XRCC1 } & INDEL & 2 & recessivo & 0,707 & 0,001 & 0,035 \\
\hline & INDEL & 2 & aditivo & 0,623 & 0,001 & 0,035 \\
\hline \multirow[t]{2}{*}{ NFKB1 } & INDEL & 1 & dominante & 1,883 & 0,121 & 0,365 \\
\hline & INDEL & 1 & aditivo & 1,23 & 0,376 & 0,564 \\
\hline$M D M 2$ & INDEL & 2 & dominante & 0,325 & 0,138 & 0,416 \\
\hline \multirow[t]{2}{*}{$C Y P 2 E 1$} & INDEL & 1 & recessivo & 1,291 & 0,174 & 0,748 \\
\hline & INDEL & 1 & aditivo & 1,224 & 0,218 & 0,75 \\
\hline$U G T A 1$ & INDEL & 1 & aditivo & 0,935 & 0,471 & 0,811 \\
\hline$A D R B 2$ & INDEL & 2 & dominante & 0,744 & 0,132 & 0,748 \\
\hline
\end{tabular}


Gráfico12. Distribuição do polimorfismo do gene $X R C C 1$, e a influência na sobrevida dos pacientes após a HSAa.

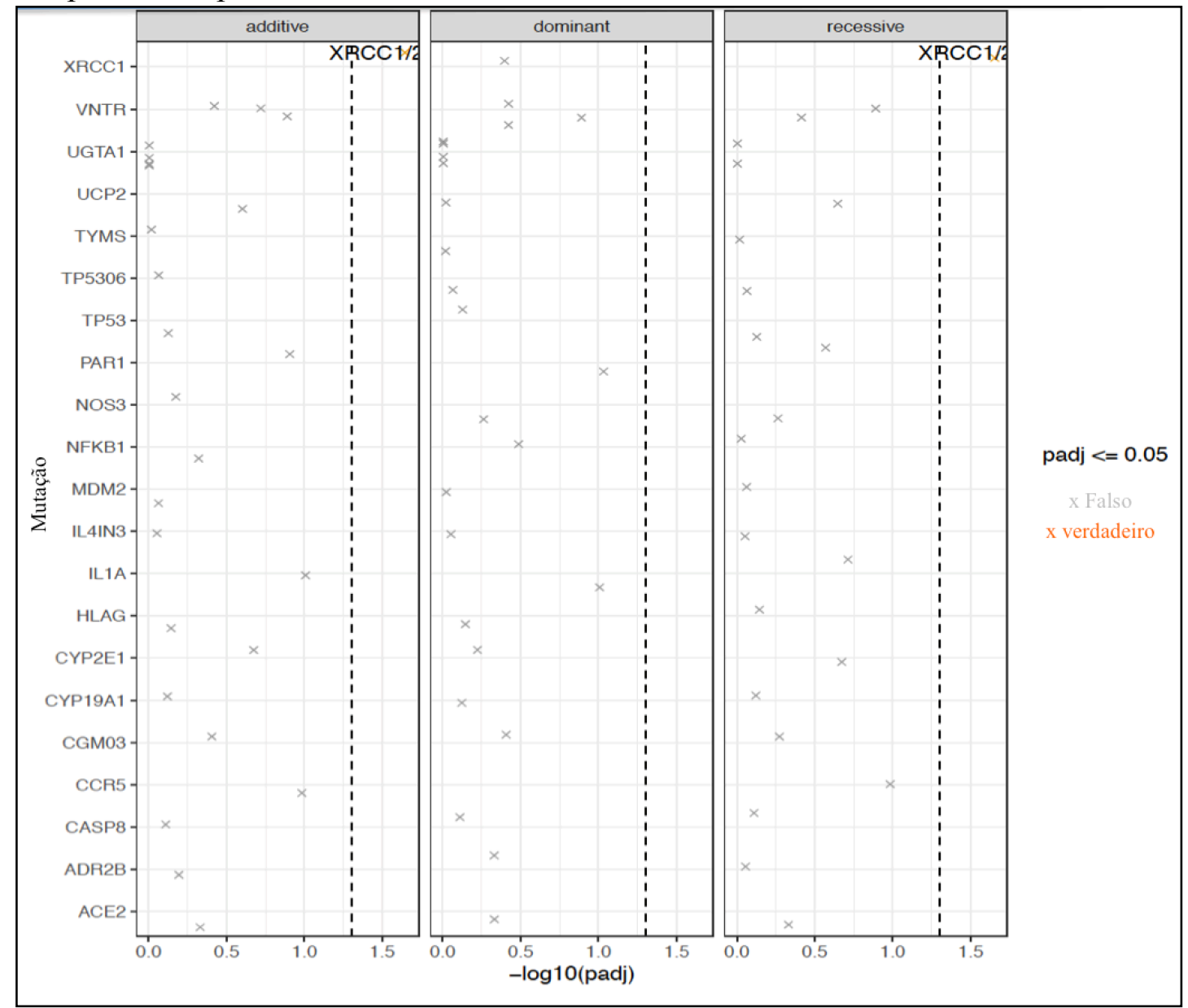

Gráfico 13. Curva de Kaplan Meier para os pacientes com o alelo 1 e 2 do XRCC1.

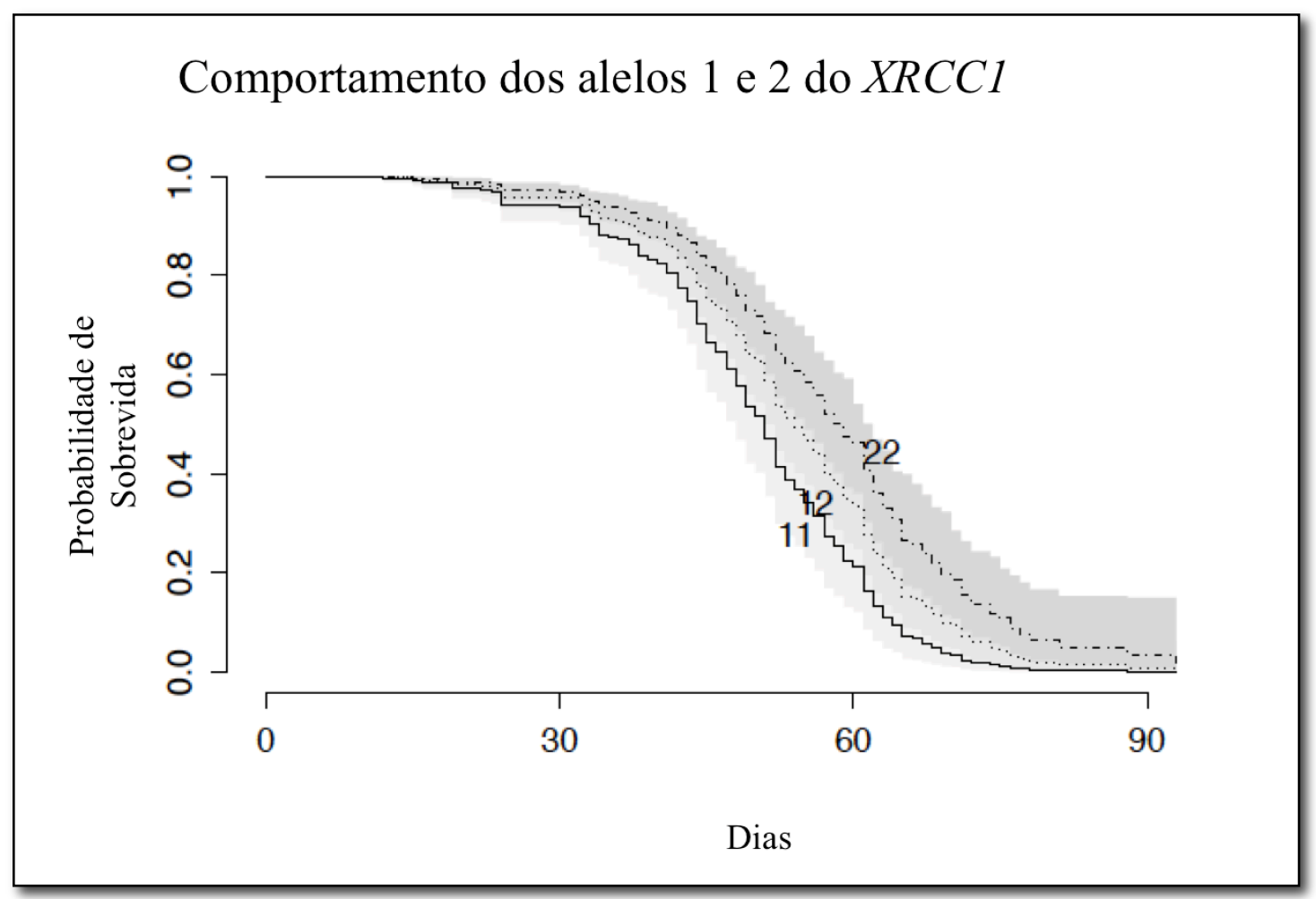




\subsection{Casos Clínicos:}

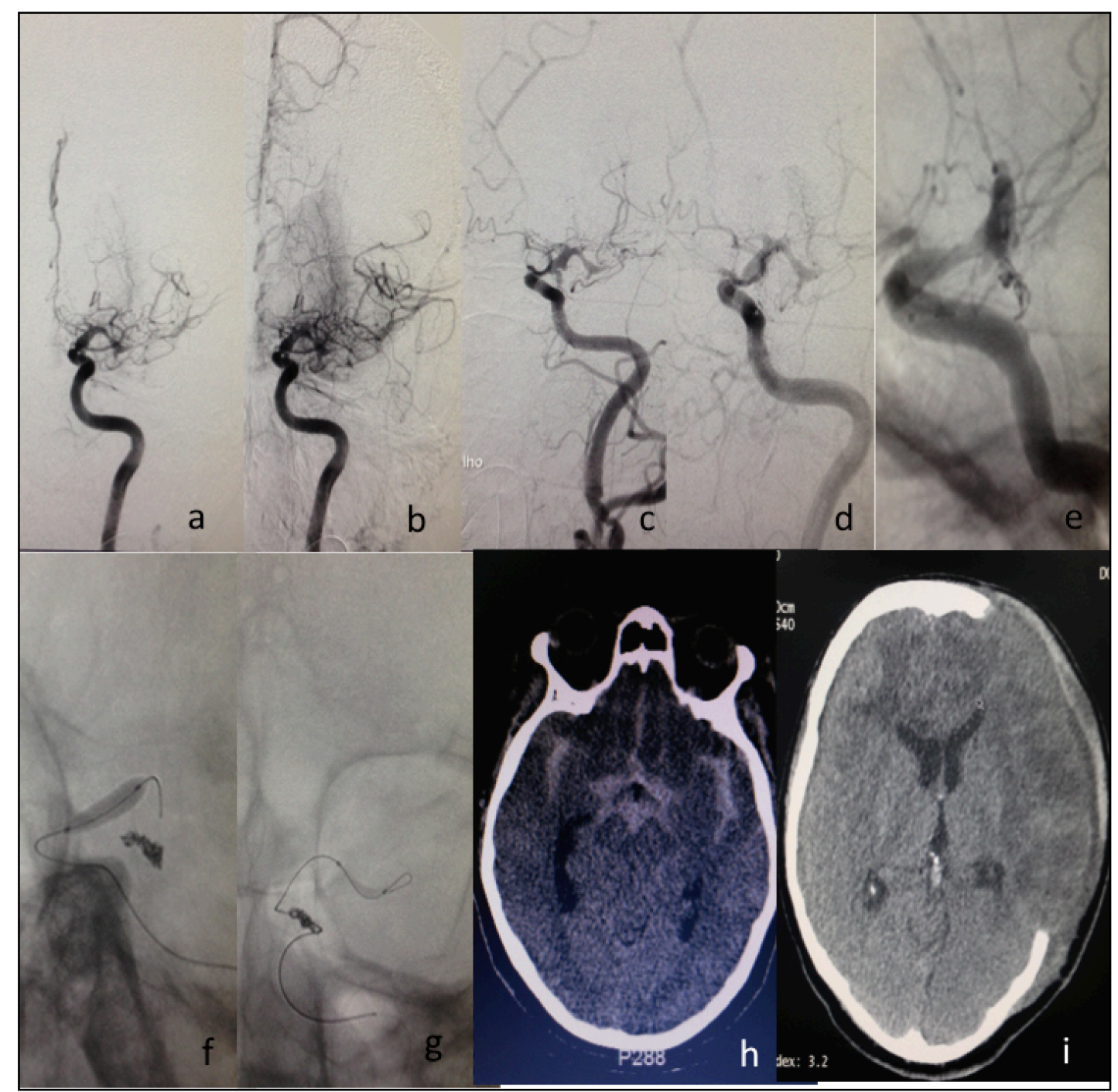

Figure 10. Paciente sexo feminino, 45 anos, admitida pós-rebaixamento do nível de consciência, com Glasgow 13, sem déficit motor e com rigidez de nuca. a e b) angiografia diagnóstica com vasoespasmo moderado e se distribui de forma difusa. c) aneurisma do segmento comunicante esquerdo da artéria carótida interna. D e E) tratamento endovascular com sinais de vasoespasmo $\mathrm{f}$ e $\mathrm{g}$ ) angioplastia em curso. $\mathrm{h}$ ) TCC com sangue na admissão Fisher modificada 3, VASOGRADE amarelo. I) TCC de crânio controle pós-craniectomia, com área de isquemia com descompressiva. 


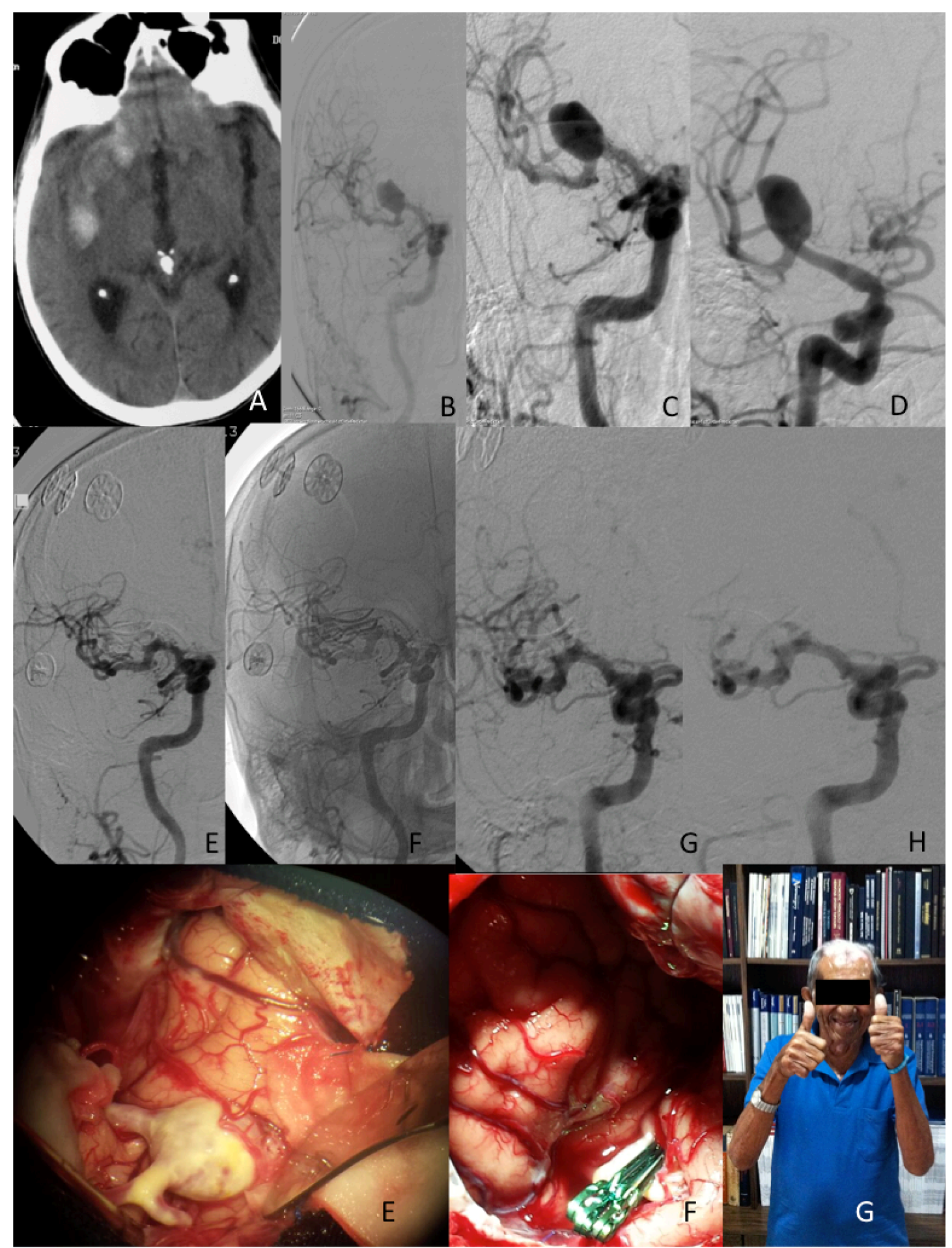

Figura 11. Homem, 71 anos, admitido consciente sonolento com hemiparesia esquerda com escore WFNS 2, Fisher modificado 3 (A), com escore VASOGRADE estimado amarelo. A ACSD evidencia uma aneurisma grande do segmento M2 direito sem sinais de vasoespasmo $(\mathrm{B}, \mathrm{C}, \mathrm{D})$; controle angiográfico pós-operatório com aneurisma excluído; (E e F) Visão microscópica intraoperatória antes e após a clipagem ; e $(\mathrm{G})$ paciente 3 meses após a terapêutica. 


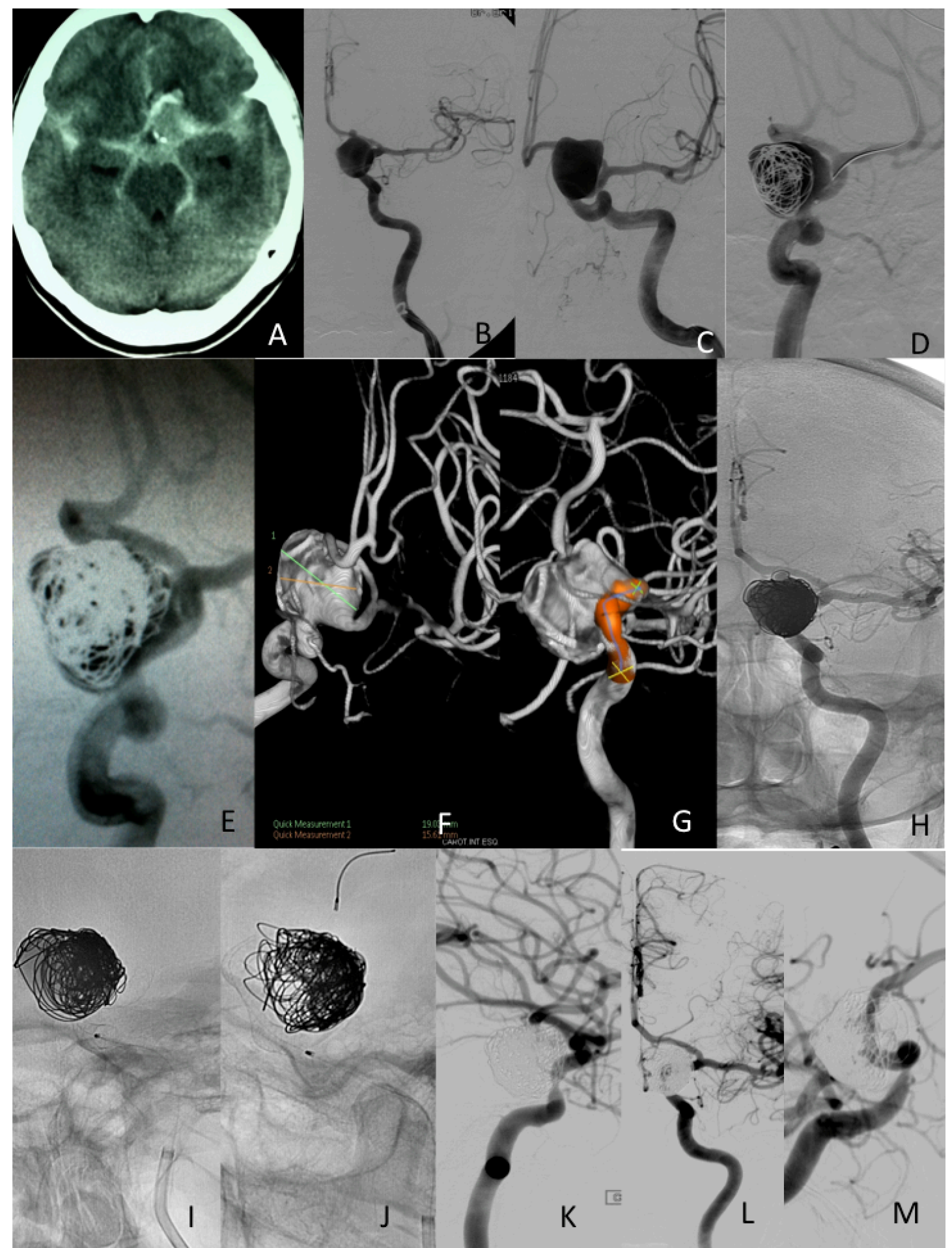

Figura 12. Sexo feminino, 51 anos, admitida com rebaixamento do nível de consciência em Glasgow 07, rigidez de nuca 3/4+. WFNS IV, Fisher modificado $4 \mathrm{e}$ escala VASOGRADE vermelho. (A) TCC com HSAa difusa; (B e C) ASCD com lesão aneurismática gigante na ACIE; (D e E) $1^{\text {a }}$ sessão embolização com espirais na fase aguda; (F e G) controle angiográfico com reconstrução $3 \mathrm{D}$; $\left(\mathrm{H}\right.$, I e J) $2^{\mathrm{a}}$ sessão embolização com stent para reconstruir o colo; (K, L e M) controle angiográfico 12 meses após o evento inicial. 




Figura 13. Sexo feminino, 52 anos, admitida com rebaixamento do nível de consciência sob ventilação mecânica. Submetida à derivação ventricular externa na admissão. WFNS 5 VASOGRADE vermelho. (A) TCC com Fisher modificado 4, com hidrocefalia; (B, C e D) aneurisma do complexo comunicante anterior grande projetado para cima sem vasoespasmo; (E) Visão microscópica da HSAa, * mostra o aneurisma sob aumento da visão, a seta demonstra o segmento A1 esquerdo; (F) 1 e 2 TCC pós operatória, e 3 Visão microscópica pós-clipagem com reconstrução. Follow up com DIND devido ao comprometimento cognitivo. 


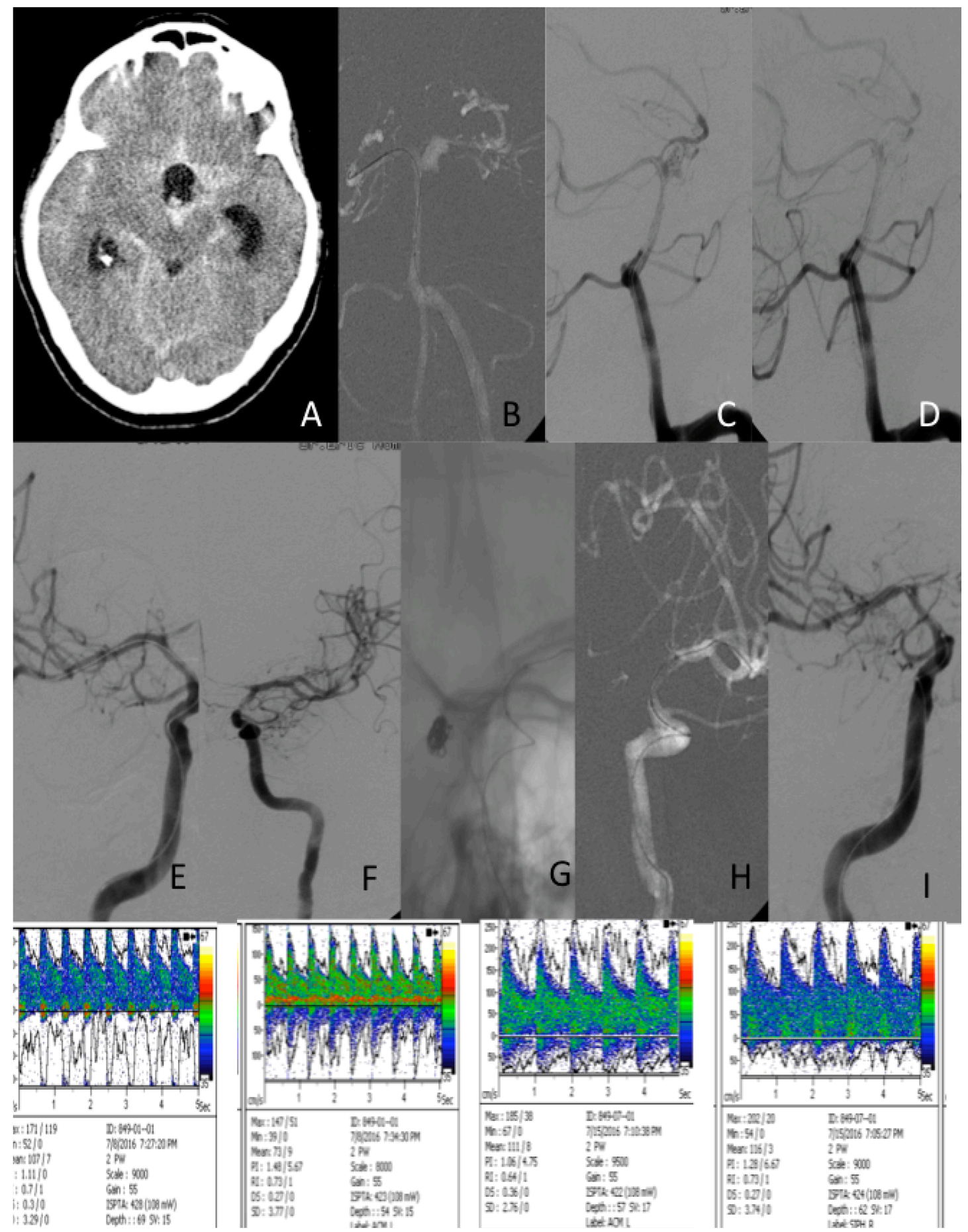

Figura 14. Paciente do sexo feminino 51 anos, admitida com cefaleia e Glasgow 15. WFNS I, Fisher 4, VASOGRADE amarelo. Submetida à DVE, sendo realizado exame e o tratamento com angioplastia precoce em $72 \mathrm{~h}$ e segunda angioplastia no $13^{\circ}$ dia pós-ictus. (A) TCC com hidrocefalia Fisher modificado 4; (B) Embolização com espirais e angioplastia; (C,D) embolização do aneurisma da artéria basilar; (E,F) $1^{\mathrm{a}}$ Angioplastia 7 dias de ictus, Doppler transcraniano D (E) e E (F) com velocidades na artéria cerebral média $(\mathrm{ACM})$ de $171 \mathrm{~cm} / \mathrm{s}$ e $147 \mathrm{~cm} / \mathrm{s} ;(\mathrm{G}, \mathrm{H}) 2^{\mathrm{a}}$ angioplastia $A C M$ Esquerda com velocidade do Doppler de $220 \mathrm{~cm} / \mathrm{s}$; e (I) $2^{\text {a }}$ angioplastia ACM Direita com velocidade do Doppler de $202 \mathrm{~cm} / \mathrm{s}$. Evolução até o $17^{\circ}$ dia com isquemia global e óbito. 


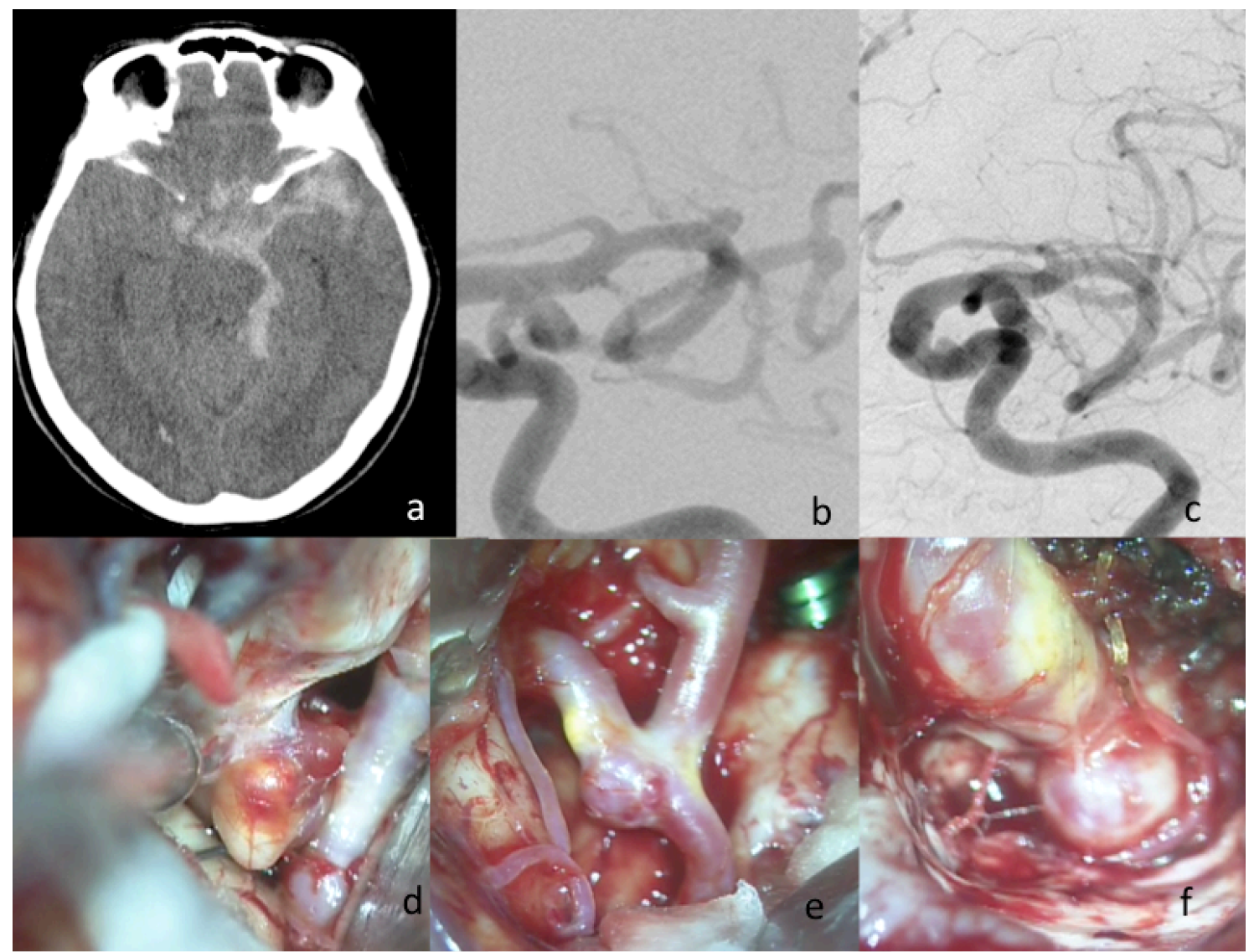

Figura 15. Paciente sexo feminino, 63 anos, admitida após perda do nível de consciência com rigidez de nuca e graduada pelo escore WFNS em grau 2, considerada segundo risco de vasoespasmo pelo VASOGRADE amarela. (a) TCC com HSAa difusa Fisher modificado grau IV; (b e c) estudo angiográfico cerebral com achados de aneurisma no segmento comunicante da artéria carótida interna esquerda, outro aneurisma no segmento M1 da artéria cerebral média (ACM) esquerda e no segmento M2 esquerdo outra lesão.; (d) visão microscópica ampliada do aneurisma na artéria carótida interna; (e) visão microscópica do aneurisma do segmento M2 de ACM esquerda; e (f) visão microscópica do aneurisma de ACM segmento M1 esquerdo. A paciente no follow up manteve a paresia do terceiro nervo 6 meses após a cirurgia. 
DISCUSSÃO 


\section{Discussão}

O presente trabalho avalia, com ineditismo, a genética da população da região Amazônica com HSA aneurismática, em termos de biomarcadores associados à vasculogênese, regulação do tônus microvascular, mecanismos inflamatórios do vasoespasmo encefálico e desfecho da doença.

\subsection{Influência do gene da eNOS sobre a HSAa}

A pesquisa acerca do perfil genético relacionado à formação e rotura dos aneurismas intracranianos revelou que alterações genômicas e epigenéticas podem influenciar o desfecho dos doentes com HSA aneurismática. O rastreio de um perfil genético que possa predizer a resposta inflamatória encefálica pós-HSA aneurismática auxiliará o direcionamento da terapia, o que contribui para desfecho clínico mais favorável.

A metanálise realizada para compreender o papel dos polimorfismos do gene da $\operatorname{eNOS}(T-786 C, G-894 T$ e 4-VNTR27) sobre a história natural dos aneurismas intracranianos, inclusive na HSAa, demonstrou que os resultados foram consistentes com a relação positiva entre o modelo dominante do polimorfismo $T$-786C e a formação de aneurisma intracraniano (OR 1,24, IC 95\%, 1,21-1,28, p <0,0001), assim como sua correlação com a presença de hemorragia subaracnoidea (OR 1,22, IC 95\%, 1,04-1,44, $\mathrm{p}=0,01)$, em que foram incluídos 1416 casos e 1289 controles, cuja contribuição ancestral para a metanálise foi de 55\% dos participantes asiáticos em que o alelo CC dominante foi o mais prevalente. Considerando os caucasianos, a distribuição genotípica foi mais homogênea com alta frequência de heterozigotos (Genótipo T/C) (Figura 16) ${ }^{105-107}$. 
Por outro lado, quando se tentou demonstrar a correlação com o vasoespasmo pós-HSAa, os autores não conseguiram demonstrar a correlação com aumento do risco de espasmo arterial quando da inserção do alelo $T$, na região promotora do gene da eNOS (T-786C). Essa metanálise, mostrou que, pela falta de metodologias similares, torna-se pouco confiável a possibilidade desta mudança alélica estar relacionada a um aumento no risco do vasoespasmo ${ }^{106}$. Muito embora outra metanálise focando o desfecho da doença com déficit neurológico isquêmico tardio (DIND) tenha revelado a importância e relevância dos achados tanto da zona intrônica com seu polimorfismo da eNOS (4-VNTR27) como do alelo 2 da haptoglobina associado com maior risco de vasoespasmo ${ }^{105}$.

Embora estudos de metanálise como aqui apresentados tenham evidenciado dados substanciais ora demonstrando e ora não demonstrando a associação de polimorfismos da eNOS envolvidos com o vasoespasmo encefálico; a casuística apresentada neste estudo permitiu replicar as informações encontradas nas revisões sistemáticas anteriormente citadas, demonstrando os achados acerca de dois biomarcadores da eNOS $(p<0,05)$ com importância no contexto do VE e do déficit isquêmico tardio. Na amostra Amazônica, os grupos foram distribuídos quanto ao percentual de ancestralidade, previamente, validados para população brasileira nas diversas regiões, em que os grupos de pacientes com vasoespasmo sintomático (grupo I) e não sintomático (grupo II) foram investigados quanto a influência ancestral. Essa avaliação não demonstrou nenhuma variação estatisticamente significativa no tocante ao perfil dos indivíduos normais. De forma que em ambos os grupos a distribuição da influência ancestral, mostrou-se com maior percentual de descendência "europeia", exatamente similar ao que se observa na população brasileira. (Tabela 9). 
Tabela 9. Distribuição amostral de acordo com a ancestralidade na população Amazônica.

\begin{tabular}{lcccc}
\hline Ancestralidade & \multicolumn{2}{l}{ Hemorragia Subaracnoidea } & $p$ aval & $p$ ajust \\
\hline & Grupo I & Grupo II & & \\
Africano & 0,2568 & 0,2468 & 0,431 & 0,933 \\
Ameríndio & 0,2886 & 0,2924 & 0,622 & 0,933 \\
Europeu & 0,4544 & 0,4608 & 0,941 & 0,941 \\
\hline
\end{tabular}

$p>0,01 ; p$ ajust (ajustado) pela correção FDR.

Essa distribuição heterogênea da população brasileira é observada em todas as regiões; o que poderia refletir inclusive a importância da contribuição genômica, de forma a ser relevante para o desenvolvimento de um desfecho piorado ou melhorado ao se comparar com outras regiões do mundo. Esse achado reforça a importância da realização do mesmo estudo em populações ainda sem o perfil étnico investigado. A distribuição da ancestralidade permite avaliar uma maior dominância de um perfil homozigótico para o gene da eNOS com genótipo TT para a população Amazônica, sendo evidenciado o seguinte perfil genômico (Tabela 10).

A presença do alelo $\mathrm{T}$ dominante nos pacientes, demonstrou maior chance de desenvolver o déficit neurológico isquêmico tardio, o que pôde ser observado com significância estatística nos pacientes do grupo I. No entanto, a mesma importância do alelo $\mathrm{T}$ não foi observada quanto a maior chance de desenvolver vasoespasmo encefálico para o biomarcador $T-786 C$ tanto para o modelo dominante quanto o aditivo $(p>0,05)$.

Quanto ao biomarcador 27bp - VNTR do gene eNOS com o alelo aditivo -4, observou-se que quando identificado na população estudada sugere maior chance de desenvolver vasoespasmo encefálico. Por outro lado, houve maior chance de 
desenvolver déficit isquêmico tardio tanto no grupo I como no grupo II nos portadores deste $S N P(\mathrm{p}<0,05)$

Tabela 10. Distribuição genotípica dos biomarcadores do gene eNOS com Vasoespasmo cerebral segundo DIND e com a escala VASOGRADE.

$\begin{array}{lllll}\text { Gene } & \text { PNU ou Alelo } & \text { OR } & p \text { aval }(5 \%) & p \text { ajust (1\%) }\end{array}$

\begin{tabular}{|c|c|c|c|c|}
\hline \multicolumn{5}{|c|}{ A) Piora clínica associada ao DIND } \\
\hline eNOS & $786 \mathrm{~T}->\mathrm{C}$ & 0,391 & 0,038 & 0,279 \\
\hline \multicolumn{5}{|c|}{ TT } \\
\hline & VNTR -4 & 0,496 & 0,045 & 0,279 \\
\hline \multicolumn{5}{|c|}{ B) Importância do VASOGRADE } \\
\hline \multirow[t]{6}{*}{ eNOS } & $786 \mathrm{~T}->\mathrm{C}$ & & & \\
\hline & dominante (TT) & 0,54 & 0,15 & 0,33 \\
\hline & $\operatorname{aditivo}(\mathrm{TT}+\mathrm{TC})$ & 0,78 & 0,22 & 0,33 \\
\hline & aditivo VNTR - 4 & 1,19 & 0,45 & 0,66 \\
\hline & aditivo VNTR -6 & 0,44 & 0,36 & 0,66 \\
\hline & dominante VNTR -5 & 1,49 & 0,50 & 0,66 \\
\hline
\end{tabular}

OR Odds ratio; $p$ ajust (ajustado) pelo correção FDR de Hochenberg.

Em relação ao polimorfismo $G$-894T do gene da $e N O S$, durante a investigação o mesmo apresentou validade em $50 \%$ da amostra, o que não demonstrava confiabilidade para o uso dos resultados. Com isso, foi abandonada sua análise e correlação com a HSAa nesta pesquisa; inclusive pois outros estudos demonstram a ausência de correlação deste SNP com aneurisma intracraniano e suas complicações $^{107}$.

$\mathrm{Na}$ avaliação do gene da eNOS com a escala VASOGRADE, deve-se considerar que o escore verde foi o de maior relevância na amostra estudada. Neste grupo de pacientes, o alelo $\mathrm{T}$ com seu polimorfismo no modelo dominante e aditivo não demonstrou significância estatística na correlação com DIND (OR 0,788, CI $95 \%, p$ avaliado $>0,05)$. 


\subsection{Influência dos genes envolvidos na inflamação}

Quanto à análise da influência dos outros 12 biomarcadores genéticos sob o chance de desenvolver vasoespasmo encefálico sintomático pós HSAa, 5 marcadores (TP53, CASP8, ACE2, IL4 e XRCC1) mostraram significância estatística.



Figure 16. Estrutura do gene NOS3 (eNOS) localizado em 7q35-36.

O papel da inflamação na formação e progressão dos aneurismas ainda não se mostra completamente explicado, mas existe evidência da participação de fatores próinflamatórios na instalação da hemorragia subaracnoidea e de suas complicações.

Neste contexto, o gene TP53 possui uma importante função, como "guardião do genoma", ao atuar na inibição das caspases e, assim, prevenindo a apoptose. Em nossa, amostra, este gene com seu modelo recessivo com alelo 1 (genótipo CC), assim como o modelo aditivo $(\mathrm{CC}+\mathrm{CG}+\mathrm{GG})$ possuem um risco menor de cursar com HSAa com espasmo, cerca de 2,27 vezes menos no modelo recessivo e 1,86 no modelo aditivo ( $p$ aval 0,009 e $p$ ajust 259). Esses dados reforçam o que foi demonstrado por Li et al., 2012, quando avaliou 590 pacientes e encontrou uma menor predisposição à presença de aneurismas naqueles indivíduos com genótipo CC em uma população de chineses. 
O gene TP53 age em conjunto sobre a mitocôndria auxiliando na liberação do citocromo $\mathrm{C}$ e sobre as procaspases aumentando a liberação da caspase 8 , ativando a via das caspases. Isso em modelos animais determina um aumento do processo inflamatório e, por conseguinte, aumenta a chance de um insulto isquêmico, que no humano, seria interpretado com o risco mais elevado de VE e até DIND. Nossa amostra pôde identificar que o gene da CASP8 com seu modelo recessivo (alelo 2) estão aumentando a chance de desenvolver vasoespasmo encefálico em até 2 vezes $(p$ avaliado $=0,01$ e $p$ ajustado $=0,031$ ), esse se mostrou hiperexpressado no grupo VASOGRADE amarelo e vermelho em que a chance de isquemia tardia é de $19 \%$ e $37 \%$, respectivamente.

O biomarcador da angiotensina representado pelo gene ACE2 demonstrou no modelo aditivo para o alelo $\mathrm{C}$ (genótipos $\mathrm{CC}+\mathrm{A} / \mathrm{C}$ ) com significância estatística para o grupo hemorragia em desenvolver espasmo arterial (OR 0,49, IC 95\%, $p$ avaliado $=$ 0,00009). Em 2016, Griessenauer et al., em uma revisão sistemática realizada em pacientes com HSAa, demonstraram que o efeito do alelo C com o $S N P$ no genótipo $\mathrm{A} / \mathrm{C}$ é dependente da idade e se mostra aumentado no grupo de pacientes com mais de 55 anos de idade ${ }^{228}$. Esses dados são similares ao obtido nesta série da Amazônia.

O gene IL4IN3 mostrou-se importante no contexto da resposta ao DIND (OR 0,48, IC 95\% e $p$ avaliado $=0,047)$, porém, o $p$ ao ser ajustado para aumentar o poder da amostra, a força da relação é perdida. Isto pode estar associado ao tamanho amostral, que por se tratar de uma doença comum, necessitaria de um NNT maior para representatividade da força estatística. Esse é um gene bastante frequente nos eventos que cursam com processo inflamatório exuberante como na HSAa ${ }^{112}$.

Outro marcador é o gene $X R C C 1$ com seu polimorfismo $A 399 G$ com maior risco para desenvolver isquemia ${ }^{127,128}$. Isso foi bem evidente em nossa série por meio 
do modelo recessivo para o alelo 1, em que a curva de sobrevida se mostrou mais curta para os indivíduos portadores desta alteração alélica com HR 1,414 mais chance de desenvolver o espasmo encefálico com DIND e ter um desfecho desfavorável ( $p$ avaliado $=0,001$ e $p$ ajustado $=0,035$ ).

O polimorfismo do tipo INDEL no gene da PAR1 em modelo deleçãoo (alelo 1) e aditivo mostrou um aumento no risco em desenvolver vasoespasmo encefálico.

A distribuição genotípica esteve de acordo com o estabelecido pelo Equilíbrio de Hardy-Weinberg (EHW) com correção do critério FDR (false discovery rate) para múltiplos testes, proposto por Benjamini \& Hochberg (1995). Esse método permitiu a redução da proporção de falsos positivos. A amostra estudada demonstrou estar em equilíbrio, permitindo, assim, a análise das mutações.

\subsection{Achados demográficos da amostra}

Comparando nossa casuística com a literatura, alguns pontos demonstram a congruência dos achados, tais como o grupo etário mais afetado na $4^{\mathrm{a}}, 5^{\mathrm{a}}$ e $6^{\mathrm{a}}$ décadas de vida, com maior prevalência no sexo feminino, assim como principais fatores de risco modificáveis o tabagismo e a hipertensão arterial.

Quanto ao grupo, pois hemorragia subaracnoidea houve maior frequência do grupo I (com vasoespasmo sintomático) do que o estimado na literatura, com cifras de $46,79 \%$, em que o esperado seria de $1 / 3$ da amostra. Por outro lado, esse achado pode ser explicado pela falta de admissão primária dos pacientes em único centro, o que pôde ter contribuído para a recepção de uma amostra com mais chances de se encontrar o espasmo em desenvolvimento por ocasião da falha nos cuidados de manutenção recomendáveis (nimodipina, normo-hidratação, entre outras) ou por ocasião da fase em que os pacientes se encontram da evolução natural da doença. 
O fato deve ser considerado, pois as distâncias na Amazônia são continentais e não permitem o acesso rápido ao centro de referência na capital (Belém) para os pacientes em situações mais críticas. Isso pode ter determinado a inclusão de uma amostra, relativamente, "viciada" com pacientes os quais apresentavam melhores condições clínicas e neurológicas de transporte. Isso deve ser considerado, em especial, quando avaliado que cerca de 76,22\% (202 casos) dos pacientes apresentaram um tempo de chegada até o hospital referência (Hospital Ofir Loyola) entre 3 a 4 semanas após a ocorrência do ictus, em virtude das grandes dimensões territoriais do estado do Pará.

Desta forma, a análise genômica não se torna prejudicada, mas casos em que o desfecho tenha ocorrido de forma agressiva podem não ter sido referenciados porque morreram antes do encaminhamento, em que a mortalidade nas primeiras $72 \mathrm{~h}$ pósictus está muito associada com a "early brain injury" (lesão cerebral precoce), depressão alastrante cortical ou microtrombose ${ }^{164}$.

O percentual de indivíduos com vasoespasmo angiográfico foi de $66,79 \%$ (177 casos), esses dados são congruentes com o que a literatura reporta.

O desfecho clínico com um número grande de pacientes com isquemia cerebral e uma mortalidade relativamente baixa para uma doença tão grave se deve à forma como a amostra para inclusão da análise foi verificada. Dos pacientes que foram admitidos no hospital referência, a grande maioria chegou com 3 a 4 semanas de ictus, quando já reduziu o pico do processo inflamatório, com isso, a mortalidade já se encontrava reduzida. Isso se reflete por uma taxa de mortalidade nesse período de $16,98 \%$ (45 casos), porém aqueles que passaram deste período ainda apresentaram uma mortalidade por conta das sequelas isquêmicas instaladas com taxas de 22,22\% (20/90 casos) em até 6 a 8 semanas no período em que se considera a instalação do 
DIND, o que, analisando já, atinge cifras elevadas de letalidade sem considerar a totalidade dos casos não recebidos nas primeiras $72 \mathrm{~h}$, bem como aqueles que não conseguiram ser encaminhados para assistência no hospital referência quer pela gravidade quer porque evoluíram a óbito antes.

Quanto ao grupo desfecho e DIND, houve maior frequência entre os indivíduos com pior escala do VASOGRADE. O que se mostra congruente com o que a literatura demonstra, em relação aos biomarcadores demográficos: quanto pior a escala clínica e tomográfica na admissão, piores serão os desfechos dos pacientes. Porém, como na amostra, além do tempo de chegada ter sido postergado, existe também um maior número de casos com melhor apresentação clínica e imagenológica, o que, sem dúvida, contribui para melhores desfechos.

A correlação da escala VASOGRADE amarela e vermelha com os casos sintomáticos quanto ao vasoespasmo no Grupo I foi bem relacionada, apesar de um número de casos ligeiramente menor que o grupo II que mostrou mais associação na escala verde. Esses dados se mostram bastante similares aos encontrados por de Oliveira Manoel et al., $2015^{177}$.

\subsection{Perspectivas}

Apesar de inúmeros esforços em pesquisa na HSAa estarem sendo realizados para compreender os mecanismos subjacentes à lesão encefálica; ainda não se consegue esclarecer com todo o conhecimento, até o momento adquirido explicar as causas diretas do sangramento aneurismático e suas complicações. Algumas hipóteses sugerem que o processo da apoptose e das vias inflamatórias estejam diretamente ligados com a cascata que determina a deterioração encefálica rápida e progressiva, inviabilizando oportunidades terapêuticas imediatas. 
Com os dados de revisão da literatura e os achados nesta série de casos, nos parece lógico que a variabilidade genotípica pode definir a susceptibilidade individual por meio da contribuição ancestral étnica tanto para lesão isquêmica precoce pósHSAa como para o DIND (até 6 a 8 semanas pós-ictus).

O DIND permanece como a principal causa de mortalidade e morbidade para aqueles pacientes que sobreviveram ao sangramento inicial. Neste momento nos parece claro que a isquemia encefálica tardia tem uma etiologia multifatorial variada além da simples vasoconstrição causada pelo espasmo arterial, possivelmente, associada às vias inflamatórias. Essa evidência nos alerta para a possibilidade de estratégias terapêuticas futuras que devem ser focadas no intervalo entre a instalação da rotura do aneurisma e o início do DIND, fornecendo uma janela farmacológica para minimizar os efeitos deletérios desta complicação. 


\section{Conclusões}

$1^{\text {a }}$. Os biomarcadores CASP8 (alelo 2 modelo recessivo), XRCC1 (alelo 1 modelo recessivo), $A C E 2$ (alelo $\mathrm{C}$ modelo aditivo), PAR1 (modelo DEL e aditivo) e 4VNTR 27 do gene eNOS mostraram maior associação com vasoespasmo encefálico. $\mathrm{O}$ alelo 1 no modelo recessivo e no aditivo do gene TP53 sugere ser um fator protetor contra o vasoespasmo encefálico;

$1^{\mathrm{b}}$. Em relação à isquemia encefálica tardia, os biomarcadores mais relevantes foram IL4IN3, XRCC1, T-786C e 4-VNTR 27;

$1^{\mathrm{c}}$. O gene da $e N O S$ mostrou significância estatística na amostra estudada para desenvolver o vasoespasmo encefálico na presença do biomarcador 4-VNTR 27. Enquanto o SNP alelo T no modelo dominante (T-786C) mostrou-se relevante para desenvolver déficit isquêmico tardio;

$1^{\text {d }}$. 50\% dos biomarcadores pesquisados mostraram desempenhar um papel relevante na hemorragia subaracnoidea aneurismática e suas complicações, em que alguns contribuíram para desenvolver o vasoespasmo encefálico e/ou isquemia tardia, enquanto outros favoreceram o efeito protetor contra o espasmo; 2. Em relação ao perfil de ancestralidade, não houve diferença entre os pacientes com vasosespasmo sintomático e não sintomático, considerando as diferenças étnicas. Nem houve um biomarcador mais relevante em qualquer dos grupos de hemorragia estudados. 
Anexo A - Escore risco de rotura do aneurisma PHASES

\begin{tabular}{|c|c|}
\hline (P) População & Pontuação \\
\hline América do Norte, Europa (exceto Finlândia) & 0 \\
\hline Japonesa & 3 \\
\hline Filandês & 5 \\
\hline \multicolumn{2}{|l|}{ (H) Hipertensão Arterial Sistêmica } \\
\hline Não & 0 \\
\hline Sim & 1 \\
\hline \multicolumn{2}{|l|}{ (I) Idade } \\
\hline$<70$ anos & 0 \\
\hline$\geq 70$ anos & 1 \\
\hline \multicolumn{2}{|l|}{ (T) Tamanho do Aneurisma } \\
\hline$<7,0 \mathrm{~mm}$ & 0 \\
\hline $7,0-9,9 \mathrm{~mm}$ & 3 \\
\hline $10,0-19,9 \mathrm{~mm}$ & 6 \\
\hline$\geq 20,0 \mathrm{~mm}$ & 10 \\
\hline \multicolumn{2}{|l|}{ (HP) HSAa precoce de outro aneurisma } \\
\hline Não & 0 \\
\hline Sim & 1 \\
\hline \multicolumn{2}{|l|}{ (L) Localização do Aneurisma } \\
\hline ACI - Artéria Carótida Interna & 0 \\
\hline ACM - Artéria Cerebral Média & 2 \\
\hline ACA/ACICo/Circulação Posterior & 4 \\
\hline \multicolumn{2}{|l|}{ (Artéria Cerebral Anterior/ Comunicante Posterior) } \\
\hline \multicolumn{2}{|c|}{$\begin{array}{l}\text { Para calcular o PHASES para um paciente, o número de pontos associado com o indicador que pode ser obtido com a soma } \\
\text { acima. Após a soma o escore correspondente é localizado no gráfico na figura abaixo e assim é estimado o risco em } 5 \text { anos. Para } \\
\text { indivíduos tabagistas o risco já se mostra mais aumentando pois é um fator de risco que multiplica o percentual em } 8 \text { vezes. }\end{array}$} \\
\hline
\end{tabular}


Anexo B - Escala de graduação de Hunt e Hess para HSAa.

Fonte: Hunt WE, Hess RM, 1968.

\begin{tabular}{|c|c|}
\hline Graduação & Descrição Clínica \\
\hline 1 & Assintomático ou cefaleia leve e rigidez de nuca leve \\
\hline $2 \mathrm{a}$ & $\begin{array}{l}\text { Cefaleia moderada a grave, nuca rígida e sem déficit neurológico } \\
\text { focal }\end{array}$ \\
\hline $2 b$ & Cefaleia moderada a grave, nuca rígida e paresia do $\mathrm{III}^{\circ}$ nervo \\
\hline 3 & Sonolência, confusão e déficit neurológico local leve \\
\hline 4 & Torpor, hemiparesia moderada a grave \\
\hline 5 & Coma profundo, rigidez de decerebração e aspecto moribundo \\
\hline
\end{tabular}

Anexo C - Escala de graduação clínica da World Federation of Neurological Surgeons (WFNS)

\begin{tabular}{ccl}
\hline Escore & $\begin{array}{c}\text { Escala de Glasgow } \\
\text { de Coma (EGC) }\end{array}$ & Descrição Clínica \\
\hline I & 15 & Sem déficit motor \\
II & $13-14$ & Sem déficit motor \\
III & $13-14$ & Com déficit motor \\
IV & $7-12$ & Com ou sem déficit motor \\
V & $3-6$ & Com ou sem déficit motor \\
\hline
\end{tabular}

Fonte: J Neurosurg 1988; 68: 985-6. 
Anexo D - Classificação da tomografia de crânio, segundo Fisher original e modificada e as taxas de risco de vasoespasmo clínico

\begin{tabular}{|c|c|c|c|c|}
\hline $\begin{array}{c}\text { Quantidade de Sangue nas } \\
\text { cisternas (HSA) }\end{array}$ & HIV & $\begin{array}{l}\text { Escala de } \\
\text { Fisher } \\
\text { Original }\end{array}$ & $\begin{array}{l}\text { Escala de } \\
\text { Fisher } \\
\text { Modificada }\end{array}$ & $\begin{array}{c}\text { Risco estimado } \\
\text { de } \\
\text { Vasoespasmo } \\
\text { Clínico }(\%)\end{array}$ \\
\hline $\begin{array}{l}\text { Sangue difuso e espesso nas } \\
\text { cisternas }\end{array}$ & Presente & 3 & 4 & 40 \\
\hline $\begin{array}{l}\text { Sangue difuso e espesso nas } \\
\text { cisternas }\end{array}$ & Ausente & 3 & 3 & 33 \\
\hline $\begin{array}{l}\text { Sangue localizado e espesso } \\
\text { nas cisternas }\end{array}$ & Presente & 3 & 4 & 40 \\
\hline $\begin{array}{l}\text { Sangue localizado e espesso } \\
\text { nas cisternas }\end{array}$ & Ausente & 3 & 3 & 33 \\
\hline $\begin{array}{l}\text { Sangue difuso e fino nas } \\
\text { cisternas }\end{array}$ & Presente & 4 & 2 & 33 \\
\hline $\begin{array}{l}\text { Sangue difuso e fino nas } \\
\text { cisternas }\end{array}$ & Ausente & 2 & 1 & 24 \\
\hline $\begin{array}{l}\text { Sangue localizado e fino nas } \\
\text { cisternas }\end{array}$ & Presente & 4 & 2 & 33 \\
\hline $\begin{array}{l}\text { Sangue localizado e fino nas } \\
\text { cisternas }\end{array}$ & Ausente & 1 & 1 & 24 \\
\hline$\underline{\text { Sem sangue nas cisternas }}$ & Presente & 4 & 2 & 33 \\
\hline Sem sangue nas cisternas & Ausente & 1 & 0 & 0 \\
\hline
\end{tabular}

Fonte: Frontera et al., 2006.

Anexo E - Escala VASOGRADE

\begin{tabular}{cccc}
\hline VASOGRADE & WFNS & $\begin{array}{c}\text { Escala de Fisher } \\
\text { modificada }\end{array}$ & Risco de DCI \\
\hline Verde & $1-2$ & $1-2$ & $15 \%$ \\
\hline Amarelo & $1-3$ & $3-4$ & $19 \%$ \\
Vermelho & $4-5$ & Qualquer & $34 \%$ \\
\hline
\end{tabular}

WFNS - World Federation of Neurosurgical Societes, DCI - Isquemia cerebral tardia

Fonte: de Oliveira Manoel et al., 2015. 
Anexo F - Sensibilidade e especificidade do DTC na detecção do vasoespasmo encefálico e critérios por artérias estudadas

\begin{tabular}{lcc}
\hline Artérias Intracranianas & Sensibilidade & Especificidade \\
\hline ACI & $25-30 \%$ & $83-91 \%$ \\
ACM & $39-94 \%$ & $70-100 \%$ \\
ACA & $13-71 \%$ & $65-100 \%$ \\
Vertebral & $44-100 \%$ & $82-88 \%$ \\
Basilar & $77-100 \%$ & $42-79 \%$ \\
ACP & $48-60 \%$ & $78-87 \%$
\end{tabular}

ACI (artéria carótida interna), ACM (artéria cerebral média), ACA (artéria cerebral anterior), ACP (artéria cerebral posterior)

Fonte: Sloan et al., 2004.

Anexo G - Critérios para detecção de vasoespasmo encefálico na ACM, pelo DTC

\begin{tabular}{lcc}
\hline $\begin{array}{l}\text { Velocidade de Fluxo } \\
\text { Média }- \text { VFM }(\mathbf{c m} / \mathbf{s})\end{array}$ & $\begin{array}{c}\text { Índice de } \\
\text { Lindegaard }\end{array}$ & Interpretação dos Dados \\
\hline$<120$ & $\leq 3$ & Hiperemia \\
$>80$ & $3-4$ & Hiperemia + Vasoespasmo leve \\
$\geq 120$ & $3-4$ & Hiperemia + Vasoespasmo leve \\
$\geq 120$ & $4-5$ & Hiperemia + Vasoespasmo moderado \\
$\geq 120$ & $5-6$ & Vasoespasmo moderado \\
$\geq 180$ & 6 & Vasoespasmo moderado a grave \\
$\geq 200$ & $\geq 6$ & Vasoespasmo grave \\
$\geq 200$ & $4-6$ & Hiperemia + Vasoespasmo grave \\
$\geq 200$ & $3-4$ & Hiperemia + Vaspespasmo moderado \\
\hline
\end{tabular}

ACM (artéria cerebral média), DTC (Doppler transcraniano).

Fonte: Sloan et al., 2004.

Anexo H - Critérios de progressão do vasoespasmo encefálico na avaliação da ACM, pelo DTC

\begin{tabular}{ll}
\hline Parâmetros & Valores a interpretar \\
\hline Velocidades & $\mathrm{ACM} \geq 180 \mathrm{~cm} / \mathrm{s}$ \\
& $\begin{array}{l}\text { Aumento rápido da velocidade }(>20 \% \text { ou }>65 \\
\mathrm{cm} / \mathrm{s} / \text { dia })\end{array}$ \\
Índice de Lindegaard & $\mathrm{ACM} / \mathrm{ACI} \geq 6$ \\
Índice de Pulsatilidade (IP) & $\mathrm{IP} \geq 1,2$ \\
ACM (artéria cerebral média), DTC (Doppler transcraniano) & \\
\hline
\end{tabular}

Fonte: Sloan et al., 2004. 
Anexo I - Biomarcadores genéticos envolvidos na patogênese da formação e/ou da rotura na vasculopatia aneurismática - alterações estruturais do DNA.

\begin{tabular}{|c|c|c|c|}
\hline Gene & Cromossomo & Tipo de Mutação & Ação e Função \\
\hline Haptoglobina (HP) & $16 \mathrm{q} 22$ & SNP HP1 e HP2 & $\begin{array}{l}\text { Proteína se liga à hemoglobina; associação } \\
\text { com VC e DIND }\end{array}$ \\
\hline Endogolina (ENG) & $9 \mathrm{q} 3$ & $\begin{array}{l}\text { SNP Intron7,23 bp } \\
\text { inserção }\end{array}$ & $\begin{array}{l}\text { HHT (Hemorragia Telangectásica } \\
\text { hereditária), transforma a expressão das } \\
\text { células endoteliais. Doença de von Hippel } \\
\text { Lindau }\end{array}$ \\
\hline Elastina (ELN) & $7 q 11$ & $\begin{array}{l}\text { SNP Intron } 20 \mathrm{~T} \rightarrow \mathrm{C} \\
\text { SNP Intron } 23 \mathrm{~T} \rightarrow \mathrm{C}\end{array}$ & $\begin{array}{l}\text { Associação com aneurismas rotos e não } \\
\text { rotos. }\end{array}$ \\
\hline Elastase 2 (ELA) & $19 \mathrm{p} 13,3$ & Sem SNP & $\begin{array}{l}\text { Secretadas por leucócitos na destruição da } \\
\text { camada elástica na ECM, formação de AI }\end{array}$ \\
\hline $\begin{array}{c}\text { SERPINA } 1 \alpha 1 \\
\text { Antitripsina (AAT) }\end{array}$ & $14 q 32$ & $\mathrm{~A} / \mathrm{T}$ & $\begin{array}{l}\text { Secretadas por leucócitos na destruição da } \\
\text { camada elástica na ECM, formação de AI }\end{array}$ \\
\hline Fibrilina (FBN1 e 2) & $\begin{array}{c}15 q 21 \\
5 q 23-q 31\end{array}$ & Sem SNP & Síndrome de Marfan, formação de AI \\
\hline $\begin{array}{l}\text { Policistina } \\
(\mathrm{PKD} 1,2,3)\end{array}$ & $16 \mathrm{p} 13$ & Indel & $\begin{array}{l}\text { Doença Renal Policística, AI em jovem com } \\
\text { rotura jovem }\end{array}$ \\
\hline $\operatorname{APOE}(\varepsilon 2,3,4)$ & $19 \mathrm{q} 13.2$ & $\begin{array}{l}\text { E4/nãoE4 } \\
\text { E2/não E2 }\end{array}$ & $\begin{array}{l}\text { Sem relação com VC e DIND, pós HSAa. } \\
\text { Papel secundário na inflamação liberando } \\
\text { citocinas. Relação direta com AVCH }\end{array}$ \\
\hline $\begin{array}{l}\text { Colágeno I e III } \\
\text { (COL3A1) }\end{array}$ & $\begin{array}{c}7 \mathrm{q} 22.1 \\
2 \mathrm{q} 31 \text { (na síndrome) }\end{array}$ & Sem SNP & $\begin{array}{l}\text { Síndrome de Ehlers Danlos, na formação da } \\
\text { parede do aneurisma }\end{array}$ \\
\hline IL-6 & $7 \mathrm{p} 21$ & G572C & $\begin{array}{l}\text { Associada a formação e rotura em } \\
\text { caucasianos e população Chinesa }\end{array}$ \\
\hline & $7 \mathrm{p} 21$ & G174C & $\begin{array}{l}\text { Sugere ser uma citocina pró-inflamatória } \\
\text { protetora para AI }\end{array}$ \\
\hline eNOS & $7 q 35-36$ & Intron 27-bp-VNTR & Associação com VC e DIND \\
\hline & & G984T & Associação com rotura dos AI \\
\hline & & $\mathrm{T} 786 \mathrm{C}$ & Associação com Formação de AI \\
\hline TNF $-\alpha$ & $6 \mathrm{p} 21.33$ & & $\begin{array}{l}\text { Evolvido nas vias inflamatórias de formação } \\
\text { e rotura dos aneurismas. Aumentado no } \\
\text { LCR pós HSAa }\end{array}$ \\
\hline TP53 & $17 \mathrm{p} 13$ & $\begin{array}{c}\mathrm{miR}-34 \mathrm{~b} / \mathrm{c} \mathrm{CC} \\
\mathrm{miR} 34 \mathrm{~b} / \mathrm{c} \mathrm{CT} / \mathrm{TT} \\
\text { Arg72Pro CG/CC/GG }\end{array}$ & $\begin{array}{l}\text { Fator protetor dos aneurismas } \\
\text { Risco de formação e rotura de AI, envolvido } \\
\text { no processo inflamatório } \\
\text { Risco de formação e rotura do AI, envolvido } \\
\text { no processo inflamatório }\end{array}$ \\
\hline PAR1 & $5 q 13.3$ & - & $\begin{array}{l}\text { Permite a ação da Trombina na } \\
\text { fisiopatologia do VC, mediado por este } \\
\text { grupo de receptores. PAR-1 hiperregulado } \\
\text { na HSAa } \uparrow \text { risco de VC }\end{array}$ \\
\hline Endotelina A (ET - A) & $4 \mathrm{q} 31.23$ & C323T & $\begin{array}{l}\text { A endotelina é um potente vasoconstritor, o } \\
\text { bloqueio de seu receptor, reduz o risco de } \\
\text { VC e DCI. ET - } 1 \text { hiperregulada na HSAa } \\
\uparrow \text { risco de HSAa. }\end{array}$ \\
\hline
\end{tabular}


Anexo J - Definições de DCI ou DIND e infarto cerebral após HSAa.

\begin{tabular}{ll}
\hline \multicolumn{1}{c}{ Piora Clínica por ocasião da DCI } & Piora Clínica por ocasião do infarto cerebral \\
\hline - Déficit neurológico focal (hemiparesia, & - Imagem de isquemia presente dentro de 6 \\
afasia, apraxia ou negligência). & semanas \\
- Diminuição da pontuação da escala de & - Pelo menos imagem de isquemia dentro de \\
Glasgow de coma em mais de dois pontos & 6-8 semanas após uma HSAa \\
- Pelo menos 1h hora de instalação & - Comprovado na necrópsia \\
- Não pode surgir imediato à oclusão do & \\
aneurisma & \\
- Outras causas devem ser excluídas &
\end{tabular}


Anexo K -Protocolo de dados dos pacientes com hemorragia subaracnoidea aneurismática.

\begin{tabular}{|c|c|c|c|c|c|}
\hline \multicolumn{2}{|c|}{ Número de registro $A V E$ : } & \multicolumn{3}{|l|}{ Nome: } & $\begin{array}{c}\text { Sexo: } \text { Masculino - M } \\
\text { Feminino - F }\end{array}$ \\
\hline \multicolumn{4}{|c|}{$\begin{array}{l}\text { Grupo de Pesquisa: } \\
\text { Grupo I - Aneurisma Roto com Vasoespasmo } \\
\text { Grupo II - Aneurisma Roto sem Vasoespasmo }\end{array}$} & Idade (anos): & $\begin{array}{l}\text { Grupo Etário (anos): } \\
-<30 \\
-30-39 \\
-40-49 \\
-50-59 \\
-60-69 \\
-\geq 70 \\
\end{array}$ \\
\hline $\begin{aligned} & \text { Etnia Inferida: } \\
& \text { 1. } \text { branca } \\
& \text { 2. } \text { asiático } \\
& \text { japonês } \\
& \text { 3. } \text { negra } \\
& \text { 4. } \text { indígena } \\
& \text { 5. } \text { parda }\end{aligned}$ & \multicolumn{3}{|c|}{$\begin{array}{l}\text { Etnia Geneticamente Identificada } \\
\text { (\%): } \\
-\quad \text { Ameríndio } \\
-\quad \text { Europeu } \\
-\quad \text { Africano }\end{array}$} & \multicolumn{2}{|c|}{\begin{tabular}{|ll} 
Fatores & de risco modificáveis: \\
1. & Fator de Risco Modificável Maior (Hipertensão \\
& Arterial Sistêmica e/ou Tabagismo) \\
2. & Fator de Risco Modificável Menor \\
& (Etilismo, Diabetes Mellitus e/ou Dislipidemia)
\end{tabular}} \\
\hline \multicolumn{3}{|c|}{$\begin{array}{l}\text { Escala da World Federation of } \\
\text { Neurological Surgeons (WFNS): } \\
\text { I - ECG 15, sem déficit motor } \\
\text { II - ECG 13-14, sem déficit motor } \\
\text { III - ECG 13-14, com déficit motor } \\
\text { IV - ECG 7-12 } \\
\text { V - ECG 3-6 } \\
\text { ECG (Escala de Coma de Glasgow) }\end{array}$} & \multicolumn{3}{|c|}{ 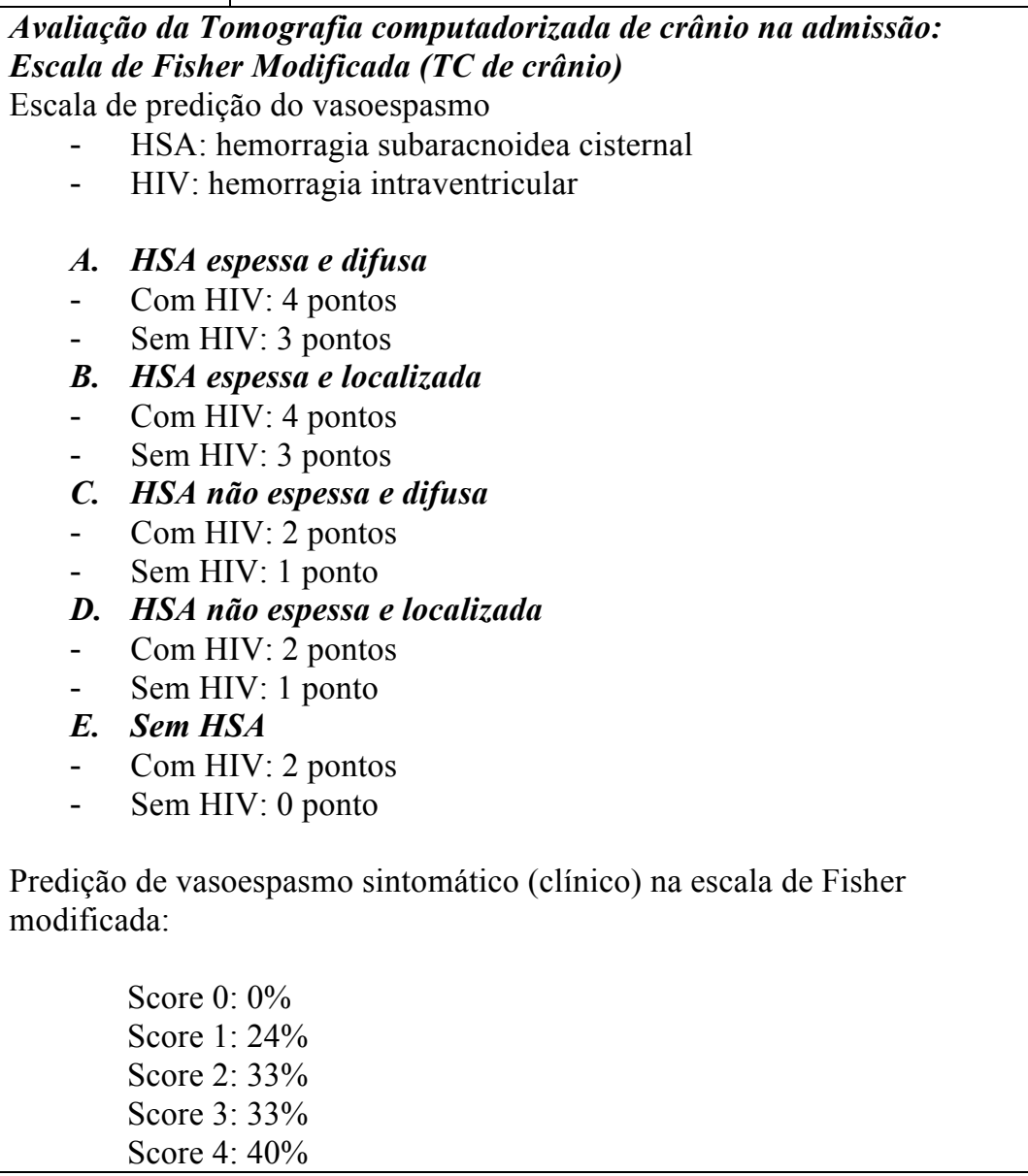 } \\
\hline \multicolumn{3}{|c|}{$\begin{array}{l}\text { Angiografia encefálico por subtração digital } \\
\text { (DSA) Diagnóstica (inicial): } \\
\text { 1) Aneurisma } \\
\text { a) Quantidade } \\
\text { b) Lesão em espelho } \\
\text { c) Localização } \\
\text { c.1. Circulação Anterior } \\
\text { (1.ACA/2.ACM/3.ACIoft/4.ACICoP/5. }\end{array}$} & \multicolumn{3}{|c|}{$\begin{array}{l}\text { Escala Preditiva de Vasoespasmo Modificada: VASOGRADE } \\
\text { WFNS + Escala de Fisher na TC de crânio modificada }\end{array}$} \\
\hline
\end{tabular}




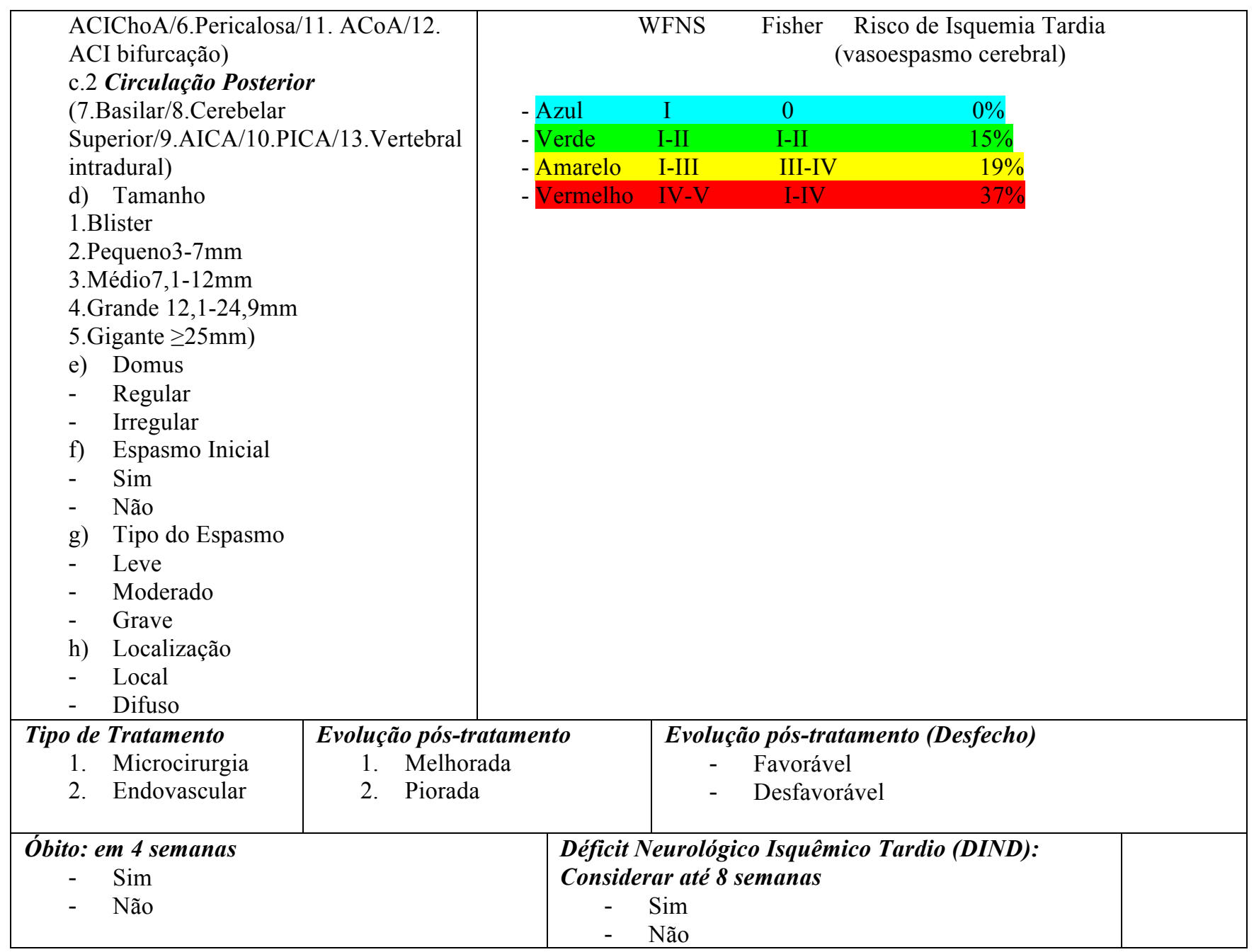


Anexo L - Termo de Consentimento Livre e Esclarecido

hospital das CLÍNICAS da faculdade de medicina DA UNIVERSIDADE dE SÃo PAULO-HCFMUSP

TERMO DE CONSENTIMENTO LIVRE E ESCLARECIDO

\section{DADOS DE IDENTIFICAÇÃO DO SUJEITO DA PESQUISA OU RESPONSÁVEL LEGAL}

1.

NOME:

$\therefore$

DOCUMENTO DE IDENTIDADE N :

SEXO : .M $\square \quad F \quad \square$

DATA NASCIMENTO: .......................

ENDEREÇO APTO:

$\mathrm{N}^{\circ}$

BAIRRO:

CIDADE

CEP:

TELEFONE: DDD

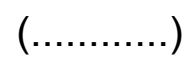

2.RESPONSÁVEL

LEGAL

NATUREZA (grau de parentesco, tutor, curador etc.)

DOCUMENTO DE IDENTIDADE :

SEXO: $M \square \quad F \square$

DATA NASCIMENTO.: ....................

ENDEREÇO:

$\mathrm{N}^{\mathrm{O}}$

APTO:

BAIRRO:

CIDADE:

CEP:

TELEFONE:

DDD

DADOS SOBRE A PESQUISA

1. TÍTULO DO PROTOCOLO DE PESQUISA:

O papel do polimorfismo genético da óxido nítrico sintetase endotelial (eNOS) na hemorragia subaracnóidea aneurismática em pacientes da Amazônia 
PESQUISADOR RESPONSÁVEL:

Prof. Dr. Manoel Jacobsen Teixeira.

CARGO/FUNÇÃO: Prof. Dr. Titular

REGIONAL N ${ }^{\circ}$

INSCRIÇÃO CONSELHO

UNIDADE DO HCFMUSP: Divisão da Clínica Neurológica

PESQUISADOR RESPONSÁVEL:

\section{Dr. Edson Bor-Seng Shu}

CARGO/FUNÇÃO: Responsável Técnico Grupo de Neurossonologia INSCRIÇÃO CONSELHO REGIONAL Nº

UNIDADE DO HCFMUSP: Divisão da Clínica Neurológica

PESQUISADOR EXECUTANTE:

Dr. Eric Homero Albuquerque Paschoal.

CARGO/FUNÇÃO: Aluno de Pós-Graduação Strictu Sensu INSCRIÇÃO CONSELHO REGIONAL N ${ }^{\circ}$

UNIDADE DO HCFMUSP: Divisão da Clínica Neurológica

2. AVALIAÇÃO DO RISCO DA PESQUISA:

$\begin{array}{lll}\text { RISCO MÍNIMO } & x & \text { RISCO MÉDIO } \\ \text { RISCO BAIXO } & \square & \text { RISCO MAIOR }\end{array}$

\section{DURAÇÃO DA PESQUISA : 6 a 12 meses}

FINALIDADE DA PESQUISA: Essa pesquisa tem como objetivo Verificar se existe associação entre o polimorfismo genético da eNOS com o vasoespasmo encefálico pós HSAa em uma casuística da Amazônia.

DESTINO DOS DADOS DO SUJEITO PESQUISADO: Os dados coletados serão utilizados somente para esta pesquisa, não sendo divulgada qualquer informação que possa levar à sua identificação. A pesquisa seguirá ainda, os preceitos da Declaração de Helsinque e do Código de Nuremberg, respeitando as Normas de Pesquisa envolvendo Seres Humanos (Rs. CNS 466/12) do Conselho Nacional de Saúde. Os questionários serão incinerados (queimados), após cinco anos de a pesquisa ser concluída.

RISCOS, PREVENÇÃO E BENEFíCIOS: A coleta de dados será feita através da análise de 300 pacientes com diagnóstico de HSAa internados no Serviço de Neurocirurgia da Clínica Neurológica do Hospital Ophir Loyola. Há, portanto, o risco de identificação dos seus dados e constrangimento devido a isto; este risco será amenizado, visto que no momento da análise dos dados, os protocolos de coleta não estarão identificados com o nome e sim com a numeração padronizada de cada paciente. Dessa forma, o seu sigilo e a privacidade serão preservados.

Não será divulgado, em hipótese alguma, qualquer dado que possa identificar os sujeitos estudados, sendo que somente os resultados estatísticos referentes às pesquisas serão utilizados e poderão também ser publicados em jornais ou revistas médicas. Assim, esta pesquisa pode lhe beneficiar ao verificar 
o melhor tipo de tratamento para cada tipo de lesão de tumoral de localização intraventricular.

Este termo será lido e explicado aos responsáveis legais dos sujeitos da pesquisa pelos pesquisadores, que deverão estar presentes no momento da assinatura. Toda e qualquer dúvida ser esclarecida pelos pesquisadores no momento ou após a assinatura.

GARANTIAS: É garantida aos pesquisados a liberdade de deixar de participar do estudo sem qualquer prejuízo, em qualquer etapa de realização, não havendo, também, nenhum pagamento material pela sua participação no trabalho. Assim como, não haverá despesas pessoais para os participantes em qualquer fase do estudo, sendo o trabalho financiado por recursos próprios dos autores, não tendo financiamento ou co-participação de nenhuma instituição de pesquisa. 0 sujeito da pesquisa tem direito a se manter informado a respeito dos resultados parciais da pesquisa. Caso ocorra exposição dos sujeitos da pesquisa, os participantes terão direito de receber assistência psicológica e indenizações legalmente estabelecidas por lei.

ESCLARECIMENTO DE DÚVIDAS: Em qualquer momento do estudo, os pesquisados, para esclarecimento de dúvidas, terão acesso ao pesquisador executante: Dr. Eric Homero Albuquerque Paschoal, cujo endereço : Comite de Ética em Pesquisa da Faculdade de Medicina da Universidade de São Paulo situado na Av. Dr. Arnaldo, 455 Cerqueira César - São Paulo - SP CEP: 01246903. Fone/Fax: 55+11+3061-8004E-mail: cep.fm@usp.br.

\section{DECLARAÇÃO}

Declaro que compreendi as informações do que li ou que me foram explicadas sobre o trabalho em questão.

Discuti com os pesquisadores sobre minha decisão em participar desse estudo, ficando claros para mim, quais são os propósitos da pesquisa, os procedimentos a serem realizados, os possíveis desconfortos e riscos, as garantias de confidencialidade e de esclarecimentos permanentes.

Ficou claro também que minha participação não tem despesas e que tenho garantia de acesso aos dados e inclusive podendo optar por desistir de participar da pesquisa.

Concordo voluntariamente em participar desse estudo podendo retirar meu consentimento a qualquer momento, antes ou durante, sem necessidade de justificar o motivo da desistência e sem haver penalidades ou prejuízos.

Belém,___ de _____ de 201_.

Assinatura do Responsável Assinatura da Testemunha

Declaro que obtive de forma apropriada e voluntária o consentimento livre e esclarecido

Profo $^{\circ}$. Eric Homero Albuquerque Paschoal

Pesquisador Executante 
Anexo M - Carta de Aceite do Comitê de Ética em Pesquisa HCFMUSP



\section{APROVAÇÃO}

O Comitê de Ética em Pesquisa da Faculdade de Medicina da Universidade de São Paulo, em sessão de 16/04/2014, APROVOU o Protocolo de Pesquisa $\mathrm{n}^{\circ}$ 015/14 intitulado: "O PAPEL DO POLIMORFISMO GENÉTICO DA ÓXIDO NÍTRICO SINTASE ENDOTELIAL (ENOS) NA HEMORRAGIA SUBARACNÓIDEA ANEURISMÁTICA EM PACIENTES DA AMAZÔNIA" apresentado pelo Departamento de NEUROLOGIA

Cabe ao pesquisador elaborar e apresentar ao CEPFMUSP, os relatórios parciais e final sobre a pesquisa (Resolução do Conselho Nacional de Saúde no 466/12).

Pesquisador (a) Responsável: Prof.Dr. Edson Bor-Seng-Shu, Prof.Dr. Manoel Jacobsen Teixeira

Pesquisador (a) Executante: Eric Homero Albuquerque Paschoal

CEP-FMUSP, 22 de Abril de 2014 .

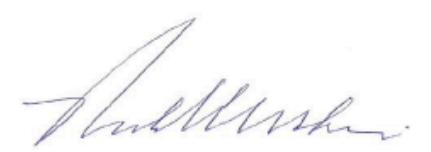

Prof. Dr. Paulo Eurípedes Marchiori

Vice-Coordenador

Comitê de Ética em Pesquisa 
Anexo N - Carta de Aceite da Pesquisa Laboratório de Genética Médica e Humana Universidade Federal do Pará.

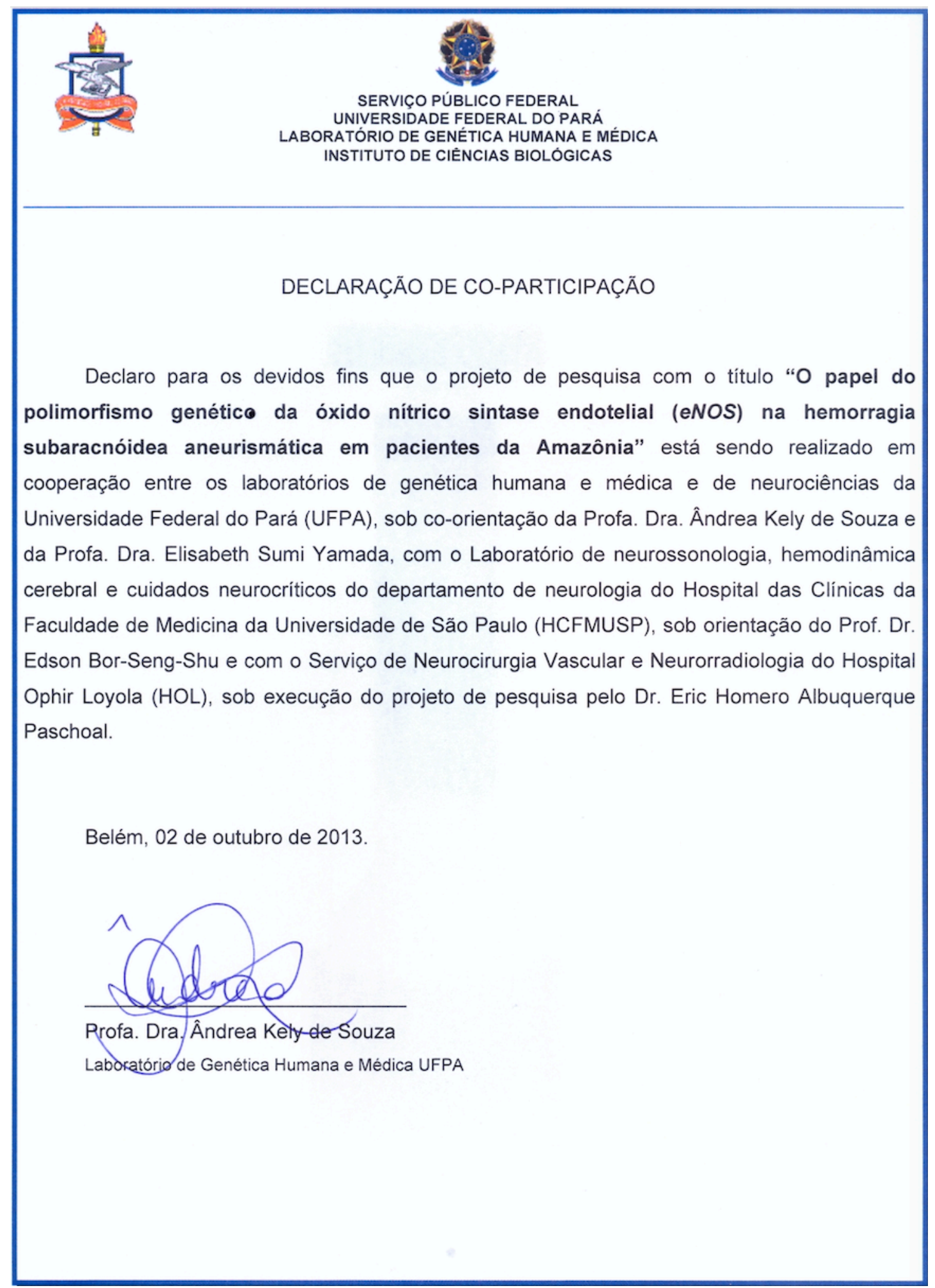


Anexo O - Aprovação do Comitê de Ética em Pesquisa do Hospital Ofir Loyola.

\section{HOSPITAL OPHIR LOYOLA - $\mathrm{HOL}$

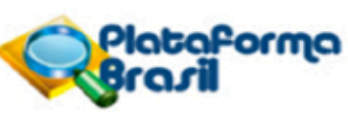

\section{PARECER CONSUBSTANCIADO DO CEP}

\section{DADOS DO PROJETO DE PESQUISA}

Título da Pesquisa: O papel do polimorfismo genético da óxido nítrico sintetase endotelial (eNOS) na hemorragia subaracnóidea aneurismática em pacientes da Amazônia.

Pesquisador: EDSON BOR-SENG-SHU

Área Temática: Genética Humana:

(Trata-se de pesquisa envolvendo Genética Humana que não necessita de análise ética por parte da CONEP;);

Versão: 2

CAAE: 21159913.9 .0000 .5550

Instituição Proponente: Hospital Ophir Loyola

Patrocinador Principal: Financiamento Próprio

\section{DADOS DO PARECER}

Número do Parecer: 433.393

Data da Relatoria: 07/11/2013

\section{Apresentação do Projeto:}

O projeto de pesquisa intitulado $O$ papel do polimorfismo genético do óxido nítrico sintetase endotelial (eNOS) na hemorragia subaracnóidea aneurismática (HSAa) em pacientes da Amazônia será realizado no HOL e a análise genética do mesmo na UFPA.

\section{Objetivo da Pesquisa:}

O projeto tem 2 objetivos, o principal é verificar se existe associação entre o polimorfismo genético do eNOS com o vasoespasmo encefálico pós HSAa em uma casuística da Amazônia e, os secundários são avaliar a frequência da presença do alelo $\mathrm{T}$ da região promotora do gen eNOS e avaliar incidência de vasoespasmo encefálico (VE) pós-HSAa na região amazônica.

\section{Avaliação dos Riscos e Benefícios:}

Esta pesquisa poderá acarretar riscos aos pacientes inerentes aos procedimentos diagnósticos e terapêuticos instituídos na pesquisa, tais como a angiografia cerebral por subtração digital e na coleta de sangue para análise genética. Com intuito de prevenir tais complicações, o paciente será submetido a todos os procedimentos pelo pesquisador responsável que deve ser capacitado e

Endereço: GOVERNADOR MAGALHAES BARATA 523/1075

Bairro: SAO BRAS CEP: $66.063-240$

UF: PA Município: BELEM

Telefone: (91)3342-1100

E-mail: cepophirloyola.pa@gmail.com 


\section{HOSPITAL OPHIR LOYOLA - $\mathrm{HOL}$}

Continuaçåo do Parecer: 433.393

habilitado para a realização dos procedimentos.

Para os pesquisadores, há riscos relacionados ao fato de não conseguirem completar a pesquisa e a consequente perda de credibilidade diante à comunidade científica, para que isso seja evitado os pesquisadores propõem-se a coletar e analisar todos os dados de formal imparcial.

Os benefícios para os pacientes ocorre na medida em que recebem diagnóstico e tratamento eficazes à sua doença, de forma a combater os altos índices de morbimortalidade da mesma.

\section{Comentários e Considerações sobre a Pesquisa:}

Serão avaliados 300 pacientes com diagnóstico de hemorragia subaracnóidea aneurismática (HSAa) internados no Serviço de Neurocirurgia da Clínica Neurológica do Hospital Ophir Loyola com a coleta de sangue para análise genética do polimorfismo genético do óxido nítrico sintetase endotelial (eNOS).

Os pacientes serão estudados pela angiografia cerebral por subtração digital, permitindo identificar a morfologia, localização e tamanho do(s) aneurisma(s) intracraniano(s), envolvidos com a HSA, bem como a presença ou não de vasoespasmo encefálico com sua graduação respectiva no momento do diagnóstico. $\mathrm{O}$ acompanhamento do espasmo será obtido através de técnicas de doppler transcraniano no pós diagnóstico antes e após o tratamento, determinando o grau de comprometimento hemodinâmico quanto a gravidade do vasoespasmo encefálico.

A análise genética será realizada no Laboratório de Genética Humana e Médica em cooperação com o Laboratório de Neurociências ambos da Universidade Federal do Pará (UFPA)

\section{Considerações sobre os Termos de apresentação obrigatória:}

Todos os termos de apresentação obrigatória estam de acordo com as resoluções CNES n 340/2004 e $n^{\circ} 466 / 12$.

\section{Recomendações:}

Conclusões ou Pendências e Lista de Inadequações:

Após nova análise, com a correção do TCLE e a inclusão do termo de conhecimento da UFPA para a realização da pesquisa, a mesma está dentro das normas das resoluções CNES n 340/2004 e n 466/12.

Situação do Parecer:

Aprovado

Endereço: GOVERNADOR MAGALHAES BARATA 523/1075

Bairro: SAO BRAS CEP: $66.063-240$

UF: PA Município: BELEM

Telefone: (91)3342-1100

E-mail: cepophirloyola.pa@gmail.com 


\section{HOSPITAL OPHIR LOYOLA - $\mathrm{HOL}$

Continuaçăo do Parecer: 433.393

Necessita Apreciação da CONEP:

Não

Considerações Finais a critério do CEP:

Foram atendidas todas as solicitações formuladas pelo relator.

BELEM, 23 de Outubro de 2013

Assinador por:

Alberto Gomes Ferreira Junior

(Coordenador)

Endereço: GOVERNADOR MAGALHAES BARATA 523/1075

Bairro: SAO BRAS

CEP: $66.063-240$

UF: PA

Município: BELEM

Telefone: (91)3342-1100

E-mail: cepophirloyola.pa@gmail.com 


\section{Referências}

1. Suarez JL, Tarr RW, Selman WR. Aneurysmal subarachnoid hemorrahage. $N$ Eng $J$ Med. 2006; 254: 387-396.

2. Connolly ES, Rabinstein AA, Carhuapoma JR, Derdeyn CP, Dion J, Higashida RT, Hoh BL, Kirkness CJ, Naidech AM, Olgivy CS, Patel AB, Thompson BG, Vespa P, Guidelines for the Management of Aneurysmal Subarachnoid Hemorrhage: A Guideline for Healthcare Professionals From the American Heart Association/American Stroke Association. Stroke 2012; 43: 1711-1737.

3. Bederson JB, Connolly ES, Batjer HH et al. Guidelines for the management of aneurysmal subarachnoid hemorrahge. A statement for healthcare professional from a special writing group of the stroke council, American Heart Association. Stroke 2009; 40:994-1025.

4. de Rooij NK, Linn FH, van der Plas JA, Algra A, Rinkel GJ. Incidence of subarachnoid haemorrhage: a systematic review with emphasis on region, age, gender and time trends. J Neurol Neurosurg Psychiatry. 2007; 78:1365-1372.

5. Ingall $\mathrm{T}$, Asplund $\mathrm{K}$, Mahonen $\mathrm{M}$, Bonita R. A multinational comparison of subarachnoid hemorrhage epidemiology in the WHO MONICA stroke study. Stroke $2000 ; 31: 1054-1061$.

6. Feigin VL, Lawes CM, Bennett DA, Barker-Collo SL, Parag V. Worldwide stroke 
incidence and early case fatality reported in 56 population-based studies: a systematic review. Lancet Neurol. 2009; 8:355-369.

7. Biros E, Golledge J. Meta-analysis of whole genome linkage scans for intracranial aneurysm. Neurosci Lett. 2008; 431: 31-35.

8. van Gijn J, Rinkel GJE. Suarachnoid hemorrhage: diagnosis, causes and treatment. Brain. 2001; 124: 249-278.

9. Rosen DS, Macdonald RL. Subarachnoid Hemorrhage Grading Scales. Neurocrit Care 2005; 2:110-118.

10. Brisman JL, Song JK, Newell DW. Cerebral Aneurysms. N Eng J Med. 2006; 355: 928-939.

11. Frontera JA, Claassen J, Schmidt JM et al. Prediction of Symptomatic Vasospasm after Subarachnoid Hemorrhage: The modified Fisher Scale. Neurosurgery 2006; 59: 21-27.

12. Malinova V, Schatlo B, Voit M et al. Identification of specific age groups with a high risk for developing cerebral vasospasm after aneurysmal subarachnoid hemorrhage. Neurosurg Rev. 2016; 39: 429-436. 
13. Khurana VG, Meissner I, Sohni YR, et al. The presence of tandem endotelial nitric oxide synthase gene polymorphisms identifying brain aneurysms more prone to rupture. J Neurosurg 2005; 102: 526-531.

14. Krischek B, Kasuya H, Akagawa $\mathrm{H}$, et al. Using endotelial nitric oxide synthase gene polymorphisms to identify intracranial aneurysms more prone to rupture in Japanese patients. J Neurosurg. 2006; 105: 717-722.

15. Su XW, Chan AH, Lu G, et al. Circulating microRNA 132-3p and 324-3p Profiles in Patients after Acute Aneurysmal Subarachnoid Hemorrhage, PloS One 2015; 10, e0144724.

16. Prinzmetal M, Kennamer R, Merliss R, Wada T, Bor N. Angina pectoris. I. A variant form of angina pectoris. Am J Med. 1959; 27:373

17. Mauritson DR, Peshock RM, Winniford MD, Stern L, Johnson SM, Hillis D. Prinzmetal's variant angina: is it transmitted genetically? Am Heart J. 1983; 105: 1049.

18. Aoki T, Nishimura M, Kataoka H, Ishibashi R, Nozaki K, Miyamoto S. Complementary inhibition of cerebral aneurysm formation by eNOS and nNOS. Laboratory Investigation 2011; 91: 619-626. 
19. Yamada S, Utsunomiya M, Inoue $\mathrm{K}$, et al. Genome-wide scan for Japanese Familial Intracranial Aneurysms - Linkage to Several Chromossomal Regions. Circulation 2004; 110: 3727-3733.

20. Nakayma M, Yasue H, Yoshimura M, Shimasaki Y, Kugiyama K, Ogawa H, Motoyama T, Saito Y, Ogawa Y, Miyamoto Y, Nakao K. T-786-->C mutation in the 5'-flanking region of the endothelial nitric oxide synthase gene is associated with coronary spasm. Circulation 1999; 99: 2864-2870.

21. Starke RM, Kim GH, Komotar RJ, et al. Endothelial Nitric Oxide Synthase Gene Single Nucleotide Polymorphism Predicts Cerebral Vasospasm following Aneurysmal Subarachnoid Hemorrhage. J Cereb Blood Flow Metab 2008; 28: 1204-1211.

22. Lai PMR, Du R. Role of Genetic Polymorphisms in Predicting Delayed Cerebral Ischemia and Radiographic Vasospasm After Aneurysmal Subarachnoid Hemorrhage: A Meta-Analysis. World Neurosurg 2015; 84: 933-941.

23. Khurana VG, Sohni YG, Mangrum WI, McClelland RL, O'Kane DJ et al. Endothelial nitric oxide synthase gene polymorphisms predict susceptibility to aneurysmal subarachnoid hemorrhage and cerebral vasospasm. J Cereb Blood Flow Metab. 2004; 24:291-297.

24. Neves M. A concepção de raça humana em Raimundo Nina Rodrigues. Filosofia e História da Biologia 2008; 3:241-261. 
25. Cardena MMSG, Ribeiro-dos-Santos A, Santos S, Mansur AJ, Pereira AC,

Fridman C. Assessment of the relationshipbetween self-declared ethnicity, mitochondrial haplogroups and genomic ancestry in Brazilina individuals. Plos One $2013 ; 8: 1-6$

26. Francez PAC, Riberio-Rodrigues EM, dos Santos SEB. Allelic frequencies and statistical data obtained from 48 AIM INDEL loci in an admixed population from the Brazilian Amazon. Forensic Science International: Genetics 2012; 6:132-135

27. Edlow JA, Caplan LR. Avoiding pitfalls in the diagnosis of subarachnoid hemorrhage. N Engl J Med. 2006; 342: 29-36.

28. D’Souza S. Aneurysmal Subarachnoid Hemorrhage. J Neurosurg Anesthesiol. 2015; 27: 222-240.

29. Macdonald RL. Origins of the Concept of Vasospasm. Stroke 2015; 46:1-5.

30. Snow CP. The Two Cultures and The Scientific Revolution. Cambridge University Press, 1959.

31. Ecker A, Riemenschneider PA. Arteriographic demonstration of spasm of the intracranial arteries, with special reference to saccular arterial aneurysms. $J$ Neurosurg. 1951; 8:660-667.

32. Macdonald RL. Delayed neurological deterioration after subarachnoid 
haemorrhage. Nat Rev Neurol. 2014; 10:44-58.

33. Farlow JL, Lin H, Sauerbeck L, Lai D, Koller DL, Pugh E, Hetrick K, Ling H, Kleinloog R, van der Vlies P, Deelen P, Swertz MA, Verweij BH, Regli L, Rinkel GJE, Ruigrok YM, Doheny K, Liu Y, Broderick J, Foroud T, Fia Study Investigators. Lessons learned from whole eome sequencing in multiplex families affected by a complex genetic disorder, intracranial aneurysm. PLoS One 2015; 10:e121104.

34. Saugstad JA. MicroRNAs as efforts of brain function with roles in ischemia and injury, neuroprotection and neurodegenaration. Journal of Cerebral Blood Flow \& Metabolism 2010; 30:1564-1576.

35. Meurer WJ, Walsh B, Vilke GM, Coyne CJ. Clinical guidelines for the emergency department evaluation of subarachnoid hemorrhage. J Emerg Med 2016; Apr 50 (4): 696-701.

36. Kaptain GJ, Lanzino G, Kassell NF. Subarachnoid haemorrhage: epidemiology, risk factors and treatment options. Drugs \& Aging. 2000; 17:(3):183-96.

37. de Rooij NK, Rinkel GJ, Dankbaar JW, Frijns CJ. Delayed cerebral ischemia after subarachnoid hemorrhage: a systematic review of clinical laboratory and radiological predictors. Stroke. 2013;44 (1):43-45.

38. Connolly ES, Poisik A, Winfree CJ, Kim LJ, Huang J, McMahon DJ, Solomon RA. Cigarette Smoking and the Development and Rupture of Cerebral Aneurysms in 
a Mixed Race Population: Implications for Population Screening and Smoking Cessation. 1999; 8(4): 248-253.

39. Sawyer DM, Amenta PS, Medel R, Dumont AS. Inflammatory Mediators in Vascular Disease: Identifying Promisin Targets for Intracranial Aneurysm Research. Mediators of Inflammation 2015; 2015:896283.

40. Kataoka K, Taneda M, Asai T, Kinoshita A, Ito M, Kuroda R. Structural fragility and inflammatory response of ruptured and unruptures cerebral aneurysms. Stroke 1999; 30:1396-1401.

41. Chalouhi N, Ali MS, Starke Jabbour PM, Tjoumakaris SI, Gonzalez LF, Rosenwasser RH, Koch WJ, Dumont AS. Cigarette smoke and inflammation: role in cerebral aneurysm formation and rupture. Mediators Inflamm 2012; 1-12.

42. Bonita R, Duncan J, Truelsen T, Jackson RT, Beaglehole R. Passive smoking as well as active smoking increases the risk of acute stroke. Tabacco Control 1999; 8: 156-160.

43. Tulamo R, Frosen J, Junnikkala S, Paetau A, Kangasniemi M, Pelaez J, Hernesniemi J. Niemela M, Meri S. Complement system becomes activated by the classical pathway in intracranial aneurysm walls. Lab Invest. 2010; 90:168-179. 
44. Aoki T, Kataoka H, Morimoto M, Nozaki K, Hashimoto N. Macrophage-derived matrix metalloproteinase- 2 and -9 promote the progression of cerebral aneurysms in rats. Stroke 2007; 38:162-169.

45. Jin D, Sheng J, Yang X, Gao B. Matrix metalloproteinases and tissues inhibitors of metalloproteinases expression in human cerebral ruptured and unruptured aneurysm. Surgical Neurology 2007; 68 upplement 2 (6): S11-S16.

46. Raveendran M, Wang J, Senthil D, et al. Endogenous nitric oxide activation protects against cigarette smoking induced apoptosis in endothelial cells. Febs Letters 2005; 579: 733-750.

47. Andrew PJ, Mayer B. Enzymatic function of nitric oxide synthases. Cardiovascular Research 1999; 43: 521-531.

48. Aoki T, Kataoka H, Moriwaki T, Nozaki, K, Hashimoto N, Role of TIMP-1 and TIMP-2 in the progression of cerebral aneurysms. Stroke 2007; 38(8): 2337-2345.

49. Abbruscato TJ, Lopez SP, Mark KS, Hawkins BT, Davis TP. Nicotine and cotinine modulate cerebral microvascular permeability and protein expression of ZO1 through nicotinic acetylcholine receptors expressed on brain endothelial cells. Journal of Pharmaceutical Sciences 2002; 91: 2525-2538. 
50. Owens GK, Kumar MS, Wamhoff BR. Molecular regulation of vascular smooth muscle cell differentiation in development and disease. Physiological Reviews 2004; 84: 767-801.

51. Kilic T, Sohrabifar M, Kurtkaya O, et al. Expression of structural proteins and angiogenic factors in normal arterial and unruptured and ruptured aneurysm walls Neurosurgery 2005; 57: 997-1006.

52. Zhang Y, Griendling KK, Dikalova A, Owens GK, Taylor WR. Vascular hypertrophy in angiotensin II-induced hypertension is mediated by vascular smooth muscle cellderived H2O2. Hypertension 2005; 46: 732-737.

53. Hossain M, Sathe T, Fazio V et al. Tobacco smoke: a critical etiological factor for vascular impairment at the blood-brain barrier. Brain Research 2009; 1287: 192-205.

54. Jayaraman $\mathrm{T}$, Berenstein $\mathrm{V}, \mathrm{Li} \mathrm{X}$, et al. Tumor necrosis factor alpha is a key modulator of inflammation in cerebral aneurysms. Neurosurgery 2005; 57:558-564.

55. Hasan T, Timofeev EV, Saito T, Shimizu H, Ezura M, Matsumoto Y, Takayama K, Tominaga T, Takahashi A. A proposed parent vessel geometry-based categorization of saccular intracranial aneurysms: computational flow dynamics analysis of the risk factors for lesion rupture. J Neurosurg 2005; 103:662-680.

56. Clarke G, Mendelow AD, Mitchell P. Predicting the risk of rupture of intracranial aneurysms based on anatomical location. Acta Neurchir 2005; 147:259-263. 
57. Shiue I, Arima H, Anderson CS; ACROSS Group. Life events and risk of subarachnoid hemorrhage: the Australasian Cooperative Research on Subarachnoid Hemorrhage Study (ACROSS). Stroke 2010;41:1304-1306.

58. Etminan N, Beseoglu K, Steiger HJ, Hänggi D. The impact of hypertension and nicotine on the size of ruptured intracranial aneurysms. J Neurol Neurosurg Psychiatry 2011;82:4-7.

59. Burns JD, Huston J 3rd, Layton KF, Piepgras DG, Brown RD Jr. Intracranial aneurysm enlargement on serial magnetic resonance angiography: frequency and risk factors. Stroke 2009; 40:406-411.

60. Chalouhi N, Jabbour P, Magnotta V, Hasan D. Molecular Imaging of Cerebrovascular Lesions. Transl Stroke Res. 2013; 5: 260-8.

61. Hasan D, Chalouhi N, Jabbour P, Magnotta VA, Kung DK, Young WL. Imaging aspirin effect on macrophages in the wall of human cerebral aneurysms using ferumoxitol-enhanced MRI: preliminary results. J Neuroradiol. 2013; 40: 187-91.

62. International Study of Unruptured Intracranial Aneurysms Investigators. Unruptured intracranial aneurysms: natural history, clinical outcome, and risks of surgical and endovascular treatment. Lancet $2003 ; 362: 103-10$.

63. International Study of Unruptured Intracranial Aneurysms Investigators. 
Unruptured intracranial aneurysms: risk of rupture and risks of surgical intervention. N Engl J Med. 1998; 339: 1725-1733.

64. Greving JP, Wermer MJH, Brown Jr RD, Morita A, Juvela S, Yonekura M, Ishibashi T, Torner JC, Nakayama T, Rinkel GJE, Algra A. Development of the PHASES score for prediction of risk of rupture of intracranial aneurysms: a pooled analysis of six prospective cohort studies. Lancet Neurol. 2014; 13:59-66.

65. Przybycien-Szymanska MM, Ashley WW. Biomarker discovery in cerebral vasospasm after aneurysmal subarachnoid hemorrhage: review article. Journal of Stroke and Cerebrovascular Diseases 2015; 24: 1453-1464.

66. Pryor WA, Stone K, Cross CE, Machlin L, Packer L. Oxidants in cigarette smoke: radicals, hydrogen peroxide, peroxynitrate, and peroxynitrite. Annals of the New York Academy of Sciences 1993; 686:12-28.

67. Chalouhi N., Chitale R., Jabbour P, Tjoumakaris S, Dumont AS, Rosenwasser R, Gonzalez LF. The case for family screening for intracranial aneurysms. Neurosurgical Focus 2011; 31(6): Article ID E8.

68. Frösen J, Piippo A, Paetau A et al. Remodeling of saccular cerebral artery aneurysm wall is associated with rupture: histological analysis of 24 unruptured and 42 ruptured cases. Stroke 2004; 35: 2287-2293. 
69. Kanematsu Y, Kanematsu M, Kurihara C, Tada Y, Tsou TL, van Rooijen N, Lawton MT, Young WL, Liang EI, Nuki Y, Hashimoto T. Critical roles of macrophages in the formation of intracranial aneurysm. Stroke 2011; 42:173-178.

70. Yasuno K, Bilguvae $\mathrm{K}$, Bijenga $\mathrm{P}$, et al. Genome-widw association stdy of intacranial aneurysm identifies three new risk loci. Nature Genetics 2010; 42: 420427.

71. Krings T, Piske RL, Lasjaunias PL. Intracranial arterial aneurysm vasculopathies: targeting the outer vessel wall. Neuroradiology 2005; 47: 931-937.

72. Libby P. Collagenases and cracks in the plaque. Journal of Clinical Investigation 2013; 123: 3201-3203.

73. Makino H, Tada Y, Wada K et al. Pharmacological stabilization of intracranial aneurysms in mice: a feasibility study. Stroke, 2012; 43:2450-2456.

74. Macdonald RL. Aneurysm wall inflammation. J Neurosurg 2014; 120:70-72.

75. Jayaraman T, Paget A, Shin YS, et al. TNF- $\alpha$-mediated inflammation in cerebral aneurysms: a potential link to growth and rupture. Vascular Health and Risk Management 2008; 4: 805-817.

76. Hokari M, Nakayama N, Nishihara H, Houkin K. Pathological findings of saccular cerebral aneurysms - impact of subintimal fibrin deposition on aneurysm 
rupture. Neurosurg Rev 2015; 38: 531-540.

77. Moriwaki T, Takagi Y, Sadamasa N, Aoki T, Nozaki K, Hashimoto N Impaired progression of cerebral aneurysms in interleukin- 1beta-deficient mice. Stroke 2006; 37:900-905.

78. Inagawa, T. Timing of admission and management outcome in patients with subarachnoid hemorrhage. Surg Neurol. 1994; 41:268-76.

79. Ingall TJ, Whisnant JP, Wiebers DO, O'fallon WM. Has there been a decline in subarachnoid hemorrhage mortality? Stroke 1989; 20:718-24.

80. Kassell NF, Adams HP, Torner JC, Sahs AL. Influence of timing of admission after aneurysmal subarachnoid hemorrhage on overall outcome: report of the cooperative aneurysm study. Stroke 1981; 12620-3.

81. Hartl DL. Princípios de Genética de Populações. Vol.3. FUNPEC Editora 2008, Ribeirão Preto, SP. 217p.

82. Snustad and Simmons. Fundamentos de Genética. Vol.6. Guanabara Koogan 2013, Rio de Janeiro. 5651p.

83. Metzger IF, Souza-Costa DC and Tanus-Santos JE. Farmacogenética: Princípios, aplicações e perspectivas. Medicina 2006; 39:515-521. 
84. Beiguelman, B. Genética de Populações Humanas. Ribeirão Preto: SBG 2008; 235.

85. Suarez-Kurtz G, Pena SDJ, Struchiner CJ and Hutz MH. Pharmacogenomic diversitity among Brazilians: influence of ancestry, self-reported color, and geographical origin. Frontiers in Phamacology 2013; 3:191.

86. Sagne C, Marcel V, Amadou A, Hainaut P, Olivier M and Hall J. A meta-analysis of cancer risk associated with the geographic and tumor-specific effects. Cell Death and Disease 2014; 4:e492-497.

87. Pardini B, Verdeiro P, Pizzamiglio S, Nici C, Maiorana MV, Naccarati A, Vodickova L, Vymetalkova V, Veneroni S, Daidone MG, et al. Association between CASP8 -652 6N Del Polymorphism (rs3834129) and Colorectal Cancer Risk: Results from a Multi-Centric Study. Plos One 2014; 9:e85538.

88. Ebegbulem VN and Ozung PO. Application of Molecular Markers in Farm Animal Improvement : Prospects and Challenges. Online Journal of Animal and Feed Research 2013; 3:149-152.

89. Khlestkina EK. Molecular markers in genetic studies and breeding. Russian Journal of Genetics: Applied Research 2014; 4:236-244. 
90. Khokhar JY, Ferguson CS, Zhu AZX and Tyndale RF. Pharmacogenetics of drug dependence: role of gene variations in susceptibility and treatment. Annals Rev Pharmacol Toxicol. 2010; 50: 39-61.

91. Hormi-Carver K and Souza RF. Molecular Markers and Genetics in Cancer Development. Surgical Oncology Clinics of North America 2009; 18:453-467.

92. Mavaddat N, Antoniou AC, Eastona DF and Garcia-Closas M. Genetic susceptibility to breast cancer. Molecular Oncology 2010; 4:174-191.

93. Bodian DL, McCutcheon JN, Kothiyal P, Huddleston KC, Iyer RK, Vockley JG, Niederhuber JE, et al. Germline Variation in Cancer-Susceptibility Genes in a Healthy, Ancestrally Diverse Cohort: Implications for Individual Genome Sequencing. PLoS One 2014; 9:e94554.

94. Hunter K. The role of individual inheritance in tumor progression and metastasis. J Mol Med 2015; 1:1-7.

95. Folkman L, Yang Y, Li Z, et al. DDIG-in: detecting disease-causing genetic variations due to frameshifting indels and nonsense mutations employing sequence and structural properties at nucleotide and protein levels. Bioinformatics 2015; 31:1599-1606.

96. Bermejo-das-Neves C, Nguyen H, Poch O and Thompson JD. A comprehensive study of small non-frameshift insertions/deletions in proteins and prediction of their 
phenotypic effects by a machine learning method (KD4i). BMC Bioinformatics 2014; 15:111.

97. Zhang N, Huang T and Cai YD. Discriminating between deleterious and neutral non-frameshifting indels based on protein interaction networks and hybrid properties. Molecular Genetics and Genomics 2015; 290:343-352.

98. Zhang $\mathrm{X}$, Lin $\mathrm{H}$, Zhao $\mathrm{H}$, et al. Impact of human pathogenic micro-insertions and micro-deletions on post-transcriptional regulation. Human Molecular Genetics 2014; 23:3024-3034.

99. Kleinloog R, van’t Hof FNG, Wolters FJ, Rasing I, van der Schaaf I, Rinkel GJE, Ruigrok YM. The association between genetic risk factors and the size of intracranial aneurysms at time of rupture. Neurosurgery 2013; 73:705-708.

100. Juvela S, Siironen J, Lappainen J. Apolipoprotein E genotype and outcome after aneurysmal subarachnoid hemorrhage. J Neurosurg 2009; 110:989-995.

101. Francis SE, Tu J, Qian Yi, Avolio AP. A combination of genetic, molecular and haemodynamic risk factors contributes to the formation, enlargement and rupture of brain aneurysms. Journal of Clinical Neuroscience 2013; 20:912-8.

102. Leclerc JL, Blackburn S, Neal D, Mendez NV, Wharton JA, Waters MF, Dore S. Haptoglobin phenotype predicts the development of focal and global cerebral 
vasospasm and may influence outcomes after aneurysmal subarachnoid hemorrhage. PNAS 2015; 112:1155-1160.

103. Ohnishi H, Iihara K, Kaku Y, Yamauchi K, Fukuda, Nishimura K, Nakai M,

Satow T, Nakajima N, Ikegawa M. Haptoglobin phenotype predicts cerebral vasospasm and clinical deterioration after aneurysmal subarachnoid hemorrhage. Journal of Stroke and Cerebrovascular Diseases 2013; 22:520-526.

104. Kantor E, Bayir H, Ren D, et al. Haptoglobin genotype and functional outcome after aneurysmal subarachnoid hemorrhage. J Neurosurg 2014;120:386-390.

105. Aoki T, Nishimura M, Kataoka H, Ishibashi R, Nozaki K, Miyamoto S. Complementary inhibition of cerebral aneurysm formation by eNOS and nNOS. Laboratory Investigation 2011; 91: 619-626.

106. Paschoal EHA, Yamaki VN, Teixeira RK, Paschoal Junior FM, Jong-A-Liem GS, Teixeira MJ, Yamada ES, Ribeiro-dos-Santos A, Bor-Seng-Shu E. Relationship between endothelial nitric oxide synthase (eNOS) and natural history of intracranial aneurysms: meta-analysis. Neurosurg Review 2016; 23: epub ahead print.

107. Yang C, Qi Z-y, Shao C, Xing W-k, Wang Z. Association three eNOS Polymorphisms and Intracranial Aneurysm Risk. Medicine 2015; 94:1-11.

108. Kuruppu S, Chou SH, Feske SK, Suh S, Hanchapola I, Lo EH, Ning M, Smith AI Soluble and catalytically active endothelin converting enzyme-1 is present in 
cerebrospinal fluid of subarachnoid hemorrhage patients. Mol Cell Proteomics 2014; 13:1091-1094.

109. Lei Q, Zheng R, Xu K, Li S et al. Endothelin-1 expression and alterations of cerebral microcirculation after experimental subarachnoid hemorrhage. Neuroradiology 2015; 57:63-70.

110. Sathyan S, Koshy LV, Srinvas L, Easwer HV, Premkumar S, Nair S, Bhattacharya RN, Alapatt JP, Banerjee M. Pathogenesis of intracranial aneurysm is mediated by proinflammatory cytokine TNFA and IFNG and through stochastic regulation of IL10 and TGFB1 by comorbid factors. Journal of Neuroinflammation $2015 ; 12: 135$.

111. Tong YQ, Ye JJ, Wang ZH, Zhang YW, Zhan FX, Guan XH, Geng YJ, Hou SY, Li Y, Cheng JQ, Lu ZX, Liu JF. Association of variable number of tandem repeat polymorphism in the IL-4 gene with ischemic stroke in the Chinese Uyghur population. Genetics and Molecular Research 2013; 12:2423-2431.

112. Papacleovoulou G, Critchley HOD, Hillier SG and Mason JI. IL1A and IL4 signalling in human ovarian surface epithelial cells. Journal of Endocrinology 2011; 211:273-283.

113. Wu W, Guan Y, Fu XJ, Guo TZ, Liu YT, Ren XL, Wang W, Liu HR, YQ. Elevated IL-6 and TNF $\alpha$ levels in cerebrospinal fluid of subarachnoid hemorrhage patients. Mol Neurobiol 2015 June; 53 (5): 3277-85. 
114. Liu Y, Sun J, Wu C, Cao X, He M, You C. The interleukin-6-572G/C gene polymorphism and the risk of intracranial aneurysms in a Chinese population. Genetic Testing and Molecular Biomarkers 2012; 16:822-826.

115. Pera J, Dziedzic T, Adamski M Jagiella J, Krupa M, Moskala M, Szczudlik A, Slowik A. Interleukin 6-174G $>$ C polymorphism and risk of aneurysmal subarachnoid hemorrhage: case-control study and metaanalysis. Acta Neurol Scand 2012; 125 : $111-115$.

116. Beeftink MMA, Ruigrok YM, Tinkel GJE, van den Bergh WM. Relation of Serum TNF-a and TNF-a Genotype with Delayed Cerebral Ischemia and Outcome in Subarachnoid Hemorrhage. Neurocrit Care 2011; 15:405-409

117. Eck SM, Blackburn JS, Schmucker AC, Burrage PS and Brinckerhoff CE. Matrix metalloproteinase and G protein coupled receptors: co-conspirators in the pathogenesis of autoimmune disease and cancer. Journal of Autoimmunity 2009; $33: 214-221$.

118. Kai Y, Hirano K, M Y, N J, Sasaki T, Kanaide H. Prevention of the contractile response to thrombin by proteinase-activated receptor-1 antagonist in subarachnoid hemorrhage. Stroke 2007; 38:3259-3265.

119. Maeda Y, Hirano K, Kai Y, Hirano M, Suzuki SO, Sasaki T, Kanaide H. Upregulation of proteinase-activated receptor 1 and increased contractile responses to 
thrombin after subarachnoid haemorrhage. British Journal of Pharmacology 2007; $152,1131-1139$.

120. Hirano K, Hirano M. Current perspective on the role of the thrombin receptor in cerebral vasospasm after subarachnoid hemorrhage. J Pharmacol Sci 2010; 114, 127 133.

121. Almeida A. Genetic determinants of neuronal vulnerability to apoptosis. Cell. Mol. Life Sci. 2013; 70:71-88.

122. Catucci I, Verderio P, Pizzamiglio S, Manoukian S, Peissel B, Zaffaroni D, Roversi G, Ripamonti CB, Pasini B, Barile M, Viel A, Giannini G, Papi L, Varesco L, Martayan A, Riboni M, Volorio S, Radice P, Peterlongo P. The CASP8 rs3834129 polymorphism and breast cancer risk in BRCA1 mutation carriers. Breast Cancer Res Treat 2011; 125:855-60.

123. Ghavami S, Hashemi M, Ande SR, Yeganeh B, Xiao W, Eshraghi M, Bus CJ, Kadkhoda K, Wiechec E, Halayko AJ, Los M. Apoptosis and cancer: mutations within caspase genes. J Med Genet 2009; 46:497-510.

124. Stojnev S, Golubovic M, Babovic P. TP53 gene mutations - from guardian of the genome to oncogene. Acta Medica Medianae 2009; 49:59-63.

125. Bourdon JC, Fernandes, K, Murray-Zmijewski F, et al. p53 isoforms can regulate p53 transcriptional activity. Genes Dev. 2005; 19:2122-2137. 
126. Li L, Sima X, Bai P, Zhang L, Sun H, Liu J, Zhang L, Gao L. Interactions of miR-34b/c and TP53 polymorphisms on the risk of intracranial aneurysm. Clinical and Developmental Immunology 2012; Vol Article ID 567586.

127. Orhan G, Elkama A, Mungan SO, Eruyar e, Karahalil B. The impact of detoxififying and repair gene polymorphisms on oxidative stress in ischemic stroke. Neurol Sci 2016 March; published online.

128. Dutra AVC, Lin HF, Juo SHH, Mohrenweiser H, Sen S, Grewal RP. Analysis of the $\mathrm{XRCC} 1$ gene as a modifier of the cerebral response in ischemic stroke. $B M C$ Medical Genetics 2006; 7:78.

129. Powers CJ, Dickerson R, Zhang SW, Rink C, Roy S, Sen CK. Human cerebrospinal fluid microRNA: temporal changes following subarachnoid hemorrhage, Physiological genomics. 2016; 48: 361-366.

130. Li H, Wang W, Zhang L, Lan Q, Wang J, Cao Y, Zhao J. Identification of a long noncoding RNA associated competing endogenous RNA network in intracranial aneurysm. World Neurosurg 2017; 97:684-692.

131. Ferreira LB, Mendes-Junior CT, Wiezel CEV, Luizon MR and Simoões AL Genomic Ancestry of a Sample Population From the State of São Paulo, Brazil. American Journal of Human Biology 2006; 18:702-705. 
132. Palha T, Ribeiro-Rodrigues EM, Ribeiro-dos-Santos AK, Guerreiro JF, Moura LSS and Santos SEB Male ancestry structure and interethnic admixture in Africandescent communities from the Amazon as revealed by Y-chromosome STRs. American Journal of Physical Anthropology 2015; 144:471-478.

133. Parra FC, Amado RC, Lambertucci JR, Rocha J, Antunes CM and Pena SDJ Color and genomic ancestry in Brazilians. Genetics 2003; 100:177-182.

134. Resque RL, Freitas NSC, Ribeiro-Rodrigues EM, et al. Estimates of Interethnic Admixture in the Brazilian Population Using a Panel of 24 X-Linked Insertion/Deletion Markers. American Journal of Human Biology 2010; 22: 849-852.

135. Santos SEB and Guerreiro JF The indigenous contribution to the formation of the population of the Brazilian Amazon Region. Rev Brasil Genet 1995; 18:311-315.

136. Santos SEB, Rodrigues JD, Ribeiro-dos Santos AK, Zago MA. Differential contribution of indigenous men and women to the formation of an urban in the Amazon region as revealed by mtDNA and Y-DNA. Am J Phys Anthropol 1999; 109:175-180.

137. Pimenta JR, Zuccherato LW, Debes A, Maselli L, Soares RP, Moura-Neto RS, Rocha J, Bydlowski SP and Pena SDJ. Color and genomic ancestry in Brazilians: A study with forensic microsatellites. Human Heredity 2006; 62:190-195. 
138. Santos NPC, Ribeiro-Rodrigues EM, Ribeiro-dos-Santos AKC, Pereira R, Gusmão L, Amorim A, Guerreiro JF, Zago MA, Matte C, Hutz MH and Santos SEB Assessing individual interethnic admixture and population substructure using a 48Insertion-Deletion (INSEL) Ancestry-Informative Marker (AIM) Panel. Human Mutation 2010; 31:184-190.

139. Florentino, M. Em Costas Negras. Companhia das Letras 1997, São Paulo, 304p.

140. Diegues-Júnior M. Etnias e Culturas no Brasil. Rio de Janeiro, Biblioteca do Exército Editora. 1980.

141. MaCarron MO, Alberts MJ, MaCarron P. A systematic review Terson's syndrome: frequency and prognosis after subarachnoid hemorrhage. J Neurol Neurosurg Psychiatry 2004; 75: 491-3.

142. Le Roux PD, Winn HR. Management of the ruptured aneurysm In: Le Roux PD, Winn HR, Nwewll DW eds. Management of cerebral aneurysms. Philadelphia: Saunders 2004:303-33.

143. Snead AN, Insel PA. Definig the cellular repertoire of GPCRs identifies a profibrotic role for the most highly expressed receptor, protease-activated receptor 1 , in cardiac fibroblasts. FASEB J 2012; 26 (11): 4540-7.

144. van Heuven AW, Mees SMD, Algra A, Rinkel GJE. Validation of a prognostic subarachnoid hemorrhage grading scale derived directly from the Glasgow coma 
scale. Stroke 2008; 39: 1347-1348.

145. Yundt KD, Grubb RL Jr, Diringer MN, Powers WJ. Autoregulatory vasodilatation of parenchymal vessels is impaired during cerebral vasospasm. J Cereb Blood Flow Metab 1998; 18:419-424.

146. Rädberg JA, Olsson JE, Rädberg CT. Prognostic parameters in spontaneous intracerebral hematomas with special reference to anticoagulant treatment. Stroke $1991 ; 22: 571-6$

147. Fukuhara T, Douville CM, Eliott JP, Newell DW, Winn HR. Relationship between intracranial pressure and the development of vasospasm after aneurysmal subarachnoid hemorrhage. Neurol Med Chir (Tokyo) 1998; 38:710-5.

148. Cancilla PA, Torner JC, Nibbelink DW. Pathological results from patients who died in randomized study (phase II). In: Sahs AL, Nibbelink DW, Torner JC. eds. Aneurysmal subarachnoid hemorrhage: report of the cooperative study. Baltimore, Urban \& Schwarzenberg 1981; p. 277-84.

149. Vermeij FH, Hasan D, Bijvoet HW, Avezaat CJ. Impact of medical treatment on the outcome of patients after aneurysmal subarachnoid hemorrhage. Stroke 1998; 29:924-30. 
150. Kassell NF, Torner JC, Haley EC Jr, Jane JA, Adams HP, Kongable GB. The international cooperative study on the timing of aneurysm surgery. part I - Overall management results. $J$ Neurosurg 1990 a ;73:18-36.

151. Kassell NF, Torner JC, Jane JA, Haley EC, Adams HP. The international cooperative study on the timing of aneurysm surgery. part II - Surgical results. $J$ Neurosurg 1990b; 73:37-47.

152. Inagawa $\mathrm{T}$, Kamiya $\mathrm{K}$, Ogasawara $\mathrm{H}$, Yano $\mathrm{T}$. Rebleeding of ruptured intracranial aneurysms in the acute stage. Surg Neurol 1987; 28:93-9.

153. Hillman J, von Essen C, Leszniewski W, Johansson I. Significance of "ultraearly" rebleeding in subarachnoid hemorrhage. J Neurosurg 1988; 68:901-7.

154. Mayberg MR, Batier HH, Dacey R, Diringer M, Haley C, Heros RC, Sternau LL, Torner $\mathrm{J}$ Guidelines for the management of aneurysmal subarachnoid hemorrhage. a statement for healthcare professionals from a special writing group of the stroke council, American Heart Association. Stroke 1994; 25:2315-28.

155. Fujii Y, Takeuchi S, Sasaki O, Minakawa T, Koike T, Tanaka R. Ultra-early rebleeding in spontaneous subarachnoid hemorrhage. J Neurosurg 1996; 84:35-42.

156. Komiyama M, Tamura K, Nagata Y, Fu Y, Yagura H, Yasui T. Aneurysmal rupture during angiography. Neurosurgery 1993; 33:798-803. 
157. Graff-Hadford NR, Torner J, Adams HP, Kassell NF. Factors associated with hydrocephalus after subarachnoid hemorrhage: a report of the cooperative aneurysm study. Arch Neurol 1989; 46:744-52.

158. Rinkel GJ, Wijdicks EF, Ramos LM, van Gijn J. Progression of acute hydrocephalus in subarachnoid haemorrhage: a case report documented by serial CT scanning. J Neurol Neurosurg Psychiatry 1990; 53:354-5.

159. Choi KS, Chun HJ, Yi HJ, Ko Y, Kim YS, Kim JM. Seizures and Epilepsy following aneurysmal subarachnoid hemorrhage : incidence and risk factors. J Korean Neurosurg. 2009; 46: 93-98.

160. Kim JA, Rosenthal ES, Biswal S, Zafar S, O’Connor KL, Bechek SC, Valdery Moura J, Shafi MM, Patel AB Cash SS, Westover MB. Epileptiform abnormalities predict delayed cerebral ischemia in subaracnoid hemorrhage. Cliinical Neurophysiology 2017 ; Jan epub ahead of print.

161. Weir B, Grace M, Hansen J, Rothberg C. Time course of vasospasm in man. $J$ neurosurg. 1970; 33:395-406.

162. Biller J, Godersky JC, Adams Jr HP. Management of anerysmal subarachnoid hemorrhage. Stroke 1988; 19:1300-50.

163. Francoeur CL, Mayer SA. Management of delayed cerebral ischemia after subarachnoid hemorrhage. Critical Care 2016; 20:277-289. 
164. Eagles ME, Jaja BNR, Macdonald RL. Incorporating a modified Graeb score to the modified Fisher scale for improved risk prediction of delayed cerebral ischemia following aneurysmal subarachnoid hemorrhage. Neurosurgery 2017; Apr epub ahead of print.

165. Longstreth WT Jr, Nelson LM, Koepsell TD, van Belle G. Clinical course of spontaneous subaracnhoid hemorrhage: a population -based study in king country, washington. Neurology 1993; 43:712-8.

166. de Oliveira Manoel AL, Turkel-Parrella D, Duggal A, Murphy A, McCredie V, Marotta TR. Managing aneurysmal subarachnoid hemorrhage: It takes a team. Cleveland Clinic Journal of Medicine 2015; 82:177-192.

167. Sloan MA, Alezandrov AV, Tegeler CH, Spencer MP, Caplan LR, Feldman E, Wechsler LR, Newell DW, Gomez CR, Babikian VL, Lefkowitz D, Goldman RS, Amon C, Hsu CY, Therapeutics and Technology Assessment Subcommittee of The American Academy of Neurology. Assessment: transcranial Doppler ultrasonography: report of the Therapeutics e Technology Assessment Subcommittee of the American Academy of Neurology. Neurology 2004; 62:1468-81.

168. Charpentier C, Audibert G, Guillemin F, Civit T, Ducrocq X, Bracard S, Hepner H, Picard L, Laxenaire MC. Multivariate analysis of predictors of cerebral vasospasm occurrence after aneurismal subarachnoid hemorrhage. Stroke 1999; 30:1402-8. 
169. Bederson JB, Levy Al, Ding WH et al. Acute vasoconstriction after subarachnoid hemorrhage Neurosurgery 1998; 42: 352-360.

170. de Lima Oliveira M, Kairalla AC, Fonoff ET, Martinez RC, Teixeira MJ, BorSeng-Shu E. Cerebral microdialysis in traumatic brain injury and subarachnoid hemorrhage: state of the art. Neurocrit care 2014; 21:152-162.

171. Öhman J, Servo A, Heiskanen O. Risk factors for cerebral infarction in goodgrade patients after aneurysmal subarachnoid hemorrhage and surgery: a prospective study. J Neurosurg. 1991b; 74:14-20.

172. Öhman J \& Heiskanen O. Timing of operation for ruptured supratentorial aneurysms: a prospective randomized study. J Neurosurg. 1989; 70:55-60.

173. Tanaka A, Kumate S, Nakayama Y, Yoshinaga S, Tomonaga M. Postoperative subarachnoid clots and the pattern of cerebral ischemia associated with symptomatic vasospasm. Surg Neurol 1998; 49:164-9.

174. Gollwitzer S, Groemer T, Rampp S, Hagge M, Olmes D, Huttner HB, Schwab S, Madzar D, Hopfengaerner, Hamer HM. Early prediction of delayed cerebral ischemia in subarachnoid hemorrhage based on quantitative EEG: A prospective study in adults. Clinical Neurophysiology 2015; 126: 1514-23.

175. Weyer GW, Nolan CP, Macdonald RL. Evidence-based cerebral vasospasm management. Neurosurg Focus 2006; 21: E8. 
176. Mocco J, Zacharia BE, Ricardo, BS, Komatar RJ, Conolly Jr ES. A review of current and future medical therapies for cerebral vasospasm following aneurysmal subarachnoid hemorrhage. Neurosurg Focus 2006; 21: E9.

177. de Oliveira Manoel AL, Jaja BN, Germans MR, Yan H, Q W, Kouzmina E, Marotta TR, Turkel-Parella D, Schweizer TA, Macdonald RL, SAHIT collaborators. The VASOGRADE, A simple grading scale for prediction of delayed cerebral ischemia after subarachnoid hemorrhage. Stroke 2015; 46:1-6.

178. Etminan N, DI Vergouwen M, Ilodigwe D, Macdonald RL. Effect of pharmaceutical treatment on vasospasm, delayed cerebral ischemia and clinical outcome in patients with aneurysmal subarachnoid hemorrhage: a systemetic review and meta-analysis. J Cereb Blood Flow Metabol. 2011; 31:1443-51.

179. Pickard JD, Murray GD, Illingwirth R, Shaw MDM, Teasdale GM Foy PM, Humphrey PRD, Lang DA, Nelson R, Richards P, Sinar J, Nailey S, Skene A. Effect of oral nimodipine on cerebral infarction and outcome after subarachnoid hemorrhage. British aneurysm nimodipine trial. Br Med J 1989; 298:636-42.

180. Pasqualin A. Epidemiology and pathophysiology of cerebral vasospasm following subarachnoid hemorrhage. J Neurosurg Sci 1998; 42(suppl.1):15-21. 
181. Jung CS, Lange B, Zimmermann M, Seifart V. The CSF concentration of ADMA, but not of ET-1, is correlated with the occurrence and severity of cerebral vasospasm after subarachnoid hemorrhage. Neuroscience Letters 2012; 524:20-24.

182. Zhang H, Weir B, Marton LS, Macdonald RL, Bindokas V, Miller RJ, Brorson JR. Mechanisms of hemolysate-induced calcium elevation in cerebral smooth muscle cells. Am J Physiol 1995; 269:h1874-h90.

183. Vollmer DG, Hongo K, Ogawa H, Tsukahara T, Kassell NF. A study of the effectiveness of the iron-chelating agent deferoxamine as vasospasm prophylaxis in a rabbit model of subarachnoid hemorrhage. Neurosurgery 1991; 28:27-32.

184. Peterson JW, Candia G, Spanos AJ, Zervas NT. The calmodulin antagonist trifluoperazine provides mild prophylactic protection against cerebral vasospasm after subarachnoid hemorrhage, but no therapeutic value. Neurosurgery 1989; 25:917-22.

185. Hängii D, The Participants in the International Multi-disciplinary Consensus Conference on the Critical Care Management of Subarachnoid Hemorrhage. Monitoring and Detection of Vasospasm II: EEG and Invasive Monitoring. Neurocrit Care 2011; 15:318-323.

186. Khurana VG, Meyer FB. Translational Paradigms in Cerebrovascular Gene Transfer. J Cereb Blood Flow Metabolism 2003; 23:1251-1262.

187. Serrone JC, Maekawa H, Tjahjadi M, Hernesniemi J. Aneurysmal subarachnoid 
hemorrhage: pathobiology, current treatment and future directions. Expert Rev Neurother. 2015; 15: 367-80.

188. Eisenhut M. Vasospasm in cerebral inflammation. International Journal of Inflammation 2014; 509707: 1-14.

189. de Lima Oliveira M, de Azevedo DS, de Azevedo MK, Nogueira RC, Teixeira MJ, Bor-Seg-Shu E. Encephalic hemodynamic phases in subarachnoid hemorrhage: how improve the protective effect in patient prognoses. Neural Regeneration Research 2015; 10:748-752.

190. Nieuwkamp Dj, Setz LE, Algra A et al. Changes in case fatality of aneurysmal subarachnoid over time, according to age, sex and region: a meta-analysis. Lancet Neurol 2009; 8 (7): 635-42.

191. Park S, Yamaguchi M, Zhou C, et al. Neurovascular protection reduces early brain injury after subarachnoid hemorrhage. Stroke 2004; 35: 2412-2417.

192. Latchaw RE, Silva P, Falcone SF. The role of CT following aneurysmal rupture. Neuroimaging. Clin North Am 1997; 7:693-708.

193. Kawamoto S, Tsutsumi K, Yoshikawa G, Shinozaki MH, Yako K, Nagata K, Ueki K. Effectiveness of the head-shaking method combined with cisternal irrigation with uroquinase in preventing cerebral vasospasm after subarachnoid hemorrhage. $J$ Neursourg 2004; 100: 236-243. 
194. Crowley RW, Medel R, Dumont AS, Ilodigwe D, Kassell NF, Mayer SA, Ruefenacht D, Schiedek P, Weidauer S, Pasqualin A, Macdonald RL. Angiographic Vasospasm is Strongly Correlated with Cerebral Infarction After Subarachnoid Hemorrhage. Stroke 2011; 42:919-923.

195. Veldeman M, Höllig A Clusmann H, Stevanovic A, Rossaint R, Coburn M. Delayed cerebral ischaemia and treatment after aneurysmal subarachnoid haemorrhage: a systematic review. Br J Anaesth 2016; Jul 117 (1):17-40.

196. Schievink WI. Intracranial Aneurysms. The New Engl J Med 2004; 336: 2839.

197. Martin MGM, Mont'Alverne Filho FEF, Gattás GS. Acidente Vascular Cerebral. In: da Costa Leite C, Amaro Jr E, Lucato LT. Neurorradiologia: diagnostic por imagem das alterações encefálicas. Rio de Janeiro: Guanabara Koogan 2008 1: 144181.

198. Grossi G, Romanzi F, Macchia G, Ruffinengo U, Calia S. Angi-CT. A proposal for emergency diagnosis in subarachnoid hemorrhage as a preliminary to therapeutic choices. Interv Neuroradiol 1995; 30:43-57.

199. Ruedinger KL, Rutkowski DR, Schafer S, Roldán-Alzate A, Oberstar EL, Strother C. Impact of image reconstruction parameters when using 3D DSA reconstructions to measure intracranial aneurysms. J NeuroIntervent Surg 2017;0:1-5 
200. Gonzalez NR, Broscardin WJ, Glenn T, Vinuela F, Martin NA. Vasospasm probability index: a combination of transcranial Doppler velocities, cerebral blood flow, and clinical risk factors to predict cerebral vasospasm after aneurysmal subarachnoid hemorrhage. J Neurosurg 2007; 107: 1101-1112.

201. Dreier JP, Ebert N, Priller J, et al. Products of hemolysis in the subarachnoid space inducing spreading ischemia in the cortex and focal necrosis in rats: a model for delayed ischemic neurological deficits after subarachnoid hemorrhage? J Neurosurg 2000; 93:658-66.

202. Dreier JP, Woitzik J, Fabricius M, et al. Delayed ischaemic neurological deficits after subarachnoid haemorrhage are associated with clusters of spreading depolarizations. Brain 2006;129(Pt 12):3224-37.

203. Dreier JP. The role of spreading depression, spreading depolarization and spreading ischemia in neurological disease. Nat Med 2011; 17:439-47.

204. Hartings JA, Wilson JA, Look AC, et al. Full-band electrocorticography of spreading depolarizations in patients with aneurysmal subarachnoid hemorrhage. Acta Neurochir Suppl 2013;115:131-41.

205. Sakowitz OW, Santos E, Nagel A, et al. Clusters of spreading depolarizations are associated with disturbed cerebral metabolism in patients with aneurysmal subarachnoid hemorrhage. Stroke 2013; 44:220-3. 
206. Esteban JM, Cervera V. CT perfusion and angioCT in the assessment of acute stroke. Neuroradiology 2004; 46: 705-715.

207. Kerneni H, Schatlo B, Dan-Ura H, Remonda L, Muroi C, Diepers M, Fandino J, Fathi AR. Proximal arterial diameters on CT angiography and digital subtraction angiography correlate both at admission and in the vasospasm period after aneurysmal subarachnoid hemorrhage. Acta Neurochir Suppl. 2015; 12: 171-5.

208. Kunze E, Pham M, Raslan F, Stetter C, Lee JY, Solymosi L, et al: Value of perfusion CT, transcranial Doppler sonography, and neurological examination to detect delayed vasospasm after aneurysmal subarachnoid hemorrhage. Radiol Res Pract 2012:231206, 2012.

209. Lagares A, Cicuendez M, Ramos A, Salvador E, Alén JF, Kaen A, et al: Acute perfusion changes after spontaneous SAH: a perfusion CT study. Acta Neurochir (Wien) 154:405-412, 2012.

210. Killeen RP, Mushlin AI, Johnson CE, Comunale JP, Tsiouris AJ, Delaney H, et al: Comparison of CT perfusion and digital subtraction angiography in the evaluation of delayed cerebral ischemia. Acad Radiol 18:1094-1100, 2011.

211. Murphy A, de Oliveira Manoel AL, Burgers K, Kouzmina E, Lee T, Macdonald RL, Bharatha A. Early CT perfusion changes and blood-brain barrier permeability after aneursmal subarachnoid hemorrhage. Neuroradiology 2015; 57: 767-73. 
212. Westermaier T, Pham M, Stetter C, Willner N, Solmosi L, Ernestus RI, Vonce

GH, Kunze E. Value of Transcranial Doppler, Perfusion CT and Neurological Evaluation to Forecast Secondary Ischemia after Aneurysmal SAH. Neurocrit Care $2014 ; 20: 46-412$.

213. Rathakrishman R, Gotman J, Dubeau F, Angle M. Using continuous electroencephalography in the management of delayed cerebral ischemia following subarachnoid hemorrhage. Neurocrit Care 2011; 14:152-161

214. Francouer CL, Mayer SA. Management of delayed cerebral ischemia after subarachnoid hemorrhage. Critical Care 2016; 20:177-189.

215. Foreman B, Claassen J. Quantitative EEG for the detection of the brain ischemia. Critical Care 2012; 12:216 -225.

216. Persson L, Hillered L. Chemical monitoring of neurosurgical intensive care patients using intracerebral microdialysis. J Neurosurg. 1992; 76:72-80.

217. Hamberger A, Runnerstam M, Nystrom B, Starmark JE, von Essen C. The neuronal environment after subarachnoid haemorrhage-correlation of amino acid and nucleoside levels with postoperative recovery. Neurol Res. 1995; 17:97-105.

218. Unterberg AW, Sakowitz OW, Sarrafzadeh AS, Benndorf G, Lanksch WR. Role of bedside microdialysis in the diagnosis of cerebral vasospasm following aneurysmal subarachnoid hemorrhage. J Neurosurg. 2001; 94:740-9. 
219. Benes $3^{\text {rd }}$ V, Jurak L, Brabec R, Nechanickà N, Sercl M, Endrych L, Buchvald P, Suchomel P. Causes of poor outcome in patients admitted with good-grade subarachnoid hemorrhage. Acta Neurochir 2017; 159: 559-565.

220. Hunt WE, Hess RM. Surgical risk as related to time of intervention in the repair of intracranial aneurysm. J Neurosurg 1968; 28:14-20.

221. Report of World Federation of Neurological Surgeons Committee on a Universal Subarachnoid Hemorrhage Grading Scale. J Neurosurg 1988; 68:985-986.

222. Spetzler RF, McDougall CG, Albuquerque FC, et al. The Barrow Ruptured Aneurysm Trial: 3-year results. J Neurosurg 2013; 119:146-157.

223. McDougall CG, Spetzler RF, Zabramski JM, et al. The Barrow Ruptured Aneurysm Trial. J Neurosurg 2012; 116:135-144.

224. Molyneux A, Kerr R, Stratton I, et al; International Subarachnoid Aneurysm Trial (ISAT) Collaborative Group. International Subarachnoid Aneurysm Trial (ISAT) of neurosurgical clipping versus endovascular coiling in 2,143 patients with ruptured intracranial aneurysms: a randomised trial. Lancet 2002; 360:1267-1274.

225. Molyneux AJ, Kerr RS, Yu LM, et al; International Subarachnoid Aneurysm Trial (ISAT) Collaborative Group. International subarachnoid aneurysm trial (ISAT) of neurosurgical clipping versus endovascular coiling in 2,143 patients with ruptured 
intracranial aneurysms: a randomised comparison of effects on survival, dependency, seizures, rebleeding, subgroups, and aneurysm occlusion. Lancet 2005; 366:809-817.

226. Weyer GW, Nolan CP, Macdonald RL. Evidence-based cerebral vasospasm management. Neurosurg Focus 2006; 21 (3): E8.

227. Boulouis G, Labeyrie MA, Raymond J, Rodriguez-Régent C, Lukaszewicz AC, Bresson D, Hassen WB, Trystam D, Meder JF, Oppenheim C, Naggara O. Treatment of cerebral vasospasm following aneurysmal subarachnoid haemorrhage: a systematic review and meta-analysis Eur Radiol 2016; epub ahead of print.

228. Griessenauer CJ, Tubbs S, Foreman P, Chua M, Vyas NA, Lipsky RH, Lin M, Iyer R, Haridas R, Walters BC, Chaudry S, Malieva A, Wikins S, Harrigan MR, Fisher III WS, Shoja MM. Associaton of renin-angiotensin system genetic polymorphisms and clinical course after aneurysmal subarachnoid hemorrhage. $J$ Neurosurg June 2016; 10:1-13. 
APÊNDICES 


\title{
Carotid rete mirabile associated with
} subarachnoid hemorrhage from intracranial aneurysm: A case report and systematic review

\author{
Eric Homero Albuquerque Paschoal ${ }^{1}$, Vitor Nagai Yamaki ${ }^{1}$ \\ Fernando Mendes Paschoal júnior ${ }^{1}$, Ronie Leo Piske ${ }^{2}$, \\ Manoel Jacobsen Teixeira ${ }^{3}$ and Edson Bor-Seng-Shu ${ }^{3}$
}

\section{Abstract}

Carotid rete mirabile (CRM) is a rare physiological vascular network in humans that is most often found in Eastern populations. This paper describes a CRM associated with an aneurysmal subarachnoid hemorrhage (aSAH) and discusses the details of the patient's treatment. A 28-year-old woman was admitted to our service with clinical signs and symptoms of a spontaneous aSAH. Computed tomography revealed a diffuse and extensive SAH (Fisher group IV), while an angiogram showed an abnormal collateral network in the right carotid system and a hypoplastic aspect to the internal carotid artery (ICA) on the same side. In addition, a saccular aneurysm with a diameter of $9.5 \mathrm{~mm}$ was present in the ophthalmic segment of the left ICA. This case is extremely uncommon. To avoid rebleeding in the patient, we successfully treated the patient by clipping the aneurysmal lesion. No procedure was performed for the CRM.

\section{Keywords}

Cerebrovascular disorders, collateral circulation, subarachnoid hemorrhage, case report

\section{Introduction}

Congenital artery collateral networks are rare in humans and frequently occur as a result of an embryonic abnormality in the formation of the native vessel. Lie defined agenesis as a complete failure of the organ to develop, aplasia as a lack of development, and hypoplasia as incomplete development. Evaluation of the skull base for the presence or absence of the carotid canal is required to distinguish aplasia from agenesis because the precursor of the internal carotid artery (ICA) is a prerequisite for the development of the carotid canal at five to six weeks. ${ }^{1}$

Carotid rete mirabile (CRM) is a transdural arterial network found in the cavernous portion of the ICA and is most often supplied by branches of the external carotid artery (ECA), particularly branches of the maxillary artery and ascending pharyngeal artery. 2,3

CRM is a physiological communication between the external carotid and internal carotid systems in mammals such as pigs and sheep. ${ }^{4}$ These lower mammals have an incomplete circle of Willis that is frequently supplied by other branches of the ECA. During embryonic development, the ICA likely undergoes secondary atrophy, and as a result of this late regression, the CRM physiological network serves to replace the arterial supply to the circle of Willis. ${ }^{5}$
When considering the physiological formation of CRM in these animals, it helps to examine the physiopathology of this condition in humans, where CRM associated with developmental abnormalities of the ICA works as a pathway to compensate for deficient blood flow in the ICA. ${ }^{6}$ In other animals, these changes are required to facilitate heat exchange and regulate intracerebral blood pressure and flow, as a beneficial adaptation. $^{7}$

CRM is a rare disorder that most frequently occurs in Asian populations. However, there are reports of the condition in Western patients. ${ }^{5}$ Patients with CRM exhibit a wide variety of clinical symptoms, from asymptomatic patients to patients presenting with headache, loss of balance, cognitive disturbances

${ }^{1}$ Division of Neurosurgery, Hospital Ophir Loyola, Federal University of Para, Belem, Brazil

${ }^{2}$ Division of Neuroradiology, Hospital Beneficência Portuguesa de São Paulo, São Paulo, Brazil

${ }^{3}$ Division of Neurosurgery, Hospital das Clinicas, University of São Paulo, São Paulo, Brazi

Corresponding author:

Eric Homero Albuquerque Paschoal, Trav. Dom Romualdo de Seixas, 1164 apt 1601 CEP, 66055-200, Belem, PA, Brazil.

Email: ericpaschoal@yahoo.com.br 
Neurosurg Rev

DOI 10.1007/s10143-016-0761-4

REVIEW

\section{Relationship between endothelial nitric oxide synthase (eNOS) and natural history of intracranial aneurysms: meta-analysis}

Eric Homero Albuquerque Paschoal ${ }^{1,2}$ - Vitor Nagai Yamaki ${ }^{3}$.

Renan Kleber Costa Teixeira ${ }^{4}$ - Fernando Mendes Paschoal Junior ${ }^{2,5}$.

Glaucia Suzanna Jong-A-Liem ${ }^{3}$ - Manoel Jacobsen Teixeira ${ }^{2}$ - Elizabeth Sumi Yamada ${ }^{6}$.

Ândrea Ribeiro-dos-Santos ${ }^{6} \cdot$ Edson Bor-Seng-Shu ${ }^{2}$

Received: 13 May 2016/Accepted: 9 June 2016

(C) Springer-Verlag Berlin Heidelberg 2016

Abstract The aneurysmal subarachnoid hemorrhage is a major public health problem described as a sudden drastic event with no warning symptoms and high morbidity and mortality rates. The role of the endothelial isoform of nitric oxide synthase gene polymorphism in intracranial aneurysms (IAs) is still a matter of controversy with divergent findings among European, American, and Asian populations. Our study purposed to test the association between intracranial aneurysms formation and nitric oxide gene polymorphisms through a systematic review and meta-analysis. Systematic search on Medline, Lilacs, and EMBASE was performed. The primary search resulted in 139 papers, out of which 9 met our inclusion criteria after a full text analysis. The dominant T786C model found a significant association with IA (OR 1.22, $95 \%$ CI $1.04-1.44, p=0.01)$, so did studies of the recessive T786C model (OR $0.37,95 \%$ CI $0.30-0.45, p<0.0001$ ) but with opposite effect. Our findings support the presence of the

\section{eNOS and Intracranial Aneurysms}

Eric Homero Albuquerque Paschoa ericpaschoal@yahoo.com.br

1 Department of Neurosurgery, Universidade Federal do Pará, Rua Bernal do Couto, 106; Apt 1202, 66055-080 Belem, PA, Brazil

2 Department of Neurosurgery, Universidade de São Paulo, São Paulo, SP, Brazil

3 Department of Neurosurgery, Universidade do Estado do Pará, Belém, PA, Brazil

4 Department of Surgery, Universidade do Estado do Pará, Belém, PA, Brazil

5 Department of Neurology, Universidade Federal do Pará, Belem, PA, Brazil

6 Department of Genetics, Universidade Federal do Pará, Belem, PA, Brazil
T786C polymorphism as a predictor for the development of intracranial aneurysm in the cerebral vascular system. More studies are necessary in order to elucidate the pathways of the endothelial nitric oxide synthase (eNOS) in cerebrovascular diseases and in defining how different allelic combinations of the eNOS gene single-nucleotide polymorphism (SNP) could favor this pathological process.

Keywords Endothelial nitric oxide synthase · Genetic polymorphisms $\cdot$ Intracranial aneurysms $\cdot$ Meta-analysis . Subarachnoid hemorrhage

\section{Introduction}

The aneurysmal subarachnoid hemorrhage (aSAH) is a major public health problem characterized by a sudden drastic event, which is not preceded by warning signs, and withholds high morbidity and mortality rates [36]. The prevalence of an aSAH is 10 to 11 per 100.000 , with a rupture rate varying from 0.05 to $6 \%$ per year $[10,11,13]$. Half of these patients die or become disabled with severe neurological deficits [18].

The sudden and unexpected onset of this condition, as well as the high costs of treatment and screening, have encouraged the search of susceptible elements that can possibly predict an aneurysmal rupture. With this purpose, the International Study of Unruptured Intracranial Aneurysm (ISUIA) [11] first substantiated a higher rupture rate in aneurysms over $10 \mathrm{~mm}$ in diameter and located in the posterior circulation. In same manner, several reports identified environmental insults (such as risk factors sex, age, smoking, and hypertension) and genetic factors to influence in the formation and rupture of intracranial aneurysms (IA) [11, 32].

In 2003, Khurana et al. questioned, "Can brain aneurysms that are more prone to rupture be identified genetically?" This 
Artigo 3 -

\title{
FRONTIERS IN BIOSCIENCE
}

Cited by index medicus, MEDLINE, Current Contents, Swets-Blakwell, BIOSIS and chemical abstracts

\author{
Ândrea Ribeiro-dos-Santos \\ Managing editor
Frontiers in Bioscience \\ Fabiano Cordeiro Moreira \\ Co-Managing editor \\ Amanda Ferreira Vidal \\ Co-Managing editor \\ Frontiers in Bioscience \\ Tel: +559132017843 \\ E-mail: akelyufpa@gmail.com \\ plugfcm@gmail.com \\ $\frac{\text { amandaferreiravidal@yahoo.com.br }}{\text { http://www.bioscience.org }}$
}

Dear Eric Homero A. Paschoal,

Thank you for submitting your manuscript entitled: "MicroRNA findings associated with intracranial aneurysm and subarachnoid hemorrhage: systematic review and meta-analysis" (Eric Homero A. Paschoal, Glaucia Suzanna Jong-A-Liem, ,Vitor N. Yamaki, Fernando M. Paschoal Junior, Barbara Natana M.M. Silva, Gloria Tatiana V. Sandoval, Vanessa A.P.A. Bastos, Elizabeth Sumi Yamada, Sidney Emanuel B. Santos, Manoel J. Teixeira, Edson Bor-Seng-Shu). We declare that the manuscript mentioned above was sent to the reviewers and you and your colleagues will be notified about our decision by Email as soon as possible.

Cordially,

Ândrea Ribeiro-dos-Santos

Managing Editor

Frontiers in Bioscience

Amanda Ferreira Vidal

Co-Managing Editor

Frontiers in Bioscience 